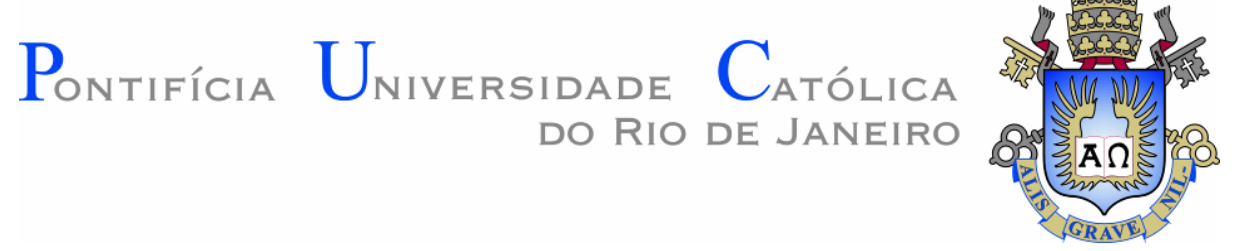

Geovane de Almeida Santos da Silva

Desenvolvimento e Caracterização de Blendas PEAD/PA12

Dissertação de Mestrado

Dissertação apresentada como requisito parcial para obtenção do grau de Mestre pelo programa de Pós-graduação em Engenharia de Materiais e Processos Químicos e Metalúrgicos da PUC - Rio

Orientador: Prof. José Roberto Moraes d'Almeida

Rio de Janeiro

Agosto de 2018 


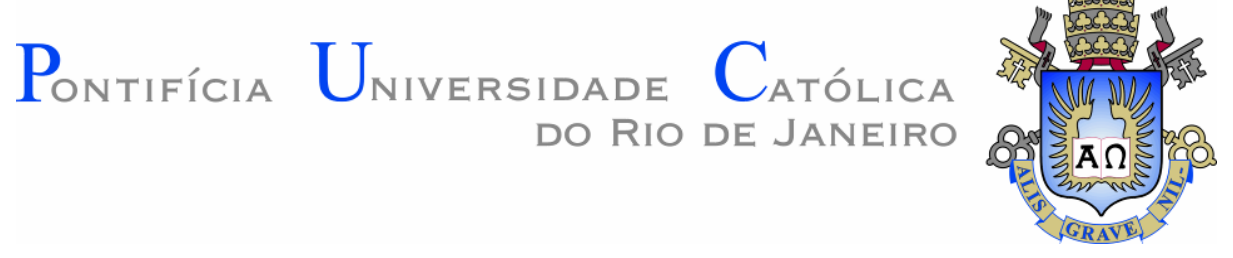

Geovane de Almeida Santos da Silva

\section{Desenvolvimento e Caracterização de Blendas PEAD/PA12}

Dissertação apresentada como requisito parcial para obtenção do grau de Mestre pelo programa de Pós-graduação em Engenharia de Materiais e Processos Químicos e Metalúrgicos da PUC - Rio

Prof. José Roberto Moraes d'Almeida

Orientador

Departamento de Engenharia Química e de Materiais - PUC-Rio

Profa. Sonia Letichevsky Departamento de Engenharia Química e de Materiais - PUC-Rio

Prof. Daniel Carlos Taissum Cardoso Departamento de Engenharia Civil e Ambiental - PUC-Rio

Dr. Marcos Henrique de Pinho Maurício Departamento de Engenharia Química e de Materiais - PUC-Rio

Prof. Marcio da Silveira Carvalho Coordenador Setorial do Centro Técnico Científico - PUC-Rio 
Todos os direitos reservados. É proibida a reprodução total ou parcial do trabalho sem a autorização da universidade, do autor e do orientador.

\section{Geovane de Almeida Santos da Silva}

Graduou-se em Engenharia Mecânica na Universidade do Estado do Rio de Janeiro (UERJ) em 2016. Trabalha no laboratório de microcaracterização de materiais da PUC-RJ com processamento e caracterização de polímeros e compósitos, tendo participado de alguns congressos relativos a estes assuntos.

Ficha Catalográfica

Silva, Geovane de Almeida Santos da

Desenvolvimento e caracterização de blendas PEAD/PA12 / Geovane de Almeida Santos da Silva ; orientador: José Roberto Moraes d'Almeida. - 2018.

181 f. : il. color. ; $30 \mathrm{~cm}$

Dissertação (mestrado)-Pontifícia Universidade Católica do Rio de Janeiro, Departamento de Engenharia Química e de Materiais, 2018.

Inclui bibliografia

1. Engenharia de Materiais - Teses. 2. Engenharia Química Teses. 3. Polietileno. 4. Poliamida. 5. Blendas poliméricas. 6. Miscibilidade. 7. Tração. I. Almeida, José Roberto Moraes d'. II. Pontifícia Universidade Católica do Rio de Janeiro. Departamento de Engenharia Química e de Materiais. III. Título. 


\section{Agradecimentos}

Primeiramente a Deus por me proteger, cuidar da minha família e me dar forças para seguir meus sonhos e conquistar o título de Mestre.

Aos meus pais e amigos por estarem sempre comigo e me apoiarem durante a minha trajetória.

Ao meu orientador José Roberto Moraes d'Almeida pela orientação, atenção, paciência e pela grande confiança depositada em mim. Agradeço também pelo compartilhamento dos seus conhecimentos que foram de grande contribuição na elaboração desta Dissertação.

À PUC-Rio, CAPES e CNPq pelas contribuições financeiras que foram fundamentais durante meu Mestrado.

À Daphne e todos os colaboradores do Laboratório de Biocombustíveis (LABIO)

- Departamento de Química - PUC-Rio pela realização da análise por FTIR.

À professora Sonia pela realização dos ensaios de DRX, ao professor Avillez pelas análises dos difratogramas e ao meu amigo Ayrton Pereira pela montagem das imagens das curvas das áreas cristalina e amorfa e pelo tempo cedido pelos mesmos em tais atividades.

À professora Veronica Calado por ter cedido o laboratório Lateq da UFRJ para a realização do ensaio reométrico no reômetro de placas paralelas.

Ao Dr. Marcos Henrique por ter cedido seu tempo e atenção para análise da morfologia no MEV.

Aos membros da banca examinadora por terem aceitado participar da mesma e compartilharem seus conhecimentos comigo.

À PUC-Rio por toda a infraestrutura com ótimos laboratórios disponíveis para realizar os ensaios necessários no desenvolvimento do trabalho. 


\section{Resumo}

Silva, Geovane de Almeida Santos da; d'Almeida, José Roberto Moraes. Desenvolvimento e Caracterização de blendas PEAD/PA12. Rio de Janeiro, 2018. 181p. Dissertação de Mestrado - Departamento de Engenharia Química e de Materiais, Pontifícia Universidade Católica do Rio de Janeiro.

Blenda polimérica é a mistura física de dois ou mais polímeros, sem reação química intencional entre os componentes. O objetivo básico é combinar as melhores propriedades de cada componente da blenda que, consequentemente, terá propriedades intermediárias àquelas dos polímeros misturados. As maiores vantagens das blendas são a grande variedade e a versatilidade de suas aplicações, que, somadas à facilidade de processamento, possibilitam a produção dos mais diversos produtos, tornando-as competitivas em relação a outros materiais. Outra finalidade das blendas é otimizar a relação custo/benefício e melhorar a processabilidade de polímeros de alta temperatura. Os materiais utilizados neste trabalho foram o PEAD e a PA12, ambos os polímeros sendo de grande importância industrial. O objetivo do trabalho é produzir blendas poliméricas de PEAD/PA12, avaliar a sua miscibilidade e realizar ensaios para extrair suas propriedades. As blendas foram feitas em três composições: 75/25, 50/50 e 25/75 e foi feita a caracterização mecânica com ensaios de tração e fluência, química com análise FTIR e DRX, reológica e análise por MEV e os resultados foram usados para avaliar a combinação das propriedades dos polímeros puros nestas blendas.

\section{Palavras-chave}

Polietileno; poliamida; blendas poliméricas; miscibilidade; tração. 


\section{Abstract}

Silva, Geovane de Almeida Santos da; d'Almeida, José Roberto Moraes (Advisor). Development and Characterization of HDPE/PA12 blends. Rio de Janeiro, 2018. 181p. Dissertação de Mestrado - Departamento de Engenharia Química e de Materiais, Pontifícia Universidade Católica do Rio de Janeiro.

Polymer blend is the physical mixture of two or more polymers without any intentional chemical reaction between the components. The basic goal is to combine the best properties of each blend component that, consequently, will have intermediary properties to those of the polymers used. The biggest advantages of the blends are the great variety and the versatility on their applications that added to the good processability, make possible the production of many products making them competitive in relation to other materials. Another objective of the blends is to optimize the cost/benefit relation and improve the processability of high temperature polymers. The materials used on this work were the HDPE and the PA12, both polymers being of great industrial importance. The interest of this work is to produce HDPE/PA12 blends and evaluate their miscibility and make tests to know their properties. The blends were made in three compositions: 75/25, $50 / 50$ and $25 / 75$ and it was done the mechanical characterization with uniaxial tension and creep behavior, chemical characterization with FTIR analysis and xray diffraction, rheology and SEM analysis and the results were used to evaluate the combination of the properties of the neat polymers used in these blends.

\section{Keywords}

Polyethylene; polyamide; polymer blends; miscibility; uniaxial tension. 


\section{Sumário}

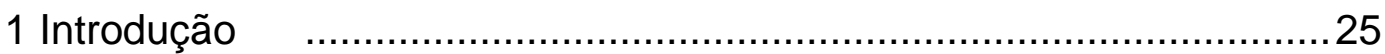

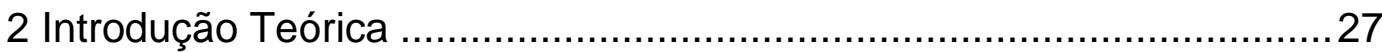

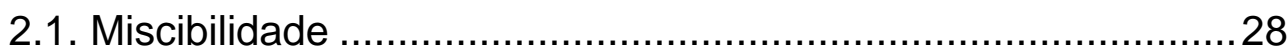

2.1.1. Termodinâmica das blendas poliméricas .......................29

2.1.2. Blendas poliméricas miscíveis ....................................... 31

2.1.3. Blendas poliméricas imiscíveis ...................................... 32

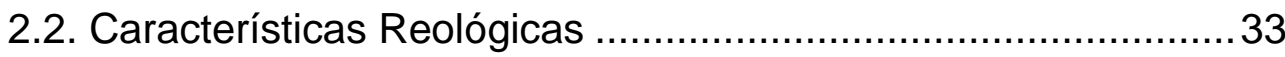

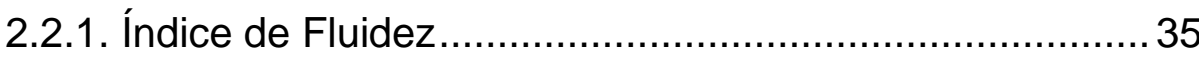

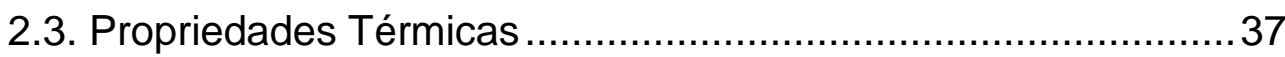

2.3.1. Temperatura de Transição Vítrea $\left(T_{g}\right)$...........................37

2.3.1.1. Sistemas homogêneos, miscíveis ou monofásicos (Copolímeros homogêneos ou Poliblendas Compatíveis) ..............37

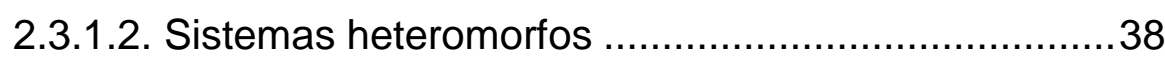

2.3.1.2.1. Aleatório ou alternado .......................................38

2.3.1.2.2. Em bloco e copolímeros grafitizados

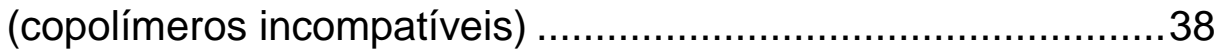

2.3.2. Temperatura de fusão cristalina $(\mathrm{Tm})$............................ 39

2.3.2.1. Sistemas homogêneos, miscíveis ou monofásicos ..39

2.3.2.2. Sistemas heterogêneos, imiscíveis ou polifásicos....40

2.4. Espectro Infravermelho (FTIR) ............................................. 41

2.5. Difração de Raios-X (DRX) ...................................................... 42

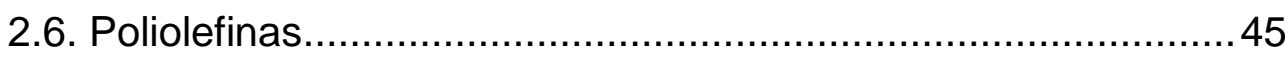

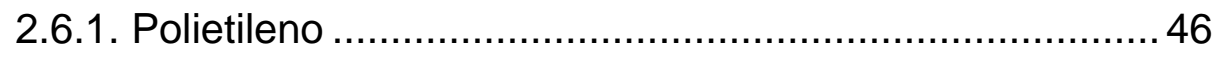

2.6.1.1. Polietileno de Alta Densidade (PEAD) .....................46

2.6.1.1.1. Processos de polimerização ...............................46

2.6.1.1.2. Propriedades ................................................4

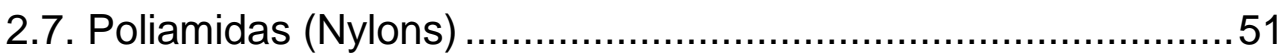

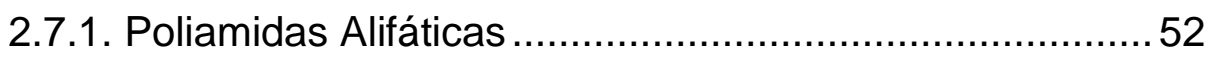




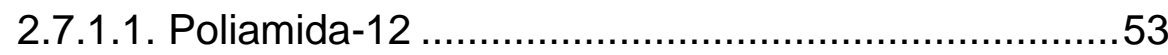

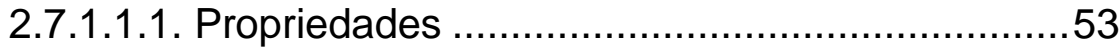

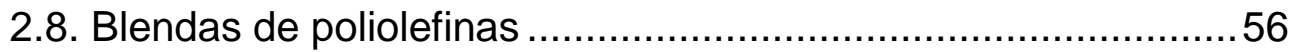

2.8.1. Blendas de Poliolefina-Poliamida .................................57

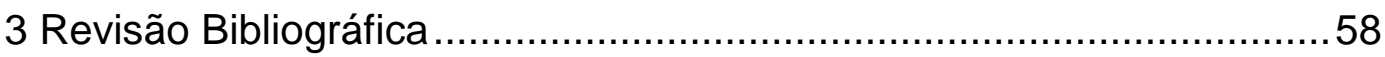

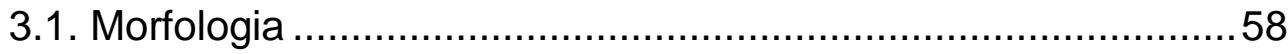

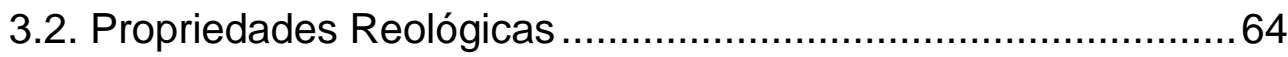

3.3. Efeitos do Polietileno na Reologia e Morfologia das Blendas

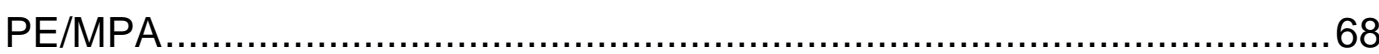

3.4. Propriedades Mecânicas........................................................ 70

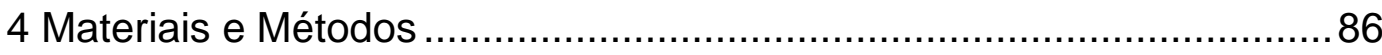

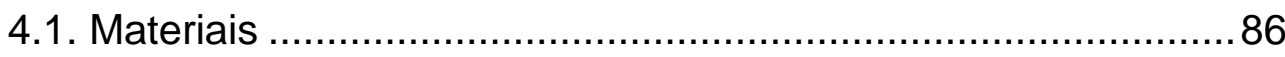

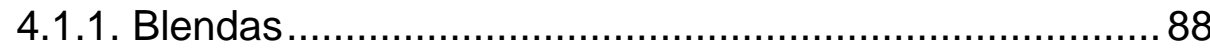

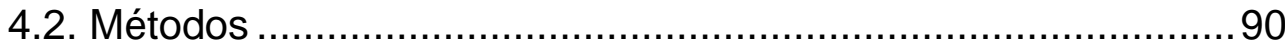

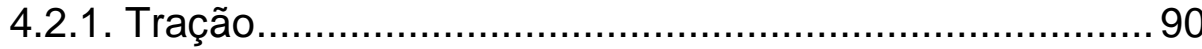

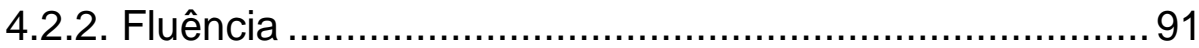

4.2.3. Análise por Infravermelho (FTIR) .................................91

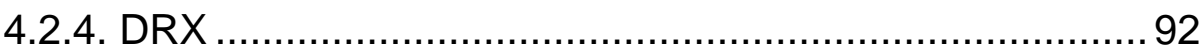

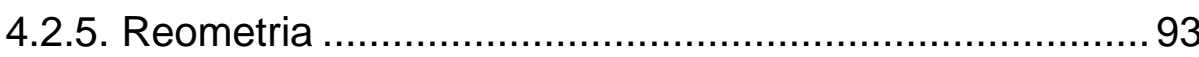

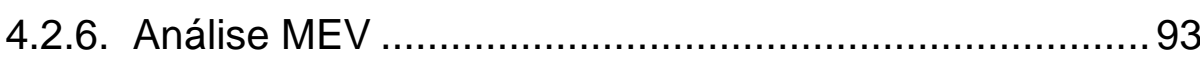

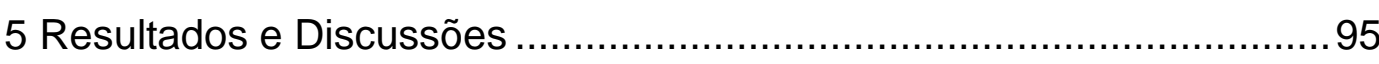

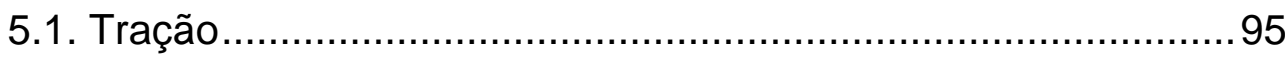

5.1.1. Efeito do teor de compatibilizante ..................................95

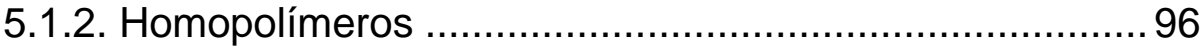

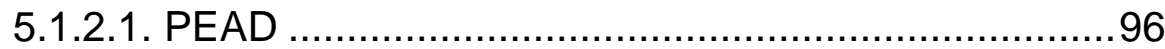

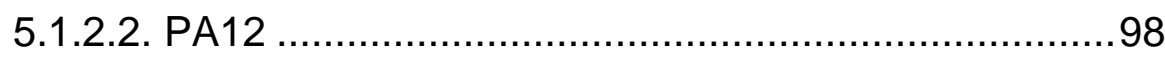

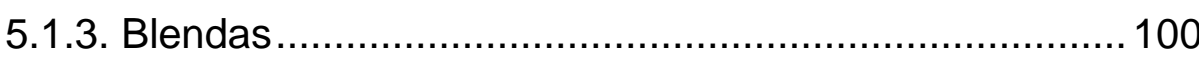

5.1.3.1. PEAD/PA12 75/25 ........................................... 100

5.1.3.2. PEAD/PA12 50/50 ................................................ 103

5.1.3.3. PEAD/PA12 25/75 ................................................. 105 


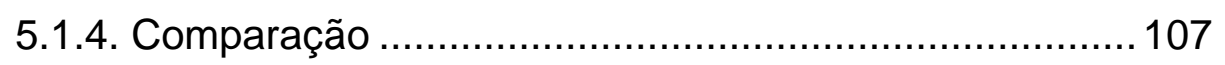

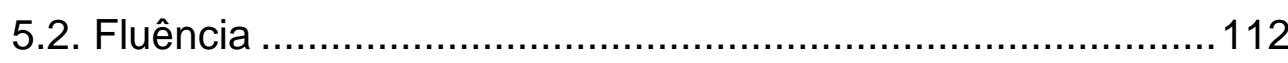

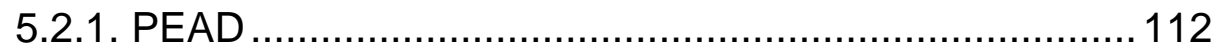

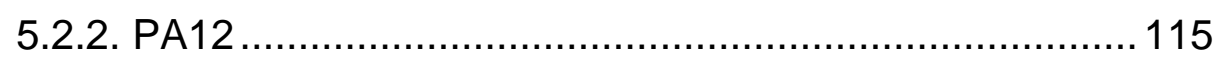

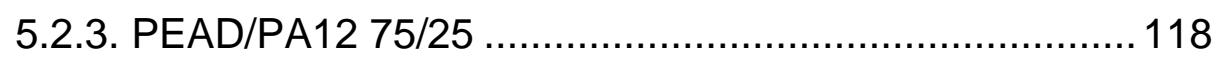

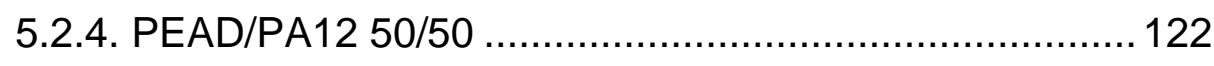

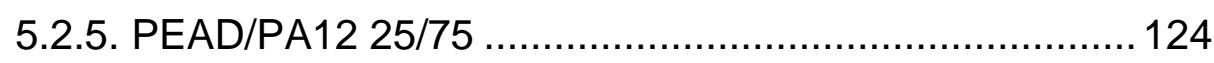

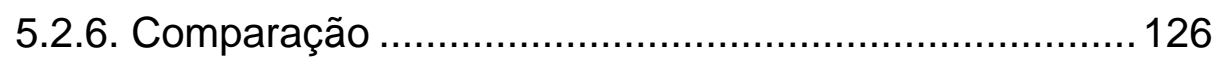

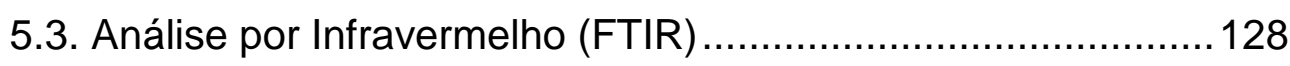

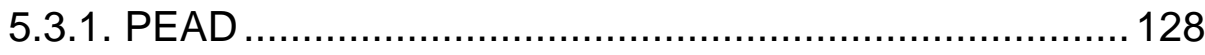

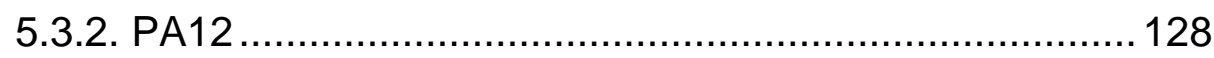

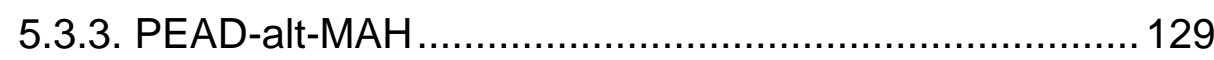

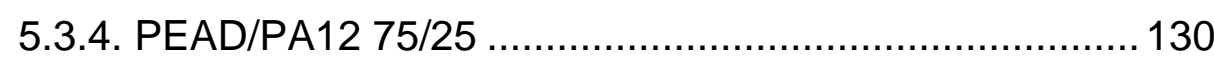

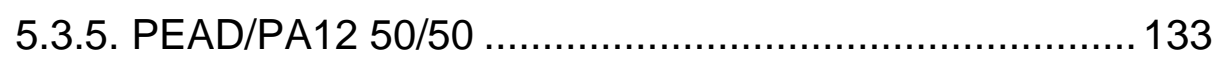

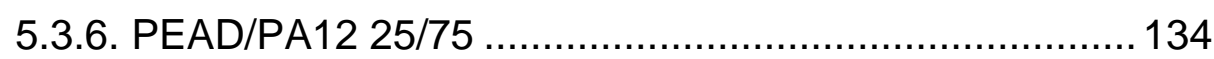

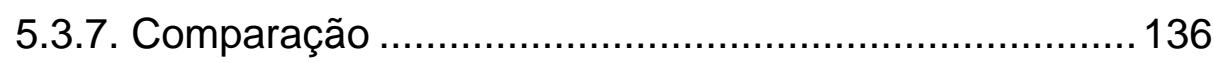

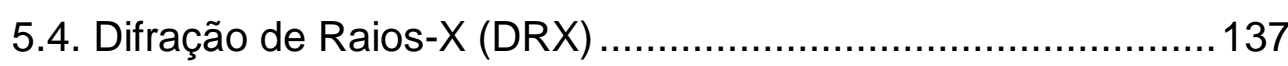

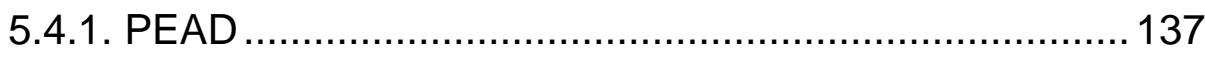

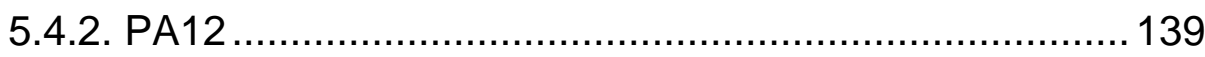

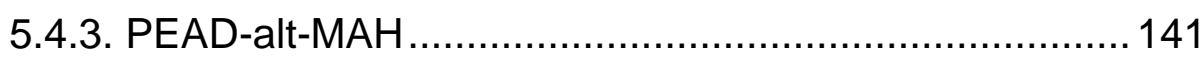

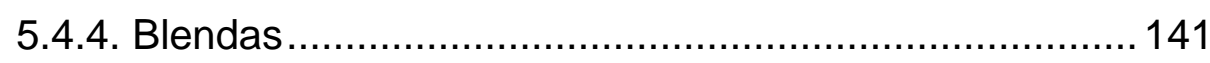

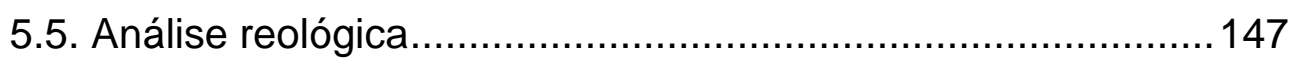

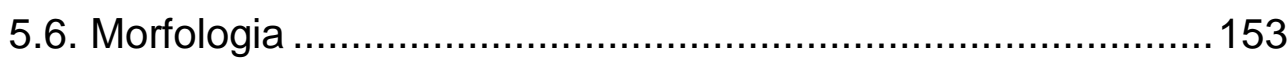

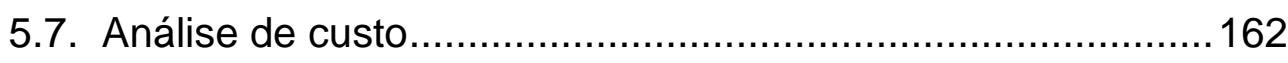

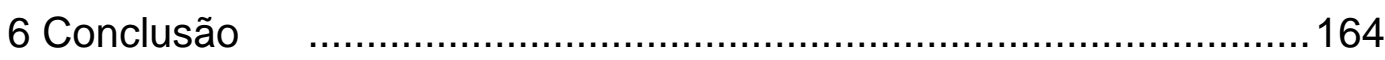

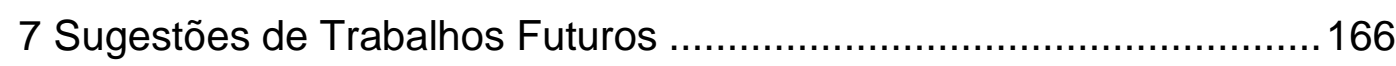

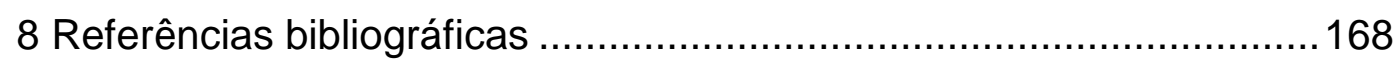

ANEXO A - ETAPAS DO PROCESSO DE SEGMENTAÇÃO ..................174 
ANEXO B - HISTOGRAMAS DOS DIÂMETROS DAS FASES

DISPERSAS

179 


\section{Lista de Figuras}

Figura 1. Representação da Mistura Mecânica realizada em blendas poliméricas.

Figura 2. Terminologia das ligas poliméricas e blendas [3] 29

Figura 3. Geometria dos reômetros: a) placas paralelas e b) cone e placa [20]. 35

Figura 4. Variação da Temperatura de Transição Vítrea da blenda homogênea na curva 1 [2]. As curvas 2 e 3 serão explicadas a seguir....37 Figura 5. Queda do módulo de elasticidade denotando as duas $T_{g} \mathrm{~s}$ presentes em sistemas imiscíveis [1]. 39

Figura 6. Temperaturas de fusão de poli(hexametileno sebacamida co - hexametileno tereftalamida) e poli (hexametileno adipamida - co hexametileno tereftalamida) [1] 40

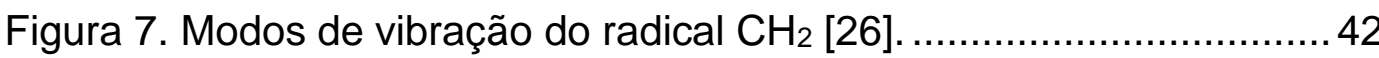

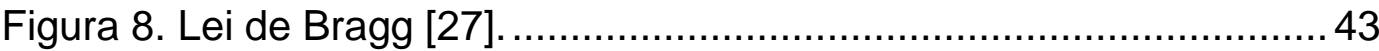

Figura 9. Geometria parafocal Bragg-Brentano [27]........................... 43

Figura 10. Difratograma típico usado no cálculo do percentual de cristalinidade. $A_{a}=$ contribuição amorfa, $A_{c}=$ contribuição cristalina [29]. 44

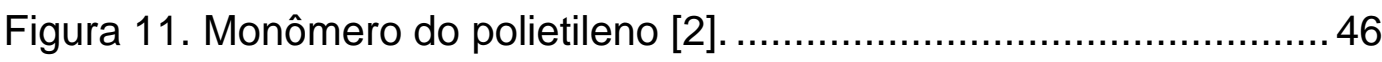

Figura 12. Reação de polimerização do polietileno................................. 47

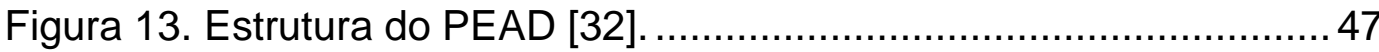

Figura 14. Estrutura geral dos nylons [35]........................................... 51

Figura 15. Nomenclatura e reação química dos nylons [2] .....................52

Figura 16. Estrutura molecular da PA 12 [36].......................................53

Figura 17. Absorção de umidade de poliamidas em função da umidade relativa [5]. 55

Figura 18. Micrografia no MEV de $10 \%$ PA6 extrudado à $200^{\circ} \mathrm{C} \mathrm{e}$ $1230 \mathrm{~s}^{-1}$; (A) centro e (B) borda do extrudado a um aumento de 1000x [6]. 
Figura 19. Micrografia no MEV de $20 \%$ PA6 extrudado à $150^{\circ} \mathrm{C} \mathrm{e}$ $1110 \mathrm{~s}^{-1}$; (A) centro e (B) borda do extrudado a um aumento de 1000x [6]. 59

Figura 20. Micrografia no MEV de $20 \%$ PA6 extrudado à $250^{\circ} \mathrm{C}$ e 12 $\mathrm{S}^{-1}$; (A) centro e (B) borda do extrudado a um aumento de 1000x [6]. 59

Figura 21. Micrografia no MEV de $30 \%$ PA6 extrudado à $150^{\circ} \mathrm{C}$ e 370 $\mathrm{S}^{-1}$; (A) centro e (B) borda do extrudado a um aumento de 500x [6]. 59 Figura 22. Micrografia no MEV de $30 \%$ PA6 extrudado à $250^{\circ} \mathrm{C}$ e 116 $\mathrm{s}^{-1}$; (A) centro e (B) borda do extrudado a um aumento de 1000x [6]. ....66 60 Figura 23. Micrografia no MEV de $30 \%$ PA extrudado a $250^{\circ} \mathrm{C}$ e 1110 $\mathrm{s}^{-1}$. (A) visão geral (B) detalhes do extrudado sob, respectivamente, um aumento de 43x e 1000x [6].

Figura 24. Superfícies fraturadas das amostras de garrafas prémoldadas com composição de 90\% PE e 10\% (a) PA, (b) MPAa, (c) MPAb, (d) MPAc [38]

Figura 25. Superfícies fraturadas das amostras de garrafas prémoldadas com blendas de PE e (a) 5\%, (b) 10\%, (c) 15\%, (d) 20\%, (e) $25 \%$, (f) $30 \%$ MPAb [38].

Figura 26. Superfícies fraturadas das amostras de garrafas de PE/MPAb pré-blendadas na extrusora antes da moldagem por sopro com (a) $10 \%$, (b) $20 \%$, (c) $30 \%$ de MPAb [38]. 64

Figura 27. Viscosidades reduzidas: cisalhante, п/aт, extensional,

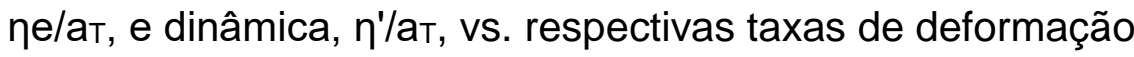
reduzidas: $\boldsymbol{\gamma}$.ат, $\boldsymbol{\varepsilon}$.ат е $\omega$. ат para PEAD [6]. 65

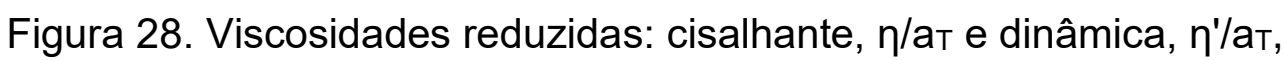
vs. taxa de cisalhamento reduzida, $\gamma$.ат, e frequência, $\omega$. aт, para $10 \%$ PA [6]. 65

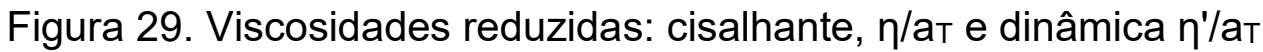
vs. taxa de cisalhamento reduzida, $\gamma$.ат е frequência $\omega$.ат para $20 \%$ PA [6] 66

Figura 30. Curvas mestra para PEAD, 10\% PA, 20\% PA e 30\% PA. A temperatura de referência $T_{R}=250^{\circ} \mathrm{C}$ foi usada [6] 
Figura 31. Módulo de energia armazenada, $G$ ' vs. frequência reduzida wat, para PEAD e 10\% PA à 150, 200 e $250^{\circ} \mathrm{C}$ e para PA-6 à $250^{\circ} \mathrm{C}$. A temperatura de referência é $T_{R}=250^{\circ} \mathrm{C}$ [6].

Figura 32. Viscosidades de cisalhamento do PE1 (+), PE2 (॰), PE3 $(\circ)$, PE4 $(\Delta)$, PE5 $(x)$, PE6 $(\diamond)$, MPA1 $(\Delta)$ e MPA2 $(\bullet)$ medidos a $230^{\circ} \mathrm{C}$ e taxas de cisalhamento variáveis [39]. 69

Figura 33. Razões de viscosidade de cisalhamento entre (a) MPA1 e PE1 (+), PE2 ( $)$, PE3 (-), PE4 (০), PE5 (), PE6(x), e (b) MPA2 e PE1 $(+)$, PE2 ( $\diamond)$, PE3 (-), PE4 (०), PE5 (口), PE6 (x) determinados a $230^{\circ} \mathrm{C}$ e taxas de cisalhamento variáveis [39]

Figura 34. Torque Barbender de blendas de nylon 6 (Capron 8207F) com vários polietilenos maleados. As medidas dos torques foram tomadas após 10 minutos a $240^{\circ} \mathrm{C}$ e $60 \mathrm{rev} \cdot \mathrm{min}^{-1}$ [41]. 74

Figura 35. Efeito da temperatura na resistência a impacto Izod das blendas de Capron 8207F e L-PE(0,9\% MA). Esse polietileno linear de baixa densidade tem uma baixa viscosidade e um alto conteúdo de anidrido [41].

Figura 36. Micrografias do MET das blendas de Capron 8207F e L$\mathrm{PE}(0,9 \% \mathrm{MA})$ contendo as seguintes frações de PELBD maleado: (a) $10 \%$; (b) $20 \%$; e (c) $30 \%$. A fase da poliamida está tingida de preto pelo ácido fosfotúngstico (PTA) [41]. 76

Figura 37. Propriedades de impacto de blendas de Capron 8207F e $\mathrm{H}-\mathrm{PE}(0,9 \% \mathrm{MA})$ : (a) resistência ao impacto Izod à temperatura ambiente; e (b) temperatura de transição dúctil-frágil. [41]. 77

Figura 38. Micrografias no MET das blendas de Capron 8207F e H$\mathrm{PE}(0,9 \% \mathrm{MA})$ contendo as seguintes frações de $\mathrm{H}-\mathrm{PE}(0,9 \% \mathrm{MA})$ : (a) $10 \%$; (b) $20 \%$; (c) $30 \%$; (d) $40 \%$; (e) $50 \%$; e (f) $60 \%$. A poliamida é tingida de preto por PTA [41]. 78

Figura 39. Propriedades de impacto de blendas de Capron 8207F e $\mathrm{H}-\mathrm{PE}(0,3 \% \mathrm{MA})$ : (a) Resistência a impacto Izod à temperatura ambiente; e (b) temperatura de transição dúctil-frágil. Este PELBD maleado tem uma alta viscosidade e uma baixa fração de anidrido [41]. 
Figura 40. Micrografias no MET de blendas de Capron 8207F e H$\mathrm{PE}(0,3 \% \mathrm{MA})$ contendo as seguintes frações de $\mathrm{H}-\mathrm{PE}(0,3 \% \mathrm{MA})$ : (a) $10 \%$; (b) $20 \%$; (c) $30 \%$; (d) $40 \%$; (e) $50 \%$; e (f) $60 \%$. A fase da poliamida está tingida de preto por PTA [41].

Figura 41. Torque Brabender de blendas de nylon 6 (Capron 8209F) com vários polietilenos maleados. A leitura dos torques foi tomada após 10 minutos a $24^{\circ} \mathrm{C}$ e 60 rev. $\mathrm{min}^{-1}[41]$.

Figura 42. Efeitos da temperatura na resistência a impacto Izod em blendas de Capron 8209F e L-PE(0,9\% MA). Este PELBD maleado tem uma baixa viscosidade e uma alta porção de anidrido [41] 82

Figura 43. Micrografias no MET de blendas de Capron 8209F e L$\mathrm{PE}(0,9 \% \mathrm{MA})$ contendo as seguintes frações do PELBD maleado: (a) $10 \%$; (b) $20 \%$; e (c) $30 \%$. A fase da poliamida está tingida de preto por PTA [41] 83

Figura 44. Efeito da temperatura na resistência a impacto Izod em blendas de Capron 8209F e H-PE(0,9\% MA). Este PELBD maleado tem uma alta viscosidade e uma alta porção de anidrido [41] 84 Figura 45. Micrografias no MET de blendas de Capron 8209F e L$\mathrm{PE}(0,9 \% \mathrm{MA})$ contendo as seguintes frações do LLPE maleado: (a) $10 \%$; (b) $20 \%$; e (c) $30 \%$. A fase da poliamida está tingida de preto por PTA [41]. 85

Figura 46. Pellets dos polímeros usados: a) PEAD; b) PA 12. 86

Figura 47. Estrutura química do agente compatibilizante utilizado neste trabalho [45]

Figura 48. Extrusora (a) e injetora (b) utilizadas na fabricação dos

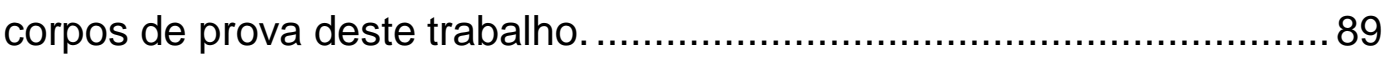

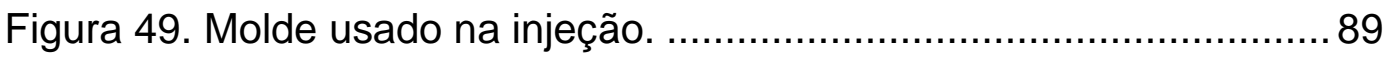

Figura 50. Máquina de ensaios de tração. .............................................90

Figura 51. Corpos de prova de PA12 100\% usados nos ensaios de tração. 90

Figura 52. Corpo de prova de PA12 100\% usado nos ensaios de fluência.

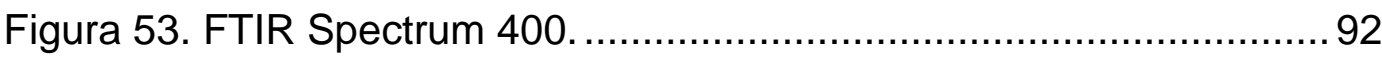

Figura 54. Reômetro de placas paralelas............................................. 93 
Figura 55. Gráfico tensão x deformação de engenharia do Corpo de Prova número 1 de PEAD.

Figura 56. Gráfico tensão x deformação verdadeira do Corpo de

Prova número 1 de PEAD.

Figura 57. Gráfico Tensão x Deformação de engenharia do Corpo de

Prova número 1 de PA12. 98

Figura 58. Gráfico Tensão x Deformação verdadeira do Corpo de Prova número 1 de PA12. 99

Figura 59. Gráfico tensão x deformação do corpo de prova número 1 da blenda 75/25. Observa-se que não há a formação do platô após o escoamento.

Figura 60. Gráfico tensão x deformação do corpo de prova número 2 da blenda 75/25 (fratura frágil). 101

Figura 61. Gráfico tensão x deformação do corpo de prova número

10 da blenda 75/25. Ruptura com maior ductilidade. 102

Figura 62. Corpo de prova número 6 da blenda 75/25 após os ensaios de tração. 102

Figura 63. Gráfico tensão x deformação de engenharia do corpo de prova número 1 da blenda 50/50 104

Figura 64. Corpo de prova número 1 de 50/50 após o ensaio de tração. 105

Figura 65. Gráfico tensão x deformação de engenharia do Corpo de prova número 7 da blenda $25 / 75$ 105

Figura 66. Corpo de prova número 4 de 25/75 após o ensaio de tração. 107

Figura 67. Box Plot - Limite de Escoamento ........................................ 108

Figura 68. Box Plot - Tensão de Ruptura............................................ 109

Figura 69. Box Plot - Módulo de Elasticidade....................................... 109

Figura 70. Box Plot - Deformação na Ruptura....................................... 110

Figura 71. Box Plot - Tenacidade. .................................................. 110

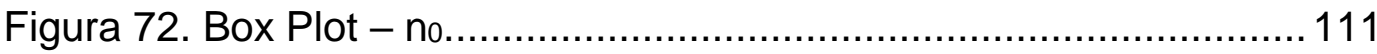

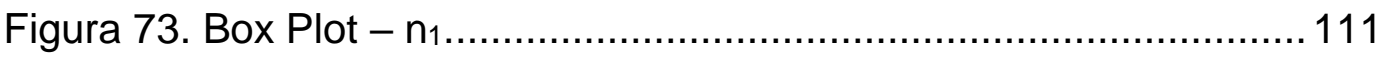

Figura 74. Gráfico Radar de comparação das propriedades das blendas em relação à PA12. 
Figura 75. Exemplo da curva deformação vs. tempo (CP 01, PEAD). ...113 Figura 76. Comparação dos modelos viscoelásticos para o CP 01 de PEAD.

Figura 77. Exemplo da curva deformação vs. tempo (CP 01, PA12) .... 115 Figura 78. Comparação dos modelos viscoelásticos para o CP 01 de PA12.

Figura 79. Exemplo da curva deformação vs. tempo (CP 02 , PEAD/PA12 75/25)

Figura 80. Comparação dos modelos viscoelásticos para o CP 02 do PEAD/PA12 75/25.

Figura 81. Curva Deformação x Tempo do CP04 da blenda 75/25....... 121

Figura 82. Curva Deformação x Tempo do CP06 da blenda 75/25....... 121

Figura 83. Exemplo da curva deformação vs. tempo (CP 01, PEAD/PA12 50/50).

Figura 84. Comparação dos modelos viscoelásticos para o CP 01 do PEAD/PA12 50/50.

Figura 85. Exemplo da curva deformação vs. tempo (CP 04, PEAD/PA12 25/75)

Figura 86. Comparação dos modelos viscoelásticos para o CP 04 do PEAD/PA12 25/75. 125

Figura 87. Box Plot - Creep Compliance. 127

Figura 88. Espectro IV do PEAD. 128

Figura 89. Espectro IV da PA12. 129

Figura 90. Espectro IV do agente compatibilizante PEAD-alt-MAH. ...... 130

Figura 91. Espectro IV comparativo das blendas 75/25 no intervalo entre $4000-2500 \mathrm{~cm}^{-1}$.

Figura 92. Espectro IV comparativo das blendas $75 / 25$ no intervalo entre $2000-1000 \mathrm{~cm}^{-1}$. 131

Figura 93. Reação entre uma amida e um anidrido [53]. 132

Figura 94. Representação da imida formada na reação de compatibilização [54].

Figura 95. Espectro IV das blendas 50/50 no intervalo entre 4000 $2500 \mathrm{~cm}^{-1}$ 
Figura 96. Espectro IV das blendas 50/50 no intervalo entre 2000 $1000 \mathrm{~cm}^{-1}$.

Figura 97. Espectro IV das blendas $25 / 75$ no intervalo entre $4000-$ $2500 \mathrm{~cm}^{-1}$

Figura 98. Espectro IV das blendas $25 / 75$ no intervalo entre 2000 -

$1000 \mathrm{~cm}^{-1}$

Figura 99. Comparativo dos espectros IV das blendas $2 \%$ no

intervalo de comprimentos de onda de $4000-2500 \mathrm{~cm}^{-1}$

Figura 100. Comparativo dos espectros IV das blendas $2 \%$ no intervalo de comprimentos de onda de $2000-500 \mathrm{~cm}^{-1}$. 136

Figura 101. Difratograma do PEAD

Figura 102. Difratograma do PEAD com seus respectivos picos

representativos das regiões amorfa e cristalina.

Figura 103. Difratograma da PA12

Figura 104. Difratograma da PA12 com seus respectivos picos representativos das regiões amorfa e cristalina.

Figura 105. Espectrograma do PEAD-alt-MAH com os seus dois picos mais fortes destacados em linhas verticais.

Figura 106. Difratogramas das blendas com os picos referentes ao

PEAD, PA12 e a região amorfa: a) 75/25, b) 50/50 e c) 25/75

Figura 107. Comparação do grau de cristalinidade dos

homopolímeros e das blendas.

Figura 108. Variação do tamanho dos cristalitos. 145

Figura 109. Viscosidade dinâmica $x$ taxa de cisalhamento a $200^{\circ} \mathrm{C}$...... 148

Figura 110. Tensão cisalhante $x$ taxa de cisalhamento a $200^{\circ} \mathrm{C}$ 150

Figura 111. Viscosidade em função da composição da PA12 na blenda. 152

Figura 112. Fratura de um corpo de prova da blenda $75 / 25 \mathrm{com} 0 \%$ de compatibilizante. 153

Figura 113. Morfologias da blenda 75/25 com: a) e b) $0 \%$, c) e d) $2 \%$, e) e f) $3 \%$ de PEAD-alt-MAH, com magnificação de 2000x (a, c e e) e $5000 x$ (b, d e f). 
Figura 114. Morfologias da blenda 50/50 com: a) e b) 0\%, c) e d) $2 \%$, e) e f) $3 \%$ de PEAD-alt-MAH, com magnificação de 2000x (a, c e e) e $5000 x$ (b, d e f).

Figura 115. Morfologias da blenda 25/75 com: a) e b) $0 \%$, c) e d) $2 \%$, e) e f) $3 \%$ de PEAD-alt-MAH, com magnificação de 2000x (a, c e e) e $5000 x$ (b, d e f). 156

Figura 116. Morfologia da blenda $75 / 25$ com $2 \%$ de PEAD-alt-MAH pelo detector BSE (x2000).

Figura 117. Morfologia da blenda 50/50 com 0\% de PEAD-alt-MAH pelo detector BSE (x2000).

Figura 118. Fratura no corpo de prova $50 / 50$ com $2 \%$ de PEAD-alt$\mathrm{MAH}(\mathrm{x} 25)$ 160

Figura 119. Micrografia da blenda 50/50 com 2\% de PEAD-alt-MAH com aumento de 5000x, com os círculos indicando alguns domínios presentes e as setas indicando algumas fases distintas seja dentro dos domínios ou na matriz.

Figura 120. Diâmetro das partículas dispersas em função da porcentagem de PA6 na blenda PP/PA, onde mostra a faixa onde ocorre a fase co-contínua [69] 


\section{Lista de Tabelas}

Tabela 1. Propriedades do PEAD [32].

Tabela 2. Comparativo das propriedades mecânicas do PEAD linear, PEAD Ziegler e o PEBD, onde as colunas mostram a comparação de cada propriedade [32]

Tabela 3. Comparação de características entre o PEBD e PEAD [32] ...51

Tabela 4. Propriedades da Poliamida 12 [37, 2]......

Tabela 5. Temperatura de Fusão e Absorção de Água dos tipos de nylon [2].

Tabela 6. Índices de fluidez e densidades de PE, PA e CPs [38]. ...........62

Tabela 7. Propriedades físicas dos PEs, CP e PAs [39]. 69

Tabela 8. Propriedades mecânicas das blendas de PA6/PEAD com PEAD-g-MAH [40]. .71

Tabela 9. Nylons 6 usados no trabalho de Kudva e col. [41]. ..................72

Tabela 10. Polietilenos usados neste estudo [41] .................................73

Tabela 11. Propriedades do PEAD empregado neste trabalho [43].........86

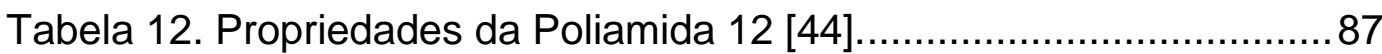

Tabela 13. Algumas propriedades do PEAD-alt-MAH $[45,46] \ldots \ldots \ldots \ldots \ldots \ldots . . .87$

Tabela 14. Grupos de materiais analisados. ....................................... 88

Tabela 15. Ensaio teste para comparação das propriedades das

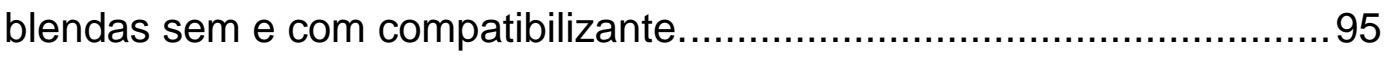

Tabela 16. Propriedades mecânicas de tração do PEAD puro. ................98

Tabela 17. Propriedades mecânicas de tração da PA12. .........................99

Tabela 18. Propriedades mecânicas de tração da blenda 75/25 .......... 103

Tabela 19. Propriedades mecânicas de tração da blenda 50/50 .......... 104

Tabela 20. Propriedades mecânicas de tração da blenda 25/75 ..........106

Tabela 21. Comparação entre as principais propriedades mecânicas de engenharia dos homopolímeros e das blendas com $2 \%$ de PEAD-alt-MAH.

Tabela 22. Comparação entre a tenacidade e resiliência das blendas com compatibilização de PEAD-alt-MAH. 
Tabela 23. Comparação dos parâmetros dos modelos viscoelásticos para o PEAD.

Tabela 24. Valores de deformação instantânea e taxa de fluência para o PEAD.

Tabela 25. Comparação dos parâmetros dos modelos viscoelásticos para a PA12.

Tabela 26. Valores de deformação instantânea e taxa de fluência para a PA12.

Tabela 27. Comparação dos parâmetros dos modelos viscoelásticos para a blenda 75/25.

Tabela 28. Valores de deformação instantânea e taxa de fluência para a blenda PEAD/PA12 75/25.

Tabela 29. Comparação dos parâmetros dos modelos viscoelásticos para a blenda 50/50.

Tabela 30. Valores de deformação instantânea e taxa de fluência para a blenda PEAD/PA12 50/50.

Tabela 31. Comparação dos parâmetros dos modelos viscoelásticos para a blenda $25 / 75$.

Tabela 32. Valores de deformação instantânea e taxa de fluência para a blenda PEAD/PA12 25/75.

Tabela 33. Coeficientes de correlação dos modelos viscoelásticos das blendas e dos homopolímeros. Os valores em negrito indicam o modelo que melhor descreveu o comportamento experimental. 126

Tabela 34. Comparação das taxas de fluência estacionárias. 127

Tabela 35. Cálculo do grau de cristalinidade do PEAD. 138

Tabela 36. Valores dos parâmetros de rede e do tamanho médio do cristalito do PEAD.

Tabela 37. Cálculo do grau de cristalinidade da PA12.

Tabela 38. Valores dos parâmetros de rede e do tamanho médio do cristalito da PA12.

Tabela 39. Grau de cristalinidade e parâmetros de rede da blenda $75 / 25$.

Tabela 40. Grau de cristalinidade e parâmetros de rede da blenda $50 / 50$. 
Tabela 41. Grau de cristalinidade e parâmetros de rede da blenda $25 / 75$.

Tabela 42. Valores da consistência e da pseudoplasticidade do PEAD e das blendas compatibilizadas com 2\% de PEAD-alt-MAH. ......152

Tabela 43. Valores dos diâmetros das fases dispersas das blendas $75 / 25$ e $25 / 75$

Tabela 44. Preço por quilo das blendas compatibilizadas com $2 \%$ de PEAD-alt-MAH. 162 


\section{Lista de Abreviaturas e Siglas}

ABS

ASME

ASTM

ATR

BSE

CP

$\mathrm{CP}$

DSC

DRX

EPDM

EVA

FTIR

GC

GE

$\mathrm{HCl}$

HF

IV

$\mathrm{K}_{2} \mathrm{Cr}_{2} \mathrm{O}_{7}$

$\mathrm{KMnO}_{4}$

MA

MET

MEV

$\mathrm{MI}$

$\mathrm{MPa}$

MPA

$N$

PA

PA6

PA12
Copolímero de Acrilonitrila, Butadieno e Estireno

American Society of Mechanical Engineers

American Society for Testing and Materials

Refletância Total Atenuada

Elétrons retro-espalhados

Agente compatibilizante

Corpo de Prova

Calorimetria Diferencial de Varredura

Difração de Raio-X

Etileno-propileno-dieno

Acetato-vinilo de etileno

Espectroscopia Infravermelho por Transformada de Fourier

Grau de Cristalinidade

General Electric

Ácido Clorídrico

Ácido Fluorídrico

Infravermelho

Dicromato de Potássio

Permanganato de Potássio

Anidrido Maleico

Microscópio Eletrônico de Transmissão

Microscópio Eletrônico de Varredura

Índice de fluidez

MegaPascal

Poliamida modificada

Newton

Poliamida

Poliamida 6

Poliamida 12 


\begin{tabular}{|c|c|}
\hline PBT & Polibutileno Tereftalato \\
\hline PE & Polietileno \\
\hline PEAD & Polietileno de Alta Densidade \\
\hline PEAD-alt-MAH & Copolímero Alternado de PEAD com Anidrido Maleico \\
\hline PEBD & Polietileno de Baixa Densidade \\
\hline PELBD & Polietileno Linear de Baixa Densidade \\
\hline PET & Politereftalato de etileno \\
\hline PEUAMM & Polietileno de Ultra Alta Massa Molar \\
\hline $\mathrm{pH}$ & Índice de acidez \\
\hline PMMA & Polimetacrilato de metila \\
\hline PP & Polipropileno \\
\hline PPE & Éter de polifenileno \\
\hline PPO & Poli(óxido de fenileno) \\
\hline PPS & Poli(sulfeto de $p$-fenileno) \\
\hline PS & Poliestireno \\
\hline PTA & Ácido tereftálico purificado \\
\hline PTFE & Politetrafluoretileno \\
\hline PVC & Policloreto de vinila \\
\hline SE & Életrons Secundários \\
\hline SEBS & Copolímero Estireno-Etileno-Butadieno-Estireno \\
\hline TGA & Análise Termo-gravimétrica \\
\hline u.a. & Unidade de Área \\
\hline UV & Radiação ultravioleta \\
\hline
\end{tabular}




\section{Lista de Símbolos}

$\Delta \mathrm{G}_{\mathrm{m}} \quad$ Variação molar da energia livre de Gibbs

$\Delta \mathrm{H}_{\mathrm{m}} \quad$ Variação molar da entalpia

$\mathrm{T}$

Temperatura absoluta

$\Delta S_{m} \quad$ Variação molar da entropia

Tg Temperatura de Transição Vítrea

$T_{m} \quad$ Temperatura de fusão cristalina

$\lambda \quad$ Comprimento de onda

$\theta \quad$ Ângulo

$\eta_{\mathrm{e}} \quad$ Viscosidade extensional

$\eta \quad$ Viscosidade cisalhante

ๆ' Viscosidade dinâmica

$\dot{\varepsilon} \quad$ Deformação extensional

$\dot{\gamma}$

Taxa de deformação cisalhante

$\omega$

Frequência

$\eta_{0}$

Viscosidade à zero cisalhamento

G'

Módulo de armazenamento

$\mu \mathrm{m}$

Micrômetro

rpm

Rotações por minuto

$\sigma y$

Limite de Escoamento

$\sigma_{R}$

Tensão de ruptura

E

Módulo de Elasticidade

$\varepsilon_{y}$

Deformação no Escoamento

$\varepsilon R$

Deformação na Ruptura

no

Coeficiente de encruamento da fase amorfa

$\mathrm{n}_{1}$

Coeficiente de encruamento da fase cristalina

Å Ângstrom

$\mathrm{nm}$

Nanômetro 


\section{Introdução}

Blenda polimérica é a mistura física de dois ou mais polímeros, sem reação química intencional entre os componentes [1]. O objetivo básico é combinar as melhores propriedades de cada componente da blenda que, consequentemente, terá propriedades intermediárias àquelas dos polímeros misturados, tais como resistência mecânica e temperatura de fusão, por exemplo. Em alguns casos é mesmo possível que a mistura gere propriedades superiores aos dos componentes individuais.

As maiores vantagens das blendas são a grande variedade e a versatilidade de suas aplicações, que, somadas à facilidade de processamento, possibilitam a produção dos mais diversos produtos, tornando-as competitivas em relação a outros materiais. Outra finalidade das blendas é otimizar a relação custo/benefício e melhorar a processabilidade de polímeros de alta temperatura [2]. Uma estratégia comum para atingir estes objetivos é combinar um polímero cristalino com um amorfo. Materiais cristalinos como o nylon, poli(butileno tereftalato) e polietileno oferecem excelente resistência química, facilidade de processamento e rigidez, mas têm pouca resistência ao impacto.

Blendas poliméricas são, na sua maioria, imiscíveis e por isso tendem a separar fases, formando misturas heterogêneas. Grandes esforços têm sido empregados com o objetivo de encontrar novas combinações miscíveis [3]. Blendas miscíveis são homogêneas, portanto apresentam uma única fase. A miscibilidade entre os polímeros que constituem a blenda tem um peso muito grande no desenvolvimento de um material polimérico [4].

Na blenda de ABS com PVC, por exemplo, o ABS contribui com aumento da temperatura de distorção térmica, tenacidade e fácil moldabilidade, enquanto o PVC possui resistência às influências do clima e retardamento do fogo, além de reduzir o custo da blenda. Aplicações desta blenda incluem acabamento interior de automóveis, bagagens e canoas [5].

Os materiais a serem utilizados neste trabalho são a Poliamida-12 (PA ou nylon-12) e o PEAD (polietileno de alta densidade). Serão fabricadas blendas 
poliméricas com diferentes porcentagens de cada componente e o objetivo será avaliar a miscibilidade entre estes dois polímeros, tanto quanto as propriedades da blenda em relação aos materiais puros mediante caracterização mecânica de tração e fluência, química com FTIR e DRX, reológica e análise por MEV.

A escolha desses materiais decorre do fato de que tanto o polietileno como a poliamida são dois polímeros de grande importância industrial. O PEAD é o plástico mais utilizado mundialmente, enquanto as propriedades muito atrativas da poliamida são responsáveis pela sua crescente aplicação. Fibras de nylon têm sido usadas na indústria têxtil por anos e foi essa aplicação que levou às tentativas recentes de produção de blendas de poliamida [6]. Compostos de polioxietilenamida, por exemplo, como poli(etileno glicol) foram misturados com poliamida para produzir fibras com propriedades antiestáticas duráveis. Outras blendas envolvendo poliamida foram estudadas com o objetivo de melhora de propriedades ao impacto [7]. As poliolefinas melhoram as propriedades mecânicas das poliamidas e estas aumentam a resistência à abrasão e a permeabilidade ao oxigênio, resultando assim, em um material adequado para a indústria de embalagens.

Além de combinar as propriedades dos dois polímeros, o trabalho visa também baratear o custo da PA12, já que é um material relativamente caro. A redução do custo, somada às boas propriedades mecânicas, pode levar a interesse industrial pelo material desenvolvido. No nível comercial, a poliamida 12 , por ser um material recente e caro, não é tão estudada como a poliamida 6, por exemplo, o que fornece mais um incentivo ao estudo deste polímero. 


\section{Introdução Teórica}

Uma grande fração dos polímeros produzidos atualmente são blendas de dois ou mais polímeros [3]. Blendas permitem a otimização de propriedades, que comumente não são obtíveis ou são menos econômicas em um homopolímero ou copolímero. Desde 1980, vem sendo observada uma crescente utilização das blendas poliméricas e ligas de materiais termoplásticos, visando a economia favorável [8].

A primeira blenda comercial de dois polímeros diferentes, denominada Noryl, era uma poliblenda miscível de poli(óxido fenileno) e poliestireno, desenvolvida pela GE nos anos 60. Desde essa época, um grande número de blendas diferentes tem sido introduzido no mercado. Diferentes tecnologias têm sido utilizadas para preparar poliblendas, como blendas mecânicas (polímeros são misturados em temperaturas acima da $\mathrm{T}_{\mathrm{g}}$, temperatura de transição vítrea, ou $\mathrm{T}_{\mathrm{m}}$, temperatura de fusão cristalina, em polímeros amorfos e semicristalinos, respectivamente) e químicas. Por razões econômicas, as blendas mecânicas predominam [5].

O desenvolvimento de materiais com as propriedades desejadas não é uma tarefa fácil. Frequentemente, um novo espectro de propriedades pode ser alcançado produzindo blendas com a seleção conveniente de componentes. Nos anos recentes, blendas elastoméricas, por exemplo, têm sido tecnologicamente interessantes para uso como elastômeros termoplásticos. Estes materiais exibem algumas das propriedades físicas de elastômeros convencionais nas temperaturas de serviço e são processáveis em temperaturas elevadas [9].

A interação molecular entre as cadeias poliméricas é predominantemente do tipo secundária (intermolecular). Em blendas poliméricas, as forças intermoleculares mais importantes são: dipolos, ligações de hidrogênio, transferências complexas de carga e interações iônicas em ionômeros. Assim, a separação dos polímeros integrantes da blenda polimérica pode ser feita através de processos físicos, como, por exemplo, através da solubilização e precipitação fracionadas. Embora tenham sido descritos segmentos de polímeros que interagem 
por transferência complexa de carga e forças iônicas em alguns estudos de miscibilidade em blendas, os sistemas mais comuns e importantes são aqueles em que há ligações de hidrogênio e interações fortes de dipolo [1, 10]. A Figura 1 representa a mistura mecânica realizada na blenda.

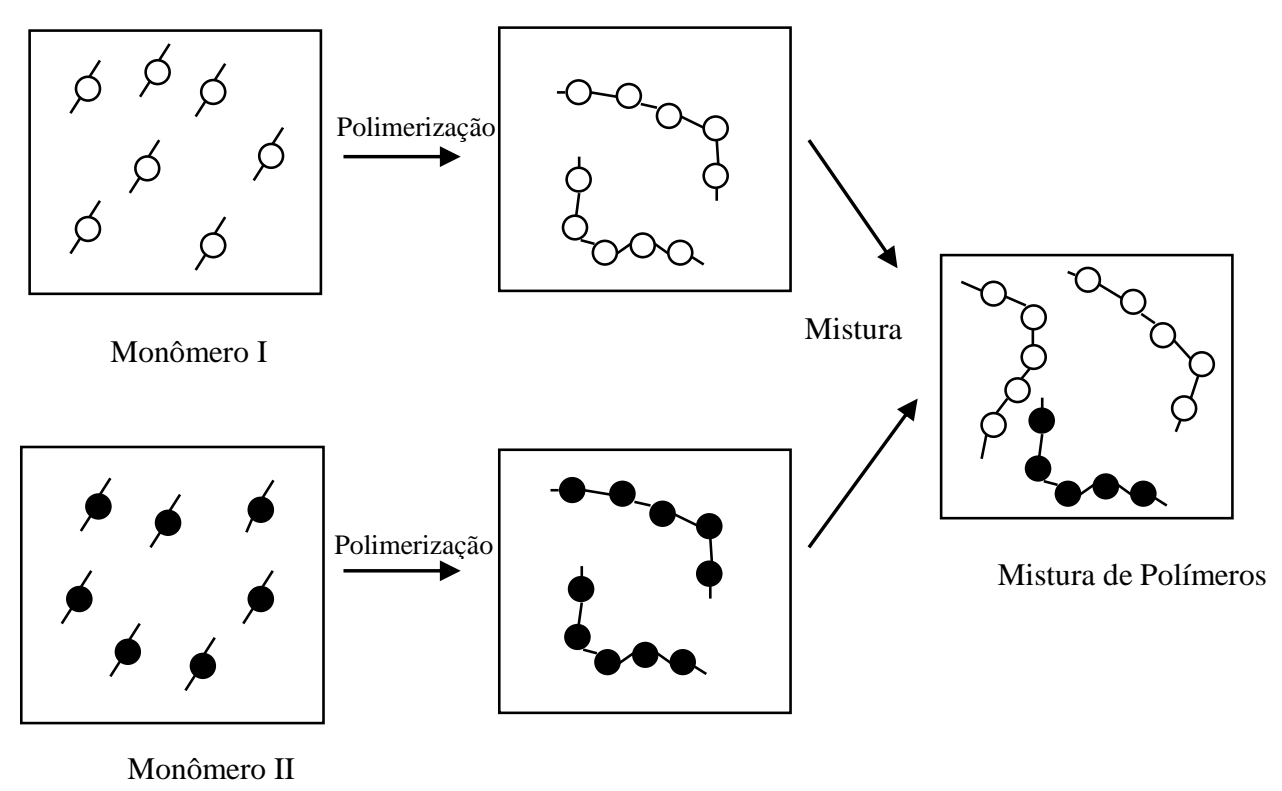

\section{Mistura Mecânica (Blenda)}

Figura 1. Representação da Mistura Mecânica realizada em blendas poliméricas.

Uma blenda pode ser miscível ou imiscível, dependendo das características termodinâmicas de seus componentes, compatibilizada ou não, dependendo do interesse tecnológico.

\subsection{Miscibilidade}

Blendas poliméricas podem ser tanto miscíveis como imiscíveis. As blendas miscíveis são divididas em blendas homogêneas (blendas do mesmo polímero) e heterogêneas (por exemplo, polietileno glicol com poliestireno) [3].

Dentre as blendas imiscíveis, há um subgrupo de polímeros compatíveis. A compatibilidade indica blendas comercialmente valiosas. Como os termos “miscível” e “imiscível” são usados em um sentido termodinâmico, consequentemente, ligas poliméricas devem ser consideradas uma subclasse de blendas poliméricas imiscíveis, formadas em vários processos de compatibilização. Os motivos principais da compatibilização são geração e 
estabilização da morfologia e maximização da performance do material [3]. As terminologias de ligas poliméricas e blendas estão ilustradas na Figura 2.

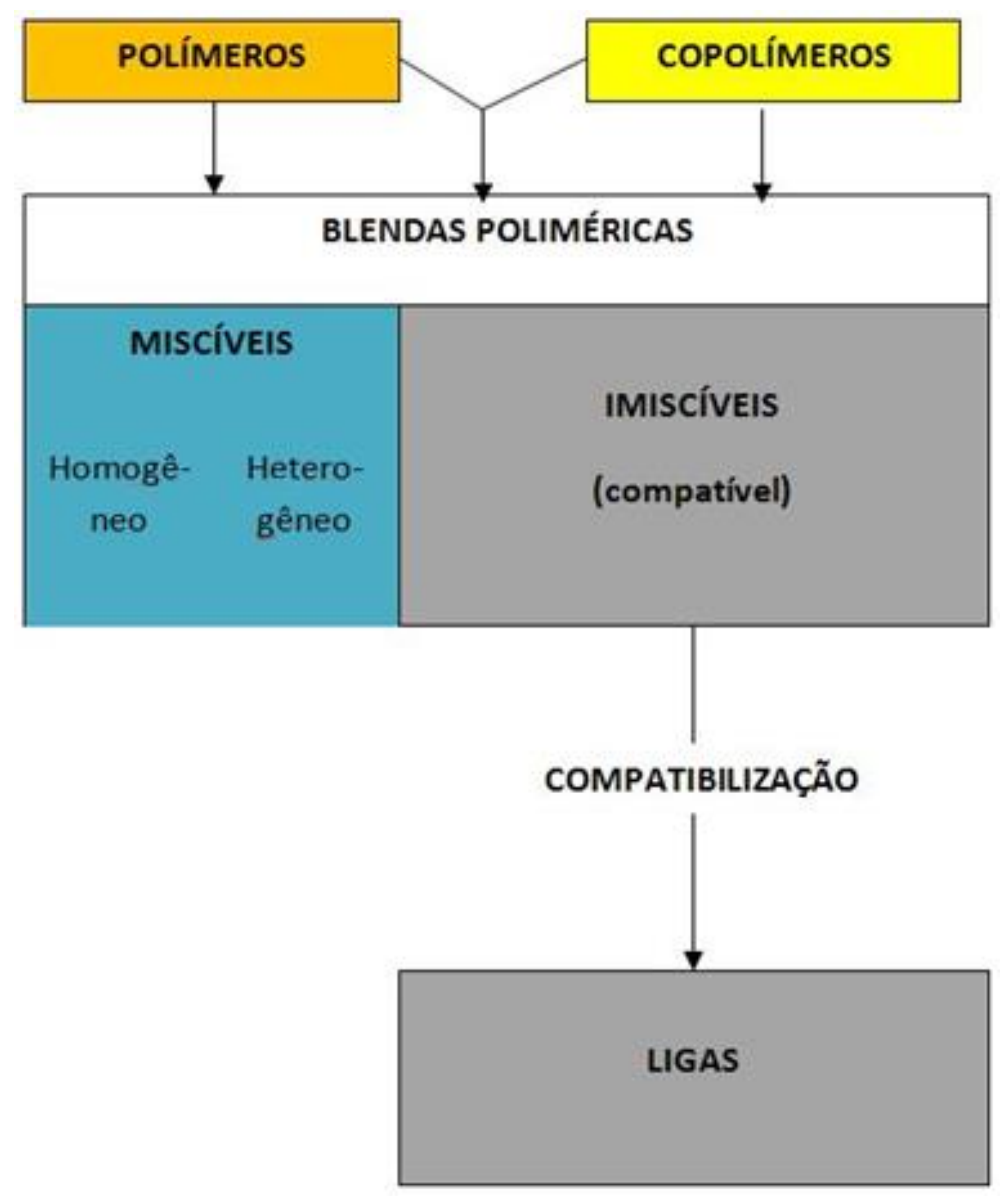

Figura 2. Terminologia das ligas poliméricas e blendas [3].

\subsubsection{Termodinâmica das blendas poliméricas}

Embora os termos ligas e blendas sejam usados indistintamente, eles diferem nos níveis de compatibilidades termodinâmicas e nas propriedades resultantes. Termodinamicamente, o comportamento de equilíbrio de fases em misturas é controlado pela variação da energia livre de mistura, por meio da equação de energia livre de Gibbs:

$$
\Delta G_{m}=\Delta H_{m}-T \cdot \Delta S_{m}
$$

onde: $\Delta \mathrm{G}_{\mathrm{m}}$ é a variação molar de energia livre de mistura;

$\Delta \mathrm{H}_{\mathrm{m}}$ é a variação da entalpia molar de mistura;

$\mathrm{T}$ é a temperatura absoluta; 
$\Delta \mathrm{S}_{\mathrm{m}}$ é a variação de entropia molar de mistura.

- Se $\Delta \mathrm{G}_{\mathrm{m}}>0$, o sistema será imiscível, havendo duas ou mais fases presentes;

- Se $\Delta \mathrm{G}_{\mathrm{m}}=0$, o sistema estará em equilíbrio termodinâmico;

- Se $\Delta \mathrm{G}_{\mathrm{m}}<0$, o sistema será miscível, constituído por uma única fase.

Geralmente devido aos grandes tamanhos das cadeias de um determinado polímero e seus requerimentos desfavoráveis de energia, elas preferem entrelaçar entre si a fazê-lo com cadeias de outro polímero. Consequentemente, a magnitude de $\Delta \mathrm{S}_{\mathrm{m}}$ é geralmente pequena. Assim, para dois polímeros serem termodinamicamente miscíveis, $\Delta \mathrm{H}_{\mathrm{m}}$ deve ser negativo, zero ou levemente positivo. Se $\Delta \mathrm{H}_{\mathrm{m}}$ for fortemente positivo, os componentes de uma mistura física separam em fases diferentes resultando em uma blenda. Entretanto, alguns polímeros tendem a ser mutuamente solúveis, pelo menos acima de uma faixa limitada de concentração. Estes são chamados de ligas [2].

Analisando com mais detalhe a Equação da Energia Livre de Gibbs (Eq.1), verifica-se que o segundo termo $\left(\mathrm{T} . \Delta \mathrm{S}_{\mathrm{m}}\right)$ é sempre positivo porque a temperatura absoluta é sempre positiva e a variação da entropia do sistema também, pois a tendência de um processo de mistura é sempre o aumento da desordem, ou seja, aumento da entropia. Como o termo entrópico é unicamente associado ao diferente número de configurações que as moléculas podem assumir e sendo os polímeros espécies de alta massa molar, o número de maneiras nas quais as moléculas dos polímeros podem se posicionar é reduzido. Assim, o valor de $\Delta \mathrm{S}_{\mathrm{m}}$ é muito pequeno e a temperatura não pode ser muito elevada para não haver degradação dos materiais poliméricos. Portanto, o sinal da variação molar da energia livre do sistema $\left(\Delta \mathrm{G}_{\mathrm{m}}\right)$ depende acentuadamente do sinal da variação molar da entalpia do sistema $\left(\Delta \mathrm{H}_{\mathrm{m}}\right)[11,12]$.

A entalpia representa as interações do tipo ligações de hidrogênio, ligações dipolo-dipolo entre as moléculas ou entre os segmentos moleculares das espécies misturadas e está diretamente relacionada a um balanço energético entre a energia necessária para a separação de moléculas idênticas e a energia liberada na formação de interações entre moléculas diferentes.

Quando $\Delta \mathrm{H}_{\mathrm{m}}=0$, atinge-se uma condição ideal e a mudança de energia livre é provocada somente pela mudança de entropia. O significado físico disto é que as interações entre as moléculas independem de suas vizinhanças. No caso das 
misturas, as interações polímero A/polímero $\mathrm{A}$, polímero A/polímero $\mathrm{B}$ e polímero B/polímero B serão todas iguais e formarão sempre soluções miscíveis, pois sempre haverá uma variação negativa da energia livre [11].

Quando as interações entre moléculas distintas forem diferentes da interação entre elas mesmas, o sistema está fora da condição ideal. Portanto $\Delta \mathrm{H}_{\mathrm{m}} \neq 0$ e assim a entalpia estará associada ao rompimento dos contatos entre moléculas similares nos componentes puros e pela troca destes contatos por contatos entre moléculas não similares. Têm-se, nessa situação, dois casos [11]:

Quando $\Delta \mathrm{H}_{\mathrm{m}}<0$, há uma condição na qual as moléculas de um tipo (polímero A) preferem a vizinhança de moléculas de outro tipo (polímero B). Neste caso, tem-se soluções miscíveis, pois a energia livre de Gibbs será negativa. $\mathrm{O}$ valor de $\Delta \mathrm{H}_{\mathrm{m}}$ é negativo somente quando ocorrem interações intermoleculares específicas entre os polímeros.

$>$ Quando $\Delta \mathrm{H}_{\mathrm{m}}>0$, os polímeros não têm interações específicas, a condição é que as moléculas de um tipo (polímero A) preferem uma vizinhança de molécula do mesmo tipo (polímero A). Neste caso, as soluções podem ser tanto miscíveis quanto imiscíveis, dependendo das magnitudes dos termos entálpicos e entrópicos e da temperatura do sistema. Por exemplo, num sistema onde é exigida uma energia muito alta para quebrar ligações entre moléculas similares para formar ligações entre moléculas não similares, o valor de $\Delta \mathrm{H}_{\mathrm{m}}$ é muito grande e positivo. Assim, em baixas temperaturas o termo entálpico deve prevalecer, gerando misturas imiscíveis. Ao contrário, em altas temperaturas e com componentes de baixa massa molar, o termo entrópico pode prevalecer, gerando misturas miscíveis.

\subsubsection{Blendas poliméricas miscíveis}

As blendas são miscíveis quando os segmentos moleculares dos componentes poliméricos se misturam intimamente sem que haja qualquer segregação entre as moléculas, ou seja, são homogêneas em escala molecular [13].

A miscibilidade de dois componentes poliméricos quaisquer é função de três parâmetros: sua compatibilidade, a proporção relativa em que se encontram, e as 
condições de temperatura e pressão a que são submetidos, ao longo de determinados tempos. A miscibilidade entre as possíveis fases presentes no sistema determinam direta ou indiretamente o comportamento do novo material desenvolvido.

Algumas blendas importantes são miscíveis, mas quase todos os pares de polímeros não são solúveis entre si; logo a maior parte das blendas comerciais é imiscível. Blendas miscíveis geralmente produzem propriedades médias entre os dois polímeros. Por exemplo, o poliestireno (PS) é adicionado ao óxido de polifenil (PPO) para reduzir a temperatura de processamento do PPO e o custo, enquanto aumenta a temperatura de deformação térmica do PS. Adicionar fluoreto de polivinilideno ao poli metil metacrilato (PMMA) melhora a resistência ao solvente e à UV do PMMA [3,14].

\subsubsection{Blendas poliméricas imiscíveis}

A blenda polimérica imiscível pode apresentar diferentes tipos de morfologias de fases, entre elas, uma fase dispersa numa matriz contínua, ou ambas as fases simultaneamente contínuas, conhecida como morfologia contínua [13].

A imiscibilidade termodinâmica que é geralmente o domínio entre pares de polímeros de alta massa molecular, assim como incompatibilidade mecânica devida à pobre adesão de fase e alta tensão interfacial, é mais bem demonstrada por blendas simples de Poliamida-6 e Polietileno, por exemplo [15, 16].

Ao contrário das blendas miscíveis, em que a compatibilidade é total, existindo apenas uma fase, pode ocorrer que o sistema apresente mais de uma fase com compatibilidade parcial ou incompatibilidade total entre os seus componentes. Quando a afinidade química é muito pequena, a adição de um terceiro componente de ação compatibilizante é fundamental.

Um crescente número de ligas poliméricas está sendo sintetizado por processamento reativo de uma blenda polimérica contendo um compatibilizante, um polímero funcional que forma o compatibilizante interfacialmente ativo in loco durante o processamento. O objetivo da compatibilização é mais que somente alcançar melhores propriedades que em outras blendas. Pelo ponto de vista 
comercial, a compatibilização envolve um equilíbrio de propriedades físicas, assim como reologia apropriada para processos subsequentes da liga [15].

Um dos efeitos do compatibilizante é reduzir a tensão interfacial entre a fase dispersa e a matriz, ou seja, apresentar um efeito emulsificante, facilitando a dispersão de uma fase na outra. Outro efeito é aumentar a interação e, portanto, a adesão entre os contornos das fases, facilitando a transferência de tensões. Um terceiro efeito é estabilizar a fase dispersa evitando a sua coalescência. Na prática, todos esses efeitos tendem a ocorrer e, além disto, promovem mudanças no comportamento reológico [17].

Como blendas de poliamidas com poliolefinas levam a um sistema bifásico termodinamicamente imiscível, compatibilizantes como PE carboxilato são constantemente usados em blendas de PE/PA para melhorar as propriedades interfaciais entre PE e PA, assim como suas propriedades mecânicas [6,18].

Uma blenda imiscível pode resultar em propriedades que excedam a qualquer um dos seus componentes. O exemplo mais comum é a melhora na dureza de polímeros frágeis com a adição de 10 a $20 \%$ de um elastômero imiscível. A performance e aceitação comercial de cada blenda depende do equilíbrio de todas as propriedades e do custo da obtenção destas propriedades [19].

\subsection{Características Reológicas}

A reologia é a ciência que estuda o escoamento e a deformação da matéria; ela analisa as respostas (deformação ou tensões) de um material provocadas pela aplicação de uma tensão ou uma deformação [20].

Os materiais poliméricos, sólidos, fundidos ou em solução, podem ser considerados como um tipo especial de material, já que apresentam ao mesmo tempo características tanto de materiais sólidos como de materiais líquidos. Esta propriedade é conhecida como viscoelasticidade e é inerente aos materiais de elevada massa molar. A viscosidade de um polímero é proporcional a sua massa molar $(M)$ quando esta é mais baixa que certo valor crítico $\left(M_{c}\right)$. O polímero que tiver $M<M_{c}$ é tratado como um polímero desemaranhado e o que tiver $M \geq M_{c}$ como polímero emaranhado [20,21]. 
Durante o escoamento, a elevada massa molar das macromoléculas faz com que estas adquiram inúmeras conformações, o que leva ao emaranhamento e desemaranhamento entre elas, fazendo com que formem entre si laços ou nós temporários, existindo uma densidade variável de emaranhamentos. Então, para determinar as condições de processamento ideais, torna-se necessário conhecer as propriedades reológicas do polímero no processamento, pois estas influenciarão as propriedades mecânicas, ópticas e elétricas do produto final [20].

A morfologia final de um sistema está relacionada com o comportamento reológico, composição, a razão de viscosidade e elasticidade dos componentes, com a tensão interfacial e a taxa e tensão de cisalhamento, desenvolvidas no processo de mistura e/ou de transformação. Portanto, esses fatores determinarão qual das fases será a dispersa e qual será a contínua. A morfologia da fase dispersa em sistemas poliméricos imiscíveis pode se apresentar na forma de gotículas (“droplets"), ou ainda na forma de fibrilas ("threads") [17].

Existem várias técnicas experimentais para a medição das propriedades reológicas de polímeros fundidos, sendo que um dos métodos mais importantes para a caracterização reológica dos materiais é a reometria rotacional. Nesta técnica a medida das propriedades reológicas é feita a partir da imposição de um escoamento de arraste. Na Figura 3 são mostradas as duas geometrias tradicionais que utilizam esse tipo de escoamento que são a de placas paralelas e a de coneplaca. O escoamento de arraste é imposto pela rotação à velocidade constante em uma dada direção (no caso de escoamento permanente ou estacionário de cisalhamento) ou oscilação (no caso de escoamento oscilatório) da placa superior a uma velocidade angular $\omega_{0}$; essa placa pode ser tanto paralela à placa inferior (Figura 3a) como possuir forma cônica (Figura 3b). A amostra polimérica fica entre as duas superfícies. Esse tipo de reômetro é utilizado para medir viscosidade a baixas taxas de cisalhamento, abaixo de $100 \mathrm{~s}^{-1}$, propriedades em regime transiente e propriedades em regime oscilatório. Assim, esse tipo de reômetro permite realizar uma caracterização reológica completa do polímero sob deformação de cisalhamento, sendo possível correlacionar os resultados à estrutura molecular do mesmo [20]. 


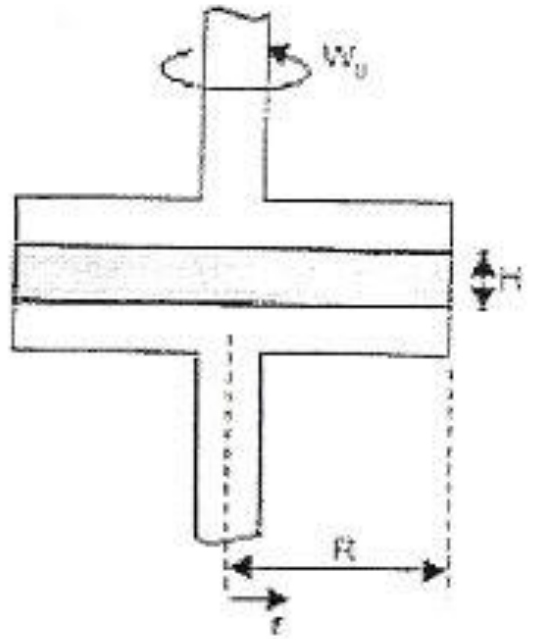

(a)

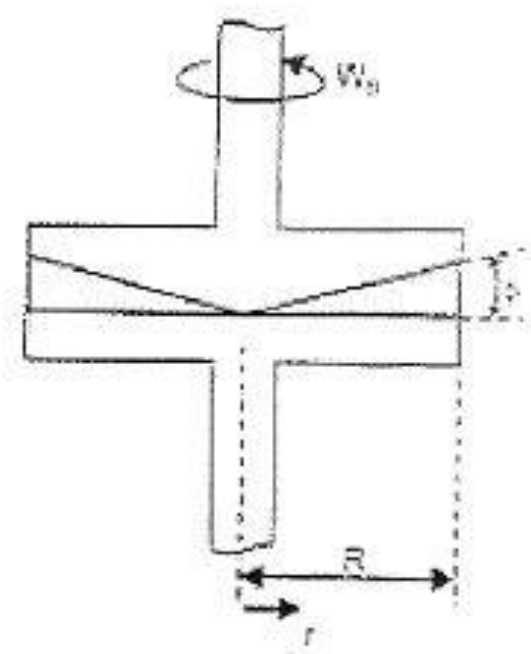

(b)

Figura 3. Geometria dos reômetros: a) placas paralelas e b) cone e placa [20].

A tensão de cisalhamento (ou deformação) aplicada varia com a frequência e a amplitude da tensão ou de deformação de cisalhamento aplicada deverá ser pequena para assegurar que as medidas ficarão dentro do regime de viscoelasticidade linear.

\subsection{1. Índice de Fluidez}

O índice de fluidez tem sido amplamente utilizado na indústria para caracterizar propriedades de fluxo dos polímeros, devido à simplicidade e à agilidade da técnica utilizada na sua determinação. $\mathrm{O}$ fato dos polímeros serem comumente classificados para as várias tecnologias de processamento de acordo com este índice é uma evidência da popularidade da técnica. Por outro lado, propriedades poliméricas, como extrusabilidade e resistência de filmes ao rasgamento são frequentemente consideradas como basicamente dependentes do índice de fluidez [22].

Esta prática industrial sugere que o índice de fluidez seja uma propriedade fundamental do polímero. Na verdade, é um parâmetro definido empiricamente, inversamente proporcional à viscosidade do material fundido a uma temperatura $\mathrm{e}$ taxa de cisalhamento especificadas pelas condições operacionais de medida. Sendo assim, é dependente de propriedades moleculares tais como peso molecular 
e ramificações, bem como da distribuição desses parâmetros. Adicionalmente, é criticamente influenciado pelas condições de medida [23].

A determinação é efetuada extrusando-se o polímero em um reômetro capilar, que consiste de um barril de extrusão aquecido, na extremidade do qual é montada uma matriz capilar de dimensões específicas. O reômetro é operado com pressão imposta, decorrente da aplicação de uma carga constante e bem definida no topo da coluna do fundido. O índice de fluidez é obtido a partir da taxa de fluxo do fluido sob imposição desta carga, e seu valor é expresso pela quantidade de material extrudado, em gramas, por 10 minutos [24].

Variações da vazão com o tempo de extrusão são frequentemente observadas e são decorrentes de efeitos elásticos no início da medida e de efeitos viscosos ou de degradação em tempos maiores. Entretanto, polímeros com características estruturais bastante diferentes respondem de forma diversa ao tempo de medida. Efeitos elásticos são mais pronunciados quanto menor for o índice de fluidez do polímero. Materiais altamente elásticos tendem a apresentar maior dependência da vazão com a aplicação da pressão [22].

Alguns mecanismos têm sido apontados para explicar o efeito viscoso observado. A importância relativa dos vários mecanismos depende do volume e diâmetro do reômetro capilar, da temperatura e da história de cisalhamento do polímero, entre outras. Assim sendo, o procedimento experimental utilizado na determinação do índice de fluidez deve ser rigorosamente definido. Apesar desses problemas, pesquisadores na área de degradação de polipropileno, por extrusão reativa, têm apresentado com sucesso correlações do índice de fluidez com propriedades dos polímeros [22]. 


\subsection{Propriedades Térmicas}

\subsubsection{Temperatura de Transição Vítrea $\left(T_{g}\right)$}

\subsubsection{Sistemas homogêneos, miscíveis ou monofásicos (Copolímeros homogêneos ou Poliblendas Compatíveis)}

Em copolímeros alternados e aleatórios e em blendas poliméricas miscíveis, em que existe uma mistura íntima a nível molecular das unidades monoméricas, o nível de energia exigido para que a molécula adquira mobilidade será o resultado da contribuição ponderada de cada constituinte [1].

Nesse tipo de sistemas, os monômeros constituintes ocupam volumes similares e são capazes de substituir uns aos outros no cristal polimérico. $\mathrm{O}$ copolímero resultante, independente da sua geometria, é necessariamente homogêneo, e poliblendas de homopolímeros individuais têm propriedades de transição similares [2]. Nestes tipos de copolímeros ou blendas, o valor da $\mathrm{T}_{\mathrm{g}}$ normalmente se situa ponderado entre os valores dos $\mathrm{T}_{\mathrm{g}}$ apresentados pelos homopolímeros individuais, como descrito pela Equação 2:

$$
T_{g}=V_{1} T_{g 2}+V_{2} T_{g 1}
$$

Onde $V_{1}$ e $V_{2}$ são as frações volumétricas dos componentes 1 e 2, respectivamente. A Figura 4 ilustra esquematicamente esta relação.

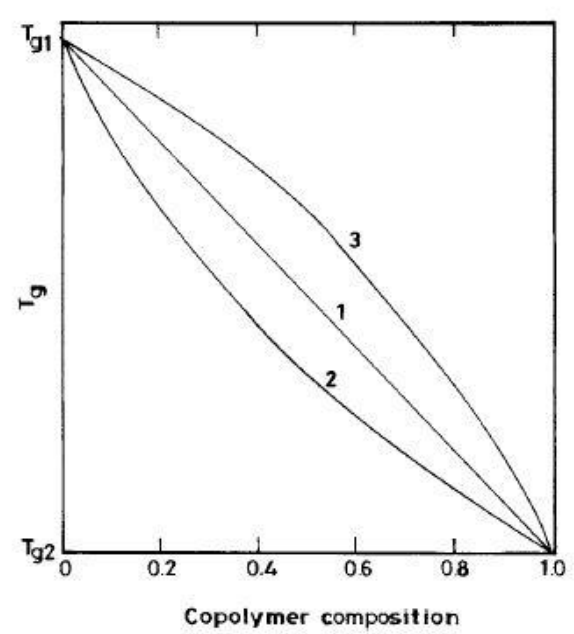

Figura 4. Variação da Temperatura de Transição Vítrea da blenda homogênea na curva 1 [2]. As curvas 2 e 3 serão explicadas a seguir. 


\subsubsection{Sistemas heteromorfos}

Em sistemas heteromorfos, os volumes específicos dos monômeros são diferentes. Neste caso, a geometria do polímero resultante se torna importante.

\subsection{Aleatório ou alternado}

Para este tipo de copolímeros, a composição é necessariamente homogênea (sem separação de fases) e, como discutido anteriormente, a transição vítrea é intermediária entre a dos dois homopolímeros. A crescente desordem resultante da distribuição aleatória ou alternada dos monômeros aumenta o volume livre e consequentemente reduz a $T_{g}$ abaixo da predita pela Equação 2 (curva 2 na Figura 4). A $T_{g}$ do copolímero, cujos componentes têm frações de peso $W_{1}$ e $W_{2}$ e transições vítreas $\mathrm{T}_{\mathrm{g} 1}$ e $\mathrm{T}_{\mathrm{g} 2}$, respectivamente, pode ser calculada pela Equação 3:

$$
\frac{1}{T_{g}}=\frac{W_{1}}{T_{g 1}}+\frac{W_{2}}{T_{g 2}}
$$

Exemplos deste tipo são copolímeros de metil metacrilato-acrilonitrila, metil-estireno metacrilato e acrilonitrila-acrilamida. Também é possível que os monômeros envolvidos no processo de copolimerização (como nos copolímeros metilacrilato-metilmetacrilato e vinilideno de cloreto de metacrilato) introduzam interações significantes entre as cadeias. Neste caso, a $\mathrm{T}_{\mathrm{g}}$ será relativamente acima do valor predito (curva 3 da Figura 4) [2].

\subsection{Em bloco e copolímeros grafitizados (copolímeros incompatíveis)}

Para copolímeros em bloco ou grafitizados nos quais os monômeros componentes são incompatíveis, ocorrerá separação de fases. Dependendo de alguns fatores - por exemplo, o método de preparo - uma fase vai ser dispersa na matriz contínua da outra. Neste caso, dois valores de transições vítreas diferentes vão ser observados, cada um correspondendo à $T_{g}$ do homopolímero. A Figura 5 mostra a queda do módulo de elasticidade com a temperatura, medida de forma dinâmico-mecânica, de uma blenda imiscível AB. Uma queda acentuada do módulo em uma faixa estreita de temperatura é característica da $\mathrm{T}_{\mathrm{g}}$. $\mathrm{O}$ componente A na sua forma pura apresenta uma $T_{\mathrm{g} 1}$ que é menor que a $\mathrm{T}_{\mathrm{g} 2}$ do componente $\mathrm{B}$. 
Blendas com frações intermediárias de cada componente (na figura 5 representada pelas curvas 40/60 e 60/40) apresentam duas quedas no módulo cada uma, relativas à $\mathrm{T}_{\mathrm{g}}$ de cada um dos componentes. A intensidade da queda é proporcional à fração em peso de cada componente $[1,2]$.

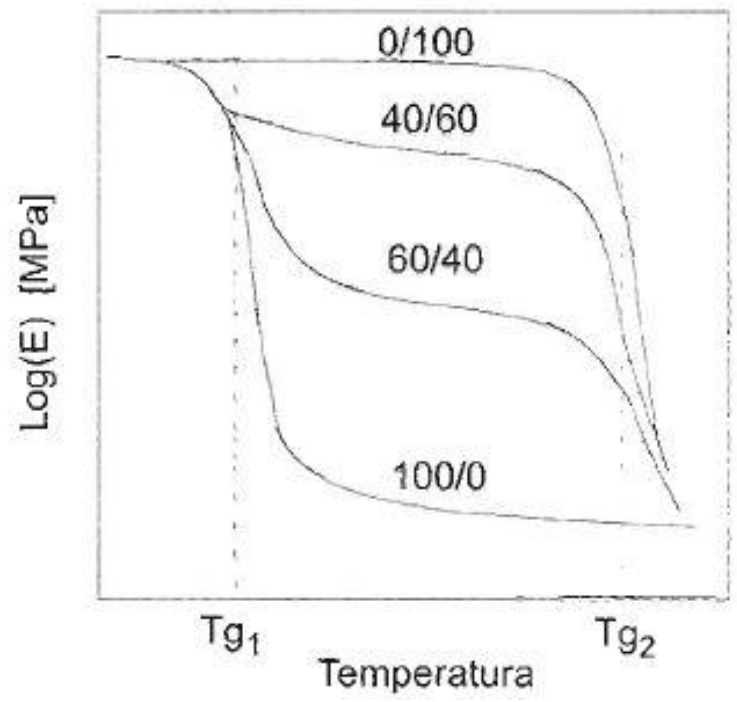

Figura 5. Queda do módulo de elasticidade denotando as duas $\mathrm{T}_{\mathrm{g}} \mathrm{s}$ presentes em sistemas imiscíveis [1].

\subsubsection{Temperatura de fusão cristalina (Tm)}

\subsubsection{Sistemas homogêneos, miscíveis ou monofásicos}

A temperatura de fusão cristalina $\mathrm{T}_{\mathrm{m}}$ de copolímeros normalmente decai com o aumento do segundo componente, de acordo com a Equação de Flory:

$$
\frac{1}{T_{m}}-\frac{1}{T_{m}^{0}}=-\frac{R}{\Delta H_{m}} \ln X_{A}=\frac{R}{\Delta H_{m}} X_{B}
$$

Assumindo-se um copolímero AB com o componente A majoritário, tem-se que: $\mathrm{T}_{\mathrm{m}}$ é a temperatura de fusão do copolímero $\mathrm{AB}, \mathrm{T}_{\mathrm{m}}{ }^{0}$ é a temperatura de fusão do homopolímero $\mathrm{A}, \Delta \mathrm{H}_{\mathrm{m}}$ é o calor latente de fusão do homopolímero $\mathrm{A}, \mathrm{X}_{\mathrm{A}}$ fração molar do comonômero majoritário A (cristalizável), $X_{B}$ fração molar do comonômero minoritário B [1]. 
Um caso típico é o do copolímero poli(hexametileno sebacamida - co hexametileno tereftalamida) que tem comonômeros não-isomorfos, tendo uma $T_{m}$ com um comportamennto quase "eutético", como mostra a Figura 6. No entanto, se os comonômeros são isomorfos, isto é, têm a mesma forma e, portanto, se substituem mutuamente dentro da célula unitária, a temperatura de fusão pode seguir uma regra aditiva, ou seja, variar linearmente entre os dois valores. Isso acontece para o poli(hexametilenoadipamida - co - hexametilenotereftalamida) visto na mesma figura.

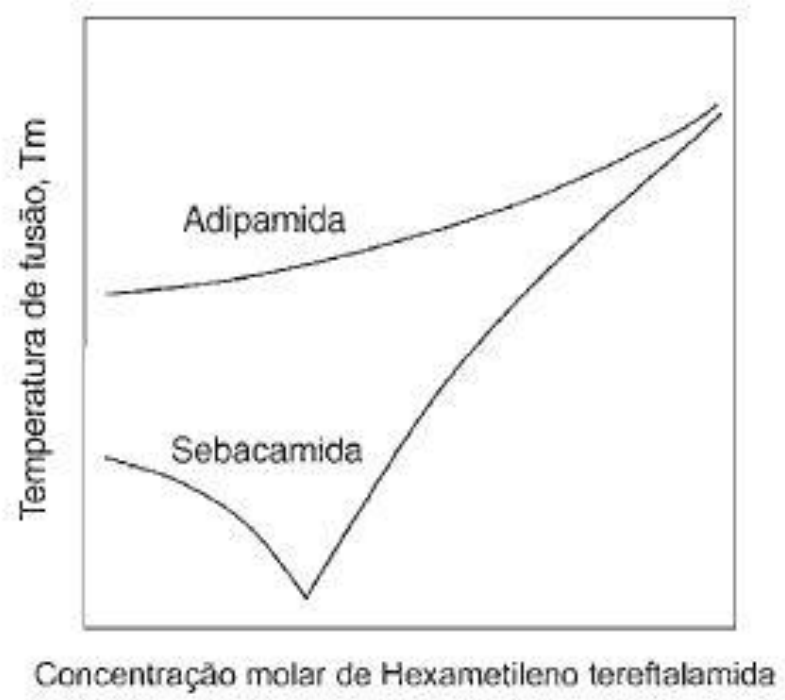

Figura 6. Temperaturas de fusão de poli(hexametileno sebacamida - co - hexametileno tereftalamida) e poli (hexametileno adipamida - co hexametileno tereftalamida) [1].

\subsubsection{Sistemas heterogêneos, imiscíveis ou polifásicos}

A temperatura de fusão cristalina $T_{m}$ nestes sistemas imiscíveis ocorrerá nas mesmas temperaturas que dos componentes isolados e existirão tantas temperaturas de fusão quanto forem os componentes no sistema. $\mathrm{T}_{\mathrm{m}}$ não é alterada, pois ocorre nos cristais, que estão dispersos no componente, e protegidos pela fase amorfa envolvente. Da mesma forma que no caso do $\mathrm{T}_{\mathrm{g}}$, a intensidade do sinal medido experimentalmente será proporcional à fração em peso da fase cristalina do componente. A cristalinidade é função da maneira como a blenda e, mais ainda, a peça foi produzida [1]. 


\subsection{Espectro Infravermelho (FTIR)}

A radiação infravermelha (IV) é uma radiação não ionizante na porção invisível do espectro eletromagnético, que está adjacente aos comprimentos de ondas longos, na região do vermelho do espectro da luz visível. As energias dos fótons desse espectro não são altas o suficiente para excitar elétrons, mas podem induzir excitação vibracional de átomos e grupos ligados covalentemente. É importante saber que, em adição à fácil rotação de grupos com ligações simples, moléculas têm uma larga variedade de movimentos vibracionais, característicos dos seus átomos componentes. Consequentemente, todos os compostos orgânicos absorvem a radiação infravermelha que corresponde à energia dessas vibrações [25].

Como cada tipo de ligação tem sua própria frequência natural de vibração e como dois tipos idênticos de ligações em dois diferentes compostos estão em dois ambientes levemente diferentes, os padrões de absorção no infravermelho em duas moléculas de estruturas diferentes nunca são exatamente idênticos. Os modos mais simples de movimento vibracional em uma molécula, ativos no infravermelho, são os modos de estiramento (stretching) e dobramento (scissoring ou bending, rocking, twisting, wagging) [26]. A Figura 7 ilustra os diferentes modos de vibração para o grupo metileno $\left(-\mathrm{CH}_{2}\right)$.

Assim, o espectrograma IV permite a identificação dos grupos funcionais presentes no material e, com isso, pode-se identificar o tipo de material analisado, permitindo também avaliar se houve absorção de umidade ou um processo de oxidação no material através da identificação das ligações $\mathrm{H}-\mathrm{O}-\mathrm{H}$ e $\mathrm{C}=\mathrm{O}$, respectivamente. 

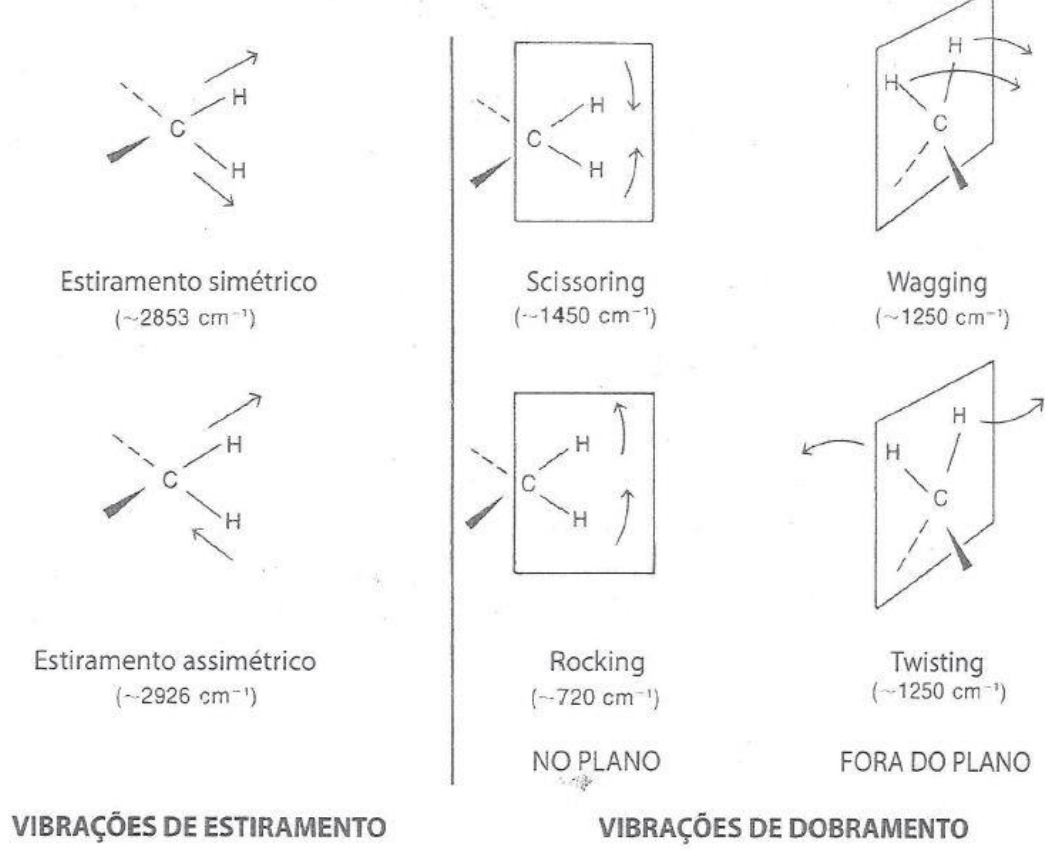

Figura 7. Modos de vibração do radical $\mathrm{CH}_{2}$ [26].

\subsection{Difração de Raios-X (DRX)}

A difração de raios-X (DRX) representa o fenômeno de interação entre o feixe de raios-X incidente e os elétrons dos átomos componentes de um material, relacionado ao espalhamento coerente. A técnica consiste na incidência da radiação em uma amostra e na detecção dos feixes difratados, que constituem o feixe difratado. Em um material onde os átomos estejam arranjados periodicamente no espaço, característica das estruturas cristalinas, o fenômeno da difração de raios-X ocorre nas direções de espalhamento que satisfazem a Lei de Bragg (Equação 5) [27].

$$
n \lambda=2 d \operatorname{sen} \theta
$$

onde $\lambda$ é o comprimento de onda de um feixe monocromático, $\theta$ é o ângulo de incidência da onda sobre um cristal, chamado de ângulo de Bragg, $d$ é a distância entre os planos de átomos e $n$ a ordem de difração. A Figura 8 representa a condição em que a Lei de Bragg é satisfeita. 


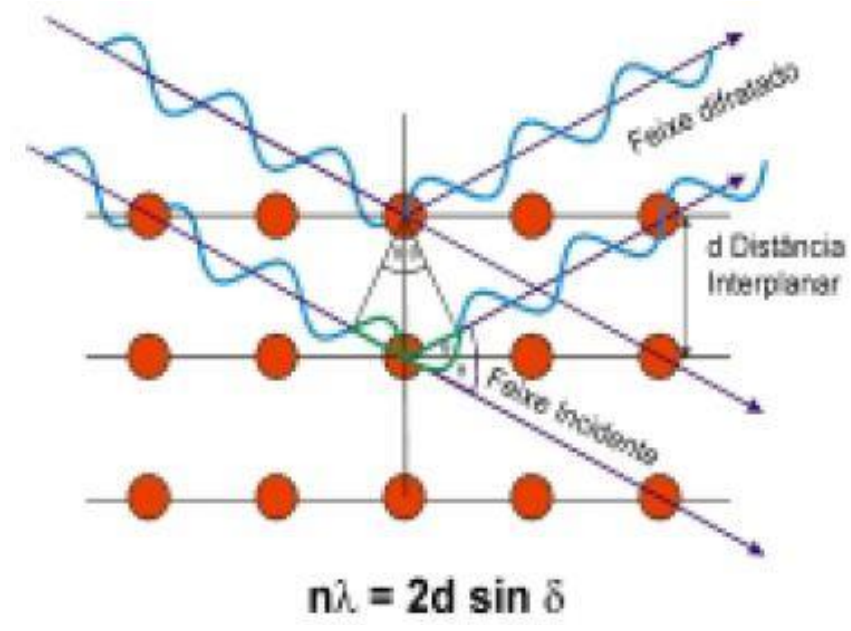

Figura 8. Lei de Bragg [27].

Os instrumentos tradicionais de medida são o difratômetro e as câmeras de monocristais, estas últimas atualmente com seu uso restrito a situações específicas para determinação de parâmetros cristalográficos. No difratômetro tradicional a captação do eixo difratado é feita por meio de um detector, segundo um arranjo geométrico conhecido como a geometria Bragg-Brentano (Figura 9), que habilita a obtenção do ângulo $2 \theta$ [27].

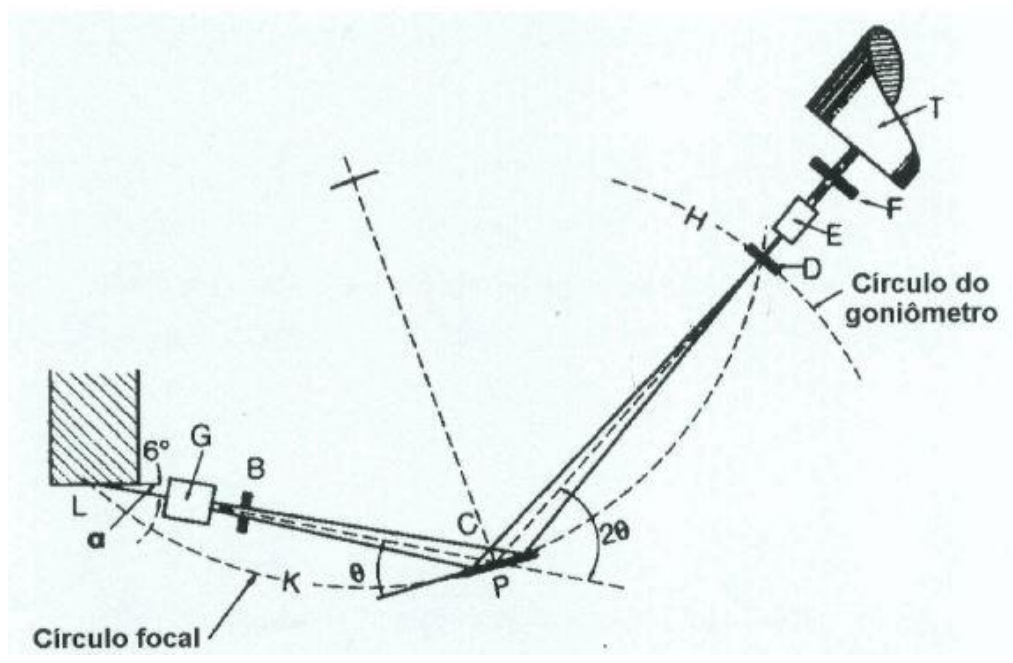

Figura 9. Geometria parafocal Bragg-Brentano [27].

As intensidades obtidas em ângulos $2 \theta$, representadas através dos picos nos difratogramas, correspondem à difração do feixe incidente por um determinado conjunto de planos do cristal, que possuem mesma distância interplanar, cada qual com índices de Miller $h k l$ [27].

A recente atividade em sistemas de polímeros multicomponentes obtidos com a combinação de dois ou mais polímeros de diferentes estruturas e 
morfologias, como blendas, tem motivado a aplicação de métodos de DRX na análise destes novos materiais. Tais análises podem revelar a composição, cristalinidade, tamanho médio do cristalito e perfeição cristalina de cada componente. Essas informações são úteis no entendimento da influência de um componente no outro, especialmente se os polímeros têm algum grau de interação mútua [28].

O método de determinação do grau de cristalinidade por difração é baseado na lei de conservação da intensidade, que diz que o valor da intensidade é determinado pela integral do quadrado da densidade eletrônica em função do volume, como mostra a Equação 6 [29]:

$$
\int I_{(s)} d V_{s}=\int \rho^{2}(r) d V_{r}
$$

A densidade eletrônica média é aproximadamente a mesma para as fases amorfa e cristalina de um polímero e é possível distinguir entre eles na suposição de que a intensidade da dispersão cristalina está concentrada nos picos das reflexões e a da amorfa no halo difuso, ambos localizados acima da linha de base ou background (Figura 10) [29].

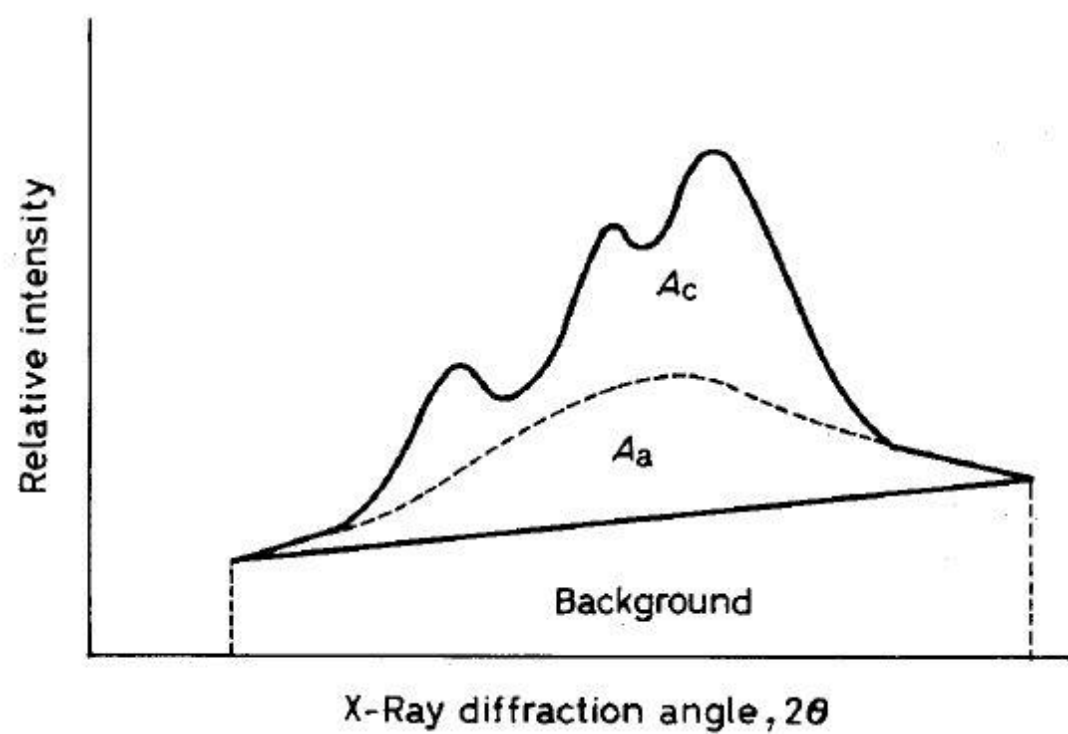

Figura 10. Difratograma típico usado no cálculo do percentual de cristalinidade. $A_{a}=$ contribuição amorfa, $A_{c}=$ contribuição cristalina [29].

O método consiste em separar e medir a integral das intensidades das fases cristalina e amorfa. A integração é definida dentro de uma faixa de $2 \theta=0^{\circ}$ a $180^{\circ}$, 
onde $\theta$ é o ângulo de Bragg [29]. O grau de cristalinidade, calculado em porcentagem, é dado por:

$$
\text { G.C. }=100 \frac{A_{c}}{\left(A_{a}+A_{c}\right)}
$$

onde $A_{a}$ e $A_{c}$ são, respectivamente, as intensidades integradas das fases amorfa e cristalina após correções de Debye-Waller, dispersão atômica e fatores de polarização de Lorentz [29].

O tamanho médio do cristalito, que é uma medida do tamanho do cristalito e do grau de perfeição cristalina, foi determinado pelo TOPAS através do método Integral Breadth, onde é realizada a integral sob a curva do pico cristalino, podendo ser representada pela Equação 8, onde $A$ representa a área sob o pico, $I$ a intensidade do mesmo e $\beta$ o valor da Integral Breadth [30]:

$$
\beta=A / I
$$

\subsection{Poliolefinas}

Poliolefinas são polímeros sintéticos de monômeros olefínicos (que contêm olefina, um hidrocarboneto alifático, ou seja, de cadeia aberta, apresentando pelo menos uma ligação dupla entre os carbonos) [31]. Eles são a maior família de polímeros por volume de produção e consumo. As poliolefinas têm tido bastante sucesso devido a sua aplicabilidade em diversas áreas industriais, ao custo relativamente baixo e as suas boas propriedades.

Poliolefinas podem ser classificadas baseado nas suas unidades monoméricas e estruturas da cadeia como: poliolefina baseada em etileno (contém em sua maioria unidades de etileno), poliolefina baseada em propileno (contém majoritariamente unidades de propileno), poliolefinas de alto peso molecular e elastômeros poliolefínicos. Poliolefinas baseadas em etileno são normalmente produzidas sob baixa pressão usando catalisadores, resultando em uma cadeia de estrutura predominantemente linear, ou sob alta pressão, usando iniciadores de oxigênio ou peróxido, resultando em cadeias de estrutura predominantemente ramificada de várias densidades e níveis de cristalinidade [31]. O polietileno faz parte deste grupo de poliolefinas e será utilizado neste trabalho. 


\subsubsection{Polietileno}

Polietileno é o material termoplástico mais utilizado mundialmente e é composto por etileno. Os dois tipos principais são PEBD (polietileno de baixa densidade) e PEAD (polietileno de alta densidade) [5], sendo este último o escolhido para fazer parte deste trabalho. Essa diferença de densidade resulta de processos de polimerização diferente [2]. Seu monômero está representado na Figura 11.

$$
\left[-\mathrm{CH}_{2}-\mathrm{CH}_{2}\right]_{\mathrm{n}}
$$

Figura 11. Monômero do polietileno [2].

\subsubsection{Polietileno de Alta Densidade (PEAD)}

\subsection{Processos de polimerização}

A principal diferença entre o processo de polimerização de etileno sob baixa pressão e o processo sob alta pressão está no tipo de sistema iniciador usado. Os iniciadores (catalisadores) utilizados para polimerizar sob pressões próximas à atmosférica foram descobertos por Ziegler e Natta, graças aos seus estudos sobre compostos organo-metálicos, particularmente organo-alumínio. $\mathrm{O}$ primeiro sistema catalítico, que forneceu resultados satisfatórios foi uma combinação de trietil-alumínio e tetracloreto de titânio. Há processos que empregam outros catalisadores, tais como o processo Phillips, que utiliza catalisador à base de óxido de cromo suportado em sílica ou alumina e o processo da Standard Oil of Indiana, que utiliza óxido de níquel suportado em carvão [32].

Sob a ação de catalisadores Ziegler-Natta, a polimerização se efetua sob pressões de etileno na faixa de 10 a 15 atm e temperaturas na faixa de 20 a $80{ }^{\circ} \mathrm{C}$ em meio de hidrocarbonetos parafínicos em presença de um composto alquilalumínio e um sal de Ni, Co, Zr ou Ti. Esses sistemas catalíticos (iniciadores) são ativos o suficiente para permitir que a reação ocorra, inclusive, à pressão atmosférica e temperaturas inferiores a $100{ }^{\circ} \mathrm{C}$. Nos processos industriais de produção, o peso molecular do polímero é controlado na faixa de 50.000 a $100.000\left(\mathrm{M}_{\mathrm{n}}\right)$ por processo de transferência de cadeia, geralmente com hidrogênio $[32,33]$. 
No processo Philips, a polimerização se realiza a baixas pressões, em torno de $50 \mathrm{~atm}$, e temperaturas brandas (inferiores a $100{ }^{\circ} \mathrm{C}$ ). Nesse processo, é empregado um catalisador suportado em alumina constituído de óxido de cromo, ativado por uma base. Comparado com o polietileno obtido com catalisadores Ziegler-Natta, o produto é menos ramificado e tem por isso maior densidade devido a mais alta cristalinidade [32].

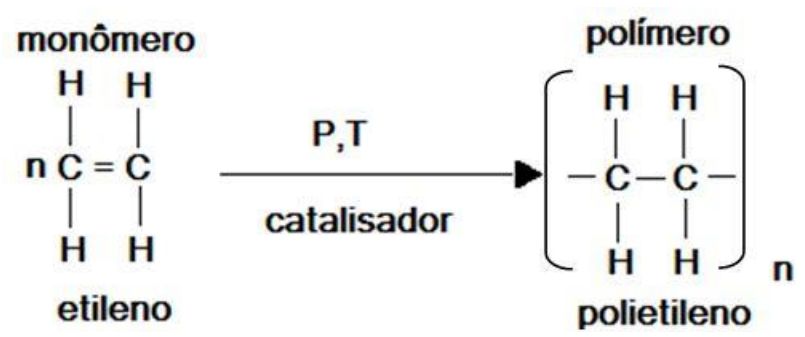

Figura 12. Reação de polimerização do polietileno.

\subsection{Propriedades}

O polietileno linear é altamente cristalino (acima de 90\%), pois apresenta um baixo teor de ramificações. Esse polímero contém menos que uma cadeia lateral por 200 átomos de carbono da cadeia principal (Figura 13), sua temperatura de fusão cristalina é aproximadamente $132{ }^{\circ} \mathrm{C}$ e sua densidade está entre 0,95 e $0,97 \mathrm{~g} / \mathrm{cm}^{3}[33]$.

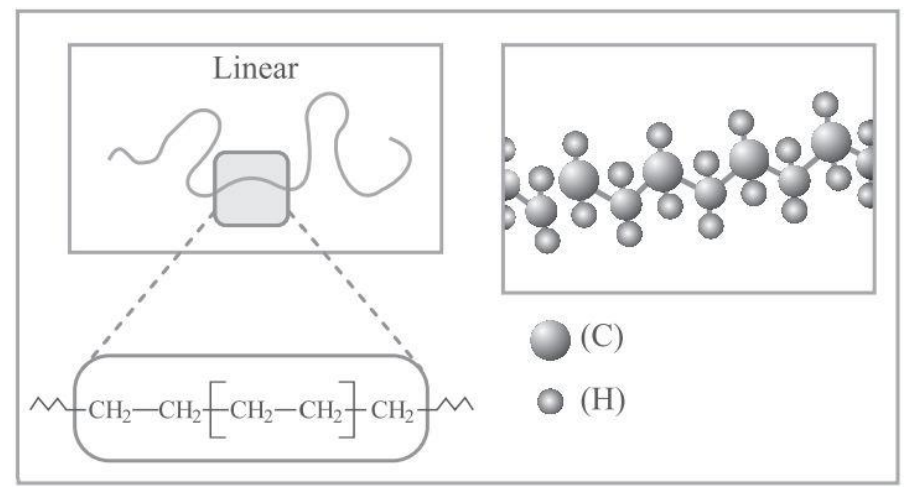

Figura 13. Estrutura do PEAD [32].

A linearidade das cadeias e consequentemente a maior densidade do PEAD fazem com que a orientação, o alinhamento e o empacotamento das cadeias sejam mais eficientes. Assim, as forças intermoleculares (Van der Waals) podem agir mais intensamente, e, como consequência, a cristalinidade é maior que no caso do 
PEBD. Sendo maior a cristalinidade, a fusão poderá ocorrer em temperatura mais alta $[32,34]$.

As características mecânicas e elétricas do polietileno de alta densidade são apresentadas na Tabela 1. Enquanto as propriedades elétricas são pouco afetadas pela densidade e pelo peso molecular do polímero, as propriedades mecânicas sofrem uma forte influência do peso molecular, do teor de ramificações, da estrutura morfológica e da orientação [32, 35].

Tabela 1. Propriedades do PEAD [32].

\begin{tabular}{|c|c|c|}
\hline Propriedades & Altamente linear & Baixo grau de ramificação \\
\hline Densidade $\left(\mathrm{g} / \mathrm{cm}^{3}\right)$ & $0,962-0,968$ & $0,950-0,960$ \\
\hline Índice de refração & 1,54 & 1,53 \\
\hline Temperatura de fusão (으) & $128-135$ & $125-132$ \\
\hline Temperatura de fragilidade ( $\mathrm{O}$ ) & $-140--70$ & $-140--70$ \\
\hline Condutividade térmica $(\mathrm{W} /(\mathrm{m} . \mathrm{K}))$ & $0,46-0,52$ & $0,42-0,44$ \\
\hline Calor de combustão (kJ/g) & 46,0 & 46,0 \\
\hline Resistividade superficial $(\Omega)$ & $10^{15}$ & $10^{15}$ \\
\hline Resistividade volumétrica ( $\Omega . \mathrm{m})$ & $1017-1018$ & $1017-1018$ \\
\hline Resistência dielétrica (kV/mm) & $45-55$ & $45-55$ \\
\hline Ponto de escoamento (MPa) & $28-40$ & $25-35$ \\
\hline Módulo de tração (MPa) & $900-1200$ & $800-900$ \\
\hline Resistência à tração (MPa) & $25-45$ & $20-40$ \\
\hline $\begin{array}{c}\text { Resistência ao cisalhamento } \\
\text { (MPa) }\end{array}$ & $20-38$ & $20-36$ \\
\hline
\end{tabular}

$\mathrm{O}$ peso molecular tem influência sobre as propriedades do PEAD, principalmente devido ao seu efeito na cinética de cristalização, cristalinidade final e ao caráter morfológico da amostra. O PEAD de baixo peso molecular é frágil e quebra sob baixas deformações, sem desenvolver estricção no ensaio de tração. Além disso, o peso molecular também exerce influência sobre a resistência ao impacto. Amostras com baixo peso molecular são frágeis, porém com o aumento do peso molecular, a resistência ao impacto aumenta e é bastante alta para o PEAD com peso molecular na faixa de $5 \times 10^{5}$ a $10^{6}$ [32].

Um aumento no teor de ramificações reduz a cristalinidade e é acompanhado por variação significativa das características mecânicas, uma vez 
que causa um aumento no alongamento na ruptura e uma redução da resistência à tração [32].

Os efeitos combinados do peso molecular e das ramificações sobre as características mecânicas são mostrados na Tabela 2 para PEAD altamente linear obtido com catalisadores suportados, PEAD obtido por catalisador de ZieglerNatta e um PEBD típico. Essas características originam-se das diferenças no teor e na natureza das ramificações [32].

A orientação das cadeias poliméricas exerce um forte efeito sobre as propriedades mecânicas do polímero. Materiais fabricados com PEAD altamente orientado são aproximadamente dez vezes mais resistentes do que os fabricados a partir do polímero não orientado, pois a orientação aumenta o empacotamento das cadeias e consequentemente aumenta a rigidez do polímero [32].

Em geral, o PEAD exibe baixa reatividade química. As regiões mais reativas das moléculas de PEAD são as duplas ligações finais e as ligações $\mathrm{CH}$ terciárias em ramificações. PEAD é estável em soluções alcalinas de qualquer concentração e em soluções salinas, independente do $\mathrm{pH}$, incluindo agentes oxidantes como $\mathrm{KMnO}_{4}$ e $\mathrm{K}_{2} \mathrm{Cr}_{2} \mathrm{O}_{7}$; não reage com ácidos orgânicos, $\mathrm{HCl}$ ou $\mathrm{HF}$ [32]. 
Tabela 2. Comparativo das propriedades mecânicas do PEAD linear, PEAD Ziegler e o PEBD, onde as colunas mostram a comparação de cada propriedade [32].

\begin{tabular}{|c|c|c|c|}
\hline Propriedade & $\begin{array}{c}\text { PEAD Linear } 1 \\
\mathrm{CH}_{3} / 1000 \\
\text { carbonos }\end{array}$ & $\begin{array}{c}\text { PEAD Ziegler, poucas } \\
\text { ramificações, } 3 \\
\mathrm{CH}_{3} / 1000 \text { carbonos }\end{array}$ & $\begin{array}{c}\text { PEBD, altamente } \\
\text { ramificado, } 20 \\
\mathrm{CH}_{3} / 1000 \text { carbonos }\end{array}$ \\
\hline Índice de fluidez (MFI) & $5-11$ & $0,9-6$ & $1-7$ \\
\hline Densidade $\left(\mathrm{g} / \mathrm{cm}^{3}\right)$ & $0,966-0,968$ & $0,955-0,970$ & $0,918-0,918$ \\
\hline $\begin{array}{l}\text { Ponto de escoamento } \\
\qquad(\mathrm{MPa})\end{array}$ & $31-33$ & $29-29$ & $6,2-11,5$ \\
\hline $\begin{array}{l}\text { Deformação no ponto } \\
\text { de escoamento (\%) }\end{array}$ & $9-9$ & $20-20$ & $100-800$ \\
\hline $\begin{array}{l}\text { Resistência à tração } \\
\text { (MPa) }\end{array}$ & $20-30$ & $22-30$ & $8,5-10,5$ \\
\hline $\begin{array}{c}\text { Alongamento limite } \\
\text { (\%) }\end{array}$ & $900-990$ & $1000-1000$ & $500-500$ \\
\hline $\begin{array}{l}\text { Módulo elástico } \\
\qquad(\mathrm{MPa})\end{array}$ & $1400-1550$ & $900-1000$ & $400-500$ \\
\hline $\begin{array}{c}\text { Resistência ao } \\
\text { impacto }\left(\mathrm{kJ} / \mathrm{m}^{2}\right)\end{array}$ & $9-50$ & $20-30$ & Não quebra \\
\hline
\end{tabular}

O PEAD é utilizado em diferentes segmentos da indústria de transformação de plásticos, abrangendo os processamentos de moldagem por sopro, extrusão e moldagem por injeção.

A comparação de algumas características do PEBD e PEAD pode ser vista na Tabela 3. 
Tabela 3. Comparação de características entre o PEBD e PEAD [32].

\begin{tabular}{|c|c|c|c|c|}
\hline & \multicolumn{2}{|c|}{ PEBD } & \multicolumn{2}{|c|}{ PEAD } \\
\hline Tipo de polimerização & \multicolumn{2}{|c|}{ Radicais livres } & \multicolumn{2}{|c|}{ Coordenação } \\
\hline $\begin{array}{c}\text { Pressão de } \\
\text { polimerização (atm) }\end{array}$ & Alta & $1000-3000$ & Baixa & $1-30$ \\
\hline $\begin{array}{c}\text { Temperatura reacional } \\
\text { (으) }\end{array}$ & Alta & $100-300$ & Baixa & $50-100$ \\
\hline Tipo de cadeia & \multicolumn{2}{|c|}{ Ramificada } & \multicolumn{2}{|c|}{ Linear } \\
\hline Densidade $\left(\mathrm{g} / \mathrm{cm}^{3}\right)$ & Baixa & $0,91-0,94$ & Alta & $0,94-0,97$ \\
\hline Cristalinidade (\%) & Baixa & $50-70$ & Alta & até 95 \\
\hline $\mathrm{T}_{\mathrm{m}}(\stackrel{\circ}{\mathrm{O}} \mathrm{C})$ & Baixa & $110-125$ & Alta & $130-135$ \\
\hline
\end{tabular}

\subsection{Poliamidas (Nylons)}

Nylons, também conhecidos como poliamidas, são sintetizados por métodos de polimerização por condensação, reagindo uma diamina alifática e um diácido. Nylon é um polímero cristalino com alto módulo, resistência, propriedades de impacto, baixo coeficiente de atrito e resistência à abrasão. Embora estes materiais possuam uma vasta gama de propriedades, todos contêm o grupamento amida (CONH-) na sua estrutura. Sua estrutura geral está ilustrada na Figura 14 [35].

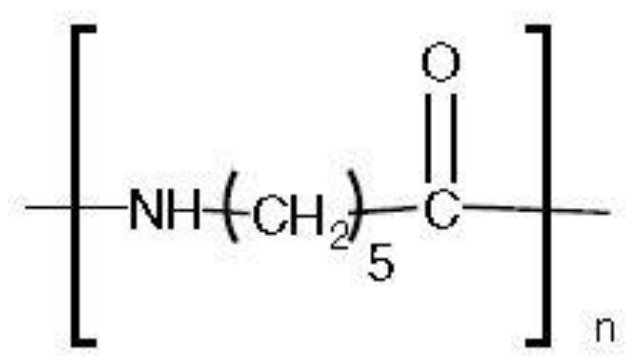

Figura 14. Estrutura geral dos nylons [35].

O tipo de nylon (nylon 6, nylon 10, etc.) é indicativo do número de átomos de carbono entre os grupamentos amida. Esse número de átomos de carbono entre os grupamentos amida também controla as propriedades do polímero. Existem vários tipos diferentes de nylons que podem ser preparados, dependendo do monômero inicial usado. Quando somente um monômero é usado (lactama ou aminoácido), o nylon é identificado com somente um número (nylon 6, nylon 12). 
Quando dois monômeros são usados na preparação, o nylon será identificado usando dois números (nylon 6,6; nylon 6,12), com o primeiro deles representando o número de átomos de carbono na diamina e o segundo referindo-se ao número total de átomos de carbono no ácido, como está ilustrado na Figura 15 [2,35].

\begin{tabular}{|c|c|c|}
\hline Monomer(s) & & Polymer \\
\hline $\mathrm{H}_{2} \mathrm{~N}-\left(\mathrm{CH}_{2}\right)_{6}-\mathrm{NH}_{2}$ & $\mathrm{HOOC}-\left(\mathrm{CH}_{2}\right)_{4}-\mathrm{COOH}$ & 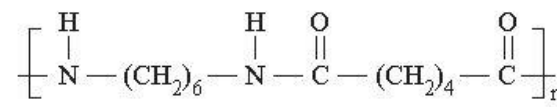 \\
\hline Hexamethylenediamine & Adipic acid & Poly(hexamethylene adipamide), nylon 6,6 \\
\hline $\mathrm{H}_{2} \mathrm{~N}-\left(\mathrm{CH}_{2}\right)_{6}-\mathrm{NH}_{2}$ & $\mathrm{HOOC}-\left(\mathrm{CH}_{2}\right)_{6}-\mathrm{COOH}$ & 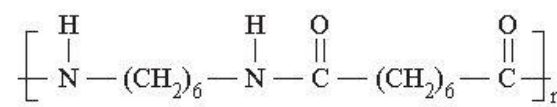 \\
\hline Hexamethylenediamine & Sebacic acid & Poly(hexamethyl ene sebacamide), nylon 6,10 \\
\hline $\mathrm{H}_{2} \mathrm{~N}-\left(\mathrm{CH}_{2}\right)_{5}-\mathrm{COOH}$ & & 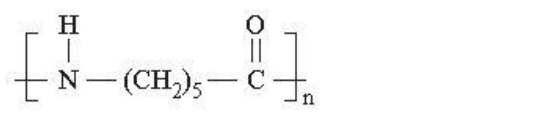 \\
\hline$\omega$-amino caproic acid & & Polycaprolactam, nylon 6 \\
\hline
\end{tabular}

Figura 15. Nomenclatura e reação química dos nylons [2].

Dentre os nylons, o nylon 6,6 e o nylon 6 são os de maior importância comercial e mais mundialmente usados. Outros materiais comercialmente usados são seus análogos nylon 6,9; 6,10; 6,12;11; e 12. Nylon 6,6 e nylon 6 são bastante usados porque oferecem um bom equilíbrio de propriedades num custo econômico favorável. Outros nylons demandam preços maiores [2]. O nylon a ser usado neste trabalho é o nylon 12.

As poliamidas podem, ainda, ser divididas em três tipos: poliamidas alifáticas, poliamidas aromáticas e as poliimidas. Porém, o único tipo de poliamida de interesse neste trabalho será o das poliamidas alifáticas.

\subsubsection{Poliamidas Alifáticas}

As poliamidas alifáticas são produzidas comercialmente por condensação de diaminas com ácidos dibásicos, por auto-condensação de um aminoácido ou por polimerização por abertura de anel de uma lactama. Para obter polímeros de alto peso molecular, deve haver equivalência estequiométrica da amina e os grupos ácidos dos monômeros. Para aminoácidos e lactamas o balanço estequiométrico é garantido pelo uso de monômeros puros; para diaminas e ácidos dibásicos isso é obtido pela formação preliminar de um sal de amônio, também referido como sal de nylon [5]. 


\subsubsection{Poliamida-12}

O Nylon-12 é produzido pela polimerização por abertura de anel da laurillactama (dodecil lactama) por aquecimento da mesma até cerca de $300{ }^{\circ} \mathrm{C}$ na presença de solução aquosa de ácido fosfórico. Diferentemente da polimerização da caprolactama, a polimerização da dodecil lactama não envolve reação de equilíbrio. Portanto, uma parcela significativa da produção do nylon-12 é obtida por essa reação e a remoção do material de baixo peso molecular é desnecessária [5]. Sua estrutura está representada na Figura 16.

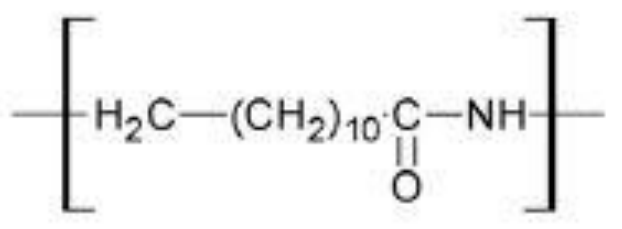

Figura 16. Estrutura molecular da PA 12 [36].

\subsection{Propriedades}

A poliamida 12 é uma poliamida alifática e suas principais propriedades são mostradas na Tabela 4 [37].

Tabela 4. Propriedades da Poliamida $12[37,2]$.

\begin{tabular}{cc}
\hline Propriedades & PA 12 \\
\hline Temperatura de fusão (ㄷ) & 180 \\
Densidade $\left(\mathrm{g} / \mathrm{cm}^{\mathbf{3}}\right.$ ) & 1,02 \\
Resistência à tração (MPa) & 52 \\
Módulo de flexão (MPa) & 1172 \\
Absorção de água (\%) em 24 h de imersão & 0,25 \\
\hline
\end{tabular}

Os grupamentos amidas são grupos polares e afetam significativamente as propriedades do polímero. A presença destes grupos permite ligações de hidrogênio entre as cadeias, melhorando a atração entre as cadeias, dando ao nylon boas propriedades mecânicas. A natureza polar dos nylons melhora também sua adesividade a diversos materiais, enquanto os grupos de carbonos alifáticos flexíveis dão aos nylons baixa viscosidade para fácil processabilidade [35]. 
Nylons são relativamente insensíveis a solventes apolares, entretanto, por causa da presença de grupos polares, nylons podem ser afetados por solventes polares, particularmente água, devido à habilidade dos grupamentos amidas em formação de ligação de hidrogênio. A água essencialmente substitui a ligação hidrogênio-amida-amida por ligação hidrogênio-amida-água. Consequentemente, a absorção de água decresce com o decréscimo da concentração dos grupamentos amida na estrutura do polímero (Tabela 5). A presença de umidade deve ser considerada em qualquer aplicação de nylon. A absorção de umidade resulta na deterioração de propriedades elétricas e estabilidade dimensional pobre em ambientes com umidade relativa variável. Assim, o material deve ser secado antes de qualquer operação $[35,2]$.

Tabela 5. Temperatura de Fusão e Absorção de Água dos tipos de nylon [2].

\begin{tabular}{ccc}
\hline Nylon & Temperatura de Fusão $\left.{ }^{\circ} \mathbf{C}\right)$ & $\begin{array}{c}\text { Absorção de Água (ASTM } \\
\text { D-570) }\end{array}$ \\
\hline $\mathbf{6 , 6}$ & 265 & $1,0-1,3$ \\
$\mathbf{6 , 8}$ & 240 & - \\
$\mathbf{6 , 9}$ & 226 & 0,5 \\
$\mathbf{6 , 1 0}$ & 225 & - \\
$\mathbf{6 , 1 2}$ & 212 & 0,4 \\
$\mathbf{4}$ & 265 & - \\
$\mathbf{6}$ & 226 & $1,3-1,9$ \\
$\mathbf{7}$ & 223 & - \\
$\mathbf{1 1}$ & 188 & $0,25-0,30$ \\
$\mathbf{1 2}$ & 180 & \\
\hline
\end{tabular}

A resistência e rigidez aumentam quando o número de átomos de carbono entre amidas diminui, porque existem mais grupos polares por unidade de comprimento ao longo da estrutura do polímero. O grau de absorção_de umidade também é fortemente influenciado pelo número de grupos polares ao longo da cadeia. Nylons com menos átomos de carbono entre as amidas vão absorver mais umidade que os com mais átomos de carbono (nylon 6 absorve mais que nylon 12). A Figura 17 mostra como a absorção de água de diferentes nylons varia com a umidade à temperatura ambiente. Além disso, nylons com um número par de átomos de carbono entre os grupamentos amida têm pontos de fusão mais altos que os com número ímpar de átomos de carbono. Por exemplo, a temperatura de 
fusão do nylon 6,6 é mais alta do que as do nylon 5,6 ou 7,6. Isto se deve à habilidade dos nylons com número par de átomos de carbono em se empacotar melhor no estado cristalino. A alta atração intermolecular também influi nos pontos de fusão dos nylons, que usualmente são maiores que $200{ }^{\circ} \mathrm{C}$. O ponto de fusão, entretanto, decresce com o aumento do segmento alifático na cadeia [5, 35].

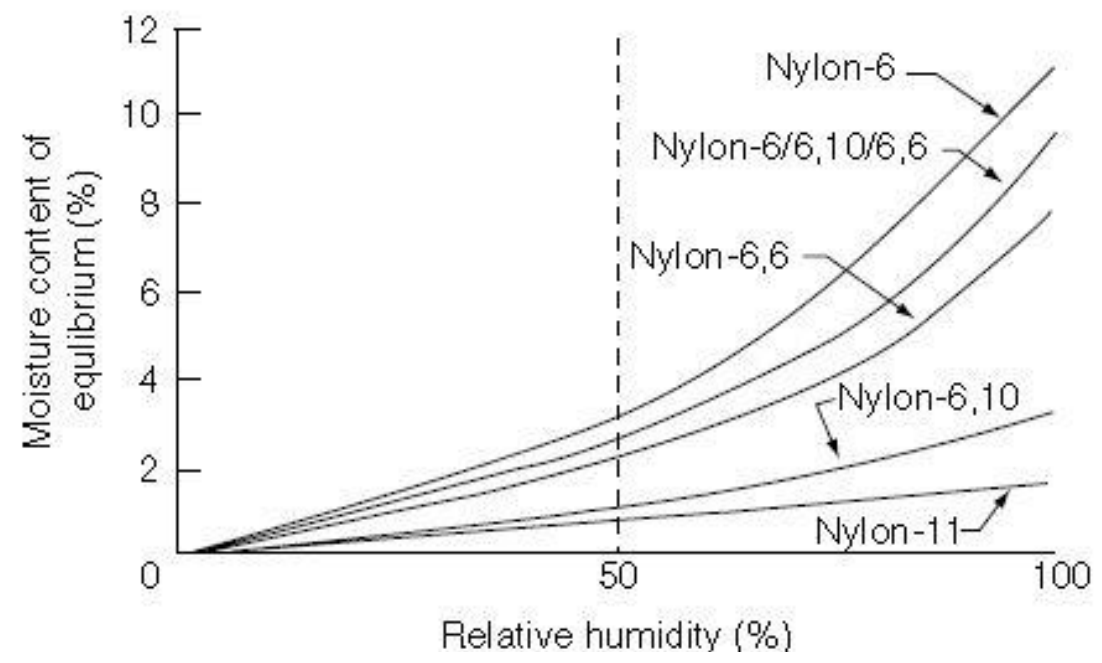

Figura 17. Absorção de umidade de poliamidas em função da umidade relativa [5].

As propriedades do nylon são afetadas pelo grau de cristalinidade, que pode ser controlado pelas condições de processamento. Um material resfriado lentamente terá uma cristalinidade significantemente superior (50 a 60\%) ao resfriado rapidamente. Não somente o grau de cristalinidade pode ser controlado, mas também o tamanho dos cristalitos. Em um material resfriado lentamente, o tamanho do cristal vai ser maior do que o resfriado rapidamente. O grau de cristalinidade afeta também a absorção de umidade, com poliamidas menos cristalinas sendo mais propensas à absorção [35].

A temperatura de transição vítrea de poliamidas alifáticas é de importância secundária para o comportamento da fusão cristalina. Polímeros secos têm valores de $\mathrm{T}_{\mathrm{g}}$ perto de $50{ }^{\circ} \mathrm{C}$, enquanto aqueles com umidade absorvida podem ter $\mathrm{T}_{\mathrm{g}}$ próximo de $0{ }^{\circ} \mathrm{C}$. A temperatura de transição vítrea pode influenciar o comportamento de cristalinização dos nylons; por exemplo, nylon 6,6 pode estar acima da sua $T_{g}$ à temperatura ambiente, fazendo com que a cristalização a esta temperatura ocorra lentamente levando a uma retração pós-moldagem [35]. 


\subsection{Blendas de poliolefinas}

Blendas de poliolefinas fazem parte de um subgrupo de blendas poliméricas e podem ser classificadas em dois grupos. O primeiro grupo contém somente poliolefinas e são formuladas para ampliar as propriedades e aplicações oferecidas pelas poliolefinas. O segundo grupo contém poliolefinas e não poliolefinas e são formuladas para mitigar algumas das desvantagens das propriedades das poliolefinas e das não poliolefinas. Para que uma blenda possa ser classificada como blenda de poliolefina, é presumido que o componente poliolefínico está em composição majoritária na blenda [31].

Em termos de miscibilidade, blendas poliolefínicas podem ser classificadas como blendas miscíveis e imiscíveis. A miscibilidade depende da estrutura molecular, composição da blenda e temperatura de mistura. Para caracterizar miscibilidade é necessário um diagrama de fases [31]. O conceito de miscibilidade de blendas foi desenvolvido no item 2.1 deste trabalho.

Os polímeros termoplásticos não olefínicos que podem ser misturados com poliolefinas incluem as poliamidas (nylons), tais como poliamida 6 , poliamida 6,6 , poliamida 12, poli (sulfeto de p-fenileno) (PPS), éter polifenileno (PPE) e óxido polifenileno (PPO); poliésters, como polietileno tereftalato (PET) e polibutileno tereftalato (PBT), entre outros polímeros, como vinis e copolímeros grafitizados [31].

As propriedades que as poliolefinas normalmente contribuem em blendas com outros polímeros incluem alta elasticidade, dureza, baixa viscosidade para processamento, baixa polaridade e constante dielétrica, boa resistência química e resistência à absorção de umidade. Não poliolefinas contribuem com alto módulo e resistência térmica. Blendas de poliolefinas com nylons e policarbonato mostram controle balanceado de permeabilidade e retenção de água [31].

Blendas de poliolefinas de importância comercial são normalmente produzidas por dois métodos: mistura feita no polímero fundido tanto durante a polimerização ou mecanicamente após o processo de polimerização. O primeiro método, chamado de mistura no reator, envolve a mistura de diferentes poliolefinas em um reator de polimerização. Esse processo ocorre na presença de múltiplas espécies de catalisadores. O segundo método, chamado mistura pós- 
reator, envolve mistura mecânica de uma poliolefina pré-polimerizada com outras poliolefinas ou não poliolefinas na extrusora [31].

\subsubsection{Blendas de Poliolefina-Poliamida}

Blendas de poliolefina-poliamida são caracterizadas pela falta de miscibilidade, levando a um sistema bifásico e também pelas altas tensões interfaciais entre as duas fases. Diversos estudos dessas blendas poliméricas têm sido realizados, apontando que suas morfologias são bem instáveis e tendem a coalescer, especialmente sob condições quiescentes (sem aplicação de deformação) ou baixas deformações. Essas blendas possuem, também, fraca adesão interfacial $[6,31]$.

Pela presença de imiscibilidade neste tipo de blenda, para aumentar a afinidade entre poliolefinas e poliamidas, alguns grupos polares, como ácido maleico ou seu anidrido, podem ser grafitizados em cadeias poliolefínicas. $\mathrm{Na}$ mistura, os grupos polares reagem com as poliamidas para formar poliolefinas graftizadas com poliamidas, que são os reais agentes compatibilizantes [31].

O grupo mais importante de compatibilizantes para blendas de polietileno/poliamida é o de copolímeros grafitizados de polietileno - que inclui copolímeros grafitizados de polietileno com ácido maleico ou seu anidrido e glicidil metacrilato, entre outros [31], SEBS, EVA, EPDM, e polipropileno com ácido insaturado ou seu anidrido. 


\section{Revisão Bibliográfica}

Nesta seção, serão apresentados resultados obtidos em experimentos com blendas de polietileno/poliamida. Nestes artigos, são discutidos parâmetros como: morfologia, reologia e propriedades mecânicas das blendas.

\subsection{Morfologia}

Um experimento realizado por Utracki [6] avaliou as propriedades reológicas das blendas de polietileno de alta densidade com poliamida 6 em termos das morfologias das amostras observadas no MEV (Microscópio Eletrônico de Varredura). Neste experimento, foram sintetizados quatro tipos de materiais poliméricos: PEAD com 0\% de PA-6, 10\%, 20\% e 30\% e as propriedades reológicas (fluxo dinâmico e estado estacionário) foram medidos em $150^{\circ} \mathrm{C}, 200^{\circ} \mathrm{C}$ e $250^{\circ} \mathrm{C}$ com dois tipos de capilares de diferentes diâmetros. O estudo da morfologia das blendas foi feito analisando, no MEV, a blenda fraturada em nitrogênio líquido [6].

As morfologias das amostras de PEAD/PA-6 estão ilustradas nas Figuras 18 a 22.

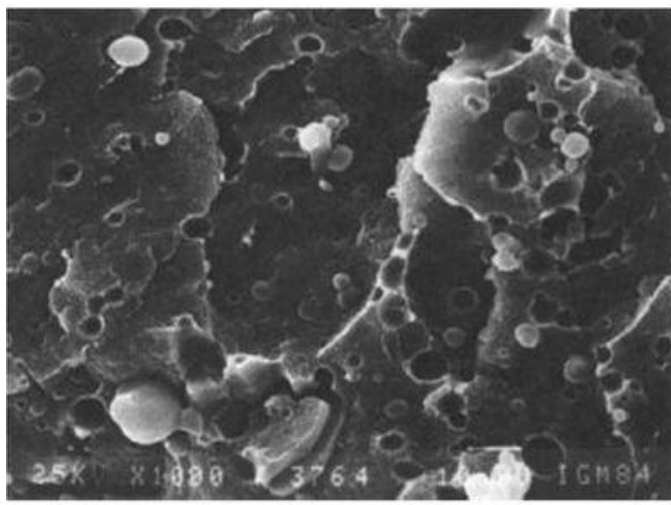

(A)

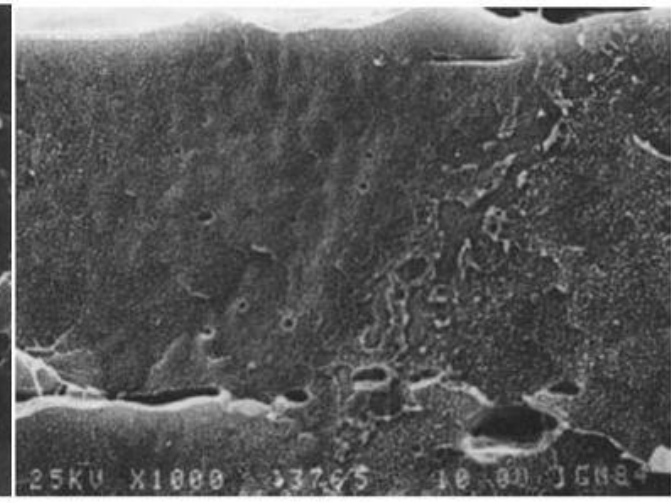

(B)

Figura 18. Micrografia no MEV de $10 \%$ PA6 extrudado à $200^{\circ} \mathrm{C} \mathrm{e} 1230 \mathrm{~s}^{-1}$;

(A) centro e (B) borda do extrudado a um aumento de 1000x [6]. 


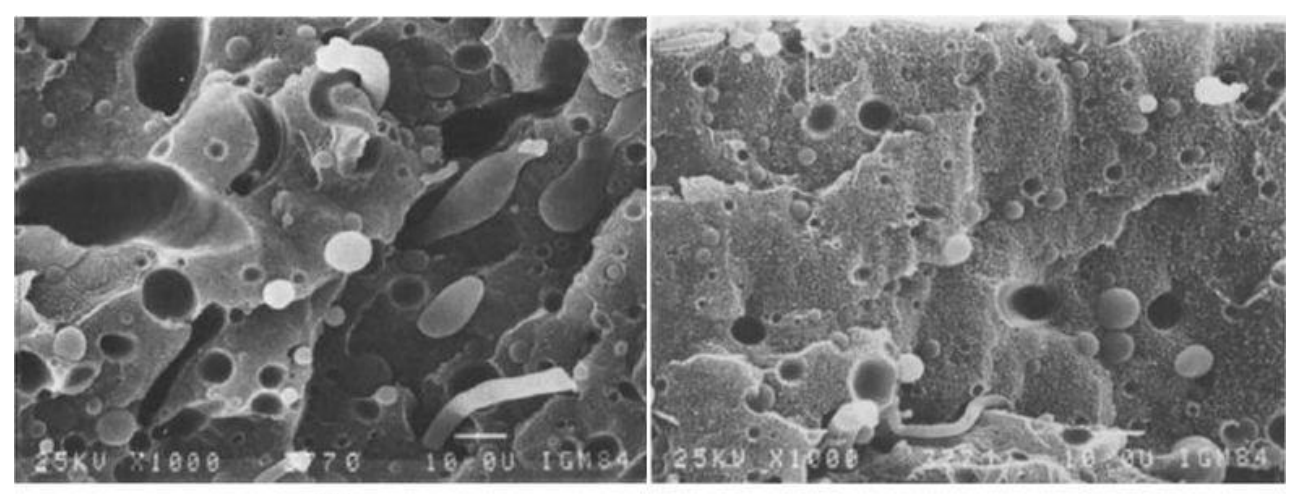

(A)

(B)

Figura 19. Micrografia no MEV de $20 \%$ PA6 extrudado à $150^{\circ} \mathrm{C}$ e $1110 \mathrm{~s}^{-1}$;

(A) centro e (B) borda do extrudado a um aumento de 1000x [6].

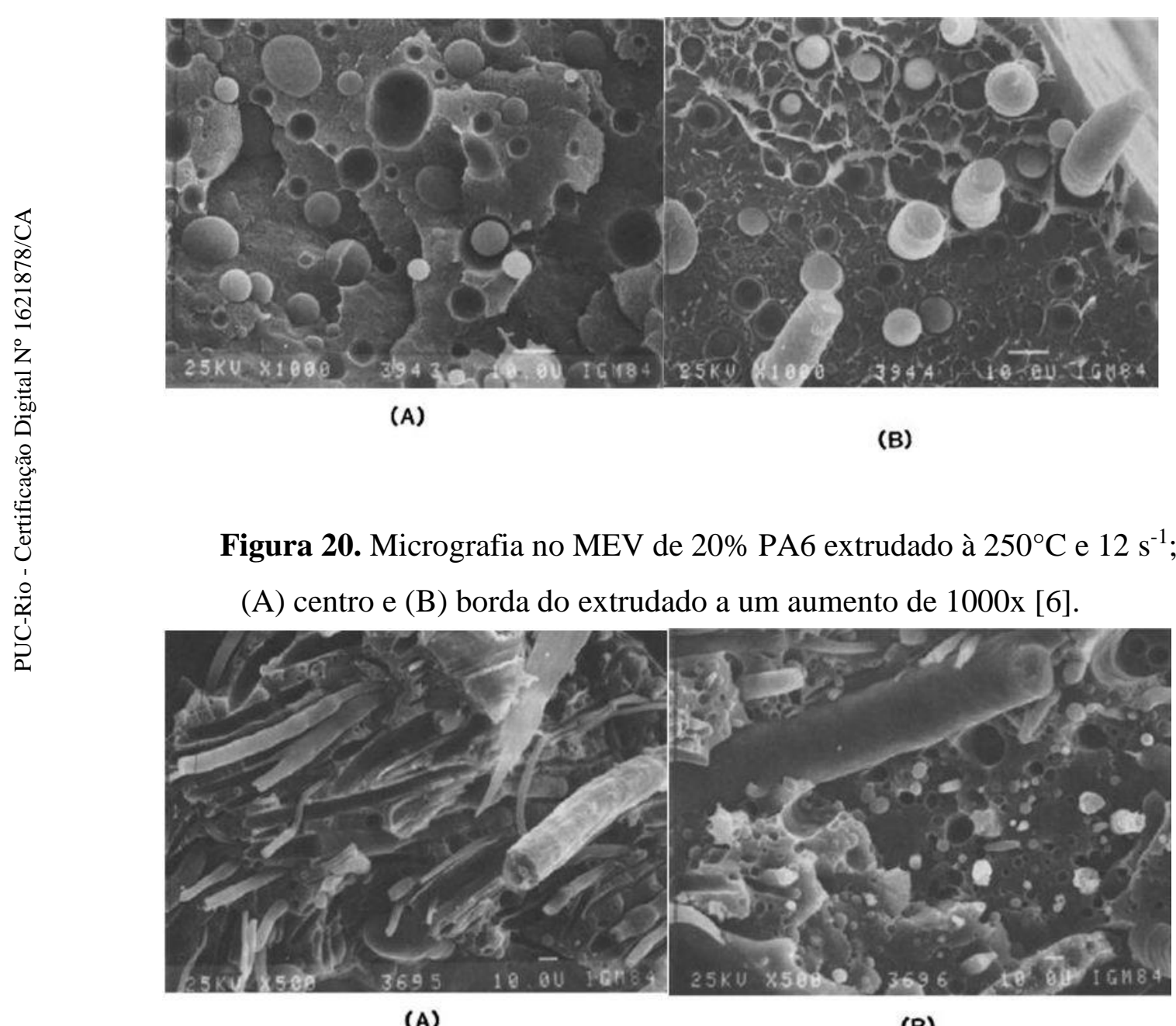

(A)

(B)

Figura 21. Micrografia no MEV de $30 \%$ PA6 extrudado à $150^{\circ} \mathrm{C}$ e $370 \mathrm{~s}^{-1}$;

(A) centro e (B) borda do extrudado a um aumento de 500x [6]. 


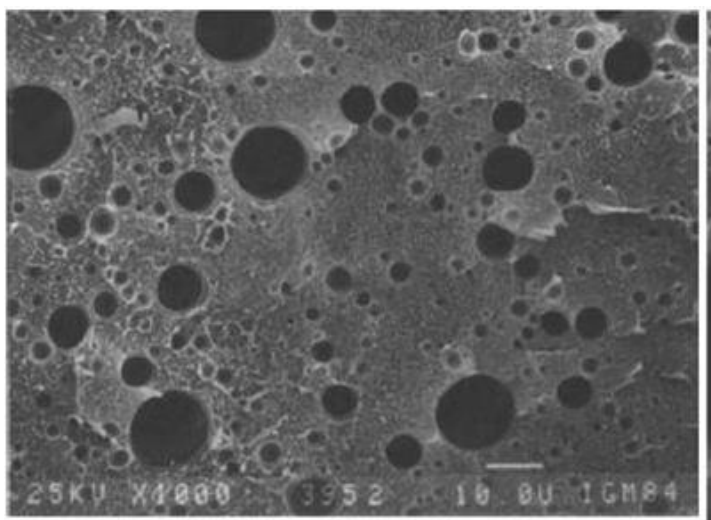

(A)

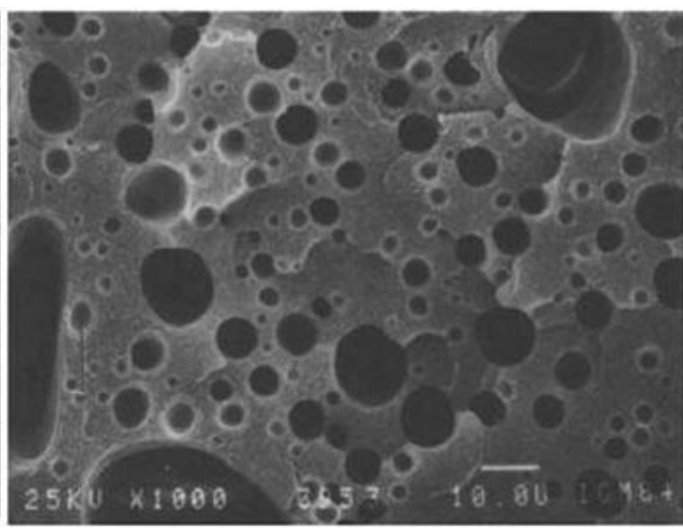

(B)

Figura 22. Micrografia no MEV de $30 \%$ PA6 extrudado à $250^{\circ} \mathrm{C} \mathrm{e} 116 \mathrm{~s}^{-1}$;

(A) centro e (B) borda do extrudado a um aumento de 1000x [6].

Através dos resultados do MEV mostrados nas figuras 18 a 22, pode-se constatar que durante o fluxo capilar, alguns efeitos induzidos por cisalhamento podem ser notados na morfologia das blendas. Devido às grandes diferenças na estrutura química dos polímeros e à tensão interfacial relativamente alta, era de se esperar imiscibilidade, levando à coalescência dos domínios a uma temperatura acima da $T_{m}$ da PA-6. Entretanto, sob condições de testes dinâmicos, a deformações menores que $10 \%$, a resposta viscoelástica do sistema foi razoavelmente estável e reproduzível, indicando pequena coalescência [6]. Quatro efeitos foram identificados pelos autores:

1. Uma segregação dos domínios do polímero induzida por cisalhamento é aparente nas Figuras 18 a 22. Comparando o MEV da parte central (foto A) com a borda (foto B), diferenças na concentração da fase dispersa (PA-6) são observadas. Para baixa concentração de PA-6 (ex: Figura 18), foram observadas segregação de domínios e dispersão dependente de tensão-deformação. A uma temperatura de $150^{\circ} \mathrm{C}$, a concentração de PA-6 é maior no centro do que nas bordas, o contrário de $250^{\circ} \mathrm{C}$, onde a viscosidade menor da PA-6 tende a encapsular a matriz de PEAD [6].

2. Uma fibrilação induzida por tensão é observada em todas as temperaturas para concentrações de PA-6 maiores que $10 \%$ em peso. A baixa concentração e baixas taxas de deformação o efeito ocorre somente próximo à borda [6]. 
3. Dispersão/coalescência dinâmica. Para descrever quantitativamente a extensão da dispersão, a razão $D / D_{0}$ foi usada onde $D$ é o diâmetro médio das partículas da fase dispersa no extrudado a $250^{\circ} \mathrm{C}$ e $D_{0}$ é o mesmo parâmetro na blenda inicial usada nos testes de fluxos capilares (que foram realizados antes da micrografia). Enquanto $\dot{\gamma}$ aumenta para $1120 \mathrm{~s}^{-1}$, a razão decresce para 0,3 no centro e 0,5 nas bordas do extrudado, indicando uma melhora progressiva na dispersão com o aumento da tensão localizada. Adicionalmente à redução do tamanho da partícula, um movimento radial da fase dispersa também pode ser observado [6].

4. O escorregamento interlamelar induzido por deformação é exemplificado na Figura 23(a), onde uma estrutura de anéis de árvore é visível. O detalhe na Figura 23(b) mostra uma separação interfásica clara [6].

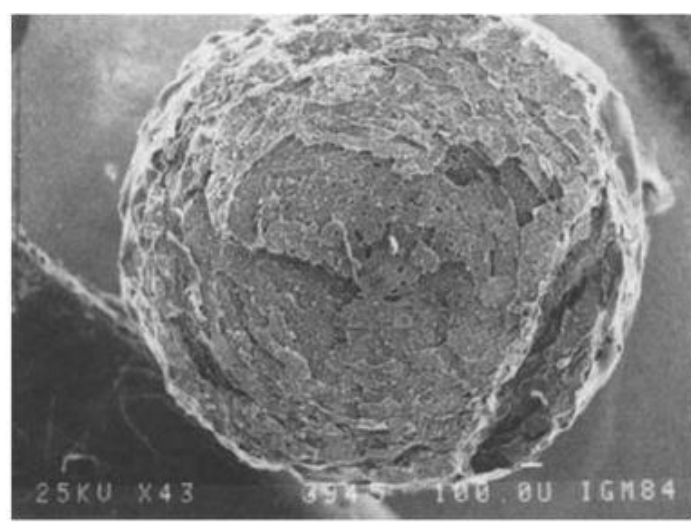

(A)

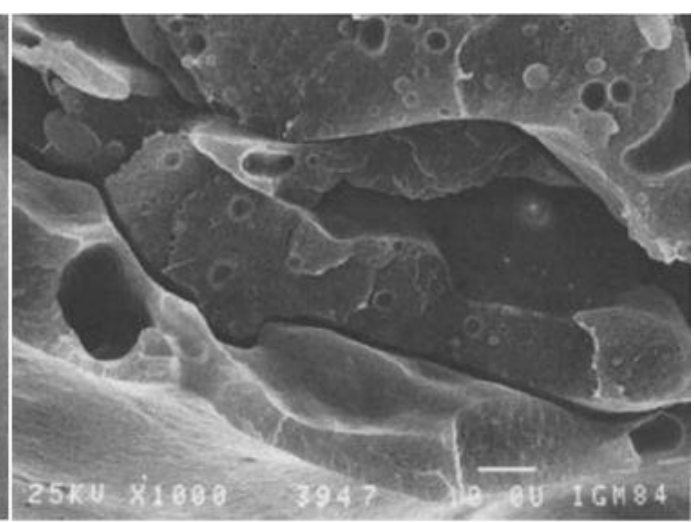

(B)

Figura 23. Micrografia no MEV de $30 \%$ PA extrudado a $250^{\circ} \mathrm{C}$ e $1110 \mathrm{~s}^{-1}$. (A) visão geral (B) detalhes do extrudado sob, respectivamente, um aumento de 43x e 1000x [6].

Yeh e col. [38] realizou experimentos para investigar os efeitos do compatibilizante nas propriedades de barreira e na morfologia de blendas PE/PA. Três compatibilizantes $(\mathrm{CPa}, \mathrm{CPb}$ e $\mathrm{CPc})$ foram selecionados para modificar a $\mathrm{PA}$ (MPA - Modified Polyamide) em uma extrusora por processo de extrusão reativa. A PA era uma blenda de $75 \%$ poliamida 6 (PA6) e $25 \%$ poliamida semi-aromática (SAPA). CPa é um copolímero etileno/ácido acrílico (89/11) 40\% neutralizado por zinco, $\mathrm{CPb}$ é um polietileno de alta densidade grafitizado com $0,4 \%$ de 
anidrido maleico e CPc é um copolímero etileno/ácido metilacrílico (96/4) 70\% neutralizado por zinco. Várias misturas de frações de massa diferentes de PE e MPAs foram moldadas por sopro, gerando garrafas da blenda [38]. As densidades e índices de fluidez do polietileno, poliamida e compatibilizantes estão resumidos na Tabela 6.

Tabela 6. Índices de fluidez e densidades de PE, PA e CPs [38].

\begin{tabular}{ccccccc}
\hline & PE & \multicolumn{2}{c}{ PA } & \multicolumn{3}{c}{ CP } \\
\hline Propriedades & & PA6 & SAPA & CPa & CPb & CPc \\
Índice de Fluidez (g/10min) & 0,27 & 8,8 & 32,3 & 0,8 & 0,6 & 5,0 \\
Densidade $\left(\mathbf{g} / \mathbf{c m}^{3}\right)$ & 0,944 & 1,13 & 1,19 & 0,96 & 0,95 & 0,94 \\
\hline
\end{tabular}

Para a análise da morfologia, as garrafas foram fraturadas em nitrogênio líquido e atacadas quimicamente com ácido fórmico. Depois as amostras foram revestidas com ouro e examinadas no MEV [38].

As superfícies fraturadas das amostras das garrafas da blenda de 90\% PE e $10 \%$ PA puro exibiram "estrutura marmoreada", como pode ser visto na Figura 24a. Em contrapartida, após a adição dos compatibilizantes, as superfícies da fratura das amostras de 90\% PE e 10\% MPAs exibiram aspecto laminar através da espessura da parede das garrafas. Vale a pena notar que os MPAs exibiram estruturas laminares mais evidentes em amostras associadas a melhores propriedades de barreira. As superfícies típicas da fratura das garrafas preparadas com misturas de PE/MPAb com percentagem crescente de MPAb são observadas na Figura 25. Entretanto, a estrutura laminar não pode ser claramente observada se PE e MPAb são pré-moldados em uma extrusora antes da moldagem por sopro (Figura 26) [38].

Esses resultados sugerem que uma estrutura laminar mais definida é essencial para propriedades de barreira melhores de blendas PE/MPA prémoldadas. Além disso, o tipo de MPA e a extensão da mistura do MPA e PE antes da moldagem por sopro tem um efeito significante na morfologia das blendas de MPA/PE [38]. 


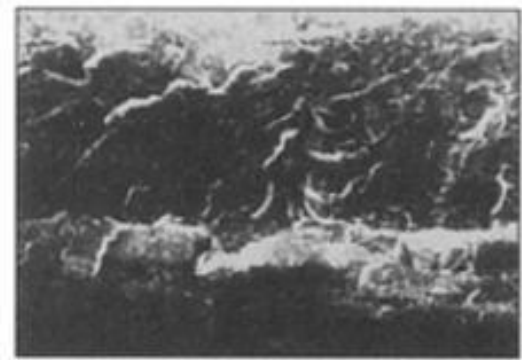

(a)

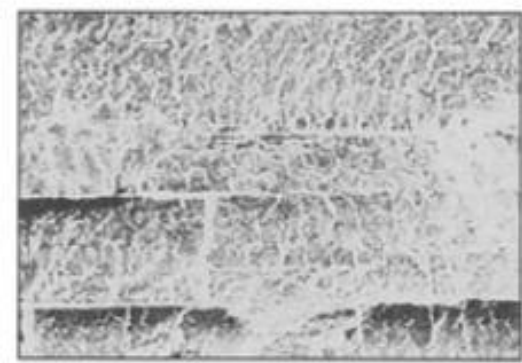

(c)

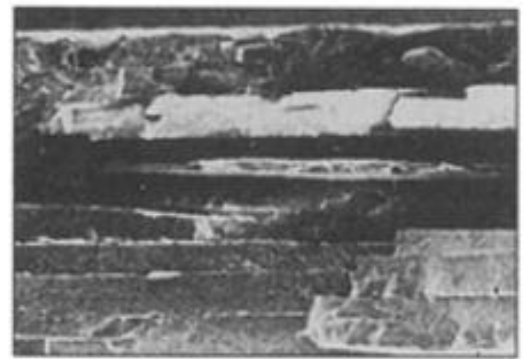

(b)

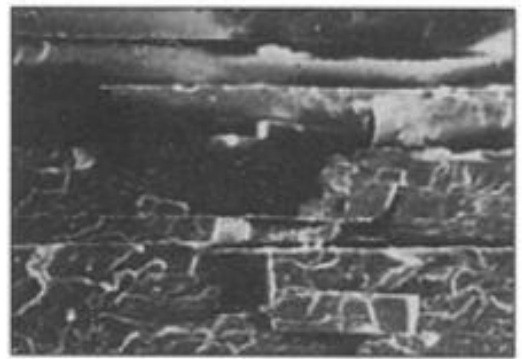

(d)

$$
\overline{500 \mu \mathrm{m}}
$$

Figura 24. Superfícies fraturadas das amostras de garrafas pré-moldadas

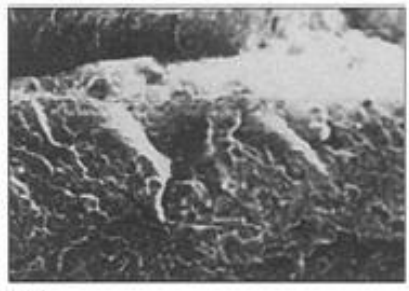

(a)

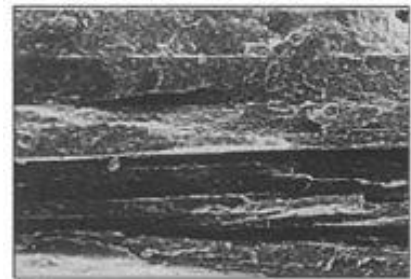

(d)

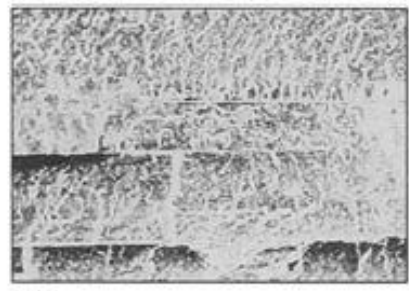

(b)

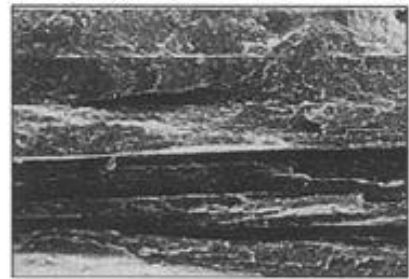

(e)

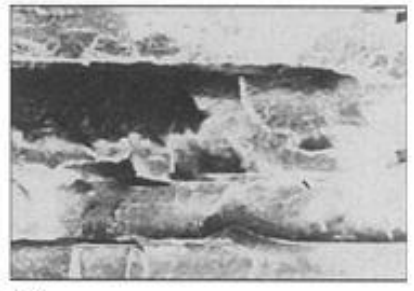

(c)

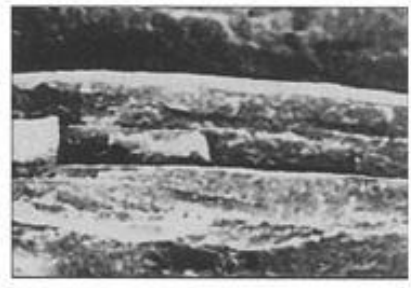

(f)

$\overline{500 \text { um }}$

Figura 25. Superfícies fraturadas das amostras de garrafas pré-moldadas com blendas de PE e (a) 5\%, (b) 10\%, (c) 15\%, (d) 20\%, (e) 25\%, (f) $30 \% \mathrm{MPAb}$ [38]. 


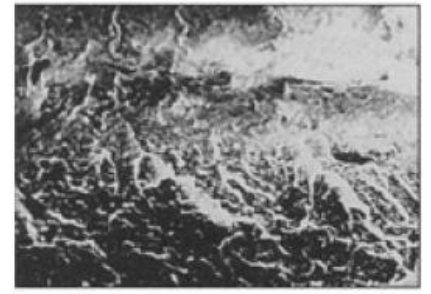

(a)

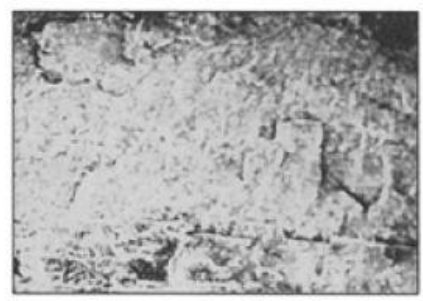

(b)

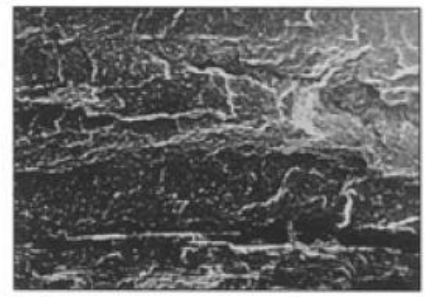

(c)

$\overline{500 \mathrm{um}}$

Figura 26. Superfícies fraturadas das amostras de garrafas de PE/MPAb pré-blendadas na extrusora antes da moldagem por sopro com (a) $10 \%$, (b) $20 \%$,

(c) $30 \%$ de MPAb [38].

A partir dos dados apresentados acima, pode-se concluir que a morfologia da blenda é altamente dependente de sua composição e das condições de processamento. Essa variação na morfologia altera também propriedades da blenda, como propriedades de barreira e algumas propriedades mecânicas, como será descrito nos próximos itens.

\subsection{Propriedades Reológicas}

Seguindo o mesmo experimento realizado por Utracki e col. [6], os testes reológicos (detalhados no item 3.1, referente ao experimento do Utracki e col. [6]) resultaram em gráficos de viscosidade vs. deformação, ilustrados nas Figuras 27 a 30 , onde as viscosidades extensional $\left(\eta_{e}\right)$, cisalhante $(\eta)$ e dinâmica $(\eta$ ') são funções, respectivamente, da taxa de deformação extensional $(\dot{\varepsilon})$, taxa de deformação cisalhante $(\dot{\gamma})$ e a frequência $(\omega)$. Foi observado que os dados obtidos em temperaturas diferentes se superpõem se plotados como $\eta / \eta_{0} v s . \dot{\gamma} \eta_{0}$, onde $\eta_{0}$ é a viscosidade à zero cisalhamento [6]. Uma temperatura de referência foi selecionada $\left(250^{\circ} \mathrm{C}\right)$ e os dados das Figuras 27 a 30 foram superpostos usando um fator de desvio $a_{T}$, definido como:

$$
a_{T}=\eta_{0}(T) / \eta_{0}\left(250^{\circ} C\right)
$$

As Figuras 27 a 30 mostram respectivamente os dados para PEAD puro, $10 \%$ PA e $20 \%$ PA, enquanto a Figura 29 resume todos os resultados, incluindo $30 \%$ PA. 


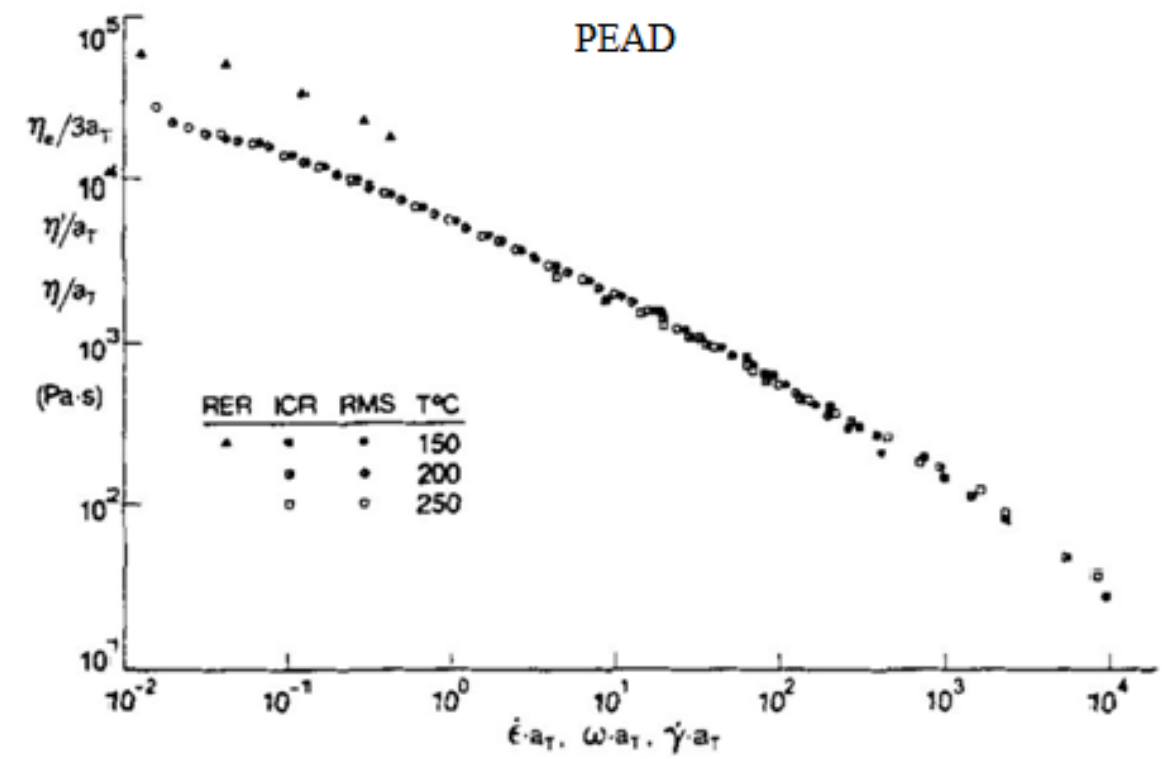

Figura 27. Viscosidades reduzidas: cisalhante, $\eta / a_{\mathrm{T}}$, extensional, $\eta \mathrm{e} / \mathrm{a}_{\mathrm{T}}, \mathrm{e}$ dinâmica, $\eta^{\prime} / \mathrm{a}_{\mathrm{T}}$, vs. respectivas taxas de deformação reduzidas: $\dot{\gamma}$.ат, $\dot{\boldsymbol{\varepsilon}}$.ат е $\omega$. ат para PEAD [6].

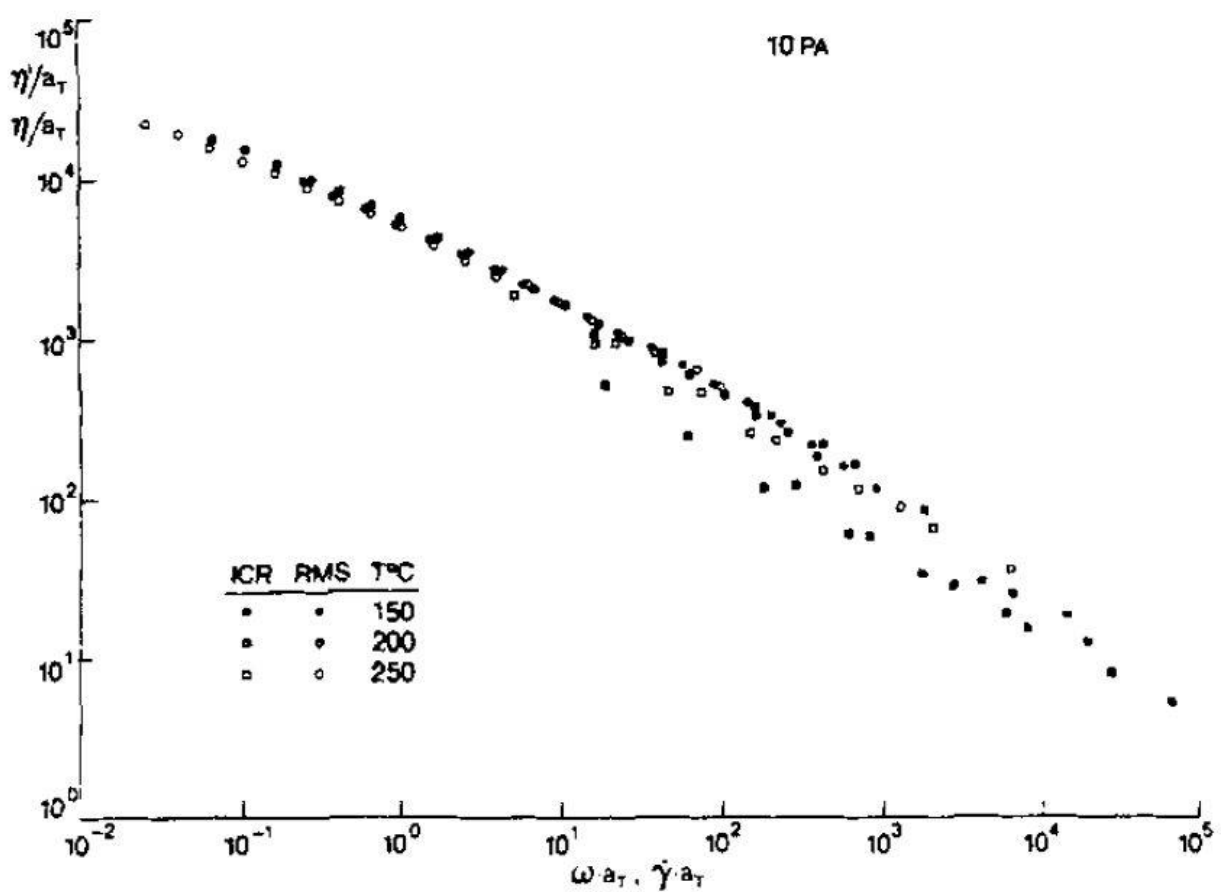

Figura 28. Viscosidades reduzidas: cisalhante, $\eta / a_{\mathrm{T}}$ e dinâmica, $\eta^{\prime} / \mathrm{a}_{\mathrm{T}}$, vs. taxa de cisalhamento reduzida, $\dot{\gamma}$.aT, e frequência, $\omega$. aT, para 10\% PA [6]. 


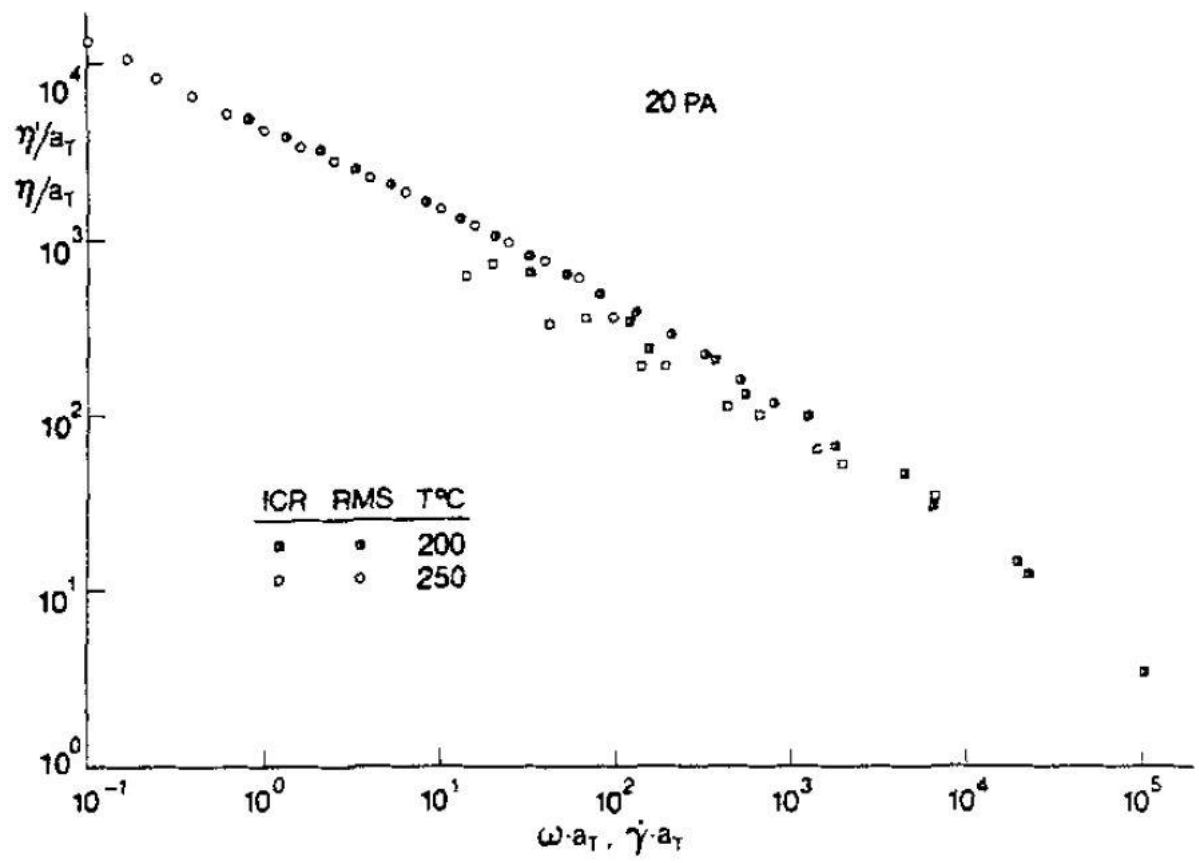

Figura 29. Viscosidades reduzidas: cisalhante, $\eta / a_{\mathrm{T}}$ e dinâmica $\eta^{\prime} / \mathrm{a}_{\mathrm{T}}$ vs. taxa de cisalhamento reduzida, $\dot{\gamma}$. a e frequência $\omega . \mathrm{aT}_{\mathrm{T}}$ para $20 \%$ PA [6].

A influência da concentração de PA-6 na viscosidade do estado estacionário (capilar), $\eta$, é muito sensível a temperatura. A $150^{\circ} \mathrm{C}$, a fase dispersa de PA-6 atua como um enchimento sólido causando um aumento da $\eta$ com sua concentração. A $250^{\circ} \mathrm{C}$, a PA-6 de baixa viscosidade migra para a borda causando redução da $\eta$ com sua concentração. A $200^{\circ} \mathrm{C}$, esses dois efeitos se compensam, resultando na $\eta$, que é independente da concentração de PA-6 [6].

Os dados resumidos na Figura 30 devem ser observados tendo em mente que a temperatura de referência foi arbitrariamente selecionada como $T_{R}=250^{\circ} \mathrm{C}$. Consequentemente, os dados foram reduzidos à plotagem das blendas fundidas, no qual a $\eta$ decresce com a concentração de PA-6 [6]. 


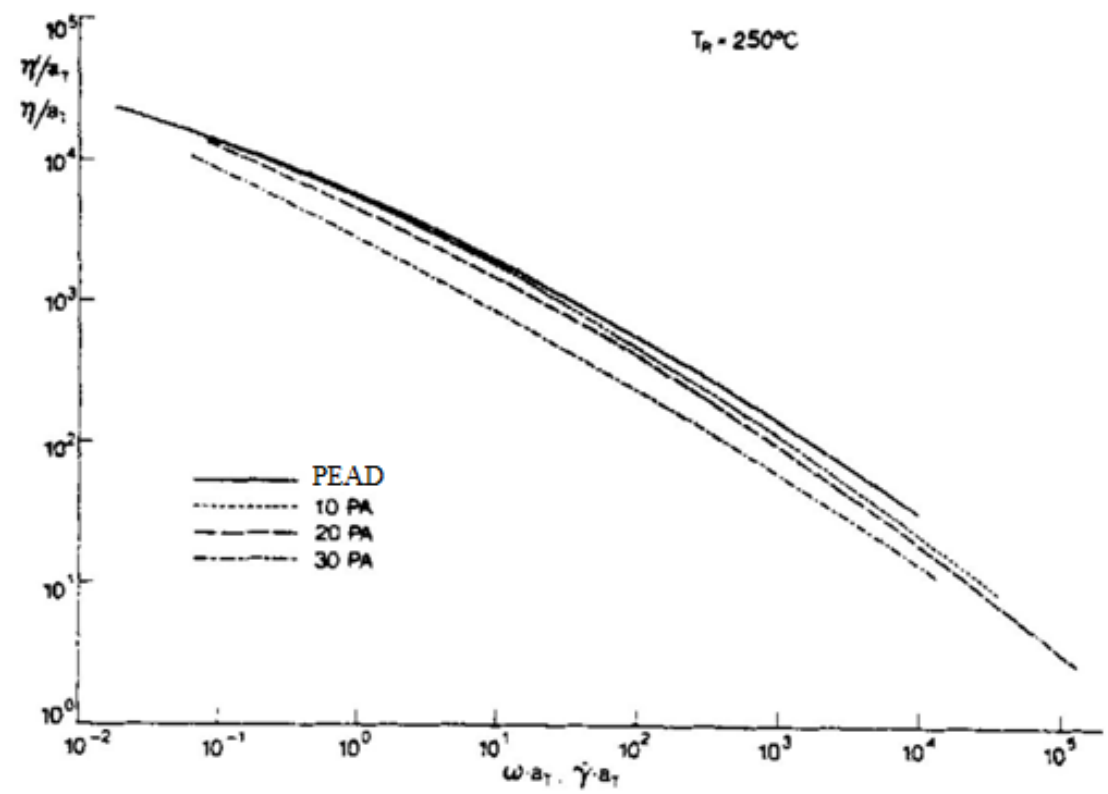

Figura 30. Curvas mestra para PEAD, 10\% PA, 20\% PA e 30\% PA. A temperatura de referência $T_{R}=250^{\circ} \mathrm{C}$ foi usada [6].

Os testes dinâmicos também permitem determinar o módulo de armazenamento, $G^{\prime}$, em função de $\omega$. Os dados de $G^{\prime} v s$. $\omega a_{T}$ para PEAD, $10 \%$ PA e PA-6 estão plotados na Figura 31 usando os mesmos valores de $T_{R}$ e aT empregados para construir a Figura 30. Como esperado, G' $($ PEAD) $>$ G' $($ PA-6). O módulo de armazenamento para blendas com concentração maior de PA-6 é maior [6].

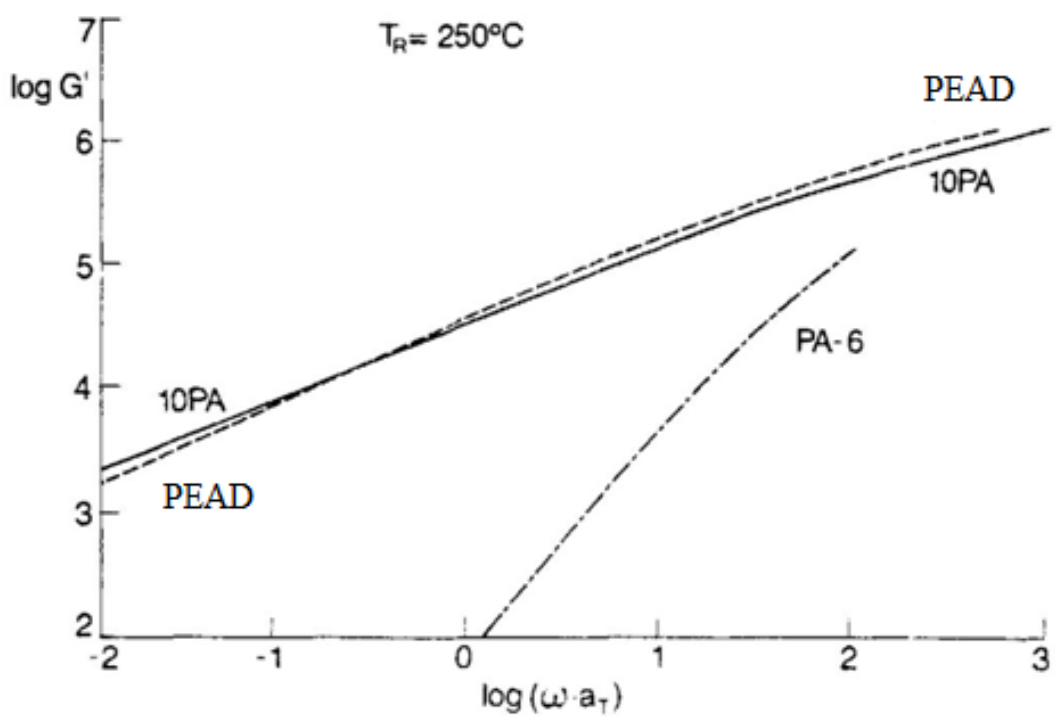

Figura 31. Módulo de energia armazenada, G' vs. frequência reduzida $\omega a_{T}$, para $\mathrm{PEAD}$ e $10 \% \mathrm{PA}$ à 150,200 e $250^{\circ} \mathrm{C}$ e para $\mathrm{PA}-6$ à $250^{\circ} \mathrm{C}$. A temperatura de referência é $\mathrm{T}_{\mathrm{R}}=250^{\circ} \mathrm{C}[6]$. 


\subsection{Efeitos do Polietileno na Reologia e Morfologia das Blendas PE/MPA}

Yeh e Jyan [39] fizeram um experimento com blendas de Polietileno (PE) Poliamida Modificada (MPA) para estudar os possíveis efeitos da viscosidade de cisalhamento dos PEs no comportamento da deformação das MPAs durante moldagem por sopro, e na morfologia, reologia e propriedades de impacto destas blendas. As poliamidas modificadas (MPA) nada mais são do que poliamida com um compatibilizante (CP), como o copolímero de etileno/ácido acrílico neutralizado por zinco [39].

Foram usados seis tipos de polietileno com dois tipos de poliamida modificada para fabricação de garrafas de PE/MPA. Os dois tipos de MPA foram preparados por extrusão reativa de dois tipos de poliamida-6 com o compatibilizante citado anteriormente. A fração em massa do ácido acrílico neste copolímero é de $26 \%$. Todos os PEs usados são de alta densidade, mas com índices de fluidez e pesos moleculares médios (Mw) diferentes [39].

Os índices de fluidez (MI) e viscosidades de cisalhamento $\left(\eta_{\mathrm{s}}\right)$ dos PEs, PAs e MPAs foram medidos para correlacioná-los com seus pesos moleculares e propriedades de extrusão durante a moldagem por sopro. O MI foi medido a $230^{\circ} \mathrm{C}$ e $2,16 \mathrm{~kg}$ de acordo com a norma ASTM D1238. Todas as $\eta_{\mathrm{s}}$ foram medidas a $230^{\circ} \mathrm{C}$ e com taxas de cisalhamento variando até $100 \mathrm{~s}^{-1}$. As $\eta_{\mathrm{s}}$ medidas nas taxas de cisalhamento até $100 \mathrm{~s}^{-1}$ e as correspondentes razões de viscosidade de cisalhamento das MPAs e PEs foram calculadas para correlacionar com o comportamento da deformação da fase dispersa de MPA durante a moldagem por sopro das blendas de PE/MPA, porque as taxas de cisalhamento dos polímeros durante a extrusão dos parisons antes da moldagem são geralmente abaixo de 100 $\mathrm{s}^{-1}[39]$.

Os índices de fluidez (MIs) e viscosidades de cisalhamento $\left(\eta_{\mathrm{s}}\right)$ dos PEs e MPAs estão resumidos na Tabela 7 e Figura 32, respectivamente. Como esperado, as viscosidades dos PEs e MPAs medidos a diferentes taxas de cisalhamento aumentam com o decréscimo do MI. Adicionalmente, é interessante notar que $\eta_{\mathrm{s}}$ dos PEs decrescem sutilmente enquanto as taxas de cisalhamento aumentam até $100 \mathrm{~s}^{-1}$. Em contraste, as $\eta_{\mathrm{s}}$ das MPAs decrescem mais significativamente com o aumento das taxas de cisalhamento do que as dos PEs [39]. 
Tabela 7. Propriedades físicas dos PEs, CP e PAs [39].

\begin{tabular}{ccccccccccccc}
\hline & \multicolumn{1}{c}{ CP } & \multicolumn{1}{c}{ PE } & & \multicolumn{1}{c}{ PA } & MPA1 & MPA2 \\
\hline Propriedades & & PE1 & PE2 & PE3 & PE4 & PE5 & PE6 & PA1 & PA2 & & \\
MI (g/10min) & 9,20 & 0,13 & 0,19 & 0,36 & 0,38 & 0,49 & 0,76 & 2,4 & 2,1 & 3,75 & 3,51 \\
$\begin{array}{c}\text { Densidade } \\
\left(\mathrm{g} / \mathrm{cm}^{3}\right)\end{array}$ & 0,96 & 0,95 & 0,95 & 0,95 & 0,96 & 0,95 & 0,95 & 1,1 & 1,1 & 1,09 & 1,08 \\
$\mathrm{M}_{\mathrm{w}}$ & 5,8 & 27,8 & 23,6 & 20,1 & 18,7 & 16,2 & 14,9 & 1,9 & 2,4 & - & - \\
\hline
\end{tabular}

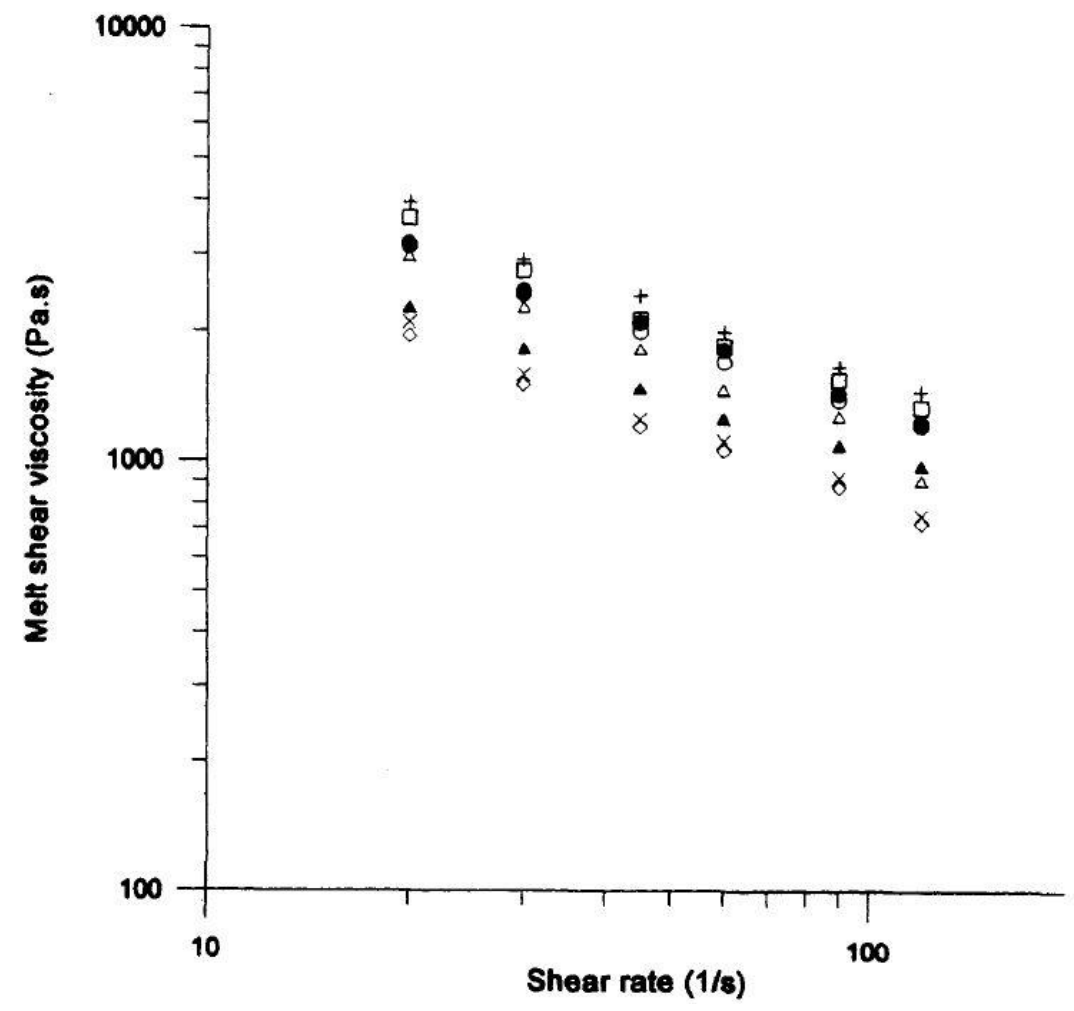

Figura 32. Viscosidades de cisalhamento do PE1 (+), PE2 ( $\square)$, PE3 (०), PE4 $(\Delta), \operatorname{PE} 5(\mathrm{x}), \operatorname{PE} 6(\diamond), \operatorname{MPA} 1(\boldsymbol{\Delta})$ e MPA2 $(\bullet)$ medidos a $230^{\circ} \mathrm{C}$ e taxas de cisalhamento variáveis [39].

Estes resultados fazem com que as razões das viscosidades dos MPAs e PEs usadas neste estudo aumentem sutilmente com o aumento das taxas de cisalhamento usadas no experimento, como se pode ver nas Figuras 33a e 33b [39]. 


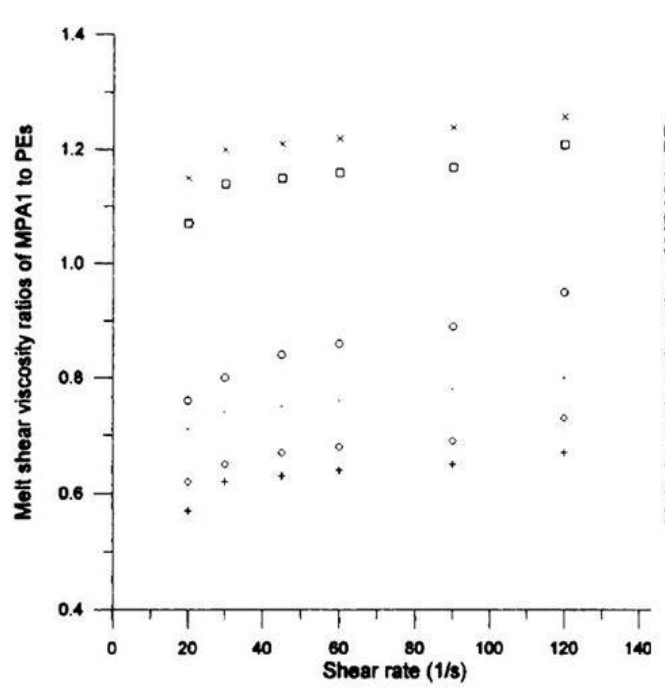

(a)

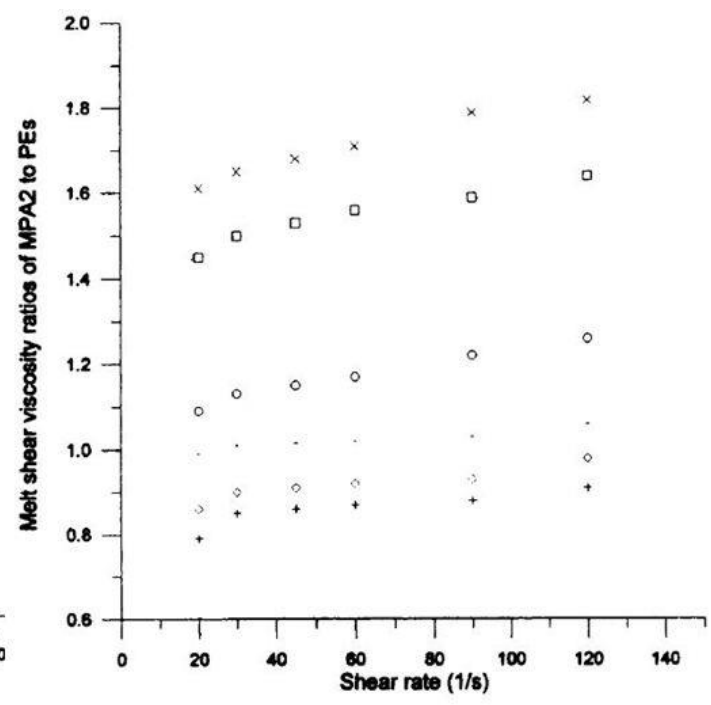

(b)

Figura 33. Razões de viscosidade de cisalhamento entre (a) MPA1 e PE1

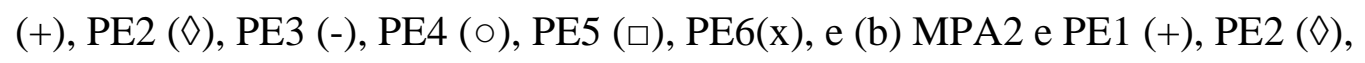
PE3 (-), PE4 (०), PE5 ( $\square)$, PE6 (x) determinados a $230^{\circ} \mathrm{C}$ e taxas de cisalhamento variáveis [39].

\subsection{Propriedades Mecânicas}

Hamid e col. [40] fabricaram blendas poliméricas de PA6/PEAD com PEAD-g-MAH (PEAD grafitizado com anidrido maleico) com uma variação na composição de 100/0, 98/2, 96/4, 94/6 e 92/8. Foram realizados ensaios mecânicos e para obtenção de propriedades, como módulo de elasticidade, resistência à tração, deformação de ruptura, módulo de flexão e resistência à flexão [40].

O índice de fluidez e a densidade do PA6 são 35g/10min e 1,14g/cm², respectivamente, à $230^{\circ} \mathrm{C}$ e $2,16 \mathrm{~kg}$. O índice de fluidez do PEAD é $4 \mathrm{~g} / 10 \mathrm{~min}$ e sua densidade é $0,957 \mathrm{~g} / \mathrm{cm}^{3}$ [40].

As propriedades mecânicas como módulo de Young, resistência à tração e deformação de ruptura foram medidas usando uma máquina de ensaio universal com extensômetro à temperatura ambiente e com velocidade de carregamento de $50 \mathrm{~mm} / \mathrm{min}$. O módulo de flexão e resistência à flexão foram determinados usando a mesma máquina com um vão de $64 \mathrm{~mm}$ a uma velocidade de $3 \mathrm{~mm} / \mathrm{min}$ [40]. 
O efeito do PEAD-g-MAH no módulo de elasticidade $(\mathrm{E})$, resistência à tração (LRT), deformação de ruptura (DR), módulo de flexão $\left(\mathrm{W}_{\mathrm{f}}\right)$ e resistência à flexão $\left(\mathrm{W}_{\mathrm{x}}\right)$ das amostras está resumido na Tabela 8 .

Tabela 8. Propriedades mecânicas das blendas de PA6/PEAD com PEAD-

$$
\text { g-MAH [40]. }
$$

\begin{tabular}{ccccccc}
\hline & & E (MPa) & LRT (MPa) & DR (\%) & $\mathbf{W}_{\mathbf{f}}$ (MPa) & $\mathbf{W}_{\mathbf{x}}$ (MPa) \\
\hline PA6 & & 2746,5 & 68,38 & 2,45 & 2153,59 & 89,21 \\
PEAD & & 1071,8 & 22,44 & 21,10 & 643,01 & 20,01 \\
PEAD-g-MAH & 1003,9 & 24,17 & 18,66 & 726,353 & 22,78 \\
\hline PA6/PEAD (\%) & PEAD-g-MAH (\%) & & & & & \\
$\mathbf{1 0 0}$ & $\mathbf{0}$ & 1595,8 & 34,75 & 7,98 & 1399,31 & 48,39 \\
$\mathbf{9 8}$ & $\mathbf{2}$ & 1828,2 & 44,81 & 2,20 & 1701,75 & 58,71 \\
$\mathbf{9 6}$ & $\mathbf{4}$ & 1519,8 & 36,11 & 8,91 & 1542,50 & 53,20 \\
$\mathbf{9 4}$ & $\mathbf{6}$ & 1480,0 & 34,60 & 17,51 & 1497,00 & 49,29 \\
$\mathbf{9 2}$ & $\mathbf{8}$ & 1387,7 & 34,39 & 26,39 & 1354,63 & 41,68 \\
\hline
\end{tabular}

Os resultados mostram que o módulo de elasticidade aumenta com a adição de PEAD-g-MAH, mas decresce com a incorporação de mais que 2\% do PEADg-MAH nas blendas. Os resultados também revelam que a resistência à tração aumentou com o aumento do PEAD-g-MAH até $2 \%$. Isso significa que $2 \%$ de compatibilizante foi o suficiente para ligar o polímero polar (PA6) com o PEAD nas blendas e eventualmente levar a uma melhora na estrutura. Entretanto, a adição excessiva do compatibilizante tem um alto potencial para enfraquecer gradualmente a estrutura das blendas [40].

De acordo com este artigo, a natureza elastomérica do compatibilizante causou este fenômeno. $\mathrm{O}$ módulo de flexão e resistência à flexão também foram aumentadas com a adição de até $2 \%$ de PEAD-g-MAH, depois decresceram continuamente até $8 \%$ de PEAD-g-MAH. A incorporação do PEAD-g-MAH (2\%) melhorou a adesão interfacial entre PA6 e PEAD, visto que o copolímero PA6-gPEAD foi blendado e, dessa forma, resultou em uma melhor fase dispersa. Ao mesmo tempo, a tensão interfacial rapidamente decresce [40].

As propriedades mecânicas de blendas de PE/PA foram avaliadas também por Kudva e col. [41], os quais realizaram experimentos com blendas de PELBD e 
PA-6 e avaliou algumas propriedades mecânicas, como resistência ao impacto, e a morfologia da blenda.

Neste estudo, os polietilenos usados foram grafitizados com anidrido maleico, dando um maior potencial de reação com os grupamentos amina do nylon 6 durante o processamento. O experimento de Kudva e col. foca nos efeitos da concentração, viscosidade e funcionalidade dos polietilenos maleados (PE-gMA) nas propriedades reológicas, morfológicas e mecânicas de blendas PA-6/PEg-MA [41].

As propriedades de impacto dessas blendas são fortemente influenciadas pela quantidade e tipo de polietileno maleado utilizado. Um polietileno maleado de baixa viscosidade mostrou-se ineficaz em endurecer nylon 6, devido à propensão do polietileno em se tornar contínuo, até mesmo quando nylon 6 é o componente majoritário [41].

A Tabela 9 resume as características das poliamidas usadas neste experimento, as quais têm quantidades equivalentes de grupamentos carboxila e amina. Os nylons 6 com pesos moleculares de 22.000 e 29.300 foram usados como base para a maior parte deste trabalho [41].

Tabela 9. Nylons 6 usados no trabalho de Kudva e col. [41].

\begin{tabular}{cccc}
\hline Designação & $\overline{\boldsymbol{M}_{\boldsymbol{n}}}$ & Grupamentos $\left(\boldsymbol{\mu e q ~ \mathrm { g } ^ { - 1 } )}\right.$ & Torque Brabender (N.m) \\
\hline Ultramid B0 & 13200 & $\begin{array}{c}{[\mathrm{COOH}]-74,2} \\
{\left[\mathrm{NH}_{3}\right]-77,0}\end{array}$ & 1,8 \\
Ultramid B2 & 19400 & $\begin{array}{c}{[\mathrm{COOH}]-48,5} \\
{\left[\mathrm{NH}_{3}\right]-54,0}\end{array}$ & 4,3 \\
& & $\begin{array}{c}{[\mathrm{COOH}]-43,0} \\
{\left[\mathrm{NH}_{3}\right]-47,9}\end{array}$ & 7,3 \\
Capron 8207 F & 22000 & $\begin{array}{c}{[\mathrm{COOH}]-28,8} \\
{\left[\mathrm{NH}_{3}\right]-34,8}\end{array}$ & 10,0 \\
Capron 8209 F & 29300 & {$[\mathrm{COOH}]-23,8$} & 16,2 \\
\hline Ultramid B5 & 37300 & {$\left[\mathrm{NH}_{3}\right]-28,1$} & \\
\hline
\end{tabular}

Algumas informações pertinentes sobre quatro polietilenos lineares de baixa densidade (PELBD) usados estão representadas na Tabela 10. Esses polietilenos podem ser divididos em dois grupos baseados em suas características viscosas; o material com baixo peso molecular é designado como L-PE, enquanto aqueles 
com pesos moleculares maiores são designados como H-PE. Dentre os PELBDs maleados, L-PE(0,9\% MA) e H-PE(0,9\% MA) têm porcentagem equivalente de anidrido, mas características viscosas diferentes; do outro lado, H-PE(0,3\% MA) e H-PE(0,9\% MA) têm características viscosas similares, mas quantidade de anidrido diferentes. Usando essas séries de polietilenos maleados foi possível fazer uma avaliação independente dos efeitos da viscosidade e funcionalidade nas propriedades da blenda [41].

Tabela 10. Polietilenos usados neste estudo [41].

\begin{tabular}{cccccc}
\hline $\begin{array}{c}\text { Nomenclatura } \\
\text { Comercial }\end{array}$ & Tipo de & $\begin{array}{c}\text { Designação usada } \\
\text { neste estudo }\end{array}$ & $\begin{array}{c}\text { Índice de } \\
\text { Fluidez }\end{array}$ & $\begin{array}{c}\text { Torque } \\
\text { Brabender } \\
\text { (N.m) }\end{array}$ & \%p MA \\
\hline MB110 & PELBD & L-PE(0.9\% MA) & 30 & 1.5 & 0.9 \\
MB158 & PELBD & H-PE(0.3\% MA) & 1.5 & 4.5 & 0.3 \\
MB226 & PELBD & H-PE(0.9\% MA) & 1.5 & 5.9 & 0.9 \\
14B3 & PELBD & H-PE(0\% MA) & 1.85 & 8.9 & 0 \\
\hline
\end{tabular}

As blendas foram preparadas por extrusão de todos os componentes em uma extrusora a $240^{\circ} \mathrm{C}$ com parafuso a uma velocidade de $40 \mathrm{rpm}$. O tipo de ensaio de impacto foi o Izod e a morfologia da blenda foi examinada usando um MET [41].

O peso molecular do nylon 6 é uma variável importante na determinação das propriedades das blendas, afetando a viscosidade e morfologia da blenda, assim como elementos de cristalinidade. Para a discussão de propriedades das blendas de nylon 6 com polietilenos maleados, foram utilizados dois materiais: Capron 8207F, que tem massa molecular numérica média de 22.000 e Capron 8209F, que tem massa molecular numérica média de 29.300 [41].

\section{Blendas de Capron $8207 F$}

A Figura 34 mostra a caracterização reológica de blendas deste nylon 6 com vários polietilenos maleados em função da composição da blenda; cada uma das blendas tem um torque Brabender mais alto que qualquer um dos componentes da blenda, o que evidencia que as reações de grafitização ocorrem. Uma comparação das blendas que contêm polietilenos com alta viscosidade mostra que o torque Brabender é maior para blendas baseadas no polietileno com índice mais alto de anidrido, isso é, uma funcionalidade maior resulta em um maior grau de 
grafitização durante o processamento. Uma comparação das blendas baseadas em polietilenos com o mesmo grau de funcionalidade do anidrido, mas viscosidades diferentes revela um torque Brabender substancialmente maior para as blendas que contêm o polietileno de maior viscosidade [41].

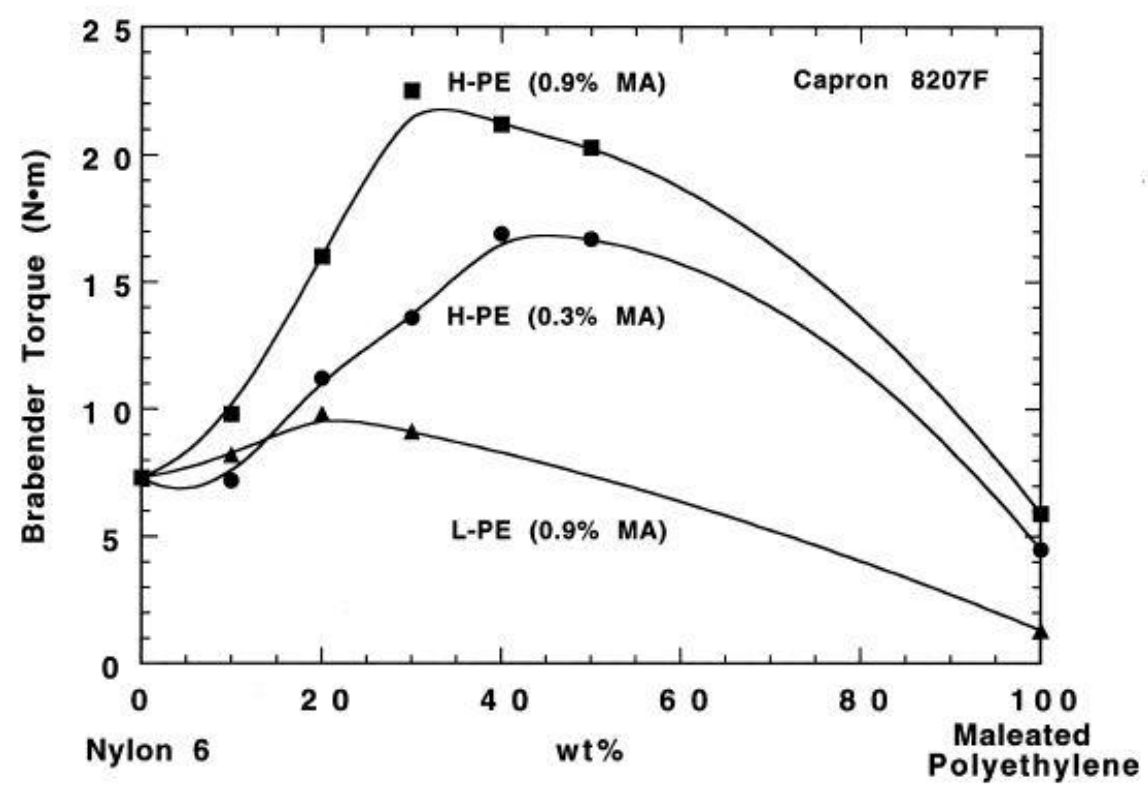

Figura 34. Torque Barbender de blendas de nylon 6 (Capron 8207F) com vários polietilenos maleados. As medidas dos torques foram tomadas após 10 minutos a $240^{\circ} \mathrm{C}$ e $60 \mathrm{rev} \cdot \mathrm{min}^{-1}$ [41].

As resistências ao impacto Izod das blendas de várias composições de L$\operatorname{PE}(0,9 \%$ MA) são ilustradas na Figura 35 em função da temperatura. O nylon 6 puro é frágil a temperatura ambiente e não se torna resistente até que a temperatura é aumentada acima da $\mathrm{T}_{\mathrm{g}}$, aproximadamente $50^{\circ} \mathrm{C}$. A incorporação de $10 \%$ desse polietileno tem um efeito mínimo nas propriedades de impacto; essas blendas têm uma resistência a impacto sutilmente mais alta que o nylon 6 a temperatura ambiente, mas são menos resistentes a temperaturas maiores. Blendas contendo $20 \%$ desse polietileno maleado têm resistência a impacto melhorada,

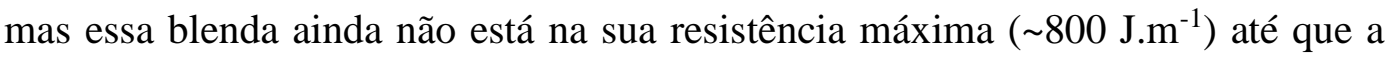
temperatura seja aumentada até cerca de $45^{\circ} \mathrm{C}$. Quando o polietileno maleado é incrementado até $30 \%$, a blenda é frágil em toda a faixa de temperatura [41]. 


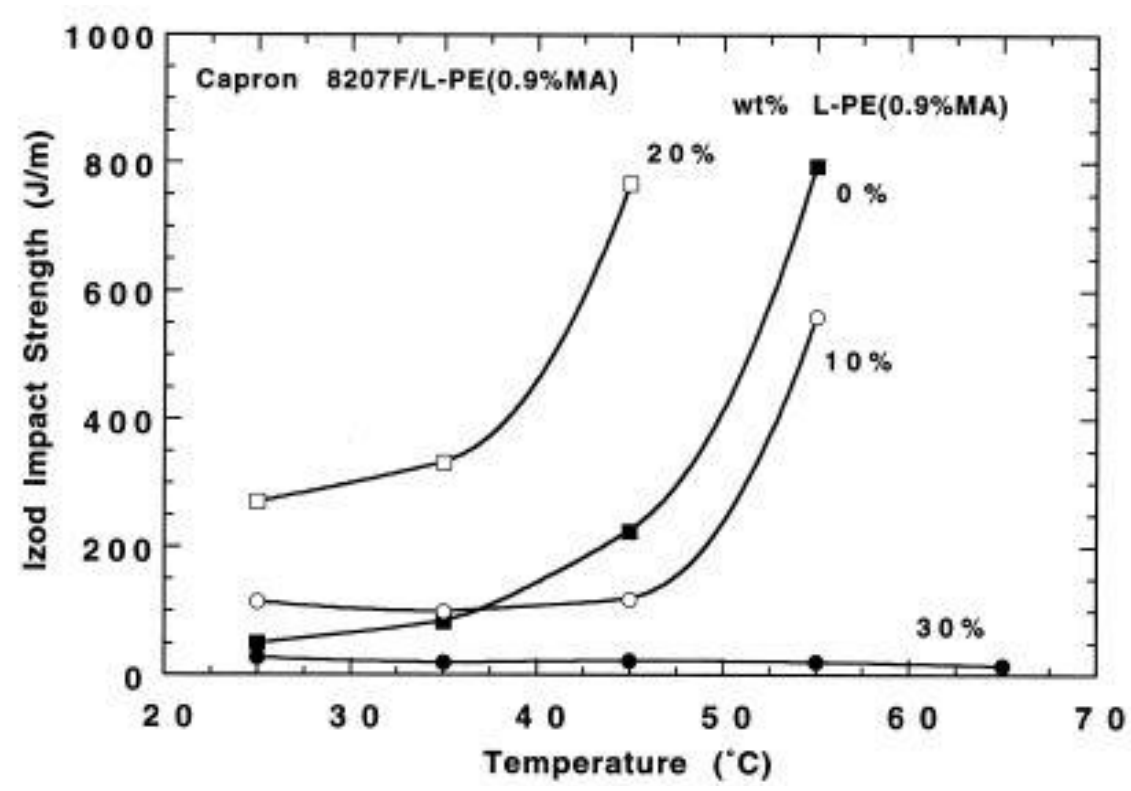

Figura 35. Efeito da temperatura na resistência a impacto Izod das blendas de Capron 8207F e L-PE(0,9\% MA). Esse polietileno linear de baixa densidade tem uma baixa viscosidade e um alto conteúdo de anidrido [41].

O estudo mostra também que a morfologia gerada durante o processamento vai influenciar o comportamento de impacto dessas blendas. As micrografias capturadas por MET na Figura 36 revelam que quando essas blendas contêm 10 ou $20 \%$ do polietileno maleado, a fase de polietileno é dispersa como pequenas partículas $(\sim 0,1-0,2 \mu \mathrm{m})$ na matriz de nylon 6. Entretanto, quando a fração do polietileno maleado é aumentada para $30 \%$, o polietileno vira a fase contínua com grandes glóbulos de nylon 6 contidos nela. Essa inversão de fase faz com que as propriedades de impacto piorem muito [41]. Já foi demonstrado em outros estudos [42] para outros sistemas, que o componente com a viscosidade mais baixa tende a encapsular a fase mais viscosa; a diferença nas viscosidades dos componentes pode fazer com que o componente minoritário se torne a fase contínua [41]. 
90/10 Capron 8207F/L-PE(0.9\%MA)

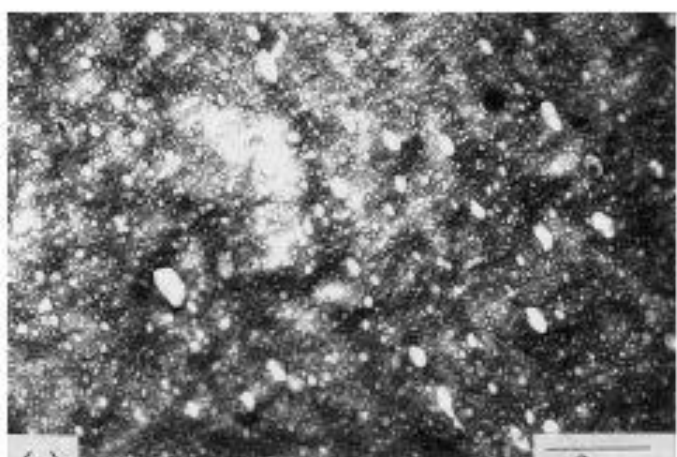

(a)

80/20 Capron 8207F/L-PE(0.9\%MA)

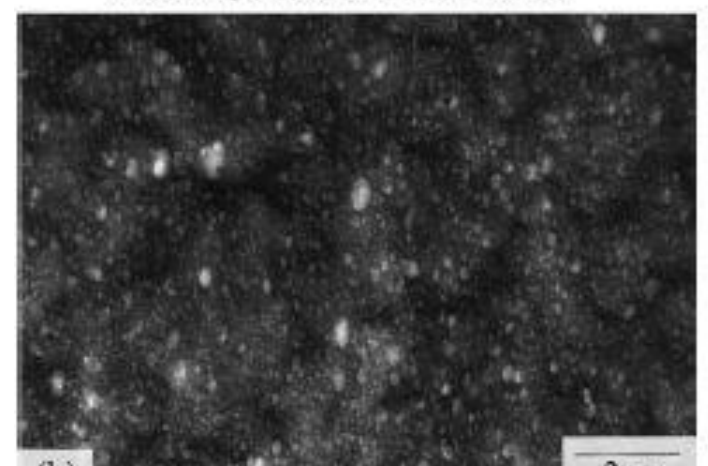

(b)

$70 / 30$ Capron $8207 \mathrm{~F} / \mathrm{L}-\mathrm{PE}(0.9 \% \mathrm{MA})$

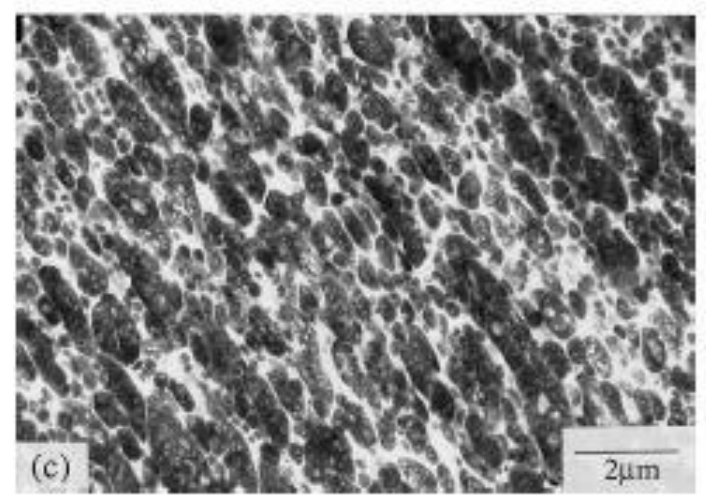

Figura 36. Micrografias do MET das blendas de Capron 8207F e L-

PE(0,9\% MA) contendo as seguintes frações de PELBD maleado: (a) 10\%; (b)

20\%; e (c) 30\%. A fase da poliamida está tingida de preto pelo ácido fosfotúngstico (PTA) [41].

A influência da viscosidade do polietileno nas propriedades de impacto da blenda pode ser explorada comparando as blendas descritas previamente com as blendas correspondentes contendo $\mathrm{H}-\mathrm{PE}(0,9 \% \mathrm{MA})$; este polietileno maleado tem uma viscosidade maior, mas o mesmo grau de funcionalidade que o $\operatorname{LPE}(0,9 \%$ MA). A Figura 37 mostra a influência da fração em massa do polietileno na resistência ao impacto à temperatura constante (parte a) e a temperatura de transição dúctil-frágil (parte b) para blendas de nylon 6 com H-PE(0,9\% MA). A 
adição de menos que $20 \%$ deste polietileno maleado não gera nenhuma melhora significativa na resistência, o que é similar com o que foi visto com blendas contendo L-PE(0,9\% MA). Entretanto, quando a fração de polietileno maleado é aumentada para 30\%, a resistência ao impacto aumenta acentuadamente e a transição dúctil-frágil é reduzida em mais de $50^{\circ} \mathrm{C}$. Um maior incremento de polietileno nas blendas reduz a resistência ao impacto, enquanto a temperatura de transição dúctil-frágil continua relativamente constante até a faixa de 40-60\% de polietileno [41].
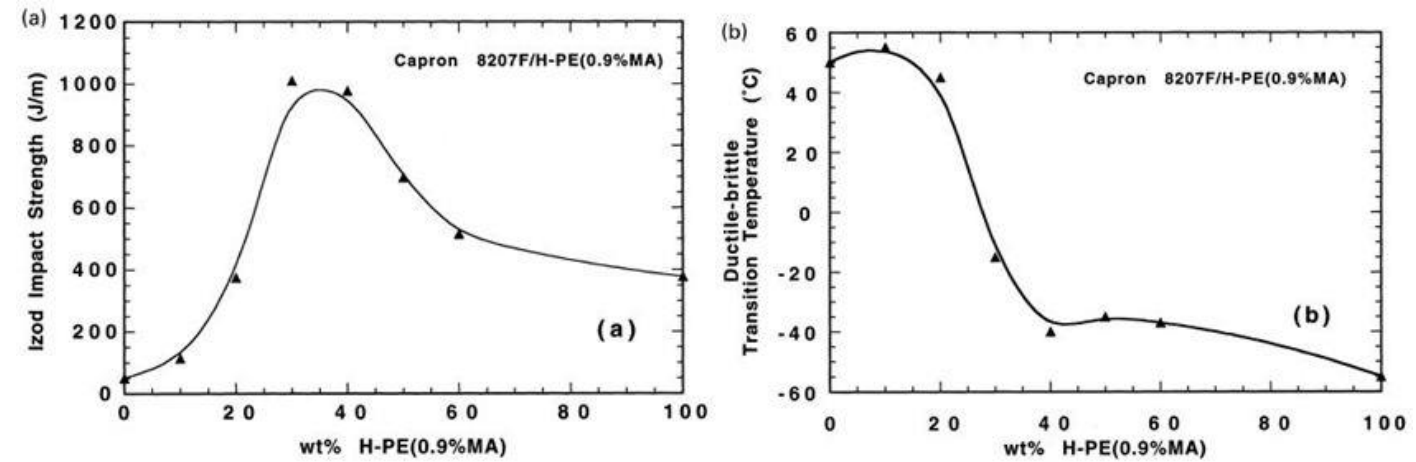

Figura 37. Propriedades de impacto de blendas de Capron 8207F e H-

$\operatorname{PE}(0,9 \% \mathrm{MA})$ : (a) resistência ao impacto Izod à temperatura ambiente; e (b) temperatura de transição dúctil-frágil. [41].

Devido às diferenças na viscosidade do polietileno, existem diferenças significativas na morfologia entre as blendas representadas nas Figuras 36 e 38. As micrografias do MET das blendas de nylon 6 com H-PE(0,9\% MA) estão representadas na Figura 38. As blendas contendo 10\% deste polietileno maleado (Figura 38(a)) contêm partículas com formatos muito mais complexos que aquelas de L-PE(0,9\% MA), o que pode ser explicado pela maior extensão de grafitização. O surgimento da alta resistência parece corresponder ao ponto onde a fase do polietileno se torna alongada (Figura 38(c)), o que marca o começo da cocontinuidade desta fase. Como esperado, a fase do polietileno tende a se tornar mais contínua ao passo que a sua fração na blenda é aumentada. Conforme a fase do polietileno se torna mais contínua, a resistência ao impacto é reduzida [41]. 
90/10 Capron $8207 \mathrm{~F} / \mathrm{H}-\mathrm{PE}(0.9 \% \mathrm{MA})$

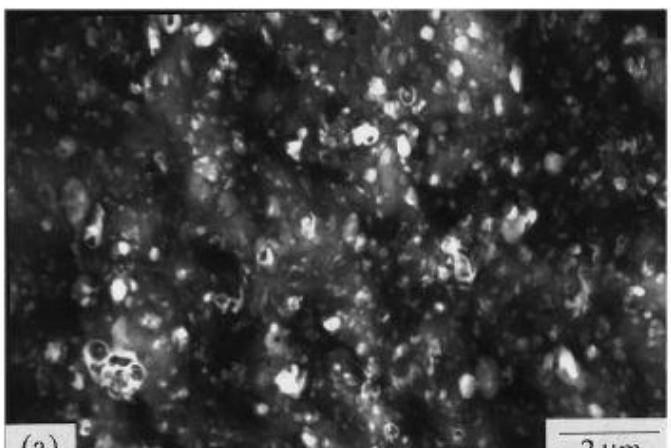

(a)

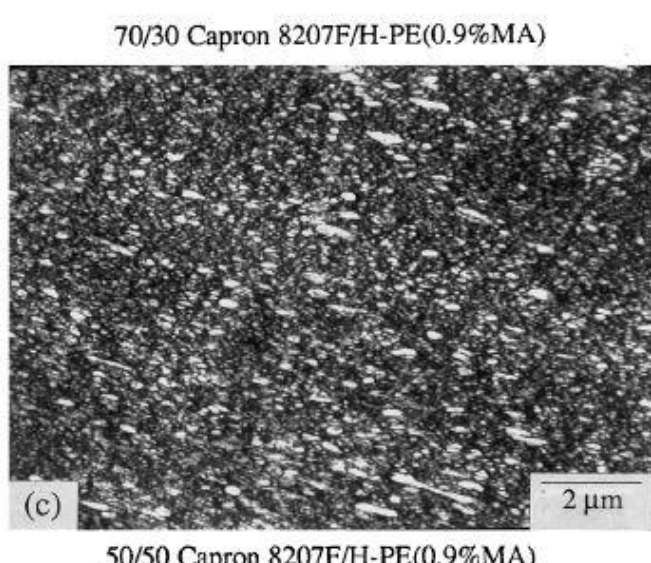

50/50 Capron 8207F/H-PE(0.9\%MA)

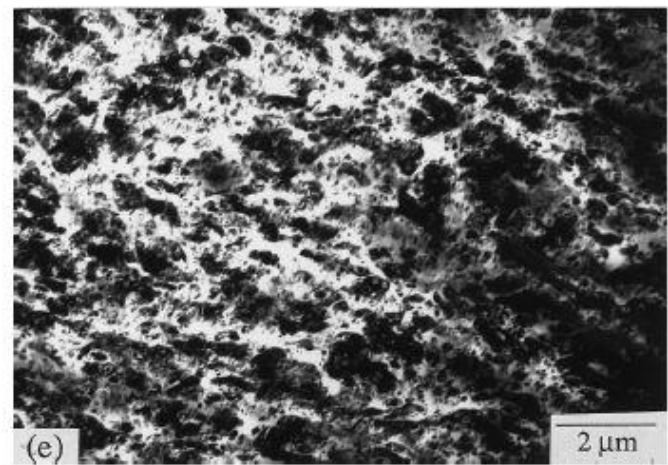

80/20 Capron $8207 \mathrm{~F} / \mathrm{H}-\mathrm{PE}(0.9 \% \mathrm{MA})$

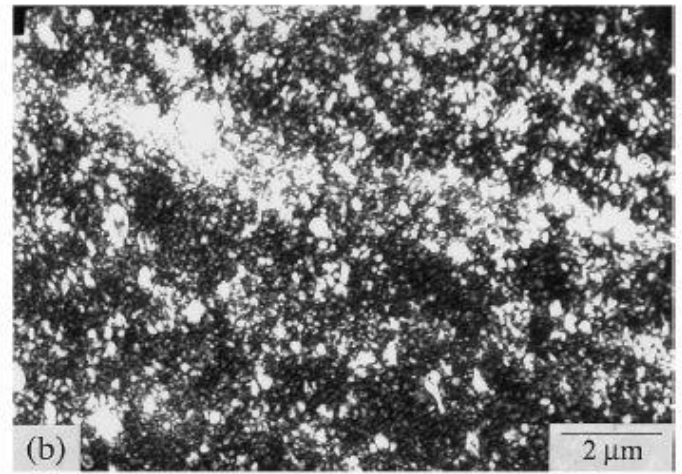

60/40 Capron $8207 \mathrm{~F} / \mathrm{H}-\mathrm{PE}(0.9 \% \mathrm{MA})$

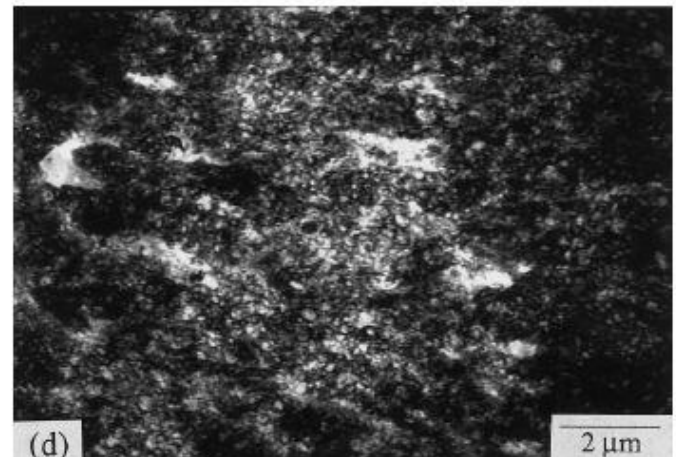

40/60 Capron $8207 \mathrm{~F} / \mathrm{H}-\mathrm{PE}(0.9 \% \mathrm{MA})$

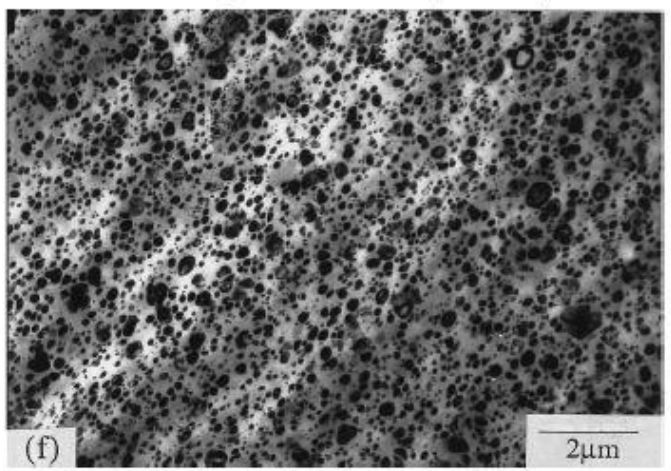

Figura 38. Micrografias no MET das blendas de Capron 8207F e H-

$\mathrm{PE}(0,9 \% \mathrm{MA})$ contendo as seguintes frações de $\mathrm{H}-\mathrm{PE}(0,9 \% \mathrm{MA})$ : (a) 10\%; (b) $20 \%$; (c) $30 \%$; (d) $40 \%$; (e) $50 \%$; e (f) $60 \%$. A poliamida é tingida de preto por

$$
\text { PTA [41]. }
$$

O conteúdo de anidrido da fase do polietileno afeta largamente a viscosidade da blenda, até mesmo quando os polietilenos têm características reológicas similares. Para determinar se essas diferenças na funcionalidade do polietileno também influenciam nas propriedades de impacto da blenda, blendas de nylon 6 com $\mathrm{H}-\mathrm{PE}(0,3 \% \mathrm{MA})$ foram preparadas; este polietileno maleado tem um grau de funcionalidade mais baixo, mas viscosidade similar, se comparado com $\mathrm{H}$ $\operatorname{PE}(0,9 \% \mathrm{MA})$. Os efeitos da composição da blenda na resistência ao impacto à 
temperatura ambiente e a temperatura de transição dúctil-frágil de blendas de nylon 6 com H-PE(0,3\% MA) são mostradas nas Figuras 39(a) e (b), respectivamente. Essas blendas têm baixas resistências ao impacto e altas temperaturas de transição dúctil-frágil quando elas contêm somente 10 ou $20 \%$ do polietileno maleado [41].
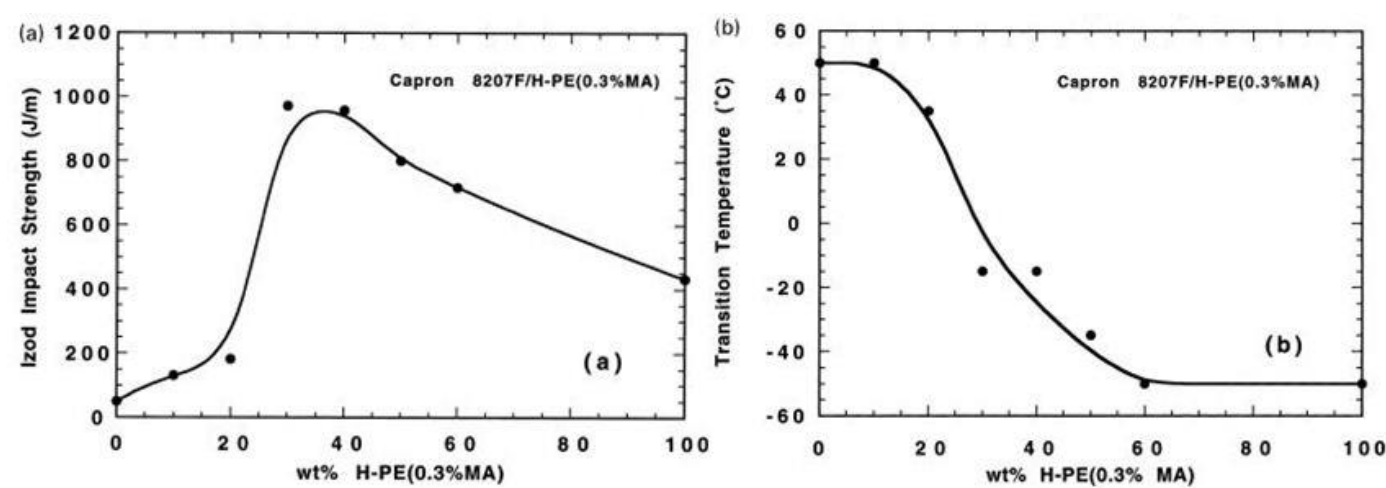

Figura 39. Propriedades de impacto de blendas de Capron 8207F e HPE(0,3\% MA): (a) Resistência a impacto Izod à temperatura ambiente; e (b) temperatura de transição dúctil-frágil. Este PELBD maleado tem uma alta viscosidade e uma baixa fração de anidrido [41].

Conforme a fração de polietileno maleado é aumentada de $20 \%$ para $30 \%$, existe uma melhora significativa na resistência a impacto à temperatura ambiente e a baixas temperaturas; esta é a mesma composição na qual as propriedades de impacto melhoram nas blendas correspondentes de H-PE(0,9\% MA). Nessas blendas, a temperatura de transição dúctil-frágil geralmente decresce com o acréscimo do H-PE(0,3\% MA). Em composições maiores que 30\% de polietileno, as melhorias em resistência à baixa temperatura são acompanhadas de uma redução na resistência a impacto à temperatura ambiente. Estes resultados demonstram que uma pequena quantidade de anidrido maléico grafitizado é suficiente para gerar blendas de nylon 6/polietileno mais resistentes [41].

A Figura 40 mostra fotomicrografias no MET de blendas, cujas propriedades foram descritas na Figura 38. A baixas porcentagens de H-PE(0,3\% MA), as partículas de polietileno são maiores que nas blendas contendo $\mathrm{H}$ $\operatorname{PE}(0,9 \% \mathrm{MA})$. Estas partículas maiores são consequência da baixa funcionalidade do $\mathrm{H}-\mathrm{PE}(0,3 \% \mathrm{MA})$. A maiores concentrações de $\mathrm{H}-\mathrm{PE}(0,3 \%$ MA), a relação entre a morfologia e resistência a impacto são similares àquelas das blendas de nylon 6 com $\mathrm{H}-\mathrm{PE}(0,9 \% \mathrm{MA})$ descritas previamente. Isto é, a resistência ao 
impacto atinge seu máximo quando os domínios de polietileno são alongados e com aparência fibrosa, depois declina enquanto a fase de polietileno se torna mais contínua [41].

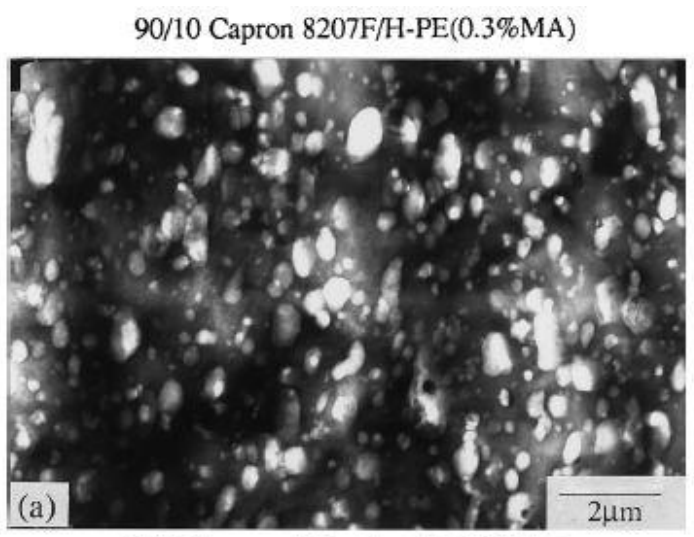

70/30 Capron $8207 \mathrm{~F} / \mathrm{H}-\mathrm{PE}(0.3 \% \mathrm{MA})$

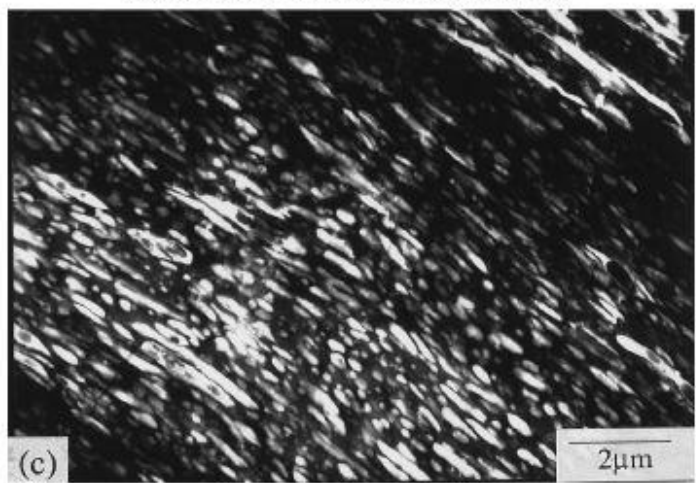

50/50 Capron $8207 \mathrm{~F} / \mathrm{H}-\mathrm{PE}(0.3 \% \mathrm{MA})$

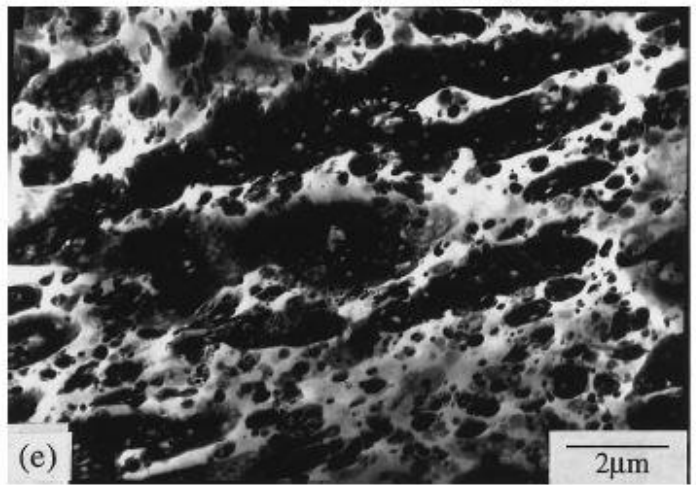

80/20 Capron $8207 \mathrm{~F} / \mathrm{H}-\mathrm{PE}(0.3 \% \mathrm{MA})$

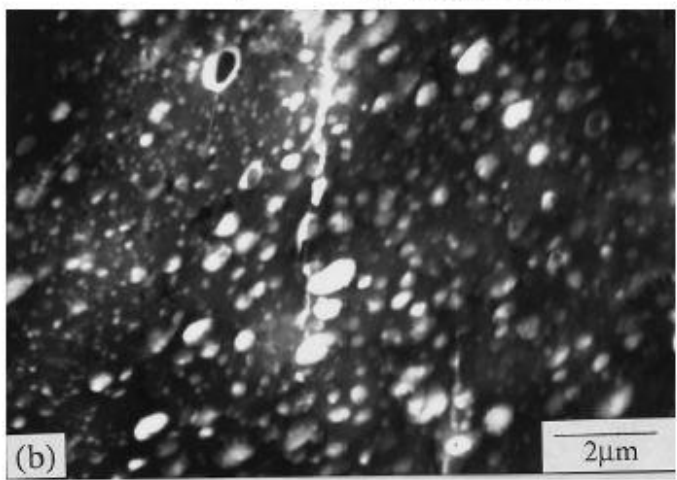

60/40 Capron $8207 \mathrm{~F} / \mathrm{H}-\mathrm{PE}(0.3 \% \mathrm{MA})$

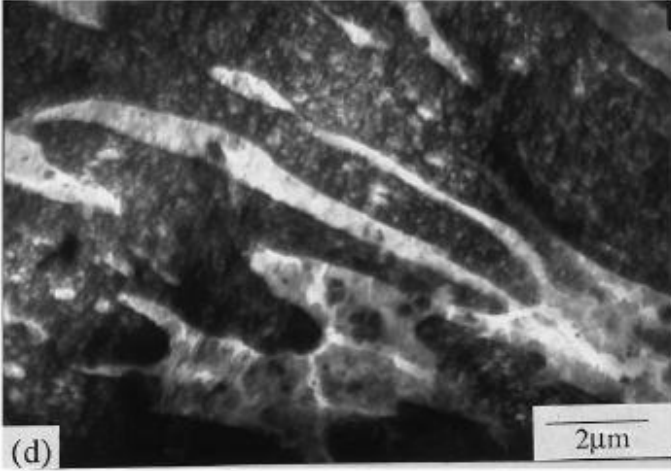

40/60 Capron $8207 \mathrm{~F} / \mathrm{H}-\mathrm{PE}(0.3 \% \mathrm{MA})$

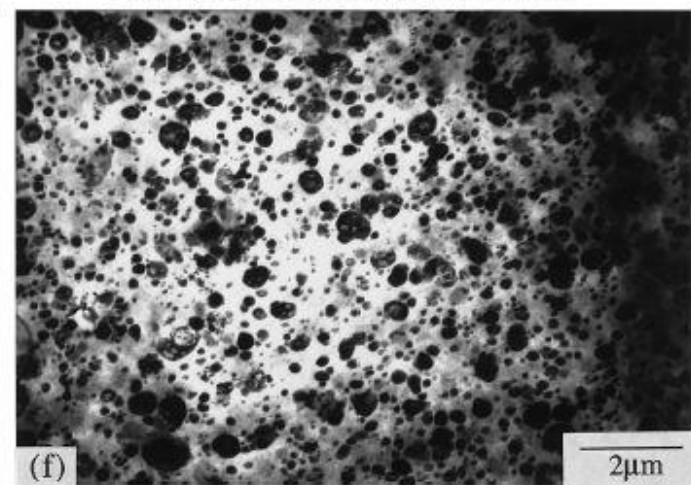

Figura 40. Micrografias no MET de blendas de Capron 8207F e H-

$\operatorname{PE}(0,3 \% \mathrm{MA})$ contendo as seguintes frações de H-PE(0,3\% MA): (a) 10\%;

(b) $20 \%$; (c) $30 \%$; (d) 40\%; (e) 50\%; e (f) $60 \%$. A fase da poliamida está tingida de preto por PTA [41].

\section{$>$ Blendas de Capron $8209 F$}

Muitos dos casos tratados no item anterior também são explorados nesta seção para blendas com nylon 6 de peso molecular mais alto $\left(\overline{M_{n}}=29.300\right) \mathrm{com}$ os polietilenos maleados. O torque Brabender para estas blendas está mostrado 
como função da composição na Figura 41. Em certos casos, os valores do torque para blendas contendo o polietileno de baixa viscosidade L-PE( $0,9 \%$ MA) são mais altos que aqueles de blendas correspondentes usando o polietileno de maior viscosidade H-PE(0,3\% MA). Claramente, a viscosidade da blenda é influenciada tanto pela viscosidade como pela funcionalidade da fase do polietileno; a $10 \%$ ou $20 \%$ de polietileno, a funcionalidade mais alta do polietileno de baixa viscosidade aumenta a viscosidade a níveis mais altos que em blendas contendo um polietileno de alta viscosidade e baixa funcionalidade [41].

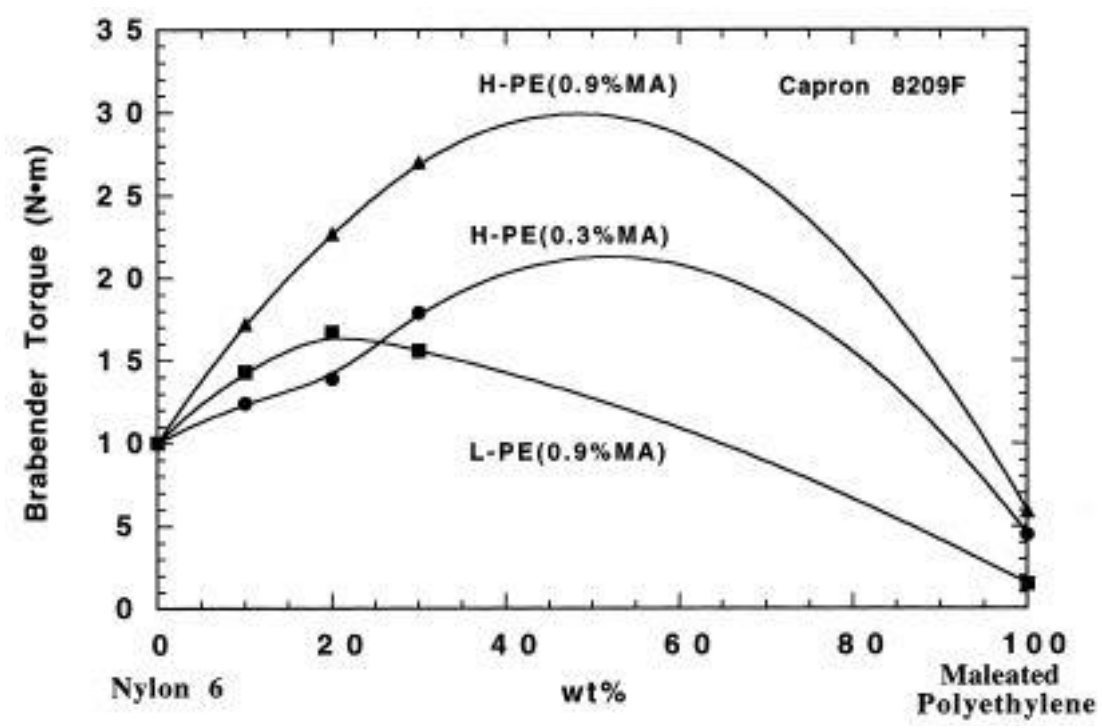

Figura 41. Torque Brabender de blendas de nylon 6 (Capron 8209F) com vários polietilenos maleados. A leitura dos torques foi tomada após 10 minutos a $24^{\circ} \mathrm{C}$ e 60 rev. $\min ^{-1}[41]$.

O nylon 6 puro descrito nesta seção é frágil até que sua temperatura aumente acima de $50^{\circ} \mathrm{C}$. Com a adição de $10 \%$ de L-PE(0,9\% MA), a blenda apresenta uma pequena melhora nas propriedades de impacto, porém a blenda ainda é frágil à temperatura ambiente, como pode ser visto na Figura 42. A adição de $20 \%$ desde polietileno maleado melhora significativamente a resistência ao impacto à temperatura ambiente. Entretanto, quando a fração de polietileno é aumentada para $30 \%$, as blendas ficam frágeis em todas as temperaturas [41]. 


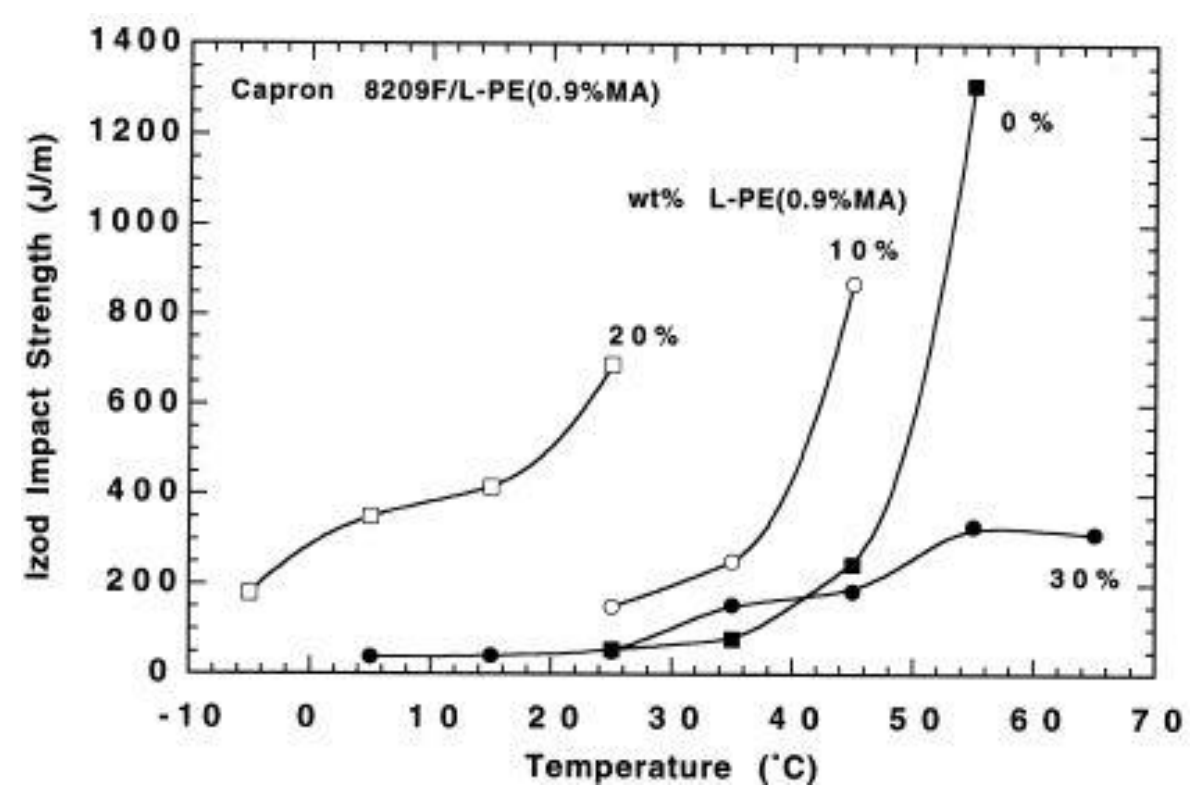

Figura 42. Efeitos da temperatura na resistência a impacto Izod em

blendas de Capron 8209F e L-PE(0,9\% MA). Este PELBD maleado tem uma baixa viscosidade e uma alta porção de anidrido [41].

As micrografias no MET ilustradas nas Figuras 42(a) e (b) demonstram que existem dois diferentes tipos de partículas de polietileno nas blendas contendo 10 e $20 \%$ L-PE(0,9\% MA), respectivamente. Uma comparação nas micrografias nas Figuras 36(a) e (b) e Figuras 43(a) e (b) claramente mostra que as partículas de polietileno se tornaram maiores ao passo que a viscosidade do nylon 6 é aumentada. As partículas da fase dispersa podem se tornar tanto maiores como menores com o aumento da viscosidade da matriz, dependendo do quão perto está a blenda do ponto de inversão de fase. A 10 ou $20 \%$ de polietileno, a diferença na viscosidade entre as duas fases faz com que o polietileno forme grandes domínios; quando o polietileno maleado é aumentado para $30 \%$, o polietileno se torna a fase contínua e as propriedades de impacto decrescem drasticamente [41]. 


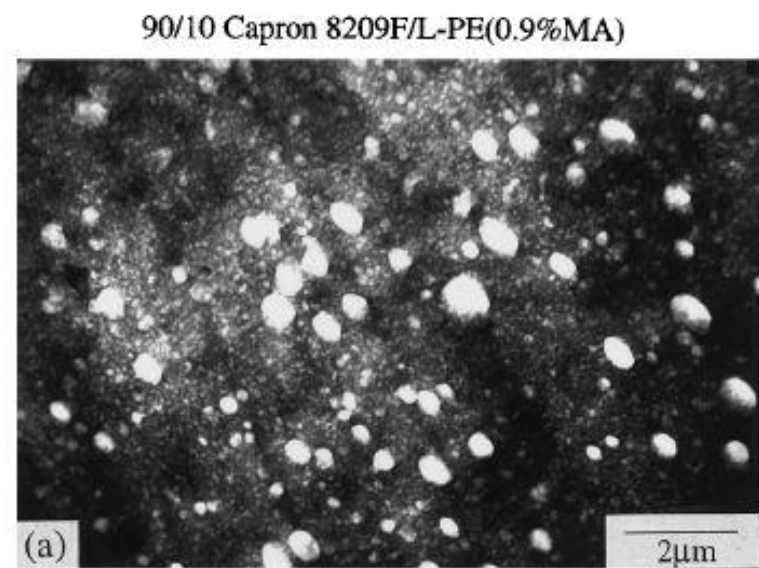

80/20 Capron $8209 \mathrm{~F} / \mathrm{L}-\mathrm{PE}(0.9 \% \mathrm{MA})$

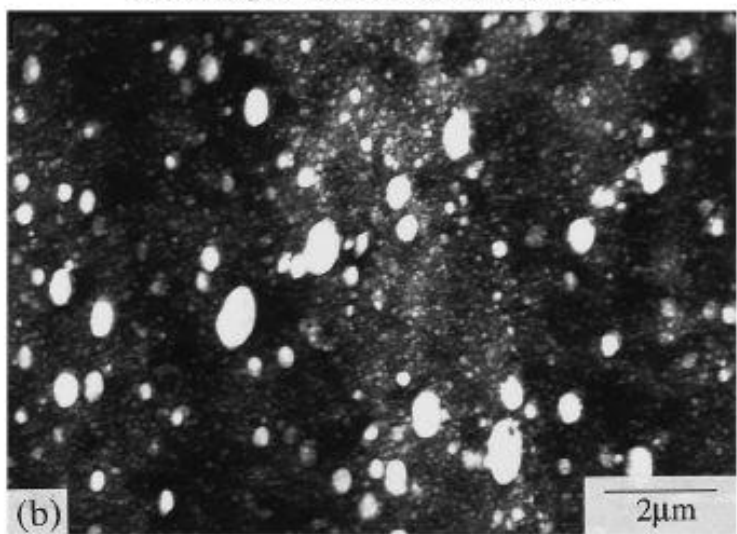

70/30 Capron 8209F/L-PE(0.9\%MA)

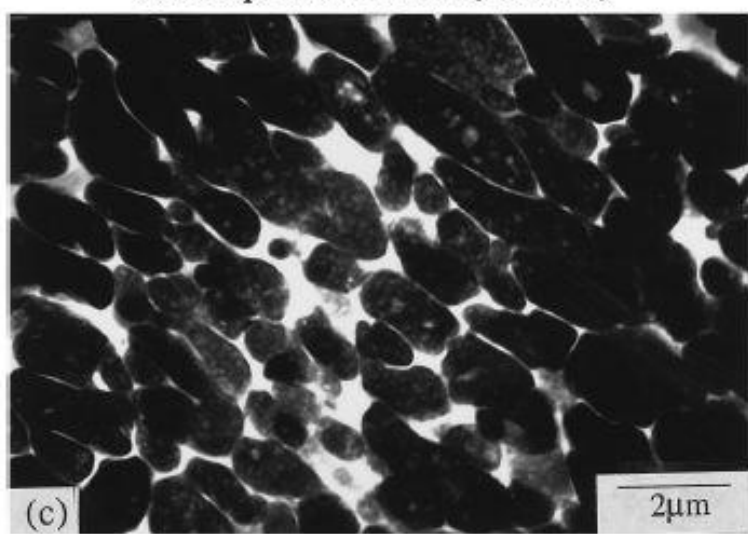

Figura 43. Micrografias no MET de blendas de Capron 8209F e LPE(0,9\% MA) contendo as seguintes frações do PELBD maleado: (a) 10\%; (b) 20\%; e (c) 30\%. A fase da poliamida está tingida de preto por PTA [41].

Em blendas de nylon 6 com H-PE(0,9\% MA), a incorporação do polietileno maleado leva a um aumento na resistência ao impacto e a melhora da resistência a baixas temperaturas, como pode ser visto na Figura 44. Quando é adicionado 10\% do polietileno maleado, a transição dúctil-frágil é movida para perto da temperatura ambiente; a adição de mais polietileno resulta em blendas que são resistentes à temperaturas abaixo de $0^{\circ} \mathrm{C}[41]$. 


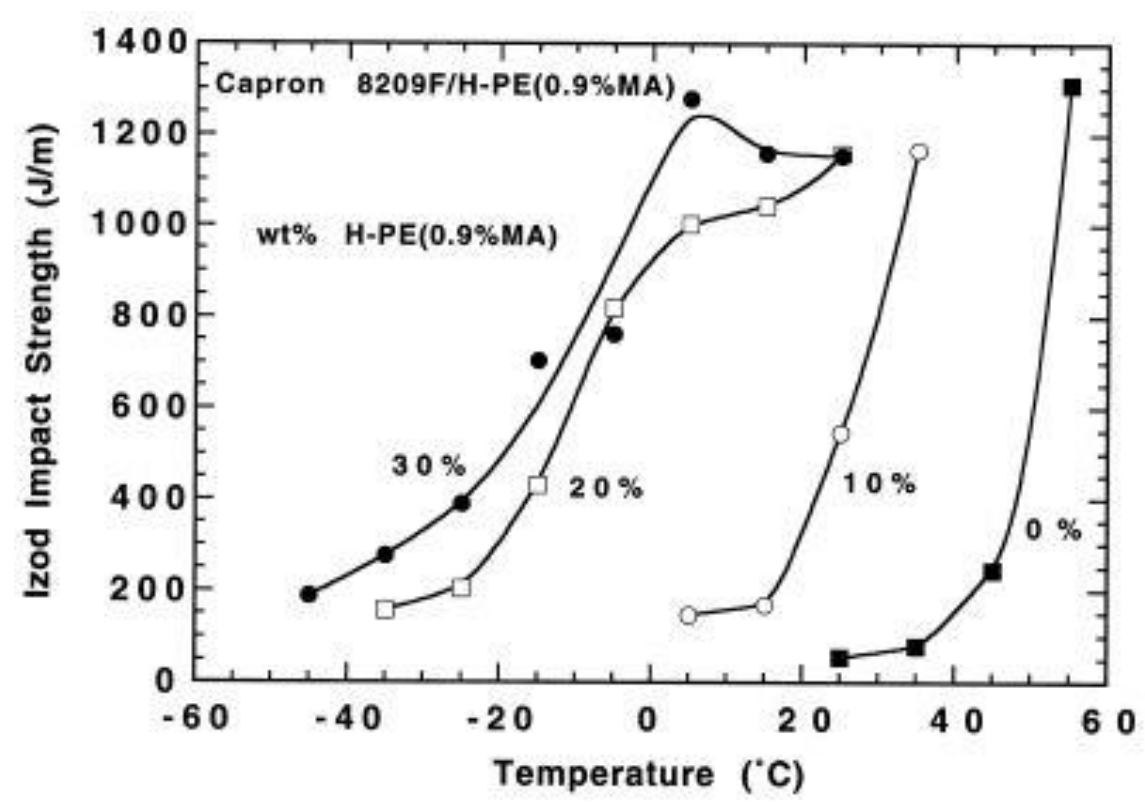

Figura 44. Efeito da temperatura na resistência a impacto Izod em

blendas de Capron 8209F e H-PE(0,9\% MA). Este PELBD maleado tem uma alta viscosidade e uma alta porção de anidrido [41].

As micrografias no MET da Figura 45 demonstram que o polietileno forma partículas pequenas e bem dispersas em cada uma destas blendas. Estas partículas de polietileno são menores que aquelas em blendas baseadas no polietileno de baixa viscosidade, L-PE(0,9\% MA). Esta melhor dispersão é, sem dúvida, uma consequência das viscosidades parecidas dos componentes da blenda, isto é, as partículas de $\mathrm{H}-\mathrm{PE}(0,9 \% \mathrm{MA})$ têm menos tendência em se tornarem contínuas e em formar grandes partículas como aquelas mostradas na Figura 45(a) e (b) [41]. 
90/10 Capron $8209 \mathrm{~F} / \mathrm{H}-\mathrm{PE}(0.9 \% \mathrm{MA})$

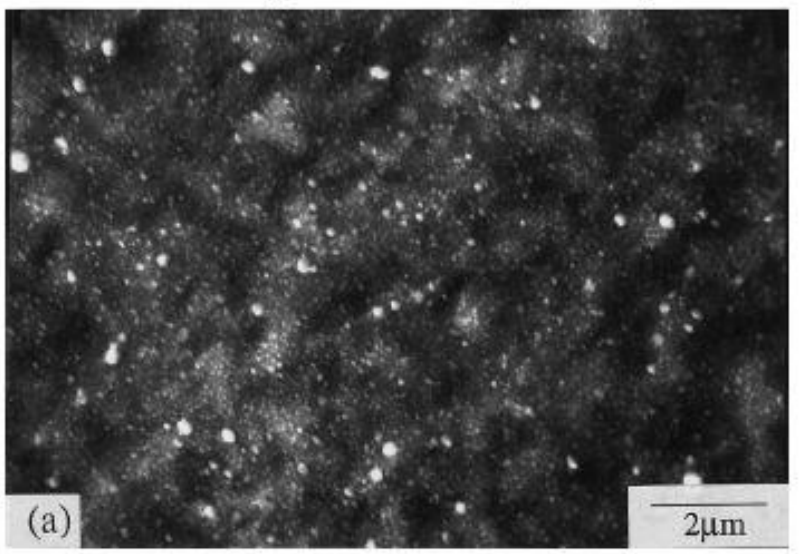

80/20 Capron $8209 \mathrm{~F} / \mathrm{H}-\mathrm{PE}(0.9 \% \mathrm{MA})$

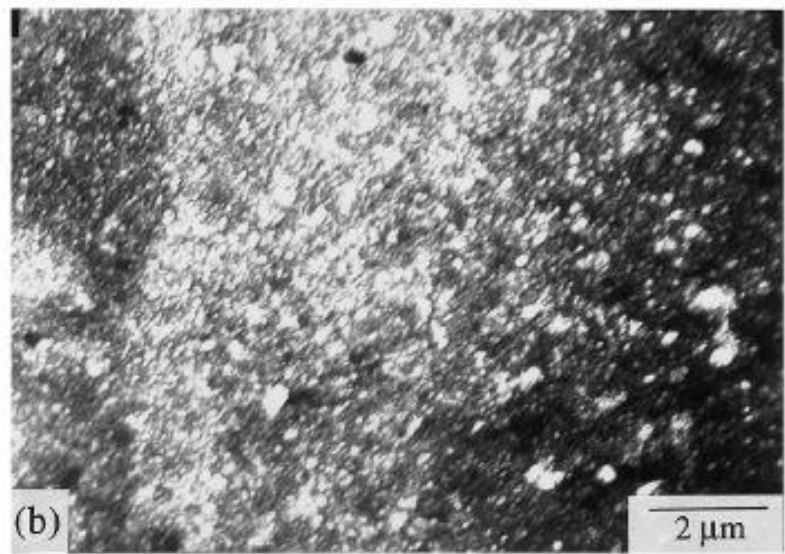

70/30 Capron $8209 \mathrm{~F} / \mathrm{H}-\mathrm{PE}(0.9 \% \mathrm{MA})$

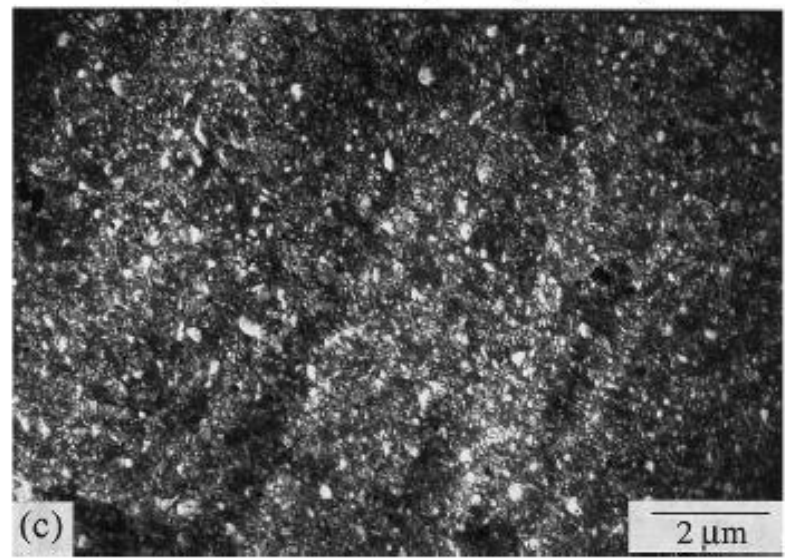

Figura 45. Micrografias no MET de blendas de Capron 8209F e LPE(0,9\% MA) contendo as seguintes frações do LLPE maleado: (a) 10\%; (b) 20\%; e (c) 30\%. A fase da poliamida está tingida de preto por PTA [41]. 


\section{Materiais e Métodos}

\subsection{Materiais}

Os materiais utilizados para a realização desse trabalho foram o polietileno de alta densidade (PEAD) e a poliamida 12 (PA12). Ambos foram recebidos sob a forma de pellets (Figura 46). O PEAD usado tem a especificação IA59U3, sendo fabricado pelo processo de solução, pela empresa BRASKEM. Algumas propriedades do PEAD empregado, fornecidas pelo fabricante, são apresentadas na Tabela 11 [43]. A PA12 foi comprada do fabricante Sigma Aldrich sob especificação CAS 24937-16-4. Algumas características dessa poliamida estão listadas na Tabela 12 [44].
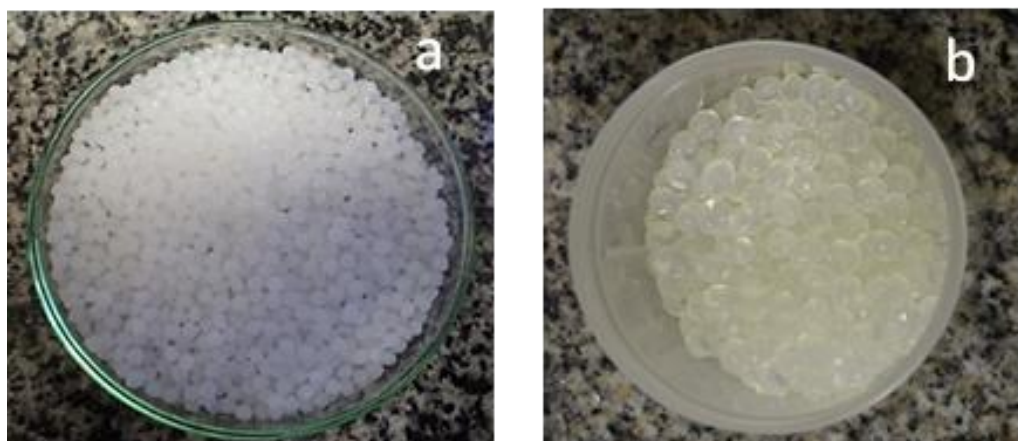

Figura 46. Pellets dos polímeros usados: a) PEAD; b) PA

Tabela 11. Propriedades do PEAD empregado neste trabalho [43].

\begin{tabular}{cccc}
\hline Propriedades & $\begin{array}{c}\text { Método } \\
\text { ASTM }\end{array}$ & Unidades & Valores \\
\hline Índice de fluidez & D 1238 & $\mathrm{~g} / 10 \mathrm{~min}$ & 7,3 \\
Densidade & $\mathrm{D} 792$ & $\mathrm{~g} / \mathrm{cm}^{3}$ & 0,960 \\
Resistência ao escoamento & $\mathrm{D} 638$ & $\mathrm{MPa}$ & 28 \\
\hline Resistência à ruptura & $\mathrm{D} 638$ & $\mathrm{MPa}$ & 25 \\
\hline $\begin{array}{c}\text { Dureza Shore D } \\
\text { Resistência ao impacto }\end{array}$ & $\mathrm{D} 2240$ & - & 58 \\
Temperatura de & $\mathrm{D} 256$ & $\mathrm{~J} / \mathrm{m}$ & 73 \\
amolecimento & $\mathrm{D} 1525$ & ${ }^{\circ} \mathrm{C}$ & 129 \\
\hline
\end{tabular}


Tabela 12. Propriedades da Poliamida 12 [44].

\begin{tabular}{ccc}
\hline Propriedades & Unidades & Valores \\
\hline Densidade & $\mathrm{g} / \mathrm{mL}$ & 1,01 \\
Temperatura de Transição & ${ }^{\circ} \mathrm{C}$ & 37 \\
Vítrea & & \\
Temperatura de Fusão & ${ }^{\circ} \mathrm{C}$ & 178 \\
\hline
\end{tabular}

O compatibilizante utilizado foi o copolímero em bloco de PEAD com anidrido maleico (PEAD-alt-MAH), que foi recebido em formato de pó. A Figura 47 mostra a estrutura química deste compatibilizante [45].

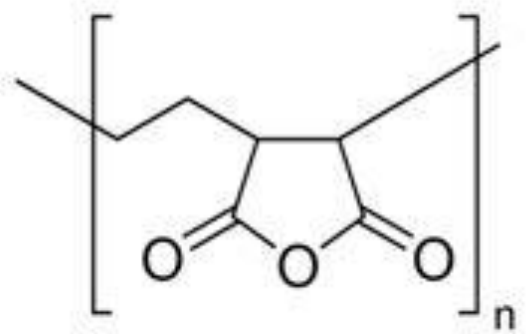

Figura 47. Estrutura química do agente compatibilizante utilizado neste trabalho [45].

A Tabela 13 mostra algumas propriedades importantes do PEAD-alt-MAH fornecidas pelo fabricante (Sigma Aldrich CAS 9006-26-2).

Tabela 13. Algumas propriedades do PEAD-alt-MAH $[45,46]$.

\begin{tabular}{cc}
\hline Propriedades & Valores \\
\hline Densidade & $0,92 \mathrm{~g} / \mathrm{mL}$ \\
Temperatura de Transição & $235{ }^{\circ} \mathrm{C}$ \\
Vítrea & $400{ }^{\circ} \mathrm{C}$ \\
Temperatura de Fusão & $0,75-1,05$ \\
Viscosidade & $\leq 0,2 \%$ \\
Viscosidade Específica & $\leq 1,5 \%$ \\
\hline (Anidrido Maleico) & \\
\hline
\end{tabular}




\subsubsection{Blendas}

Os materiais utilizados neste trabalho foram divididos em cinco conjuntos conforme mostrado na Tabela 14. Como a blenda PEAD/PA é imiscível [6], foi avaliado o uso de agentes de compatibilização para se obterem maiores valores das propriedades mecânicas.

Tabela 14. Grupos de materiais analisados.

\begin{tabular}{ccc}
\hline Material & Compatibilizante & Sem Compatibilizante \\
\hline PEAD 100\% & - & $\checkmark$ \\
PEAD/PA: 75/25 & $\checkmark$ & $\checkmark$ \\
PEAD/PA: 50/50 & $\checkmark$ & $\checkmark$ \\
PEAD/PA: 25/75 & $\checkmark$ & $\checkmark$ \\
PA 100\% & - & $\checkmark$ \\
\hline
\end{tabular}

Para a blenda de PEAD com PA12 a porcentagem ótima de compatibilizante a ser empregada para se obter propriedades mecânicas mais elevadas não é conhecida. Assim, baseado nos valores citados na literatura para blendas de PEAD e outros tipos de poliamida, foram feitos testes preliminares de tração com $0 \%$, $2 \%$ e $3 \%$ em massa de compatibilizante. A partir dos resultados obtidos foi, então, escolhida a porcentagem a ser usada. Nesses ensaios de teste, foram usados somente cinco corpos de prova de cada composição, exceto a blenda 75/25 sem compatibilizante, na qual foram usados dez corpos de prova. Depois de definida a proporção ótima de compatibilizante, com a finalidade de aumentar a confiabilidade dos resultados, foram usados dez corpos de prova das blendas com esta proporção ótima para tração. Foram fabricados, ainda, mais dez corpos de prova dos homopolímeros e das blendas com compatibilização ótima para uso em DRX e, também, para ficarem de reserva caso houvesse erro experimental em algum ensaio.

As blendas foram fabricadas em uma mini extrusora dupla rosca (DSM Xplore 5cc), na qual as temperaturas de entrada, de homogeneização e de saída foram respectivamente de 200,230 e $250^{\circ} \mathrm{C}$. A rotação usada para a mistura foi de $160 \mathrm{rpm}$. A homogeneização das blendas foi feita com um tempo de residência de aproximadamente três minutos na extrusora, sob fluxo constante de $\mathrm{N}_{2}$. Após a 
extrusão, os corpos de prova de tração foram injetados em uma mini injetora DSM Xplore $5,5 \mathrm{cc}$, com o bico injetor a uma temperatura de $250^{\circ} \mathrm{C}$ e o molde a $80^{\circ} \mathrm{C}$. A Figura 48 ilustra a extrusora e a injetora usadas na fabricação dos corpos de prova. Os corpos de prova fabricados foram do tipo V e seguem a norma ASTM D 638 e o molde usado se encontra na Figura 49. Os corpos de prova dos polímeros puros (PEAD e PA12) foram também fabricados usando o mesmo procedimento experimental acima, incluindo o tempo de residência.

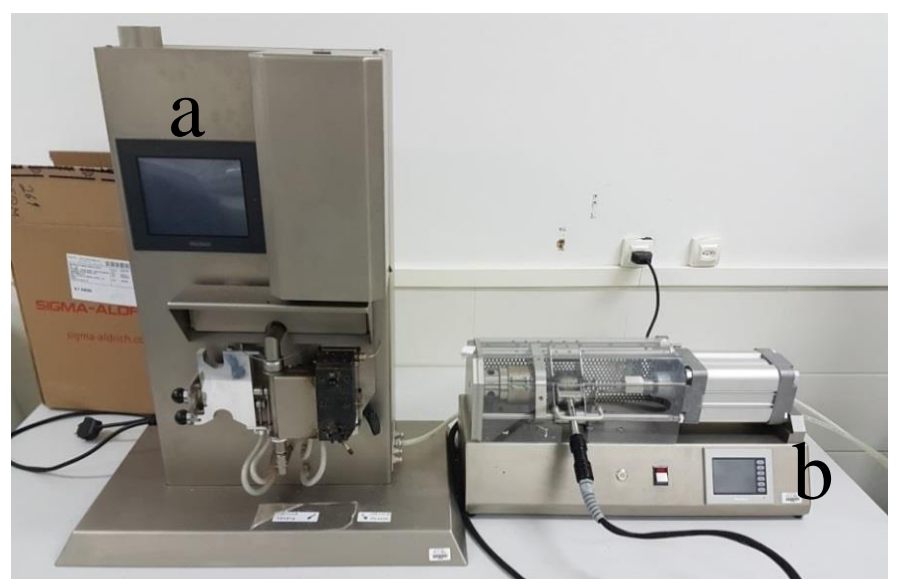

Figura 48. Extrusora (a) e injetora (b) utilizadas na fabricação dos corpos de prova deste trabalho.

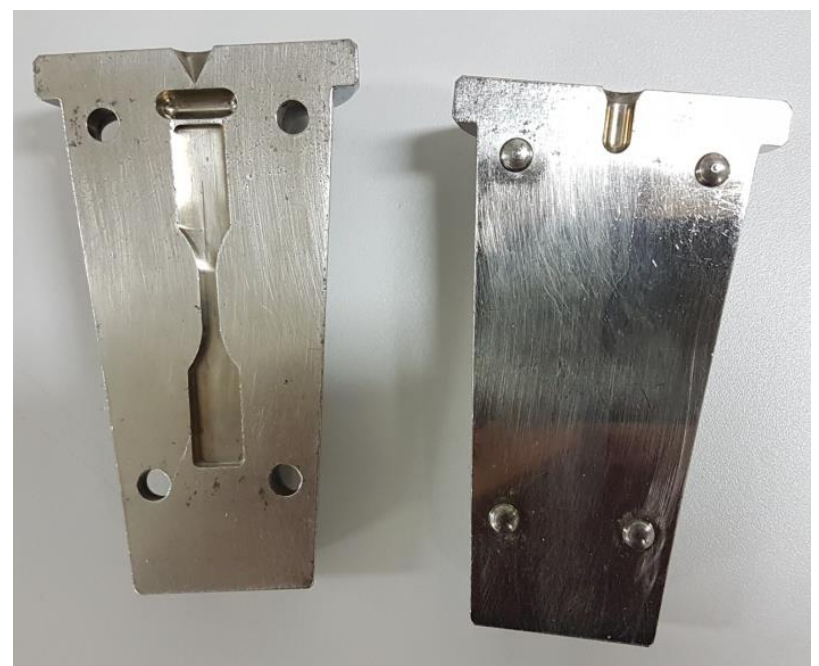

Figura 49. Molde usado na injeção. 


\subsection{Métodos}

\subsubsection{Tração}

Dentro de cada grupo de materiais fabricados, conforme descrito acima, foram selecionados dez corpos de prova para a realização dos ensaios de tração. Estes foram feitos em uma máquina de ensaio universal Oswaldo Filizola ASME$2 \mathrm{kN}$, conforme ilustrado na Figura 50.

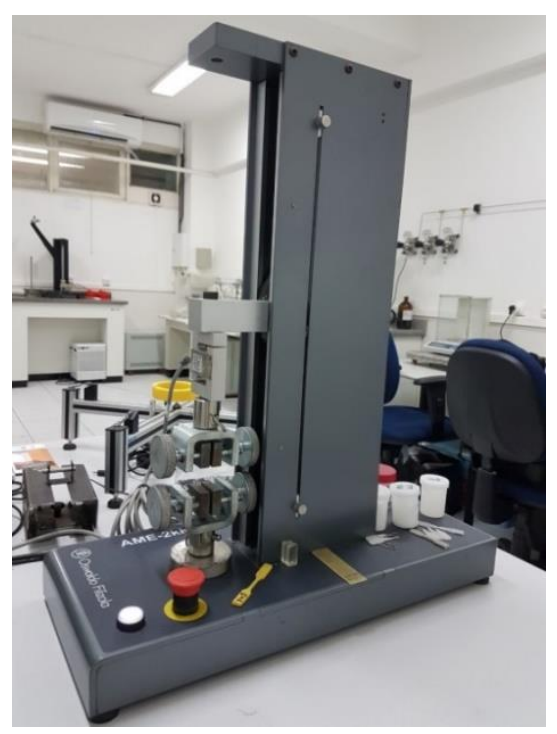

Figura 50. Máquina de ensaios de tração.

O software de captação dos dados da máquina (força aplicada por tempo) foi o Dynaview e o de obtenção das propriedades dos materiais foi o Excel. Os ensaios de tração foram feitos a uma velocidade de $50 \mathrm{~mm} / \mathrm{min}$ e com uma distância inicial entre as garras $\left(\mathrm{L}_{0}\right)$ de $25 \mathrm{~mm}$. Todos os ensaios de tração foram feitos a temperatura ambiente. A Figura 51 mostra, como exemplo, os corpos de prova de PA12, como obtidos da injetora e usados no ensaio de tração.

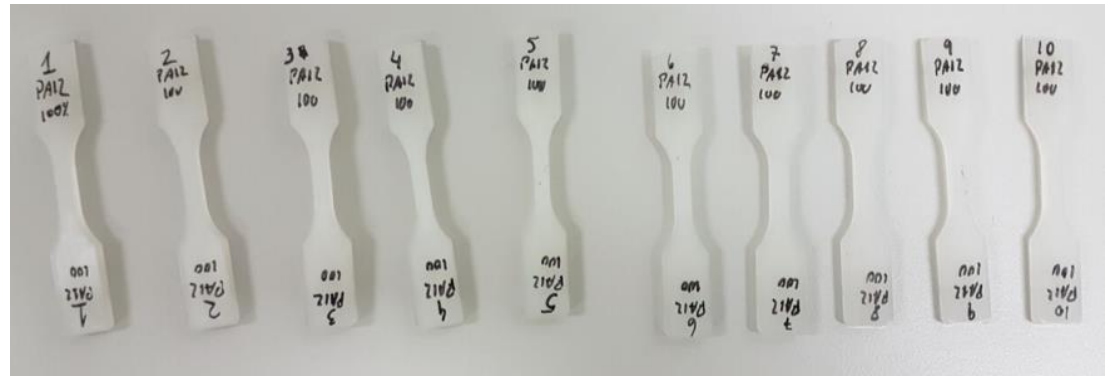

Figura 51. Corpos de prova de PA12 100\% usados nos ensaios de tração. 


\subsubsection{Fluência}

Foram utilizados cinco corpos de prova de cada material para os ensaios de fluência, que foram realizados na mesma máquina mostrada na Figura 50. Todos os ensaios foram feitos à temperatura ambiente com duração de 24 horas a temperatura ambiente e foi aplicada uma carga de tração constante equivalente a $50 \%$ do limite de escoamento de cada material.

Os resultados obtidos para todos os corpos de prova foram modelados seguindo três modelos viscoelásticos: Modelo de Três Parâmetros, Modelo de Quatro Parâmetros e o Stretched Burguers. A modelagem por regressão não-linear foi feita usando o recurso Solver do Excel.

A Figura 52 mostra, como exemplo, um dos cinco corpos de prova de PA12 utilizados no ensaio de fluência.

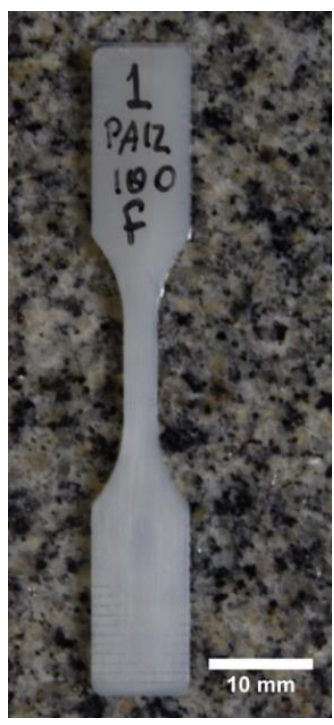

Figura 52. Corpo de prova de PA12 100\% usado nos ensaios de fluência.

\subsubsection{Análise por Infravermelho (FTIR)}

Com o objetivo de avaliar os grupos funcionais presentes nas blendas, foram comparados os espectros de infravermelho dos materiais puros (PEAD, PA12 e compatibilizante) e as blendas com $2 \%$ e $3 \%$ de compatibilizante, todos fabricados com três minutos de residência, como já explicado anteriormente. Além disso, também foi feita a análise de espectroscopia infravermelho da blenda 75/25 sem compatibilizante com tempo de residência de cinco minutos, para avaliar se nesta variação de tempo está havendo degradação do polímero. 
Os espectros de absorção na região do infravermelho médio (4000 a $400 \mathrm{~cm}^{-}$ 1) foram obtidos em um espectrofotômetro Perkin-Elmer Spectrum 400 FT-IR 2000 (Figura 53), no Laboratório de Biocombustíveis (LABIO) - Departamento de Química - PUC-Rio.

Os espectros foram obtidos com as amostras em estado sólido, com acessório ATR, resolução de $4 \mathrm{~cm}^{-1}$ e 4 scans.

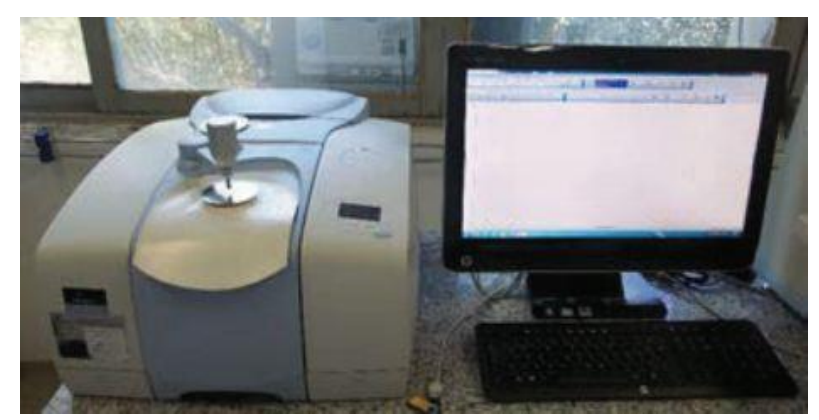

Figura 53. FTIR Spectrum 400.

\subsubsection{DRX}

Os ensaios de difração de raios-X foram realizados em um difratômetro D8 Discover da marca Bruker com tubo de cobre operando a $40 \mathrm{~mA}$ e $40 \mathrm{kV}$ e com detector Lynxeye. A faixa de varredura (20) utilizada foi de 10 a $60^{\circ}$ com passo de $0,02^{\circ}$ e tempo de 1 segundo por passo.

$\mathrm{O}$ ajuste das curvas correspondentes às áreas cristalina e amorfa, junto com a obtenção dos parâmetros cristalinos, como estrutura cristalina, parâmetros de rede, distância interplanar e tamanho médio dos cristalitos foram realizados no software TOPAS, segundo o método de Rietveld, empregando um ajuste por Pawley. O método de Rietveld realiza um ajuste do padrão de difração, refinando simultaneamente os parâmetros do equipamento, estruturais e os relacionados com as características físicas da estrutura cristalina [47].

No software TOPAS é inserido o tipo de estrutura cristalina do material e seus parâmetros de rede obtidos na literatura com um intervalo no qual o valor flutua no ajuste. Esse software fornece, também, após o ajuste, os índices de Miller da reflexão (hkl). 


\subsubsection{Reometria}

Os testes reométricos foram feitos em um reômetro de placas paralelas Anton Paar Phyica MCR 501 (Figura 54) a uma temperatura de $200^{\circ} \mathrm{C}$ e taxas de cisalhamento entre 10 e $100 \mathrm{~s}^{-1}$, gerando gráficos da viscosidade e de tensões de cisalhamento em função de taxas de cisalhamento dos polímeros a fim de avaliar a influência dos homopolímeros na reologia das blendas.

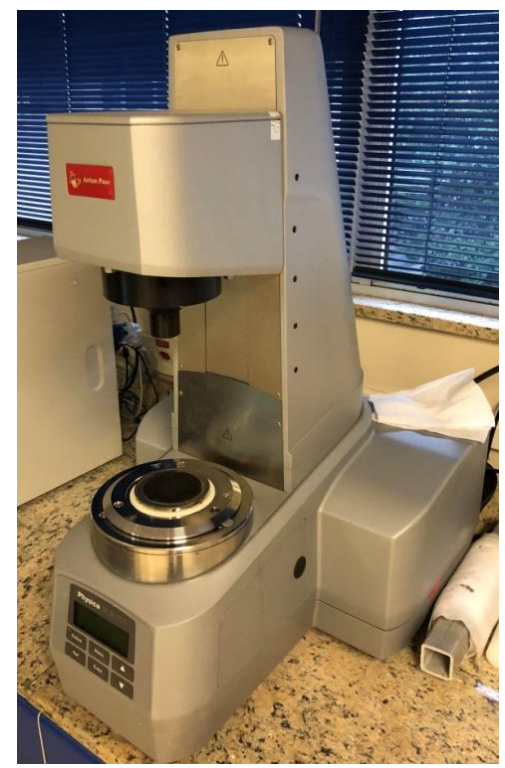

Figura 54. Reômetro de placas paralelas.

\subsubsection{Análise MEV}

A caracterização através de MEV foi realizada no laboratório de Microscopia Eletrônica (LME) da PUC-Rio. Por essa técnica foi feita uma análise qualitativa e quantitativa da morfologia das blendas poliméricas. A primeira serve para avaliar a qualidade da interface entre as fases da poliamida e do polietileno para ver se há boa adesão e distribuição de cargas. A segunda serve para avaliar a variação no diâmetro das partículas dispersas com o incremento do compatibilizante. Para isso, foram analisadas no MEV amostras das blendas com 0, 2 e $3 \%$ de PEAD-alt-MAH.

As amostras foram fraturadas no nitrogênio líquido e o microscópio utilizado foi o MEV da marca JEOL JSM-6510 LV com voltagem de aceleração de $20 \mathrm{kV}$. Os detectores utilizados foram: BSE (elétrons retro espalhados) e SE (elétrons secundários). O primeiro possibilita a visualização do diâmetro da fase 
dispersa e dos vazios e o segundo a topografia da estrutura mostrando a adesão das fases. Os aumentos utilizados foram de 25x, 2000x e 5000x.

Para fixar as fibras no porta-amostras utilizou-se fita adesiva condutora dupla face. Foi feita a metalização das amostras com deposição de ouro pelo método de deposição catódica. Para isso utilizou-se o metalizador da marca Balzers modelo SCD 050- Sputter Coater. 


\section{Resultados e Discussões}

Depois de realizados os ensaios de tração, fluência, FTIR, difração de raios$\mathrm{X}$, reometria e a análise por $\mathrm{MEV}$, foram obtidas diversas propriedades $\mathrm{e}$ características da blenda PEAD/PA12 nas suas diversas composições.

\subsection{Tração}

\subsubsection{Efeito do teor de compatibilizante}

Inicialmente foi feita uma comparação entre as principais propriedades mecânicas das blendas com $0 \%, 2 \%$ e 3\% do compatibilizante PEAD-alt-MAH, que serviu para definição de uma porcentagem "ótima" de compatibilizante. Tal comparação está mostrada na Tabela 15 através dos valores médios e desvios padrões.

Tabela 15. Ensaio teste para comparação das propriedades das blendas sem e com compatibilizante.

\begin{tabular}{cccccc}
\hline $\begin{array}{c}\text { PEAD } \\
(\%)\end{array}$ & PA12 (\%) & $\begin{array}{c}\text { PEAD-alt- } \\
\text { MAH }(\%)\end{array}$ & $\begin{array}{c}\text { Tensão de } \\
\text { Ruptura } \\
(\mathbf{M P a})\end{array}$ & $\begin{array}{c}\text { Módulo de } \\
\text { Elasticidade } \\
(\mathbf{M P a})\end{array}$ & $\begin{array}{c}\text { Limite de } \\
\text { Escoamento } \\
(\mathbf{M P a})\end{array}$ \\
\hline 75,0 & 25,0 & 0 & $28,8 \pm 0,7$ & $353 \pm 29$ & - \\
73,5 & 24,5 & 2 & $27,7 \pm 3,7$ & $448 \pm 27$ & $30,2 \pm 0,8$ \\
72,75 & 24,25 & 3 & $16,9 \pm 4,9$ & $403 \pm 22$ & $25,8 \pm 3,8$ \\
\hline 50,0 & 50,0 & 0 & $20,0 \pm 2,7$ & $387 \pm 35$ & $30,9 \pm 0,9$ \\
49,0 & 49,0 & 2 & $21,6 \pm 0,8$ & $414 \pm 47$ & $35,0 \pm 1,1$ \\
48,5 & 48,5 & 3 & $19,0 \pm 2,8$ & $399 \pm 24$ & $33,9 \pm 0,5$ \\
\hline 25,0 & 75,0 & 0 & $31,4 \pm 3,7$ & $435 \pm 40$ & $34,3 \pm 1,1$ \\
24,5 & 73,5 & 2 & $35,7 \pm 1,8$ & $435 \pm 22$ & $35,5 \pm 1,8$ \\
24,25 & 72,75 & 3 & $32,9 \pm 5,4$ & $392 \pm 26$ & $35,5 \pm 2,9$ \\
\hline
\end{tabular}

Como pode ser observado, em geral, houve aumento nas propriedades mecânicas com a adição de $2 \%$ do compatibilizante e houve queda quando o teor de compatibilizante aumentou para $3 \%$ para todas as composições. Com isso, 
definiu-se que a porcentagem a ser usada seria de $2 \%$, ou seja, desta seção em diante todas as blendas analisadas serão com $2 \%$ de compatibilizante. Lembrando que para este teste foram utilizados cinco corpos de prova de cada composição, exceto a blenda 75/25 0\%, na qual foram usados dez corpos de prova.

Hamid e col. [40] publicaram um artigo sobre blenda PEAD/PA6 com PEAD-g-MAH (polietileno grafitizado com anidrido maleico), no qual ele testou algumas combinações de blendas com compatibilizante variando entre 0, 2, 4, 6 e $8 \%$ e os resultados obtidos também indicam que a proporção de $98 \%$ de blenda e 2\% de compatibilizante fornece melhores propriedades mecânicas à blenda.

\subsubsection{Homopolímeros}

\subsubsection{PEAD}

$\mathrm{O}$ comportamento tensão $\mathrm{x}$ deformação de engenharia e, também, o comportamento tensão verdadeira $\mathrm{x}$ deformação verdadeira do PEAD foi determinado, como pode ser visto nas Figuras 55 e 56, respectivamente.

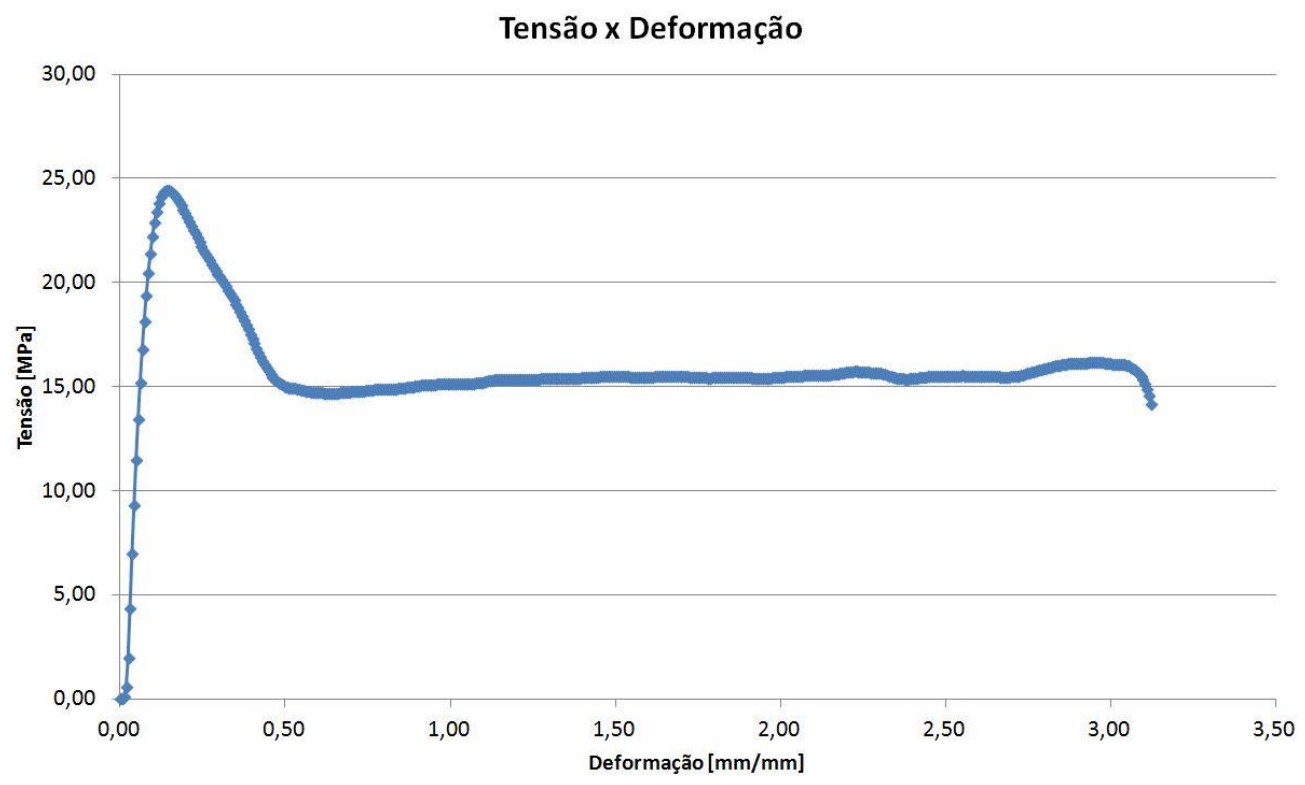

Figura 55. Gráfico tensão x deformação de engenharia do Corpo de Prova número 1 de PEAD. 


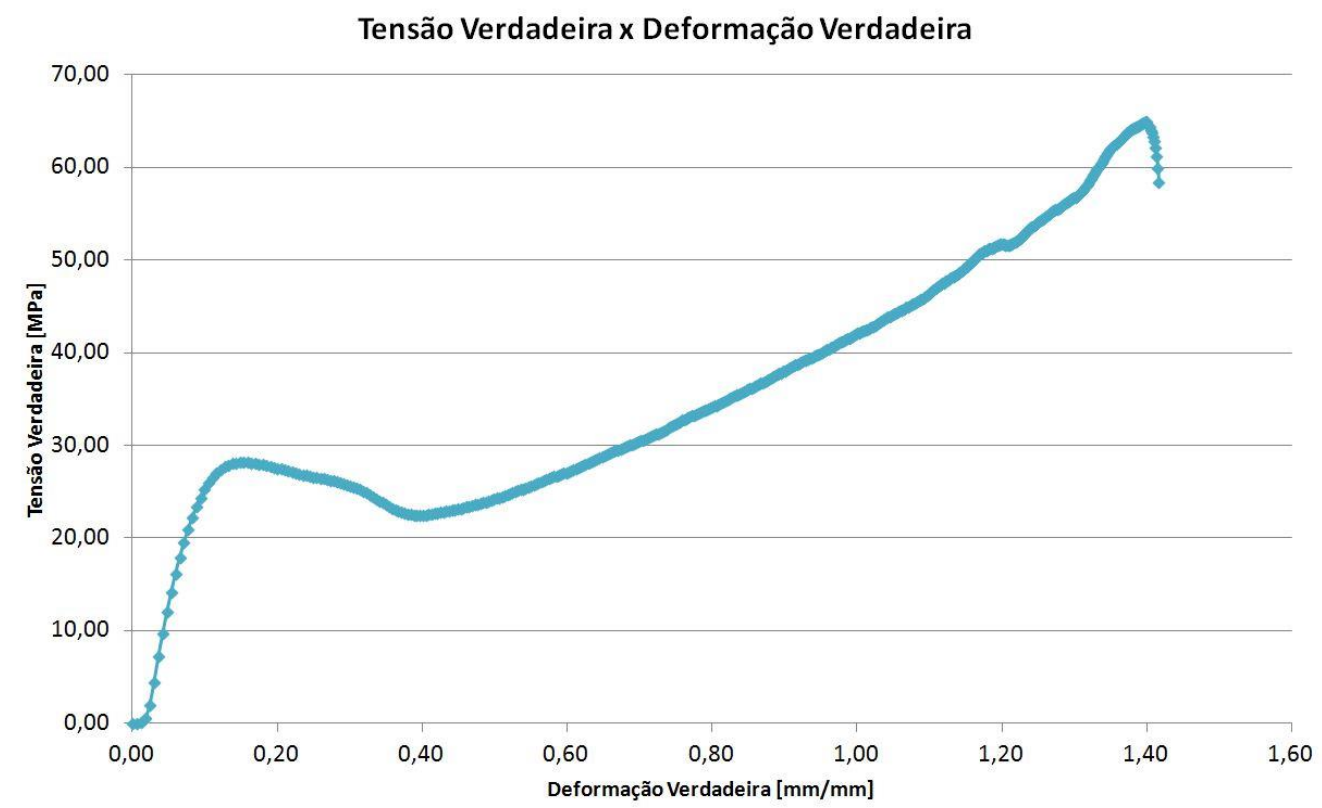

Figura 56. Gráfico tensão x deformação verdadeira do Corpo de Prova número 1 de PEAD.

A partir dos resultados obtidos no gráfico tensão $\mathrm{x}$ deformação de engenharia, foram obtidos a média e o desvio padrão das propriedades dos corpos de prova de PEAD (Tabela 16), onde $\sigma_{\mathrm{y}}$ e $\sigma_{\mathrm{R}}$ são limite de escoamento e tensão de ruptura, respectivamente, $\varepsilon_{y}$ e $\varepsilon_{R}$ são deformação no escoamento e ruptura. A tenacidade e resiliência são as energias absorvidas pelo material até a ruptura e até o escoamento, respectivamente. Na Tabela 16 também foi realizado o mesmo procedimento com $\mathrm{o}$ gráfico tensão $\mathrm{x}$ deformação verdadeira. Além das propriedades citadas acima, também foram obtidos os coeficientes $\mathrm{n}_{0}$ e $\mathrm{n}_{1}$, que são os coeficientes de encruamento na fase amorfa e cristalina, respectivamente. 
Tabela 16. Propriedades mecânicas de tração do PEAD puro.

\begin{tabular}{ccc}
\hline & $\begin{array}{c}\text { Tensão x deformação de } \\
\text { engenharia }\end{array}$ & $\begin{array}{c}\text { Tensão x deformação } \\
\text { verdadeira }\end{array}$ \\
\hline $\boldsymbol{\sigma}_{\mathbf{y}}(\mathbf{M P a})$ & $24,1 \pm 0,2$ & $27,8 \pm 0,3$ \\
$\boldsymbol{\sigma}_{\mathbf{R}}(\mathbf{M P a})$ & $18,0 \pm 1,1$ & $71,2 \pm 17,1$ \\
$\mathbf{E}(\mathbf{M P a})$ & $408 \pm 44$ & $389 \pm 28$ \\
$\boldsymbol{\varepsilon}_{\mathbf{y}}(\boldsymbol{\%})$ & $14,0 \pm 0,5$ & $15 \pm 0$ \\
$\boldsymbol{\varepsilon}_{\mathbf{R}}(\boldsymbol{\%})$ & $352,0 \pm 0,7$ & $141 \pm 20$ \\
\hline Tenacidade $\left(\mathbf{M J} / \mathbf{m}^{\mathbf{3}}\right)$ & $55,3 \pm 12,3$ & $47,2 \pm 6,1$ \\
\hline Resiliência $\left(\mathbf{M J} / \mathbf{m}^{\mathbf{3}}\right)$ & $2,1 \pm 0,1$ & $2,5 \pm 0,1$ \\
$\mathbf{n}_{\mathbf{0}}$ & - & $0,8 \pm 0,1$ \\
$\mathbf{n}_{\mathbf{1}}$ & - & $1,6 \pm 0,5$ \\
\hline
\end{tabular}

\subsubsection{PA12}

As Figuras 57 e 58 mostram os gráficos de tensão-deformação de engenharia e verdadeira, respectivamente, para a PA12.

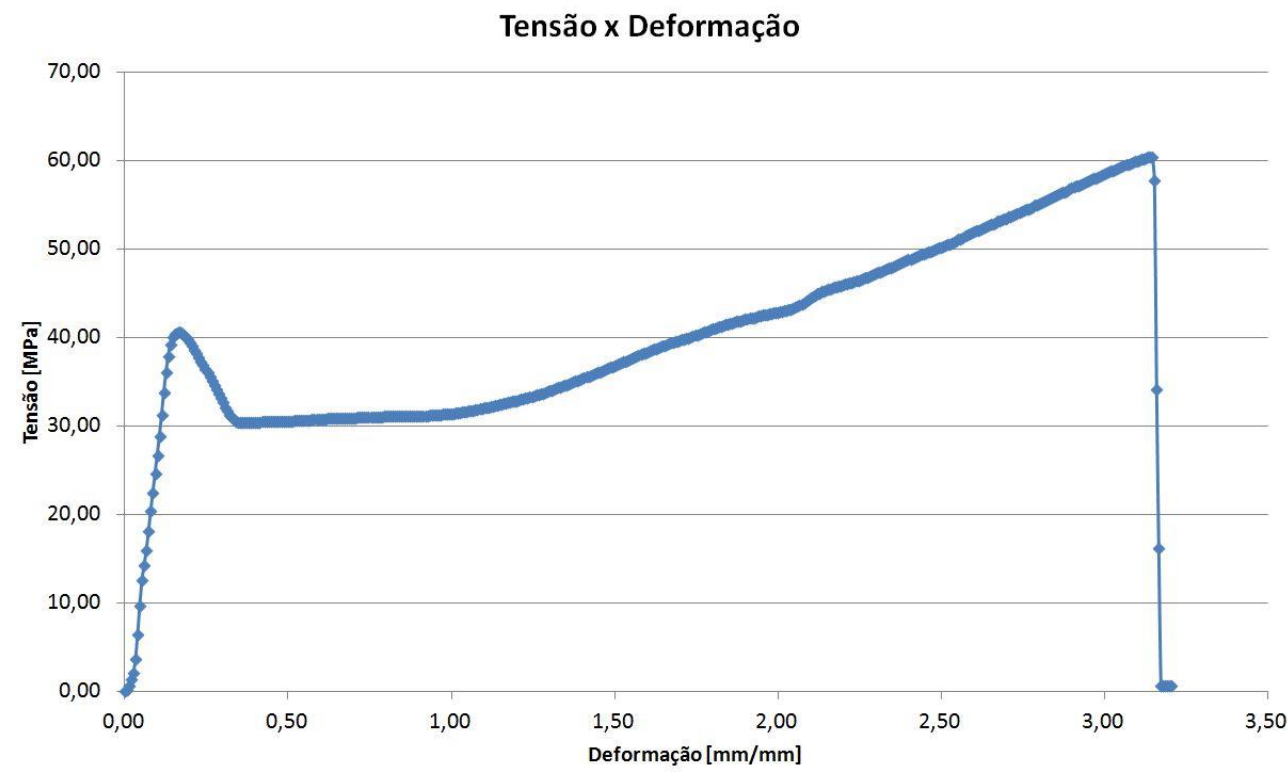

Figura 57. Gráfico Tensão x Deformação de engenharia do Corpo de Prova número 1 de PA12. 


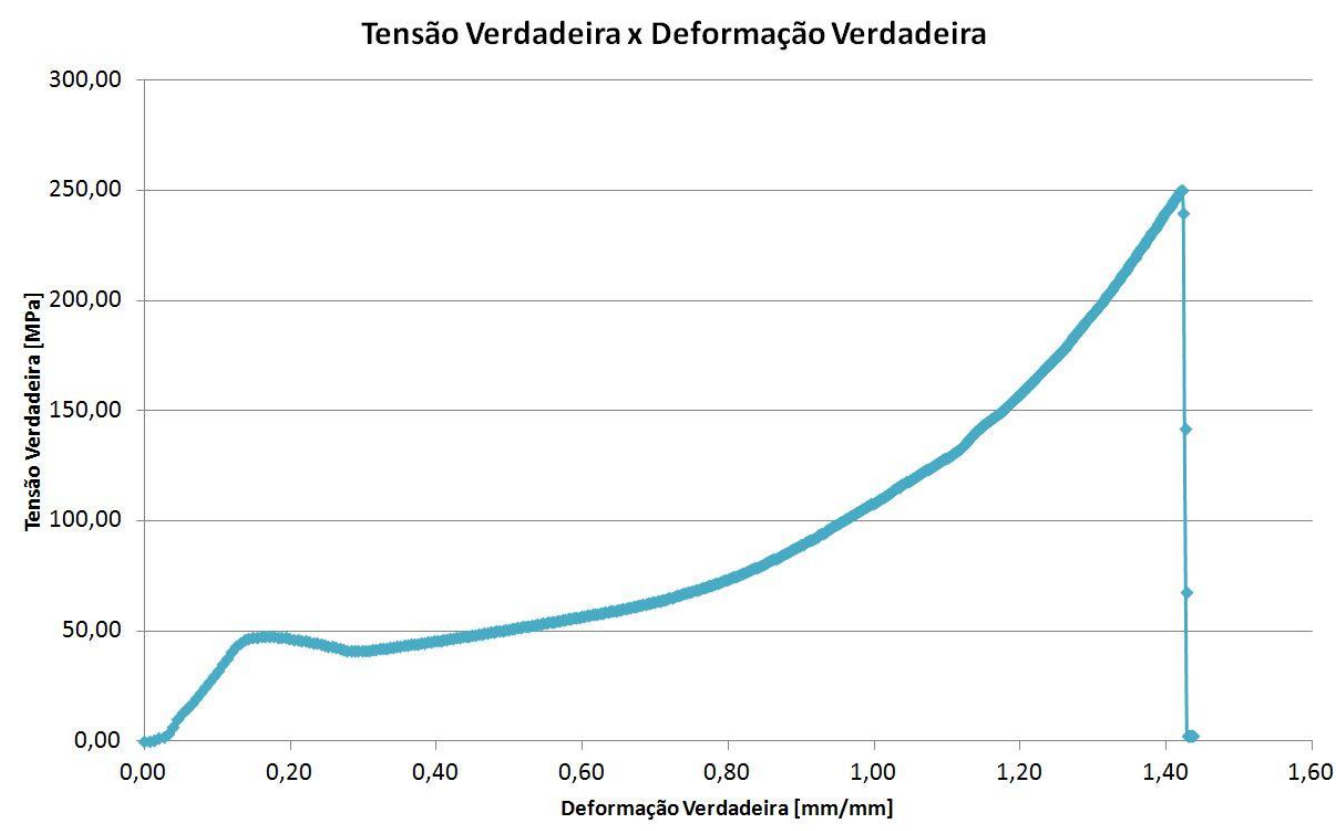

Figura 58. Gráfico Tensão x Deformação verdadeira do Corpo de

Prova número 1 de PA12.

A partir dos gráficos, foram obtidas a média e o desvio padrão das propriedades dos dez corpos de prova de PA12 puro (Tabela 17). Nesta tabela também consta os dados obtidos através do gráfico tensão $\mathrm{x}$ deformação verdadeira.

Tabela 17. Propriedades mecânicas de tração da PA12.

\begin{tabular}{ccc}
\hline & $\begin{array}{c}\text { Tensão x deformação } \\
\text { de engenharia }\end{array}$ & $\begin{array}{c}\text { Tensão x deformação } \\
\text { verdadeira }\end{array}$ \\
\hline $\boldsymbol{\sigma}_{\mathbf{y}}(\mathbf{M P a})$ & $42,0 \pm 1,8$ & $48,7 \pm 1,9$ \\
$\boldsymbol{\sigma}_{\mathbf{R}}(\mathbf{M P a})$ & $60,7 \pm 7,1$ & $245,6 \pm 52,0$ \\
$\mathbf{E}(\mathbf{M P a})$ & $412 \pm 32$ & $484 \pm 32$ \\
$\boldsymbol{\varepsilon}_{\mathbf{y}}(\boldsymbol{\%})$ & $15,0 \pm 1,0$ & $15 \pm 1,2$ \\
$\boldsymbol{\varepsilon}_{\mathbf{R}}(\boldsymbol{\%})$ & $305,0 \pm 43,7$ & $139 \pm 10,9$ \\
\hline Tenacidade $\left(\mathbf{M J} / \mathbf{m}^{\mathbf{3}}\right)$ & $126,7 \pm 25,3$ & $126,9 \pm 25,3$ \\
\hline Resiliência $\left(\mathbf{M J} / \mathbf{m}^{\mathbf{3}}\right)$ & $3,4 \pm 0,2$ & $4,0 \pm 0,3$ \\
$\mathbf{n}_{\mathbf{0}}$ & - & $1,1 \pm 0,1$ \\
$\mathbf{n}_{\mathbf{1}}$ & - & $2,8 \pm 1,1$ \\
\hline
\end{tabular}

A partir dos dados experimentais de tração dos homopolímeros, pode-se fazer uma comparação com os dados da literatura. No caso do PEAD, no artigo de Coutinho e col. [32] a tensão de ruptura compreende uma faixa entre 25 - $45 \mathrm{MPa}$, 
enquanto que nos experimentos realizados neste trabalho, a tensão encontrada foi $18 \mathrm{MPa}$, ou seja, fora da faixa apresentada pela literatura. Porém, os resultados são próximos ao limite inferior reportado na literatura [32] e, também, não apresentaram grande dispersão. As deformações no escoamento e na ruptura estão nas faixas $5-8 \%$ e $50-900 \%$, respectivamente [32]. Já nos ensaios experimentais realizados neste trabalho, a deformação na ruptura está dentro da faixa $(352 \%)$, porém a de escoamento está fora (15\%). O módulo de elasticidade experimental esteve bem abaixo da faixa da literatura (408,4 MPa para uma faixa de 900 - $1200 \mathrm{MPa}$ na literatura). Isso pode ser explicado pela compliância da máquina de ensaio. Ou seja, ao realizar o ensaio, a máquina também se deforma elasticamente [48].

No caso da PA12, a única propriedade mecânica de tração presente na literatura [37] é a tensão de ruptura. O resultado experimental obtido nesse trabalho $(60,7 \mathrm{MPa} \pm 7,1$, Tabela 18$)$ é superior ao da literatura, que faz referência a $52 \mathrm{MPa}$.

Pelos dados apresentados, nota-se que o PA12 apresenta uma menor ductilidade em relação ao PEAD, porém tem maior tenacidade e maior resistência à ruptura, além de maior limite de escoamento e maior resiliência.

\subsubsection{Blendas}

Como discutido no item 5.1.1, as blendas com $2 \%$ do compatibilizante PEAD-alt-MAH obtiveram as melhores propriedades em relação aos mesmos materiais com $0 \%$ e $3 \%$. Logo, todos os ensaios discutidos a seguir foram realizados somente com as blendas com 2\% de PEAD-alt-MAH.

\subsubsection{PEAD/PA12 75/25}

Esta blenda apresentou grande dispersão nos resultados. A maioria dos corpos de prova não apresentou encruamento após o escoamento, rompendo pouco após o mesmo, Figura 59. Algumas amostras apresentaram fratura frágil (Figura 60), enquanto outras apresentaram maior deformação plástica em relação às demais (Figura 61). Uma característica notada foi a aparência fibrosa da fratura (Figura 62). 
As Figuras 59, 60 e 61 mostram os gráficos tensão x deformação do corpo de prova número 1, que rompeu pouco após o escoamento, o corpo de prova número 2 que teve comportamento frágil, e o corpo de prova número 10 que apresentou uma zona de deformação plástica significativa, respectivamente.

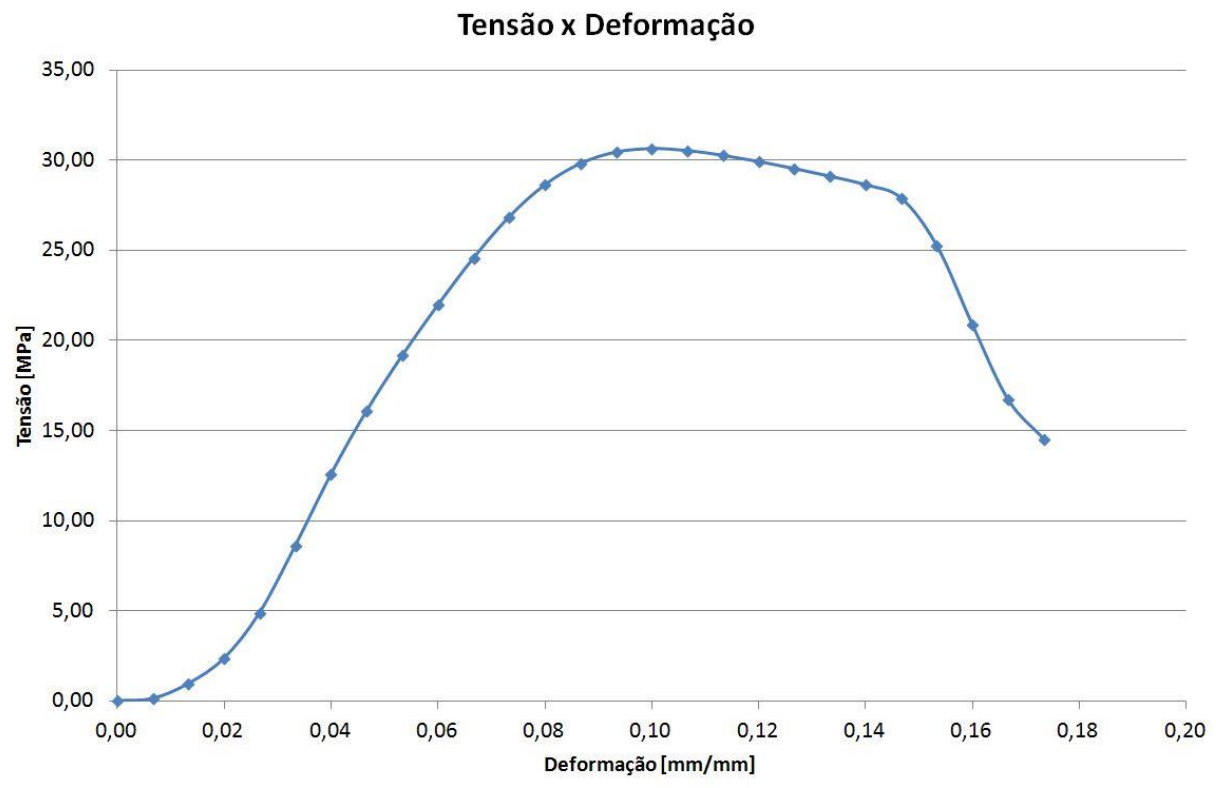

Figura 59. Gráfico tensão $x$ deformação do corpo de prova número 1 da blenda 75/25. Observa-se que não há a formação do platô após o escoamento.

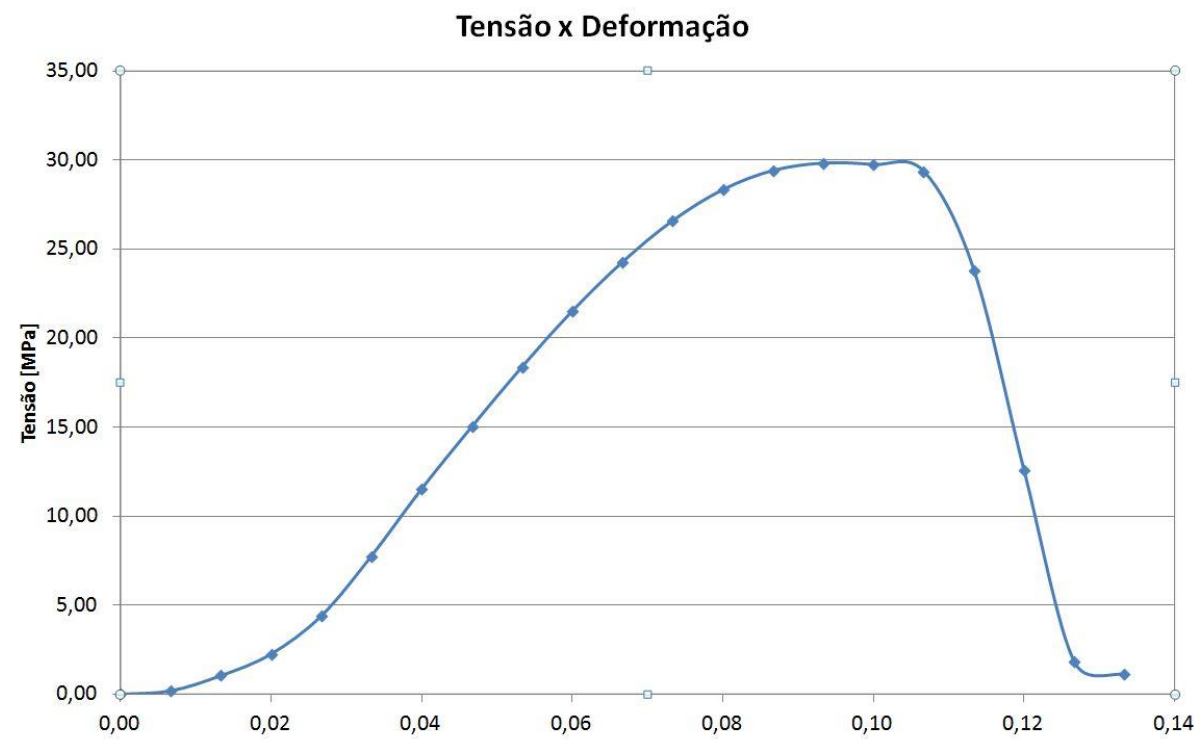

Figura 60. Gráfico tensão x deformação do corpo de prova número 2 da blenda 75/25 (fratura frágil). 


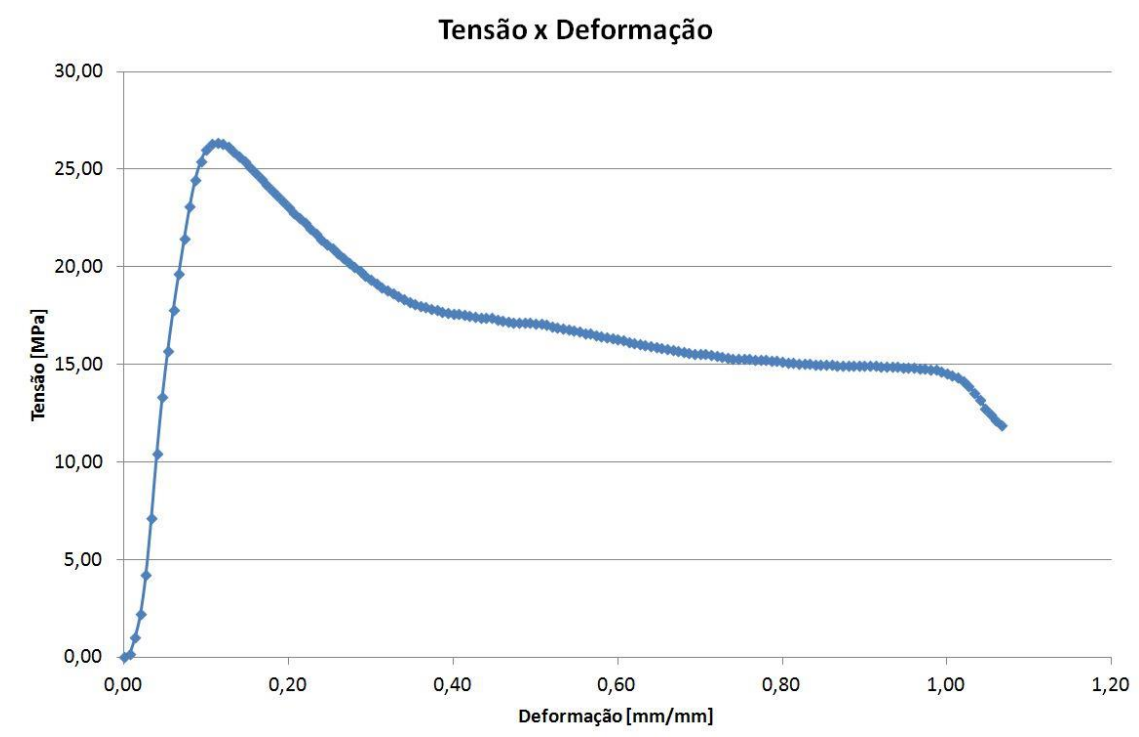

Figura 61. Gráfico tensão x deformação do corpo de prova número 10 da blenda 75/25. Ruptura com maior ductilidade.

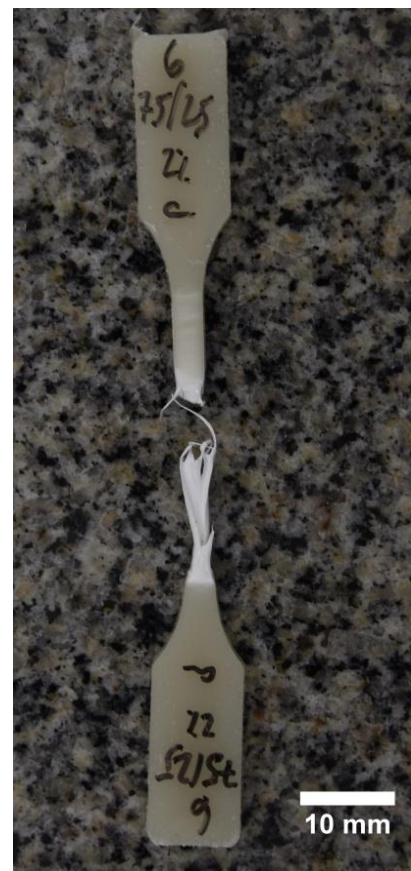

Figura 62. Corpo de prova número 6 da blenda 75/25 após os ensaios de tração.

A Tabela 18 mostra a média e o desvio padrão das propriedades mecânicas à tração da blenda PEAD/PA12 75/25, obtidas a partir do gráfico tensão $\mathrm{x}$ deformação de engenharia e verdadeira. 
Tabela 18. Propriedades mecânicas de tração da blenda 75/25.

\begin{tabular}{ccc}
\hline & $\begin{array}{c}\text { Tensão x deformação } \\
\text { de engenharia }\end{array}$ & $\begin{array}{c}\text { Tensão x deformação } \\
\text { verdadeira }\end{array}$ \\
\hline$\sigma_{\mathrm{y}}(\mathrm{MPa})$ & $27,8 \pm 1,9$ & $30,9 \pm 2,1$ \\
$\sigma_{\mathrm{R}}(\mathrm{MPa})$ & $18,0 \pm 8,7$ & $22,7 \pm 8,0$ \\
\hline $\mathrm{E}(\mathrm{MPa})$ & $404 \pm 52$ & $462 \pm 54$ \\
$\varepsilon_{\mathrm{y}}(\%)$ & $11,0 \pm 0,9$ & $11,0 \pm 0,9$ \\
\hline$\varepsilon_{\mathrm{R}}(\%)$ & $37 \pm 31$ & $29,0 \pm 21,8$ \\
\hline Tenacidade $\left(\mathrm{MJ} / \mathrm{m}^{3}\right)$ & $6,6 \pm 5,7$ & $6,7 \pm 5,6$ \\
\hline Resiliência $\left(\mathrm{MJ} / \mathrm{m}^{3}\right)$ & $1,8 \pm 0,2$ & $1,8 \pm 0,2$ \\
\hline
\end{tabular}

Nesta tabela não constam os valores de $\mathrm{n}_{0} \mathrm{e} \mathrm{n}_{1}$, pois somente dois corpos de prova apresentaram encruamento. Como prova da dispersão dos resultados, podese perceber que a tenacidade e a deformação na ruptura apresentaram grandes desvios padrões, Tabela 18.

\subsubsection{PEAD/PA12 50/50}

A Figura 63 mostra o gráfico tensão x deformação de engenharia típico desta blenda.

As propriedades mecânicas obtidas no gráfico tensão $\mathrm{x}$ deformação de engenharia e verdadeira estão listadas na Tabela 19. 


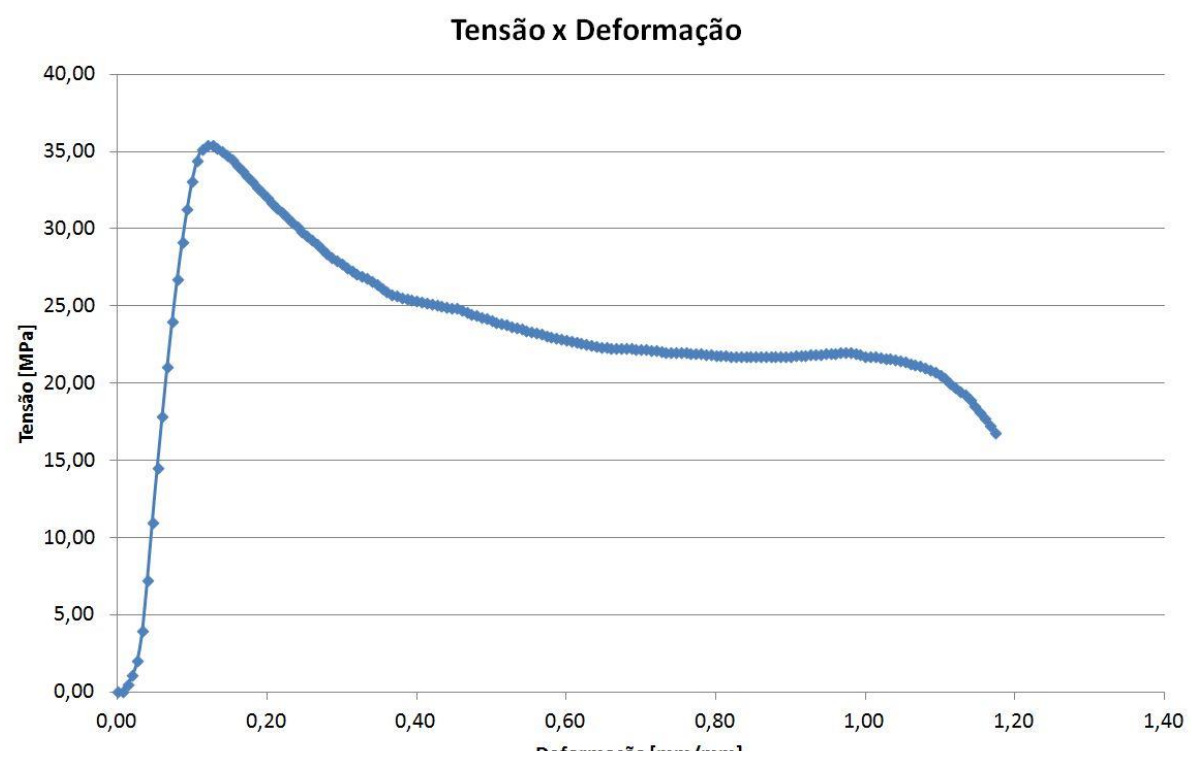

Figura 63. Gráfico tensão x deformação de engenharia do corpo de prova número 1 da blenda 50/50.

Tabela 19. Propriedades mecânicas de tração da blenda 50/50.

\begin{tabular}{ccc}
\hline & $\begin{array}{c}\text { Tensão x deformação } \\
\text { de engenharia }\end{array}$ & $\begin{array}{c}\text { Tensão x deformação } \\
\text { verdadeira }\end{array}$ \\
\hline $\boldsymbol{\sigma}_{\mathbf{y}}(\mathbf{M P a})$ & $35,1 \pm 1,7$ & $40,2 \pm 2,4$ \\
$\boldsymbol{\sigma}_{\mathbf{R}}(\mathbf{M P a})$ & $21,0 \pm 2,0$ & $43,8 \pm 10,0$ \\
$\mathbf{E}(\mathbf{M P a})$ & $466 \pm 57$ & $528,1 \pm 62,1$ \\
$\boldsymbol{\varepsilon}_{\mathbf{y}}(\boldsymbol{\%})$ & $14,0 \pm 2,1$ & $14,0 \pm 1,8$ \\
$\boldsymbol{\varepsilon}_{\mathbf{R}}(\boldsymbol{\%})$ & $106,0 \pm 34$ & $71,0 \pm 18,8$ \\
\hline Tenacidade $\left(\mathbf{M J} / \mathbf{m}^{\mathbf{3}}\right)$ & $28,1 \pm 9,0$ & $28,2 \pm 9,1$ \\
\hline Resiliência $\left(\mathbf{M J} / \mathbf{m}^{\mathbf{3}}\right)$ & $2,9 \pm 0,7$ & $3,5 \pm 0,7$ \\
$\mathbf{n}_{\mathbf{0}}$ & - & $0,3 \pm 0,1$ \\
$\mathbf{n}_{\mathbf{1}}$ & - & $0,7 \pm 0,03$ \\
\hline
\end{tabular}

A partir dos resultados mostrados na Tabela 19, percebe-se que esta blenda é mais tenaz que a blenda 75/25 e também tem uma deformação na ruptura maior. Ou seja, com uma porcentagem maior de PA o material ficou mais dúctil. Além disso, o material ficou mais resistente, já que o $\sigma_{R}$ é maior e escoou a uma tensão $\left(\sigma_{\mathrm{y}}\right)$ também superior à composição anterior. 
A Figura 64 apresenta um exemplo de corpo de prova após o ensaio de tração.

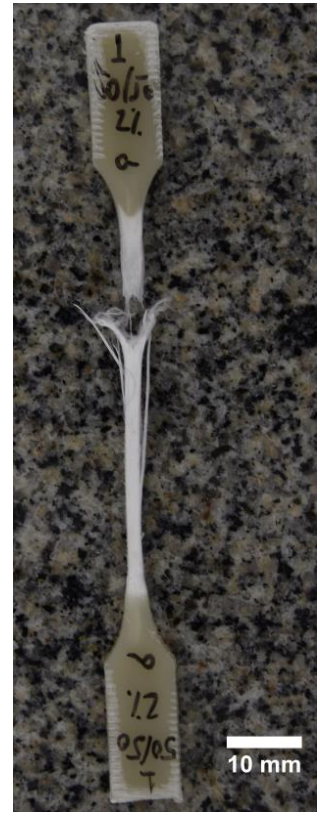

Figura 64. Corpo de prova número 1 de 50/50 após o ensaio de tração.

\subsubsection{PEAD/PA12 25/75}

A Figura 65 mostra o gráfico tensão x deformação característico desta blenda.

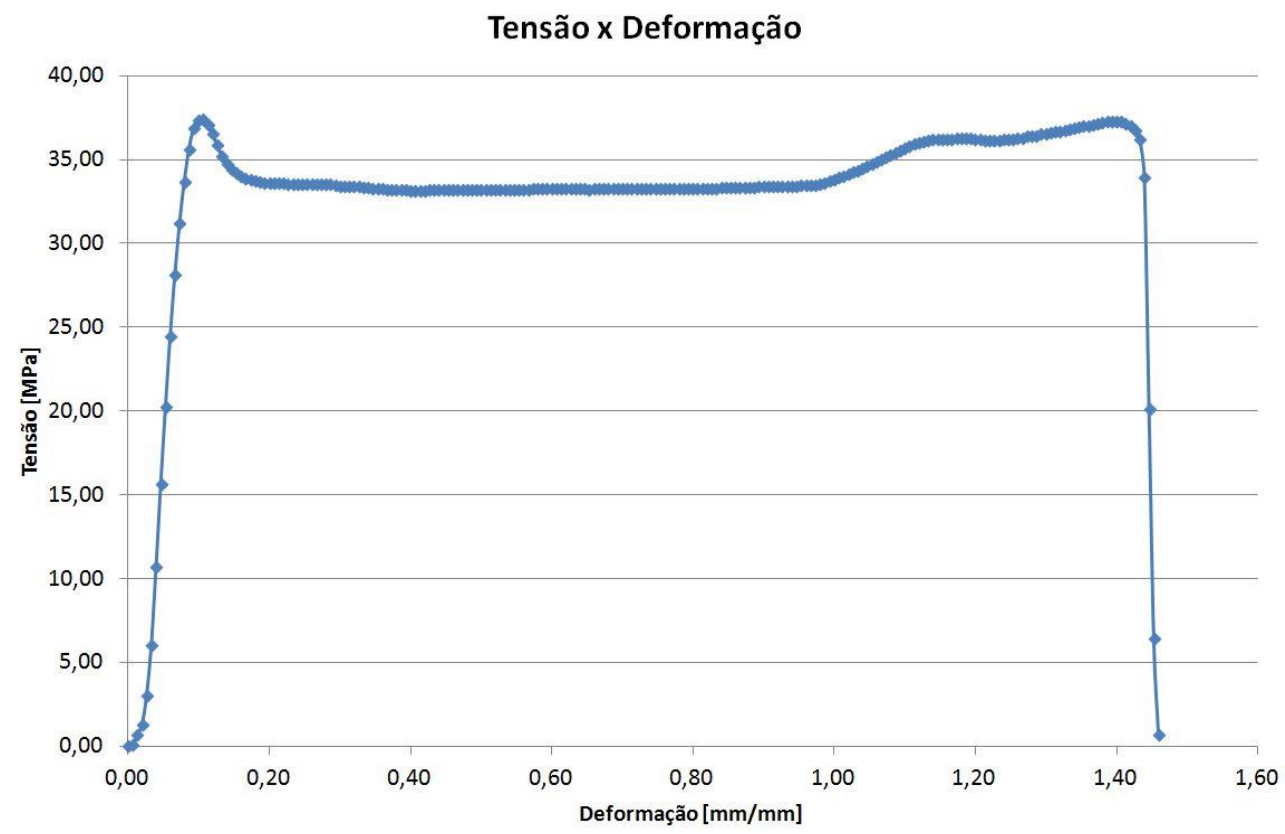

Figura 65. Gráfico tensão x deformação de engenharia do Corpo de prova número 7 da blenda 25/75. 
As propriedades mecânicas obtidas pelo gráfico tensão $\mathrm{x}$ deformação de engenharia e verdadeira estão listadas na Tabela 20.

Tabela 20. Propriedades mecânicas de tração da blenda 25/75.

\begin{tabular}{ccc}
\hline & $\begin{array}{c}\text { Tensão x deformação } \\
\text { de engenharia }\end{array}$ & $\begin{array}{c}\text { Tensão x deformação } \\
\text { verdadeira }\end{array}$ \\
\hline $\boldsymbol{\sigma}_{\mathbf{y}}(\mathbf{M P a})$ & $36,9 \pm 2,2$ & $41,9 \pm 2,6$ \\
$\boldsymbol{\sigma}_{\mathbf{R}}(\mathbf{M P a})$ & $32,9 \pm 5,2$ & $81,0 \pm 25,8$ \\
$\mathbf{E}(\mathbf{M P a})$ & $489 \pm 60$ & $558,8 \pm 69,7$ \\
$\mathbf{\varepsilon}_{\mathbf{y}}(\boldsymbol{\%})$ & $13,0 \pm 1,7$ & $13,0 \pm 2,0$ \\
$\mathbf{\varepsilon}_{\mathbf{R}}(\boldsymbol{\%})$ & $140,0 \pm 48,3$ & $86,0 \pm 21,7$ \\
Tenacidade $\left(\mathbf{M J} / \mathbf{m}^{\mathbf{3}}\right)$ & $45,5 \pm 16,8$ & $47,0 \pm 18,3$ \\
\hline Resiliência $\left(\mathbf{M J} / \mathbf{m}^{\mathbf{3}}\right)$ & $2,8 \pm 0,5$ & $3,1 \pm 0,7$ \\
$\mathbf{n}_{\mathbf{0}}$ & - & $0,5 \pm 0,2$ \\
$\mathbf{n}_{\mathbf{1}}$ & - & $1,2 \pm 0,2$ \\
\hline
\end{tabular}

Percebe-se que todas as propriedades apresentaram um aumento em relação

à blenda 50/50, exceto o limite de escoamento e a deformação no escoamento que não apresentaram mudança significativa. Isso reforça que quanto maior o teor de poliamida presente no material, maior a sua ductilidade, pois a composição 25/75 apresentou uma maior deformação na ruptura e uma maior tenacidade, ou seja, apresentou uma maior deformação plástica. Outro ponto importante a ressaltar é que esta blenda demonstrou o maior módulo de elasticidade entre as blendas apresentadas.

A Figura 66 apresenta um exemplo de corpo de prova após o ensaio de tração. 


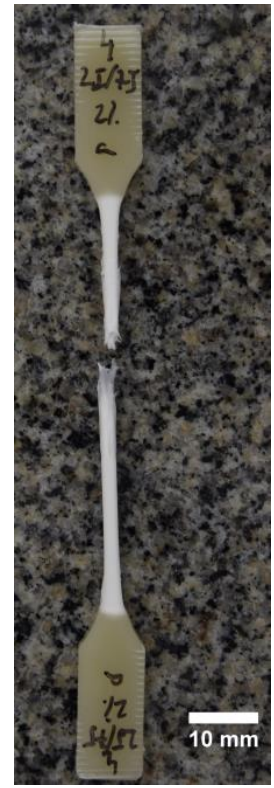

Figura 66. Corpo de prova número 4 de 25/75 após o ensaio de tração.

\subsubsection{Comparação}

A partir dos dados apresentados anteriormente, segue uma comparação entre as principais propriedades à tração das blendas compatibilizadas com $2 \%$ de PEAD-alt-MAH (Tabelas 21 e 22).

Tabela 21. Comparação entre as principais propriedades mecânicas de engenharia dos homopolímeros e das blendas com 2\% de PEAD-alt-MAH.

\begin{tabular}{cccccccc}
\hline PEAD & PA12 & $\begin{array}{c}\text { PEAD- } \\
\text { alt- } \\
\text { MAH }\end{array}$ & $\boldsymbol{\sigma}_{\mathbf{y}}(\mathbf{M P a})$ & $\boldsymbol{\sigma}_{\mathbf{R}}(\mathbf{M P a})$ & $\mathbf{E}(\mathbf{M P a})$ & $\boldsymbol{\varepsilon}_{\mathbf{y}}(\boldsymbol{\%})$ & $\boldsymbol{\varepsilon}_{\mathbf{R}}(\boldsymbol{\%})$ \\
\hline 100 & 0 & 0 & $24,1 \pm 0,2$ & $18,0 \pm 1,1$ & $408 \pm 44$ & $14,0 \pm 0,5$ & $352,0 \pm 0,7$ \\
73,5 & 24,5 & $2 \%$ & $27,8 \pm 1,9$ & $18,0 \pm 8,8$ & $404 \pm 52$ & $11,0 \pm 0,9$ & $37,0 \pm 31,8$ \\
49 & 49 & $2 \%$ & $35,1 \pm 1,7$ & $21,0 \pm 2,0$ & $467 \pm 58$ & $14,0 \pm 2,1$ & $106,0 \pm 33,9$ \\
24,5 & 73,5 & $2 \%$ & $36,9 \pm 2,2$ & $32,9 \pm 5,2$ & $489 \pm 60$ & $13,0 \pm 1,7$ & $140,0 \pm 48,3$ \\
0 & 100 & 0 & $42,0 \pm 1,8$ & $60,7 \pm 7,1$ & $413 \pm 32$ & $15,0 \pm 1,0$ & $305,0 \pm 43,7$ \\
\hline
\end{tabular}


Tabela 22. Comparação entre a tenacidade e resiliência das blendas com compatibilização de PEAD-alt-MAH.

\begin{tabular}{ccccc}
\hline PEAD & PA12 & $\begin{array}{c}\text { PEAD-alt- } \\
\text { MAH }\end{array}$ & $\begin{array}{c}\text { Tenacidade } \\
\left(\mathbf{M J} / \mathbf{m}^{3}\right)\end{array}$ & $\begin{array}{c}\text { Resiliência } \\
\left(\mathbf{M J} / \mathbf{m}^{3}\right)\end{array}$ \\
\hline 100 & 0 & 0 & $55,3 \pm 12,3$ & $2,1 \pm 0,1$ \\
73,5 & 24,5 & $2 \%$ & $6,6 \pm 5,7$ & $1,8 \pm 0,2$ \\
49 & 49 & $2 \%$ & $28,1 \pm 9,0$ & $2,9 \pm 0,7$ \\
24,5 & 73,5 & $2 \%$ & $45,5 \pm 16,8$ & $2,8 \pm 0,5$ \\
0 & 100 & 0 & $126,7 \pm 25,3$ & $3,4 \pm 0,2$ \\
\hline
\end{tabular}

A partir dos dados da tabela acima foram construídos gráficos de caixa (boxplot) de algumas propriedades mecânicas para se visualizar comparativamente possíveis variações dos valores e as respectivas dispersões de valores. As Figuras 67 a 73 mostram os box-plot do limite de escoamento, tensão de ruptura, módulo de elasticidade, deformação na ruptura, tenacidade, $\mathrm{n}_{0}$ e $\mathrm{n}_{1}$.

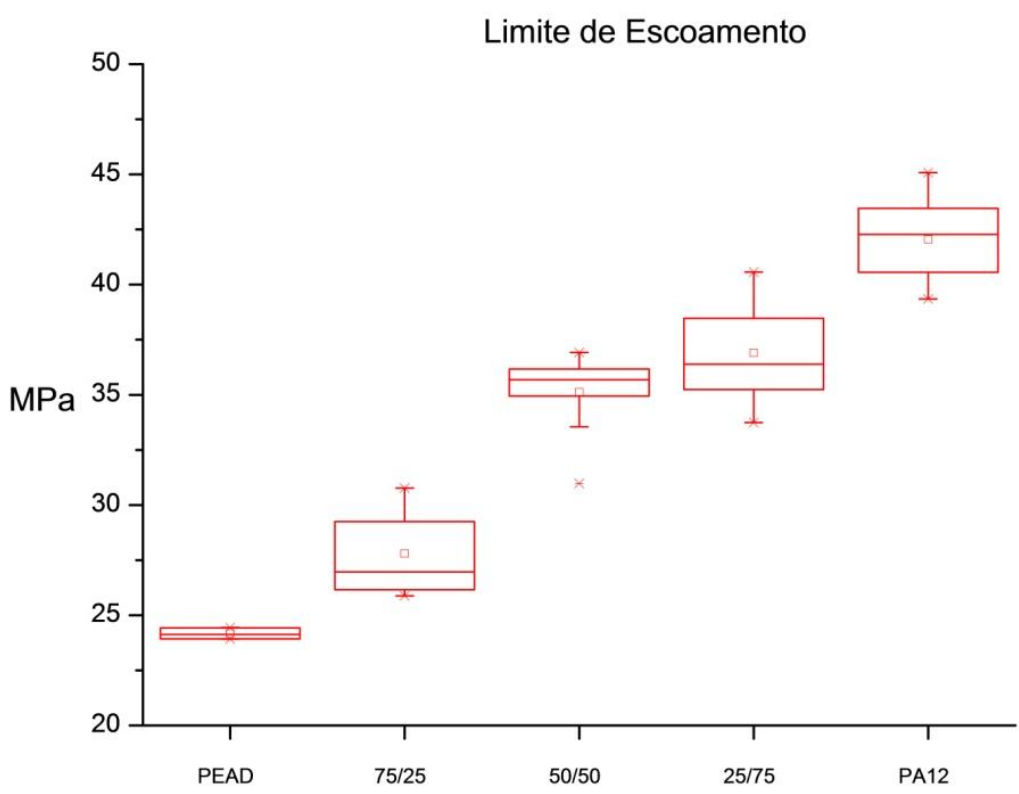

Figura 67. Box Plot - Limite de Escoamento 


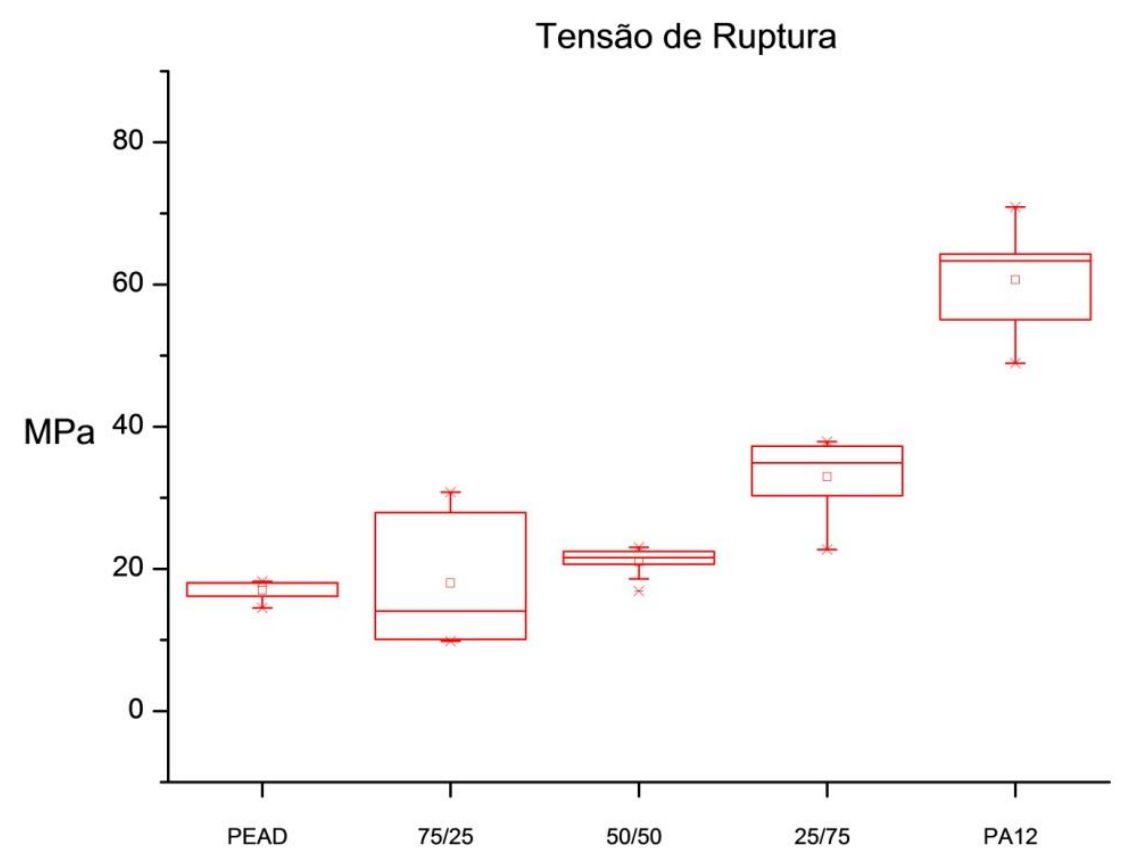

Figura 68. Box Plot - Tensão de Ruptura.

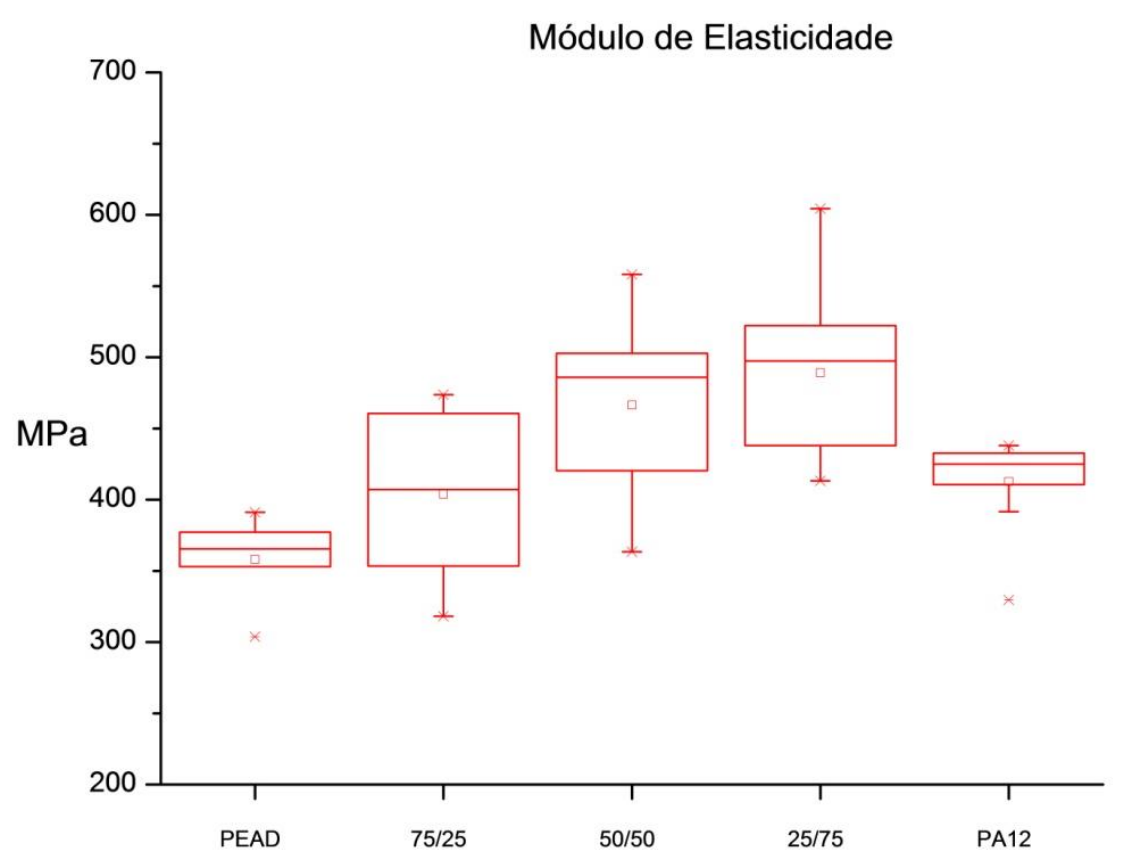

Figura 69. Box Plot - Módulo de Elasticidade. 


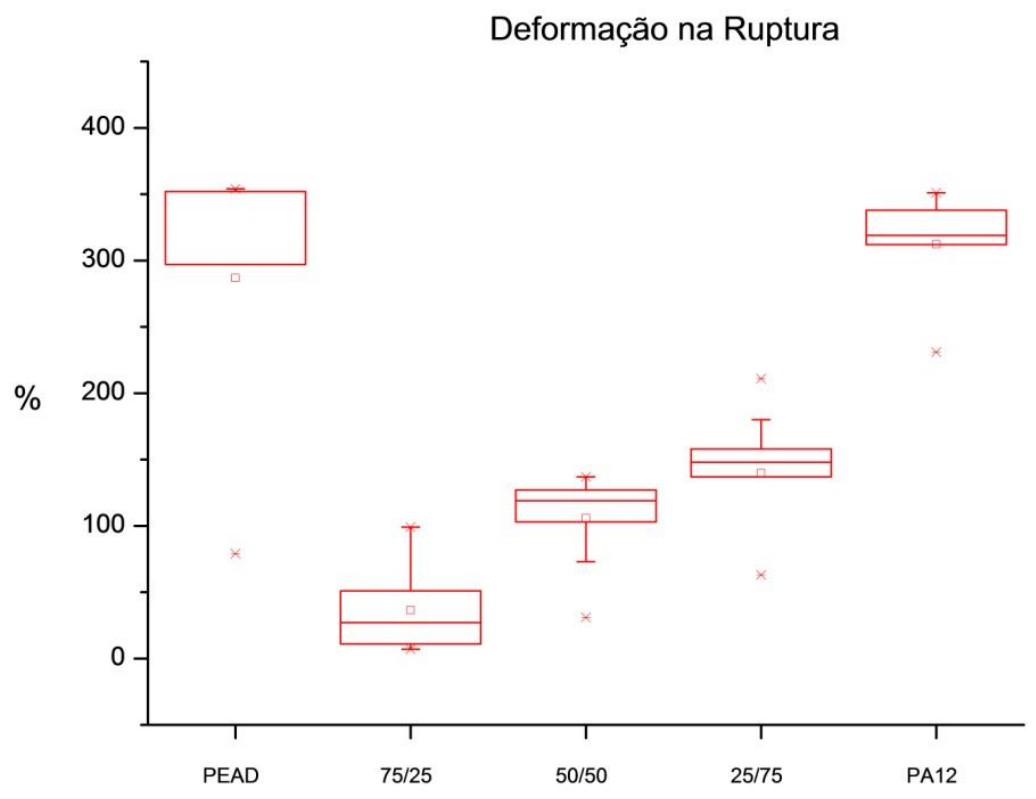

Figura 70. Box Plot - Deformação na Ruptura.

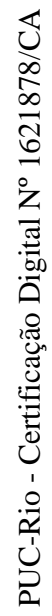

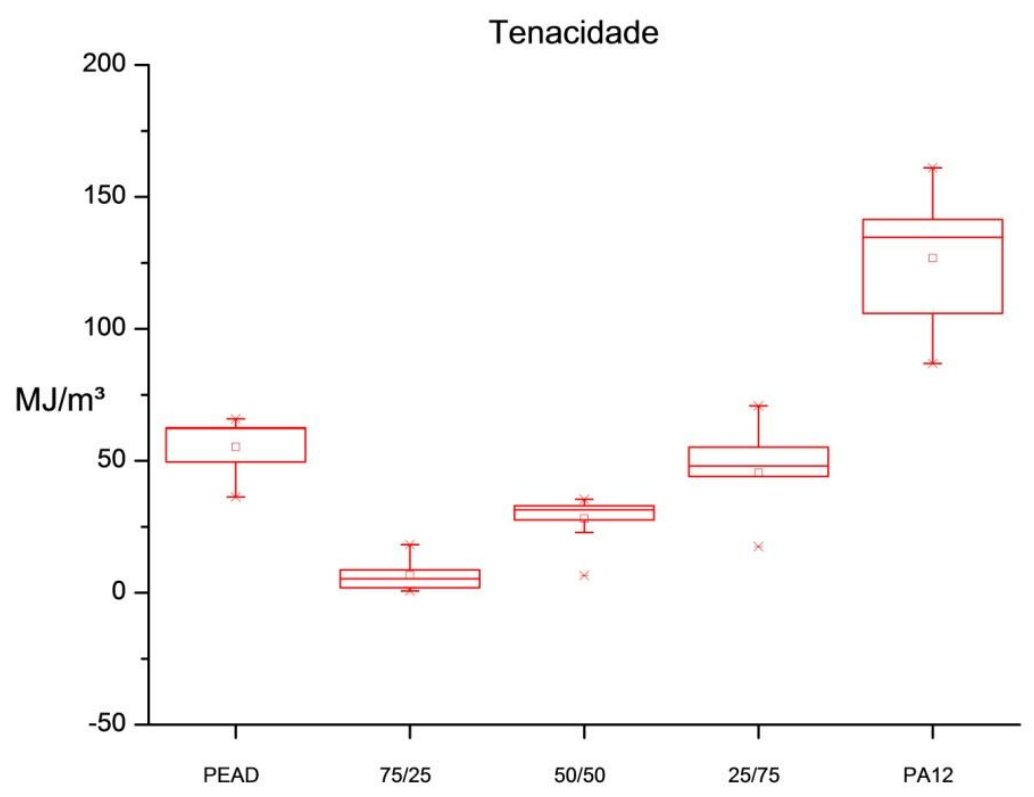

Figura 71. Box Plot - Tenacidade. 
$\mathrm{n}_{0}$

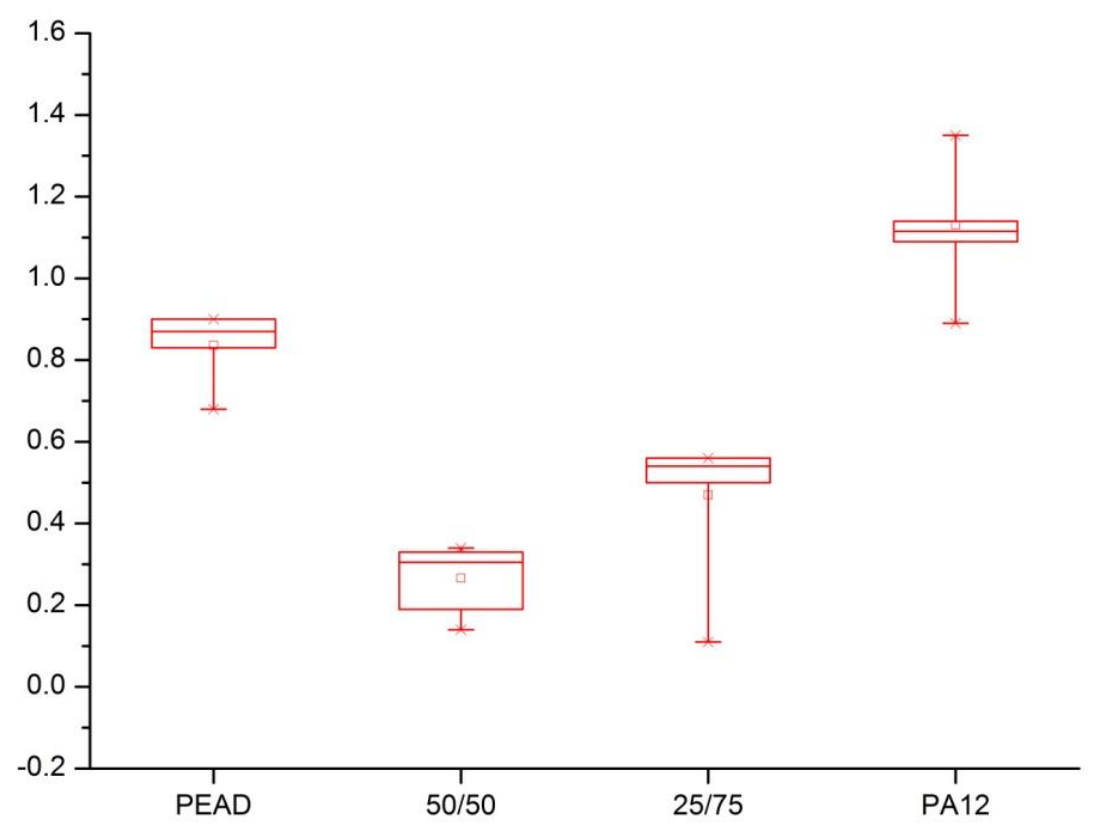

Figura 72. Box Plot $-\mathrm{n}_{0}$.

$\mathrm{n}_{1}$

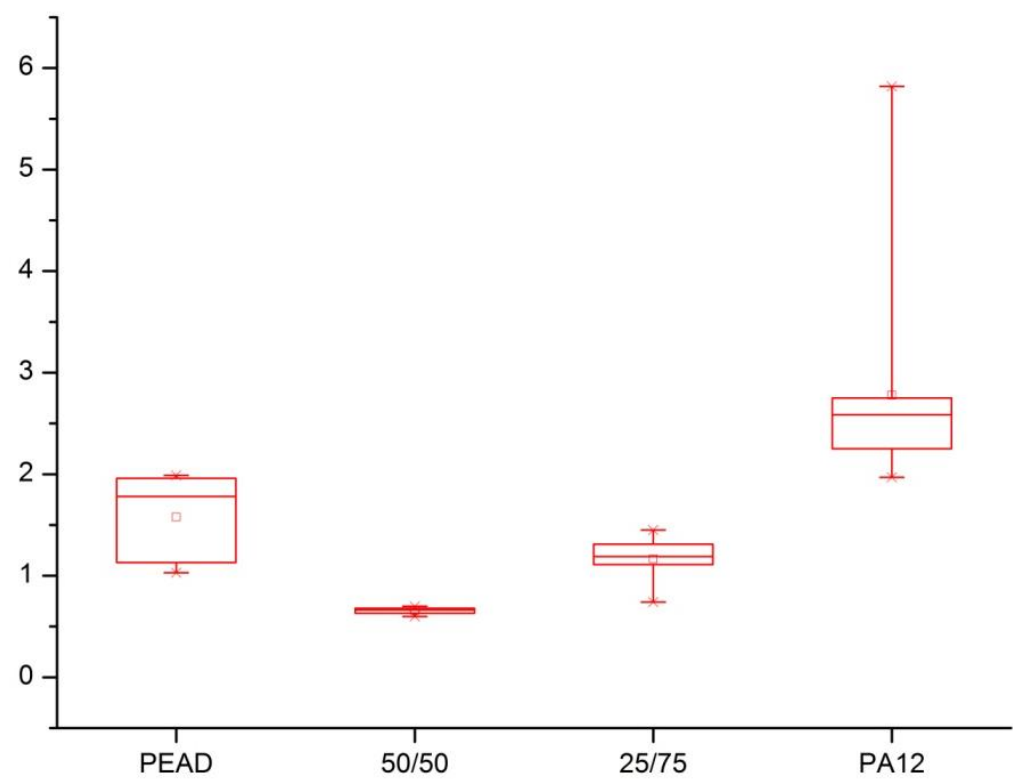

Figura 73. Box Plot $-\mathrm{n}_{1}$.

Através dos gráficos apresentados, percebe-se que os valores das propriedades das blendas são intermediários aos valores dos polímeros puros. Outra observação pertinente é que, comparando as três composições de blendas 
entre si, percebe-se que as propriedades vão gradativamente aumentando conforme aumenta o teor de PA12 no material.

Nos gráficos referentes aos coeficientes de encruamento $\left(\mathrm{n}_{0}\right.$ e $\left.\mathrm{n}_{1}\right)$, não consta a blenda 75/25, devido ao fato deste material não ter apresentado encruamento, exceto em apenas dois corpos de prova. Também se percebe que a blenda 25/75 tem maior coeficiente de encruamento que a 50/50. Com isso, conclui-se que a blenda 25/75 é a blenda que apresenta maior resistência à deformação.

Analisando o conjunto de dados por um gráfico do tipo radar (Figura 74) é possível observar que, tomando a PA12 como o material para comparação de propriedades, a blenda 25/75 é aquela que fornece o melhor compromisso entre as propriedades mecânicas $\left(\sigma_{y}, \sigma_{R}, E\right)$ e as propriedades relacionadas com a deformabilidade do material ( $\varepsilon_{\mathrm{y}}, \varepsilon_{\mathrm{R}}$, resiliência e tenacidade).

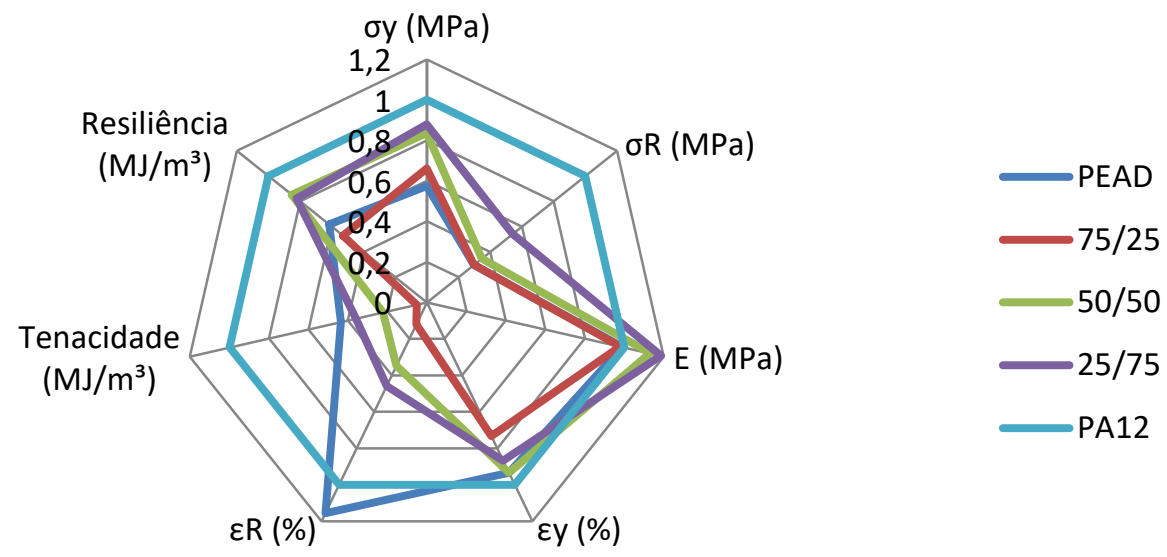

Figura 74. Gráfico Radar de comparação das propriedades das blendas em relação à PA12.

\subsection{Fluência}

\subsubsection{PEAD}

Para este material, foram utilizados cinco corpos de prova e o ensaio foi realizado a uma carga constante de $118 \mathrm{~N}$, correspondente a $50 \%$ do limite de escoamento do PEAD $(\approx 12 \mathrm{MPa})$ e à temperatura ambiente. 
Na Figura 75 está mostrado o gráfico deformação vs. tempo que retrata o comportamento à fluência do PEAD.

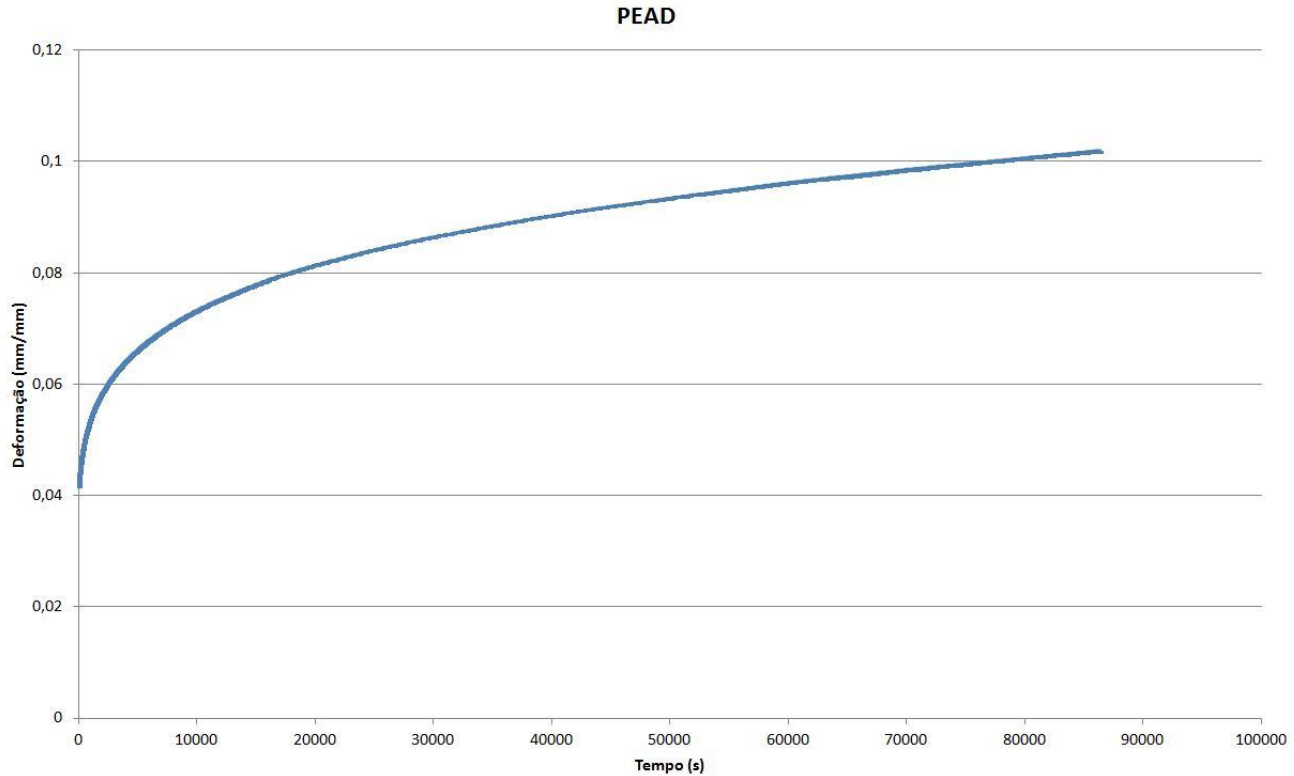

Figura 75. Exemplo da curva deformação vs. tempo (CP 01, PEAD).

A partir dos modelos viscoelásticos, foi simulado e avaliado o comportamento à fluência do PEAD, utilizando o ajuste numérico por regressão não-linear associado com o método dos mínimos quadrados. Como foi explicado anteriormente, foram avaliados os modelos do sólido linear padrão (3 parâmetros), modelo de 4 parâmetros e o modelo denominado Stretched Burgers (Burgers modificado). Foi verificado que para todos os corpos de prova de PEAD, o modelo de Stretched Burgers foi o que mais se aproximou do comportamento experimental do PEAD, pois obteve o maior coeficiente de correlação $\left(R^{2}\right)$. A Tabela 23 mostra os valores das médias e dos desvios padrões dos parâmetros de cada modelo. 
Tabela 23. Comparação dos parâmetros dos modelos viscoelásticos para o PEAD.

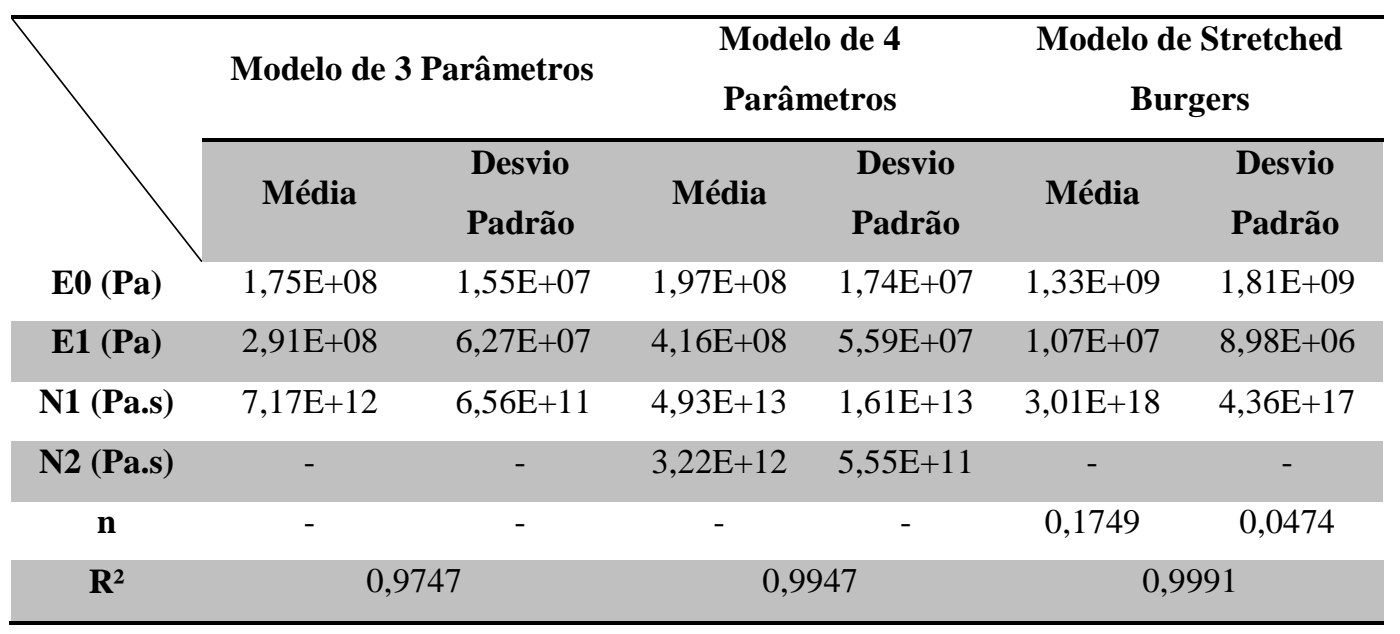

Um gráfico comparando o comportamento dos modelos descritos acima está apresentado na Figura 76.

CP01 - 24h

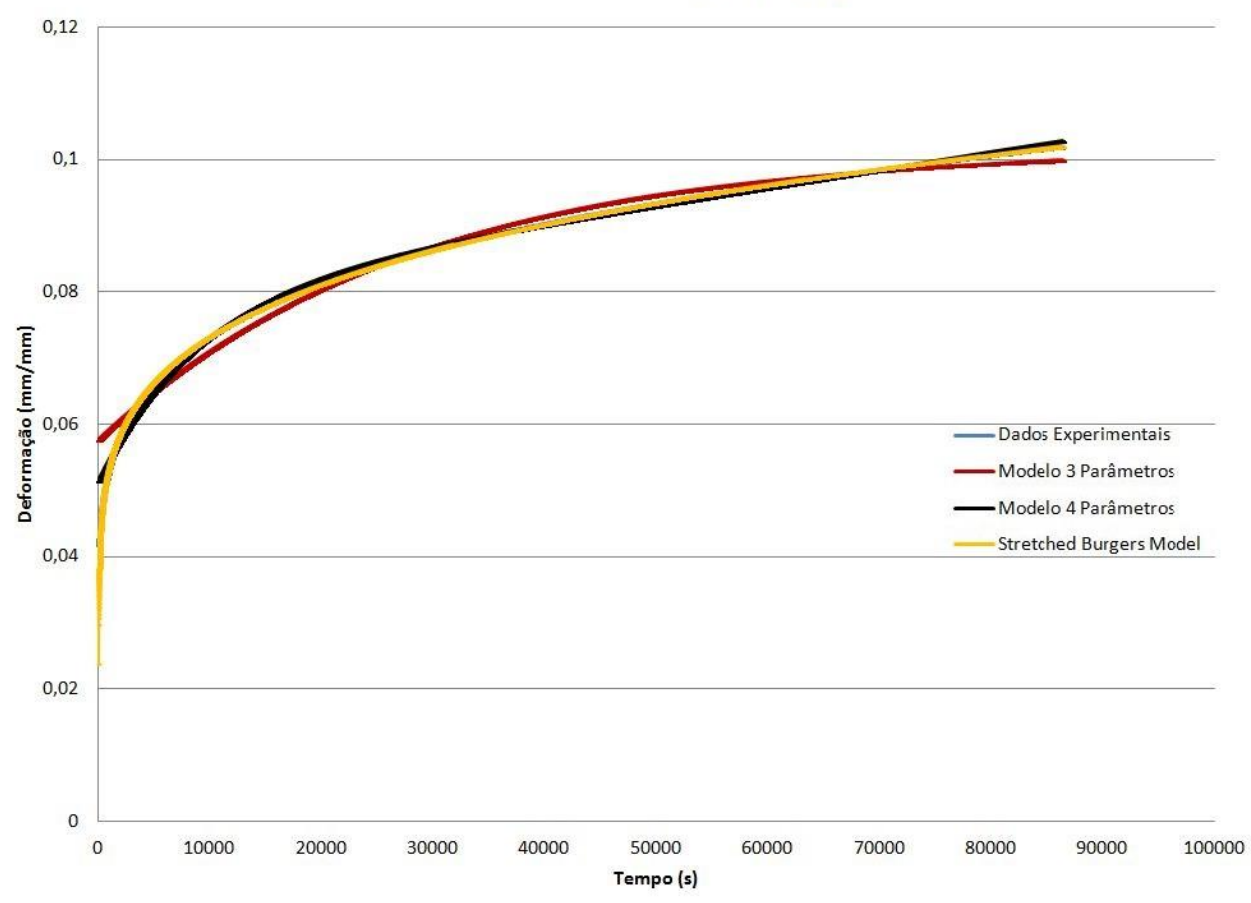

Figura 76. Comparação dos modelos viscoelásticos para o CP 01 de PEAD.

Além disso, também foram obtidas as deformações instantâneas $(\mathrm{t}=0)$ e as taxas de fluência nos seguintes intervalos: $2 \mathrm{~h}-4 \mathrm{~h}, 4 \mathrm{~h}-8 \mathrm{~h}, 8 \mathrm{~h}-12 \mathrm{~h}, 12 \mathrm{~h}-16 \mathrm{~h}$, $16 \mathrm{~h}-20 \mathrm{~h}$ e $20 \mathrm{~h}-24 \mathrm{~h}$ (Tabela 24). 
Tabela 24. Valores de deformação instantânea e taxa de fluência para o PEAD.

\begin{tabular}{rcc}
\hline & Média & Desvio Padrão \\
\hline \multicolumn{2}{c}{ Taxa de fluência $\left(\mathbf{s}^{-1}\right)$} \\
$\mathbf{2 h}-\mathbf{4 h}$ & $9,89 \mathrm{E}-07$ & 0,0046 \\
$\mathbf{4 h}-\mathbf{8 h}$ & $5,42 \mathrm{E}-07$ & $9,40 \mathrm{E}-07$ \\
$\mathbf{8 h}-\mathbf{1 2 h}$ & $3,41 \mathrm{E}-07$ & $6,85 \mathrm{E}-08-08$ \\
$\mathbf{1 2 h}-\mathbf{1 6 h}$ & $2,61 \mathrm{E}-07$ & $6,04 \mathrm{E}-08$ \\
$\mathbf{1 6 h}-\mathbf{2 0 h}$ & $2,15 \mathrm{E}-07$ & $5,52 \mathrm{E}-08$ \\
$\mathbf{2 0 h}-\mathbf{2 4 h}$ & $1,95 \mathrm{E}-07$ & $6,22 \mathrm{E}-08$ \\
\hline
\end{tabular}

Através da Tabela 24, percebe-se que após 24 horas de ensaio, o material atingiu a taxa de fluência estacionária. É importante ressaltar que o corpo de prova de número 4 apresentou um pequeno aumento na sua taxa de fluência após 20 horas de ensaio.

\subsubsection{PA12}

Para este material, foram utilizados cinco corpos de prova e o ensaio foi realizado a uma carga constante de $220 \mathrm{~N}$, correspondente a $50 \%$ do limite de escoamento da PA12 ( $21 \mathrm{MPa})$ e à temperatura ambiente. A Figura 77 mostra o gráfico deformação vs. tempo que retrata o comportamento à fluência da PA12.

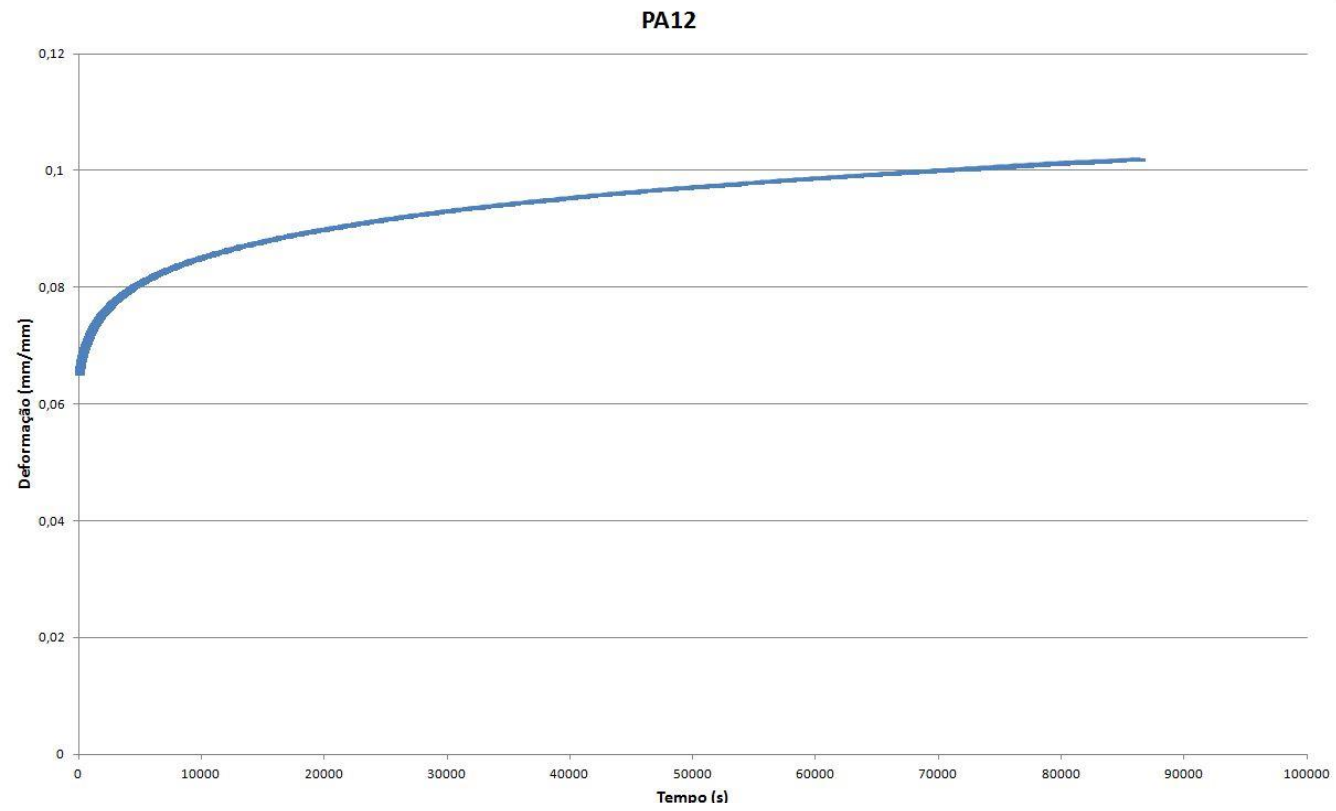

Figura 77. Exemplo da curva deformação vs. tempo (CP 01, PA12). 
Foi verificado que para a maioria dos corpos de prova, o modelo de 4 parâmetros foi o que mais se aproximou do comportamento experimental da PA12, pois obteve o maior coeficiente de correlação $\left(R^{2}\right)$. É preciso observar que a correlação com o modelo Stretched Burgers também descreveu de modo satisfatório o comportamento de alguns corpos de prova. Mas, embora a diferença entre o coeficiente de correlação desse modelo e o coeficiente de correlação do modelo de 4 parâmetros seja pequena, o coeficiente de correlação do modelo de 4 parâmetros foi maior. A Tabela 25 mostra os valores das médias e dos desvios padrões dos parâmetros de cada modelo.

Tabela 25. Comparação dos parâmetros dos modelos viscoelásticos para a

PA12.

\begin{tabular}{ccccccc}
\hline & Modelo de 3 Parâmetros & \multicolumn{2}{c}{$\begin{array}{c}\text { Modelo de 4 } \\
\text { Parâmetros }\end{array}$} & \multicolumn{2}{c}{$\begin{array}{c}\text { Modelo de Stretched } \\
\text { Burgers }\end{array}$} \\
\cline { 2 - 7 } & Média & $\begin{array}{c}\text { Desvio } \\
\text { Padrão }\end{array}$ & Média & $\begin{array}{c}\text { Desvio } \\
\text { Padrão }\end{array}$ & Média & $\begin{array}{c}\text { Desvio } \\
\text { Padrão }\end{array}$ \\
E0 (Pa) & $2,56 \mathrm{E}+08$ & $1,62 \mathrm{E}+07$ & $2,76 \mathrm{E}+08$ & $2,3 \mathrm{E} 07$ & $2,39 \mathrm{E}+14$ & $1,35 \mathrm{E}+14$ \\
$\mathbf{E 1}(\mathbf{P a})$ & $6,44 \mathrm{E}+08$ & $8,86 \mathrm{E}+07$ & $8,96 \mathrm{E}+08$ & $1,74 \mathrm{E}+08$ & $4,33 \mathrm{E}+07$ & $1,74 \mathrm{E}+07$ \\
$\mathbf{N 1}$ (Pa.s) & $1,56 \mathrm{E} 13$ & $4,18 \mathrm{E} 12$ & $1,17 \mathrm{E}+14$ & $2,08 \mathrm{E}+13$ & $2,82 \mathrm{E}+20$ & $5,74 \mathrm{E}+20$ \\
$\mathbf{N} 2$ (Pa.s) & - & - & $6,99 \mathrm{E}+12$ & $1,67 \mathrm{E}+12$ & - & - \\
$\mathbf{n}$ & - & - & - & - & 0,0973 & 0,0035 \\
$\mathbf{R}^{2}$ & & 0,9729 & & 0,9945 & 0,9913 \\
\hline
\end{tabular}

Um gráfico comparando o comportamento dos modelos descritos acima está apresentado na Figura 78. 


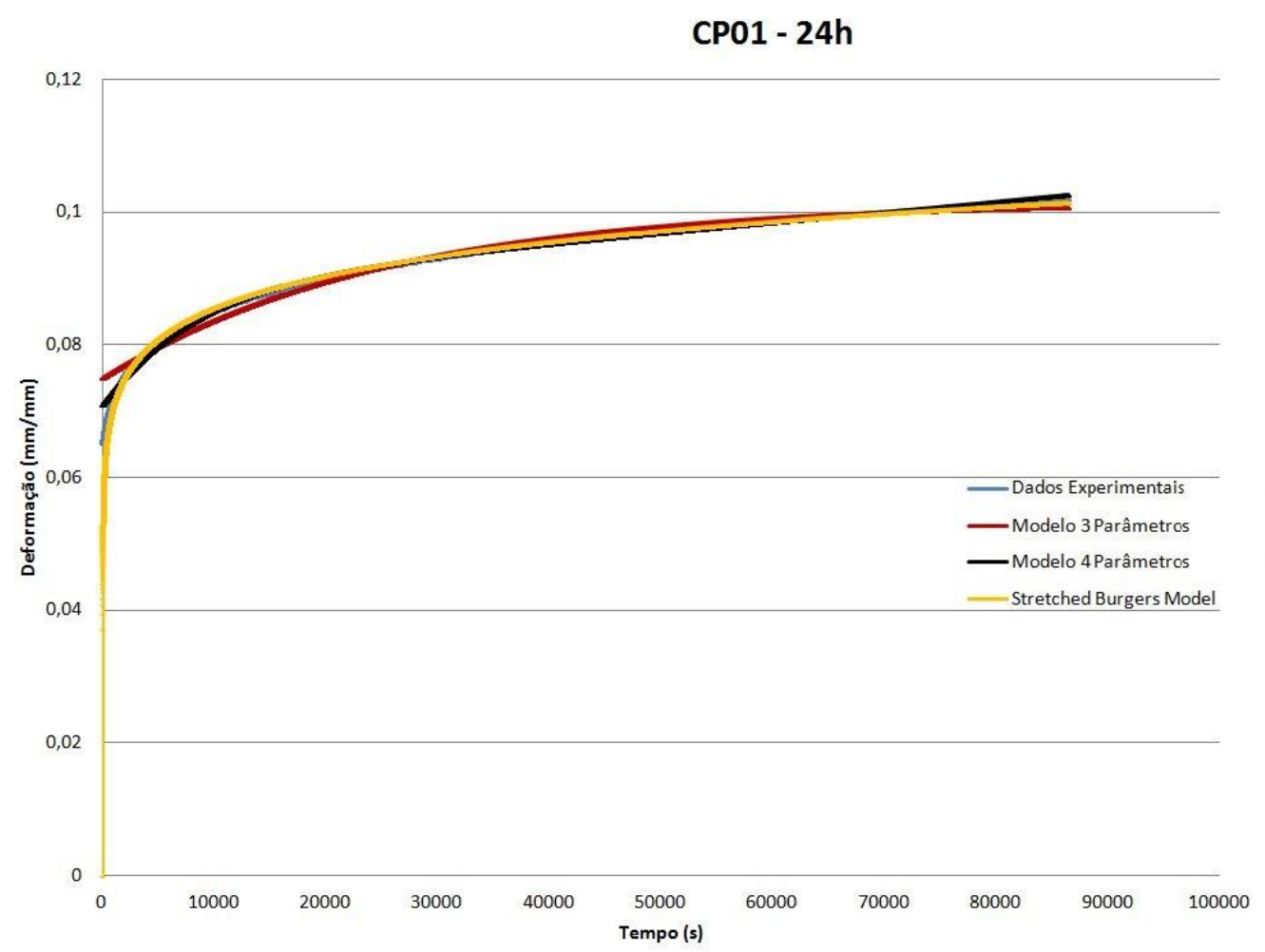

Figura 78. Comparação dos modelos viscoelásticos para o CP 01 de PA12.

Além disso, também foram obtidas as deformações instantâneas $(\mathrm{t}=0)$ e as taxas de fluência nos seguintes intervalos: $2 \mathrm{~h}-4 \mathrm{~h}, 4 \mathrm{~h}-8 \mathrm{~h}, 8 \mathrm{~h}-12 \mathrm{~h}, 12 \mathrm{~h}-16 \mathrm{~h}$, $16 \mathrm{~h}-20 \mathrm{~h}$ e $20 \mathrm{~h}-24 \mathrm{~h}$ (Tabela 26).

Tabela 26. Valores de deformação instantânea e taxa de fluência para a PA12.

\begin{tabular}{ccc}
\hline & Média & Desvio Padrão \\
\hline \multicolumn{2}{c}{ Taxa de fluência $\left(\mathbf{s}^{\mathbf{- 1}}\right)$} & 0,0047 \\
$\mathbf{2 h}-\mathbf{4 h}$ & $8,03 \mathrm{E}-07$ & $1,49 \mathrm{E}-07$ \\
$\mathbf{4 h}-\mathbf{8 h}$ & $4,35 \mathrm{E}-07$ & $8,67 \mathrm{E}-08$ \\
$\mathbf{8 h}-\mathbf{1 2 h}$ & $2,53 \mathrm{E}-07$ & $1,71 \mathrm{E}-08$ \\
$\mathbf{1 2 h}-\mathbf{1 6 h}$ & $1,80 \mathrm{E}-07$ & $1,36 \mathrm{E}-08$ \\
$\mathbf{1 6 h}-\mathbf{2 0 h}$ & $1,62 \mathrm{E}-07$ & $5,65 \mathrm{E}-08$ \\
$\mathbf{2 0 h}-\mathbf{2 4 h}$ & $1,54 \mathrm{E}-07$ & $7,94 \mathrm{E}-08$ \\
\hline
\end{tabular}

Vale ressaltar que um dos corpos de prova (CP 03) apresentou aumento na sua taxa de fluência a partir de 16 horas de ensaio. Isso pode ter sido causado ou por algum erro experimental (por exemplo, um escorregamento da amostra nas 
garras do equipamento) ou porque o material estava começando a apresentar um estágio terciário de fluência, apesar de nenhum escoamento aparente no corpo de prova ter sido observado.

Fazendo uma comparação com o PEAD, pode-se notar que a PA12 demonstrou uma maior deformação instantânea $(0,0668$ para a PA12 e 0,0497 para o PEAD) e, também, uma menor taxa de fluência estacionária (1,54E-07 para a PA12 e 1,95E-07 para o PEAD). Em relação aos modelos viscoelásticos, na PA12 o modelo de 4 Parâmetros foi o que mais se aproximou do comportamento experimental, enquanto no PEAD o melhor modelo foi o de Stretched Burgers.

\subsubsection{PEAD/PA12 75/25}

Para este material, foram utilizados seis corpos de prova e o ensaio foi realizado a uma carga constante de $150 \mathrm{~N}$, correspondente a $50 \%$ do limite de escoamento da blenda $75 / 25(\approx 14 \mathrm{MPa})$ e à temperatura ambiente.

Na Figura 79 está mostrado o gráfico deformação vs. tempo que retrata o comportamento à fluência da blenda PEAD/PA12 75/25.

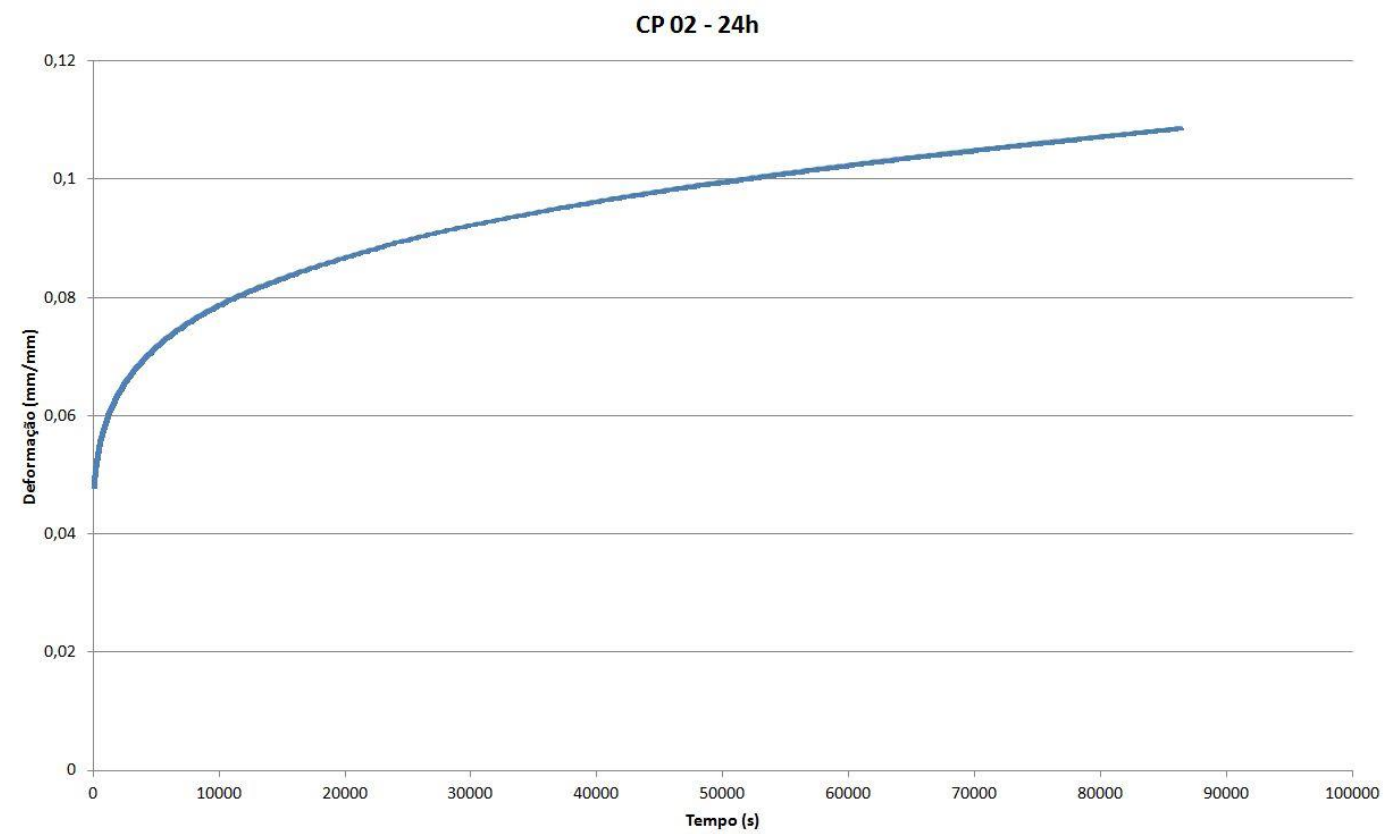

Figura 79. Exemplo da curva deformação vs. tempo (CP 02, PEAD/PA12 $75 / 25)$.

A partir da realização da modelagem, foi observado que o modelo viscoelástico que mais se aproximou do comportamento experimental da blenda 75/25 foi também o modelo de 4 Parâmetros. A Tabela 27 mostra os valores das médias e dos desvios padrões dos parâmetros de cada modelo. 
Tabela 27. Comparação dos parâmetros dos modelos viscoelásticos para a blenda 75/25.

\begin{tabular}{cccccccc}
\hline & \multicolumn{2}{c}{$\begin{array}{c}\text { Modelo de 3 } \\
\text { Parâmetros }\end{array}$} & \multicolumn{2}{c}{$\begin{array}{c}\text { Modelo de 4 } \\
\text { Parâmetros }\end{array}$} & \multicolumn{2}{c}{$\begin{array}{c}\text { Modelo de Stretched } \\
\text { Burgers }\end{array}$} \\
\cline { 2 - 8 } & Média & $\begin{array}{c}\text { Desvio } \\
\text { Padrão }\end{array}$ & Média & $\begin{array}{c}\text { Desvio } \\
\text { Padrão }\end{array}$ & Média & $\begin{array}{c}\text { Desvio } \\
\text { Padrão }\end{array}$ \\
\cline { 2 - 8 } E0 (Pa) & $2,27 \mathrm{E}+08$ & $8,00 \mathrm{E}+06$ & $2,51 \mathrm{E}+08$ & $1,11 \mathrm{E}+07$ & $2,80 \mathrm{E}+14$ & $1,97 \mathrm{E}+14$ \\
E1 (Pa) & $3,34 \mathrm{E}+08$ & $4,35 \mathrm{E}+07$ & $5,45 \mathrm{E}+08$ & $8,48 \mathrm{E}+07$ & $2,00 \mathrm{E}+07$ & $4,36 \mathrm{E}+06$ \\
N1 (Pa.s) & $9,77 \mathrm{E}+12$ & $1,68 \mathrm{E}+12$ & $5,34 \mathrm{E}+13$ & $4,93 \mathrm{E}+12$ & $2,21 \mathrm{E}+19$ & $4,40 \mathrm{E}+19$ \\
N2 (Pa.s) & - & - & $4,86 \mathrm{E}+12$ & $6,60 \mathrm{E}+11$ & - & - \\
$\mathbf{n}$ & - & - & - & - & 0,147 & 0,0174 \\
$\mathbf{R}^{2}$ & & 0,9819 & & & 0,9966 & & 0,9932 \\
\hline
\end{tabular}

Um gráfico comparando os modelos descritos acima está representado na Figura 80 .

CP02 - 24h

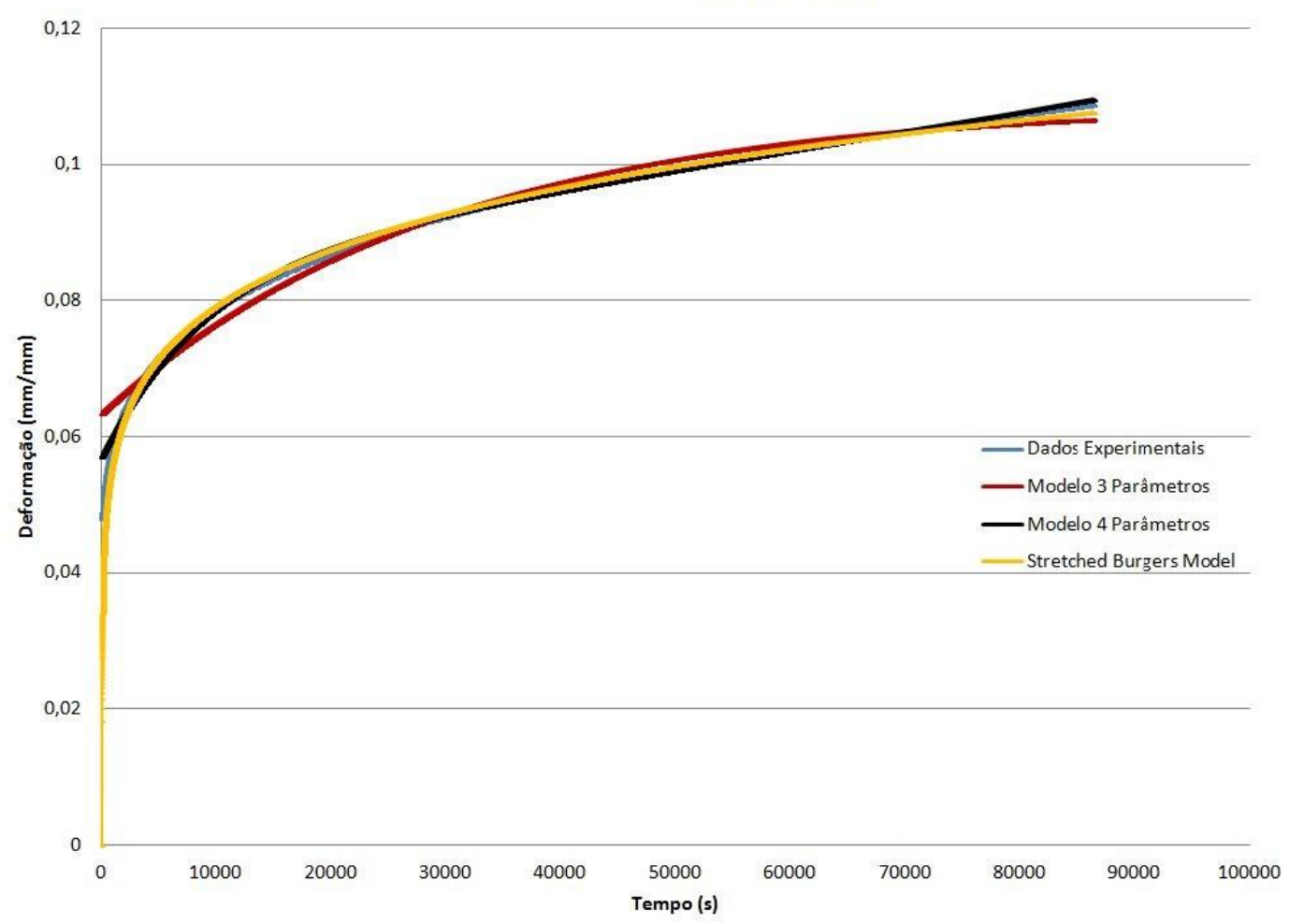

Figura 80. Comparação dos modelos viscoelásticos para o CP 02 do

PEAD/PA12 75/25.

As deformações instantâneas $(t=0)$ e as taxas de fluência nos seguintes intervalos: $2 h-4 h, 4 h-8 h, 8 h-12 h, 12 h-16 h, 16 h-20 h$ e $20 h-24 h$ estão representadas na Tabela 28 . 
Tabela 28. Valores de deformação instantânea e taxa de fluência para a blenda PEAD/PA12 75/25.

\begin{tabular}{ccc}
\hline & Média & Desvio Padrão \\
\hline Taxa de fluência $\left(\mathbf{s}^{-\mathbf{1}}\right)$ & 0,0017 \\
$\mathbf{2 h}-\mathbf{4 h}$ & $9,75 \mathrm{E}-07$ & $1,23 \mathrm{E}-07$ \\
$\mathbf{4 h}-\mathbf{8 h}$ & $5,74 \mathrm{E}-07$ & $8,28 \mathrm{E}-08$ \\
$\mathbf{8 h}-\mathbf{1 2 h}$ & $3,67 \mathrm{E}-07$ & $4,53 \mathrm{E}-08$ \\
$\mathbf{1 2 h}-\mathbf{1 6 h}$ & $2,81 \mathrm{E}-07$ & $3,09 \mathrm{E}-08$ \\
$\mathbf{1 6 h}-\mathbf{2 0 h}$ & $2,39 \mathrm{E}-07$ & $2,54 \mathrm{E}-08$ \\
$\mathbf{2 0 h}-\mathbf{2 4 h}$ & $2,15 \mathrm{E}-07$ & $2,37 \mathrm{E}-08$ \\
\hline
\end{tabular}

Os dados listados nas Tabelas 27 e 28 são referentes a apenas quatro corpos de prova, pois os outros dois escoaram num intervalo de tempo menor que 24 horas. Isso pode ser explicado, provavelmente, pela falta de homogeneidade nestes dois corpos de prova. O corpo de prova número 4 apresentou um escoamento em pouco menos de 3 h de ensaio, não chegando à fratura; já o corpo de prova número 6 apresentou fratura frágil com aproximadamente $8 \mathrm{~h}$ de ensaio.

Os gráficos deformação x tempo dos corpos de prova número 4 e 6 estão representados nas Figuras 81 e 82, respectivamente. 


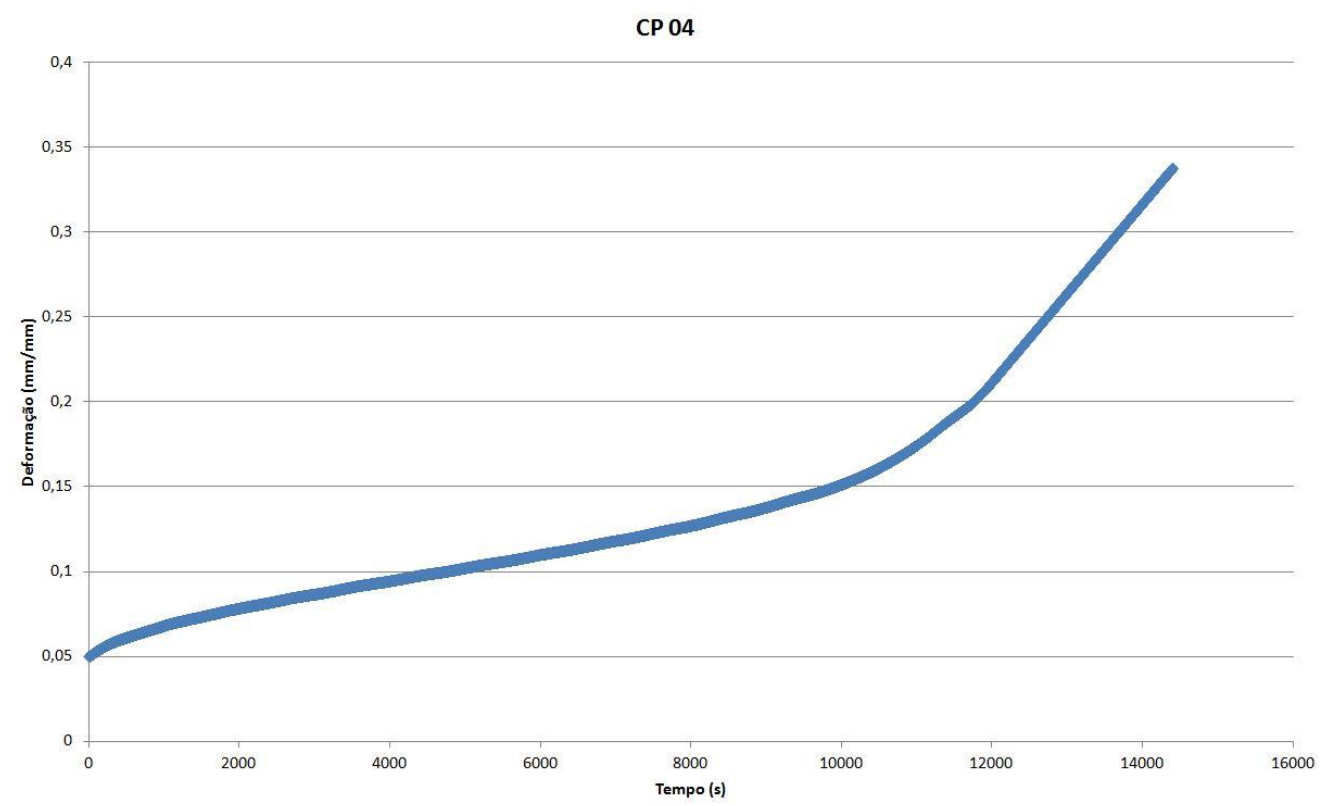

Figura 81. Curva Deformação x Tempo do CP04 da blenda 75/25.

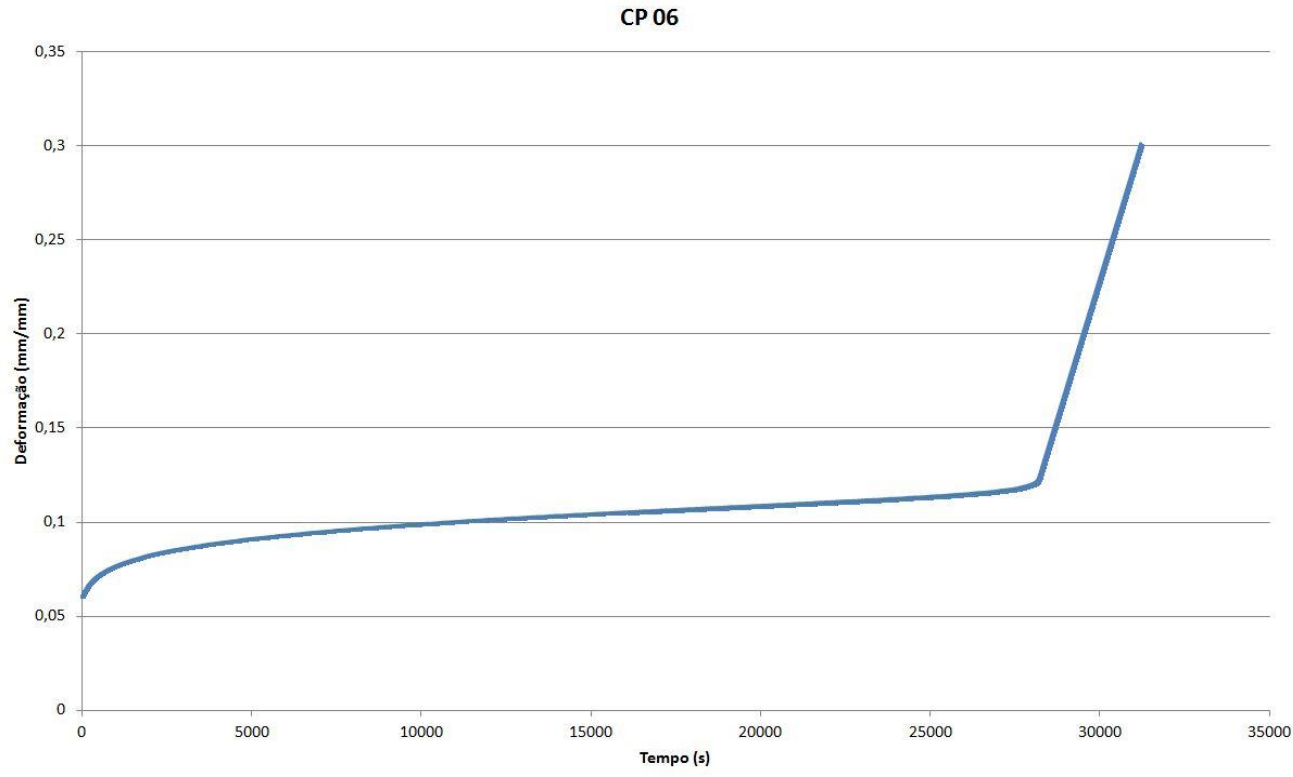

Figura 82. Curva Deformação x Tempo do CP06 da blenda 75/25. 


\subsubsection{PEAD/PA12 50/50}

Para este material, foram utilizados cinco corpos de prova e o ensaio foi realizado a uma carga constante de $180 \mathrm{~N}$, correspondente a $50 \%$ do limite de escoamento da blenda 50/50 ( $\approx 17 \mathrm{MPa})$ e à temperatura ambiente.

A Figura 83 mostra o gráfico deformação vs. tempo que retrata o comportamento à fluência da blenda PEAD/PA12 50/50.

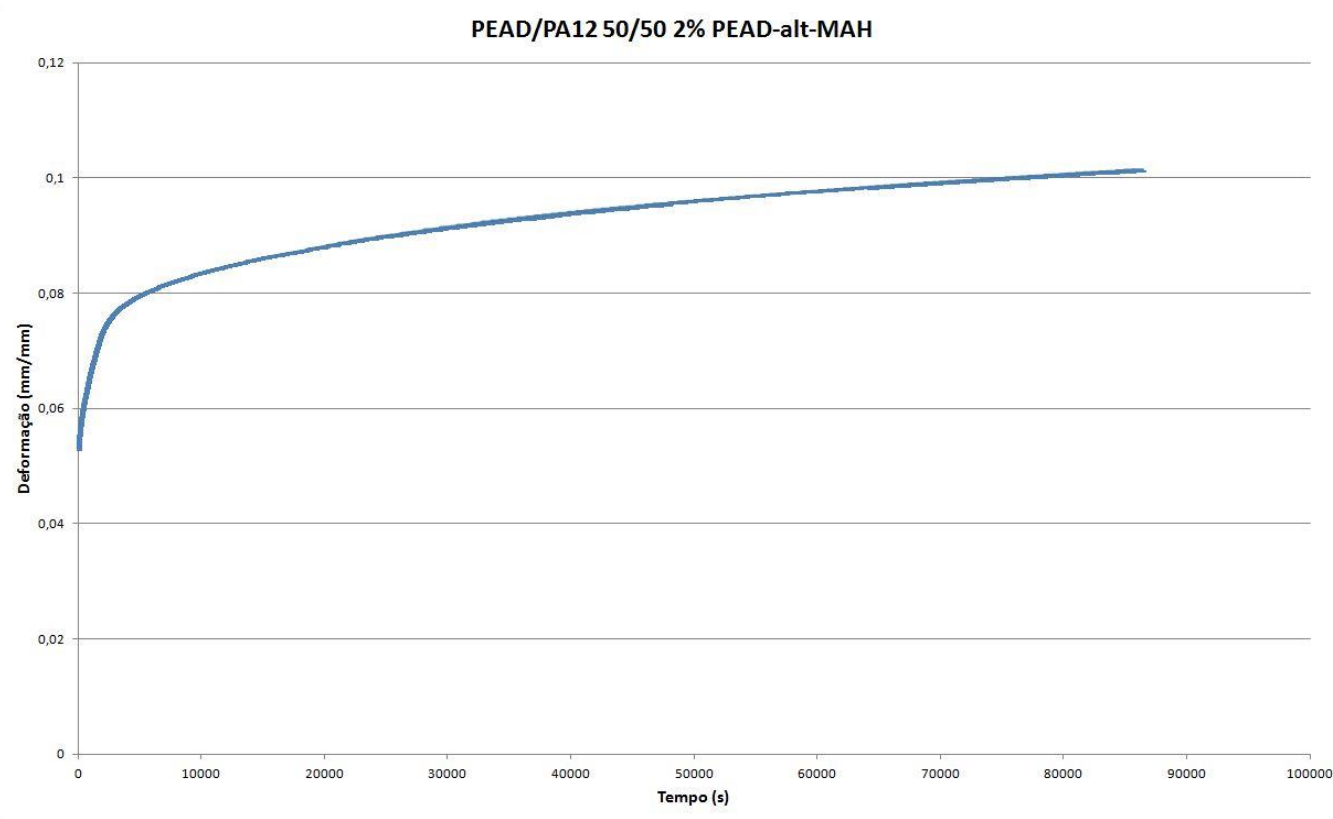

Figura 83. Exemplo da curva deformação vs. tempo (CP 01, PEAD/PA12 50/50).

A partir da realização da modelagem, foi observado que, para a maioria dos corpos de prova, o modelo viscoelástico que mais se aproximou do comportamento experimental da blenda 50/50 foi o modelo de Stretched Burgers, com somente um corpo de prova melhor correlacionado para o modelo de 4 parâmetros. A Tabela 29 mostra os valores das médias e dos desvios padrões dos parâmetros de cada modelo. 
Tabela 29. Comparação dos parâmetros dos modelos viscoelásticos para a blenda 50/50.

\begin{tabular}{|c|c|c|c|c|c|c|}
\hline \multirow[b]{3}{*}{ E0 (Pa) } & \multicolumn{2}{|c|}{ Modelo de 3 Parâmetros } & \multicolumn{2}{|c|}{$\begin{array}{l}\text { Modelo de } 4 \\
\text { Parâmetros }\end{array}$} & \multicolumn{2}{|c|}{$\begin{array}{c}\text { Modelo de Stretched } \\
\text { Burgers }\end{array}$} \\
\hline & Média & $\begin{array}{l}\text { Desvio } \\
\text { Padrão }\end{array}$ & Média & $\begin{array}{l}\text { Desvio } \\
\text { Padrão }\end{array}$ & Média & $\begin{array}{l}\text { Desvio } \\
\text { Padrão }\end{array}$ \\
\hline & $2,46 \mathrm{E}+08$ & $1,28 \mathrm{E}+07$ & $2,74 \mathrm{E}+08$ & $1,75 \mathrm{E}+07$ & $4,79 \mathrm{E}+14$ & $4,42 \mathrm{E}+13$ \\
\hline E1 (Pa) & $4,61 \mathrm{E}+08$ & $1,06 \mathrm{E}+08$ & $5,98 \mathrm{E}+08$ & $1,14 \mathrm{E}+08$ & $3,52 \mathrm{E}+07$ & $1,08 \mathrm{E}+07$ \\
\hline N1 (Pa.s) & $1,04 \mathrm{E}+13$ & $3,25 \mathrm{E}+12$ & $8,19 \mathrm{E}+13$ & $9,20 \mathrm{E}+12$ & $3,23 \mathrm{E}+17$ & $2,00 \mathrm{E}+17$ \\
\hline N2 (Pa.s) & - & - & $4,38 \mathrm{E}+12$ & $8,62 \mathrm{E}+11$ & - & - \\
\hline $\mathbf{n}$ & - & - & - & - & 0,123 & 0,0148 \\
\hline $\mathbf{R}^{2}$ & \multicolumn{2}{|c|}{0,9717} & \multicolumn{2}{|c|}{0,9926} & \multicolumn{2}{|c|}{0,9965} \\
\hline
\end{tabular}

Um gráfico comparando o comportamento dos modelos descritos acima está apresentado na Figura 84.

CP01 - 24h

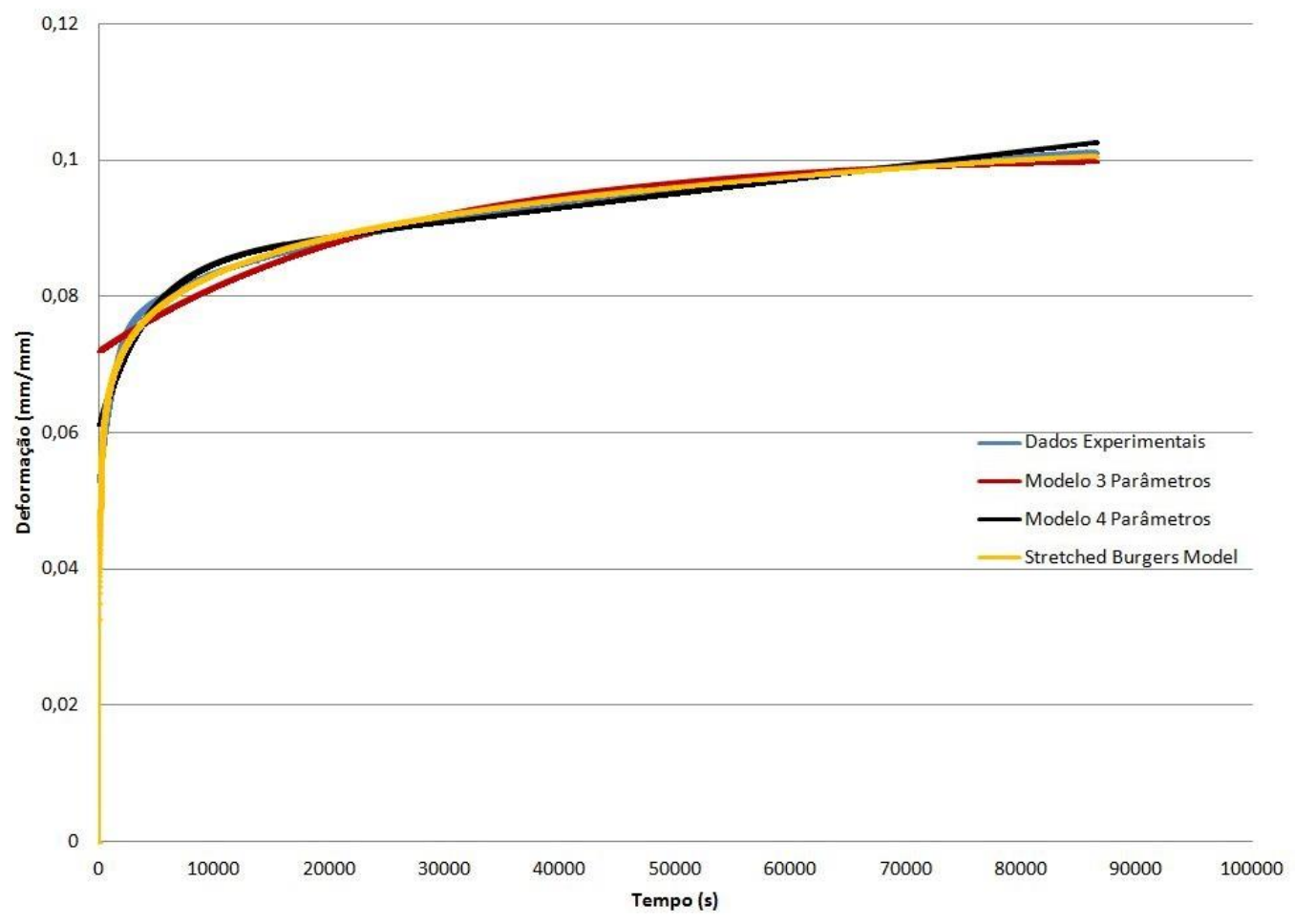

Figura 84. Comparação dos modelos viscoelásticos para o $\mathrm{CP} 01$ do PEAD/PA12 50/50.

As deformações instantâneas $(t=0)$ e as taxas de fluência nos seguintes intervalos: $2 h-4 h, 4 h-8 h, 8 h-12 h, 12 h-16 h, 16 h-20 h$ e $20 h-24 h$ estão representadas na Tabela 30 . 
Tabela 30. Valores de deformação instantânea e taxa de fluência para a blenda PEAD/PA12 50/50.

\begin{tabular}{rcc}
\hline & Média & Desvio Padrão \\
\hline Taxa de fluência $\left(\mathbf{s}^{-1}\right)$ & 0,0035 \\
$\mathbf{2 h}-\mathbf{4 h}$ & $1,00 \mathrm{E}-06$ & $3,160 \mathrm{E}-07$ \\
$\mathbf{4 h}-\mathbf{8 h}$ & $5,26 \mathrm{E}-07$ & $1,266 \mathrm{E}-07$ \\
$\mathbf{8 h}-\mathbf{1 2 h}$ & $3,17 \mathrm{E}-07$ & $5,961 \mathrm{E}-08$ \\
$\mathbf{1 2 h}-\mathbf{1 6 h}$ & $2,27 \mathrm{E}-07$ & $3,973 \mathrm{E}-08$ \\
$\mathbf{1 6 h}-\mathbf{2 0 h}$ & $1,80 \mathrm{E}-07$ & $3,436 \mathrm{E}-08$ \\
$\mathbf{2 0 h}-\mathbf{2 4 h}$ & $1,51 \mathrm{E}-07$ & $2,704 \mathrm{E}-08$ \\
\hline
\end{tabular}

\subsubsection{PEAD/PA12 25/75}

Para este material, foram utilizados cinco corpos de prova e o ensaio foi realizado a uma carga constante de $190 \mathrm{~N}$, correspondente a $50 \%$ do limite de escoamento da blenda $25 / 75(\approx 18,5 \mathrm{MPa})$ e à temperatura ambiente.

A Figura 85 mostra o gráfico deformação vs. tempo que retrata o comportamento à fluência da blenda PEAD/PA12 25/75.

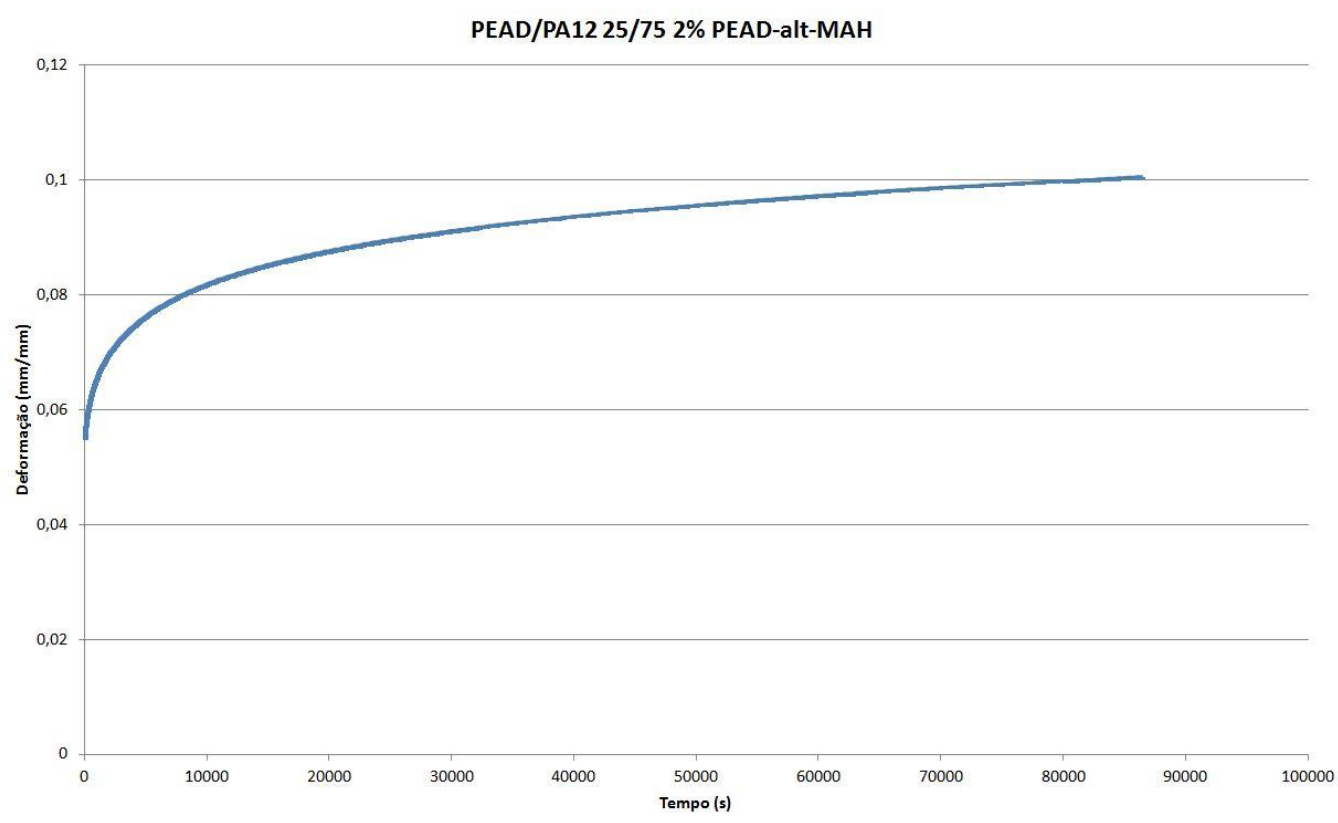

Figura 85. Exemplo da curva deformação vs. tempo (CP 04, PEAD/PA12 25/75). 
A partir da realização da modelagem, foi observado para todos os corpos de prova o modelo viscoelástico que mais se aproximou do comportamento experimental da blenda 25/75 foi o modelo de Stretched Burgers. A Tabela 31 mostra os valores das médias e dos desvios padrões dos parâmetros de cada modelo.

Tabela 31. Comparação dos parâmetros dos modelos viscoelásticos para a blenda $25 / 75$.

\begin{tabular}{ccccccc}
\hline & \multicolumn{2}{c}{$\begin{array}{c}\text { Modelo de 3 } \\
\text { Parâmetros }\end{array}$} & \multicolumn{2}{c}{$\begin{array}{c}\text { Modelo de 4 } \\
\text { Parâmetros }\end{array}$} & \multicolumn{2}{c}{$\begin{array}{c}\text { Modelo de Stretched } \\
\text { Burgers }\end{array}$} \\
\cline { 2 - 7 } & Média & $\begin{array}{c}\text { Desvio } \\
\text { Padrão }\end{array}$ & Média & $\begin{array}{c}\text { Desvio } \\
\text { Padrão }\end{array}$ & Média & $\begin{array}{c}\text { Desvio } \\
\text { Padrão }\end{array}$ \\
E0 (Pa) & $2,48 \mathrm{E}+08$ & $3,01 \mathrm{E}+07$ & $2,70 \mathrm{E}+08$ & $2,96 \mathrm{E}+07$ & $1,53 \mathrm{E}+14$ & $2,09 \mathrm{E}+14$ \\
E1 (Pa) & $5,29 \mathrm{E}+08$ & $5,95 \mathrm{E}+07$ & $6,72 \mathrm{E}+08$ & $8,51 \mathrm{E}+07$ & $1,30 \mathrm{E}+08$ & $9,99 \mathrm{E}+07$ \\
N1 (Pa.s) & $1,07 \mathrm{E}+13$ & $1,38 \mathrm{E}+12$ & $1,02 \mathrm{E}+14$ & $1,87 \mathrm{E}+13$ & $2,47 \mathrm{E}+16$ & $4,37 \mathrm{E}+16$ \\
N2 (Pa.s) & - & - & $5,07 \mathrm{E}+12$ & $1,03 \mathrm{E}+12$ & - & - \\
$\mathbf{n}$ & - & - & - & - & 0,2031 & 0,1155 \\
\hline
\end{tabular}

Um gráfico comparando o comportamento dos modelos descritos acima está apresentado na Figura 86.

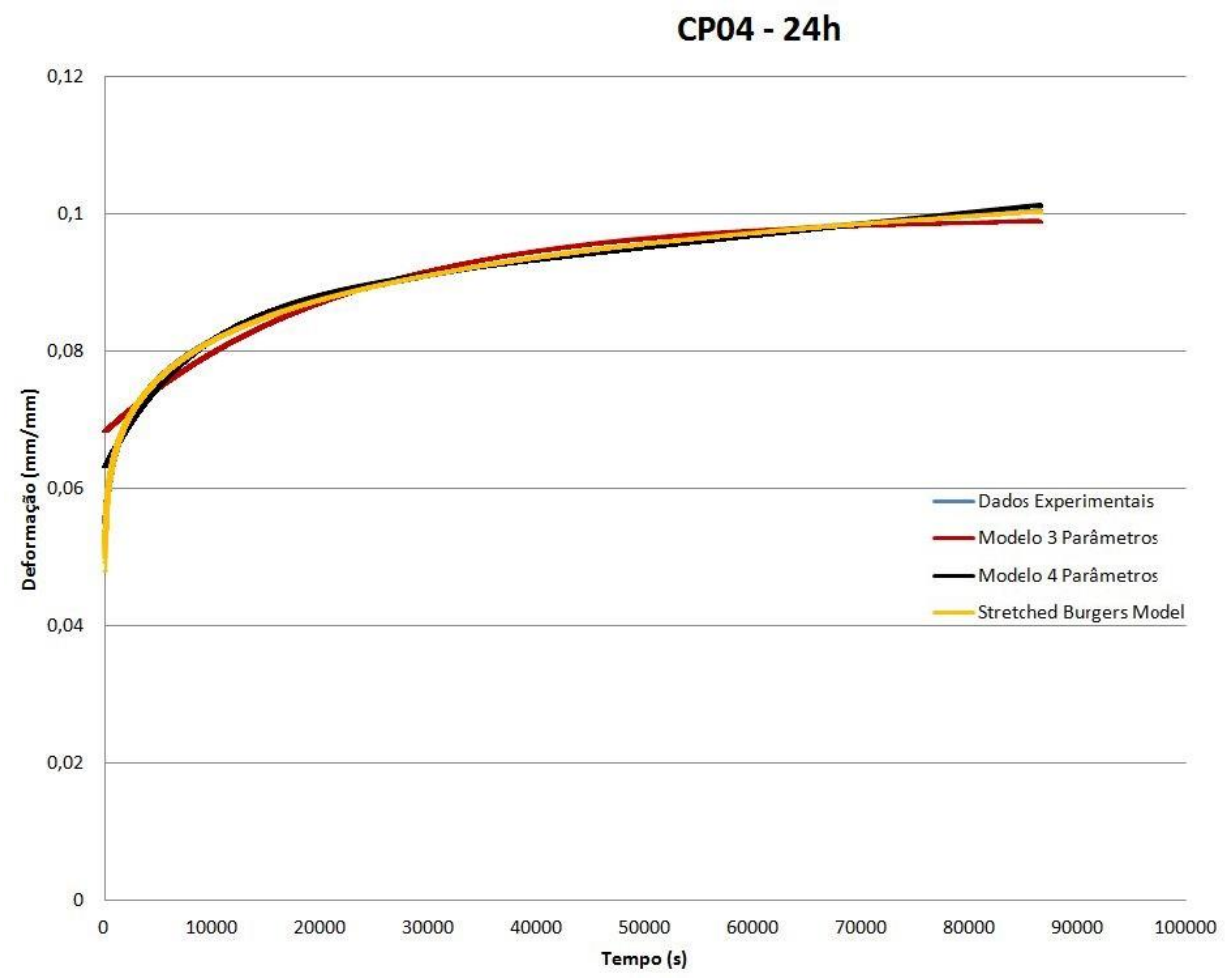

Figura 86. Comparação dos modelos viscoelásticos para o CP 04 do PEAD/PA12 25/75. 
As deformações instantâneas $(t=0)$ e as taxas de fluência nos seguintes intervalos: $2 h-4 h, 4 h-8 h, 8 h-12 h, 12 h-16 h, 16 h-20 h$ e $20 h-24 h$ estão representadas na Tabela 32.

Tabela 32. Valores de deformação instantânea e taxa de fluência para a blenda PEAD/PA12 25/75.

\begin{tabular}{rcc}
\hline & Média & Desvio Padrão \\
\hline Deformação instantânea $(\mathbf{m m} / \mathbf{m m})$ & 0,06055 & 0,0080 \\
$\mathbf{2 h}-\mathbf{4 h}$ & $9,29 \mathrm{E}-07$ & $1,232 \mathrm{E}-07$ \\
$\mathbf{4 h}-\mathbf{8 h}$ & $4,70 \mathrm{E}-07$ & $4,875 \mathrm{E}-08$ \\
$\mathbf{8 h}-\mathbf{1 2 h}$ & $2,71 \mathrm{E}-07$ & $4,319 \mathrm{E}-08$ \\
$\mathbf{1 2 h}-\mathbf{1 6 h}$ & $1,96 \mathrm{E}-07$ & $3,356 \mathrm{E}-08$ \\
$\mathbf{1 6 h}-\mathbf{2 0 h}$ & $1,55 \mathrm{E}-07$ & $2,726 \mathrm{E}-08$ \\
$\mathbf{2 0 h}-\mathbf{2 4 h}$ & $1,39 \mathrm{E}-07$ & $4,024 \mathrm{E}-08$ \\
\hline
\end{tabular}

\subsubsection{Comparação}

A Tabela 33 mostra a comparação da média dos coeficientes de correlação dos três modelos para cada tipo de material, indicando os modelos que melhor se adequaram aos comportamentos experimentais dos materiais; o que mostra a variação causada no comportamento do material pelas composições das blendas.

Tabela 33. Coeficientes de correlação dos modelos viscoelásticos das blendas e dos homopolímeros. Os valores em negrito indicam o modelo que melhor descreveu o comportamento experimental.

\begin{tabular}{cccc}
\hline & $\begin{array}{c}\text { Modelo de 3 } \\
\text { Parâmetros }\end{array}$ & $\begin{array}{c}\text { Modelo de 4 } \\
\text { Parâmetros }\end{array}$ & $\begin{array}{c}\text { Modelo de Stretched } \\
\text { Burgers }\end{array}$ \\
\hline PEAD & 0,9749 & 0,9947 & $\mathbf{0 , 9 9 9 1}$ \\
PA12 & 0,9729 & $\mathbf{0 , 9 9 4 5}$ & 0,9913 \\
PEAD/PA12 75/25 & 0,9819 & $\mathbf{0 , 9 9 6 6}$ & 0,9932 \\
PEAD/PA12 50/50 & 0,9717 & 0,9927 & $\mathbf{0 , 9 9 6 6}$ \\
\hline
\end{tabular}

A Tabela 34 mostra a taxa de fluência estacionária $(20 \mathrm{~h}-24 \mathrm{~h})$ dos polímeros e a Figura 87 mostra o Box plot do Creep compliance, que é a razão da 
deformação instantânea pela tensão aplicada no material, já que para cada material foi aplicada uma carga diferente.

Tabela 34. Comparação das taxas de fluência estacionárias.

\begin{tabular}{cc}
\hline & Taxa de fluência estacionária $\left(\mathbf{s}^{\mathbf{1}}\right)$ \\
\hline PEAD & $1,95 \mathrm{E}-07$ \\
PEAD/PA12 $75 / 25$ & $1,54 \mathrm{E}-07$ \\
PEAD/PA12 50/50 & $2,15 \mathrm{E}-07$ \\
PEAD/PA12 25/75 & $1,51 \mathrm{E}-07$ \\
\hline
\end{tabular}

Creep Compliance

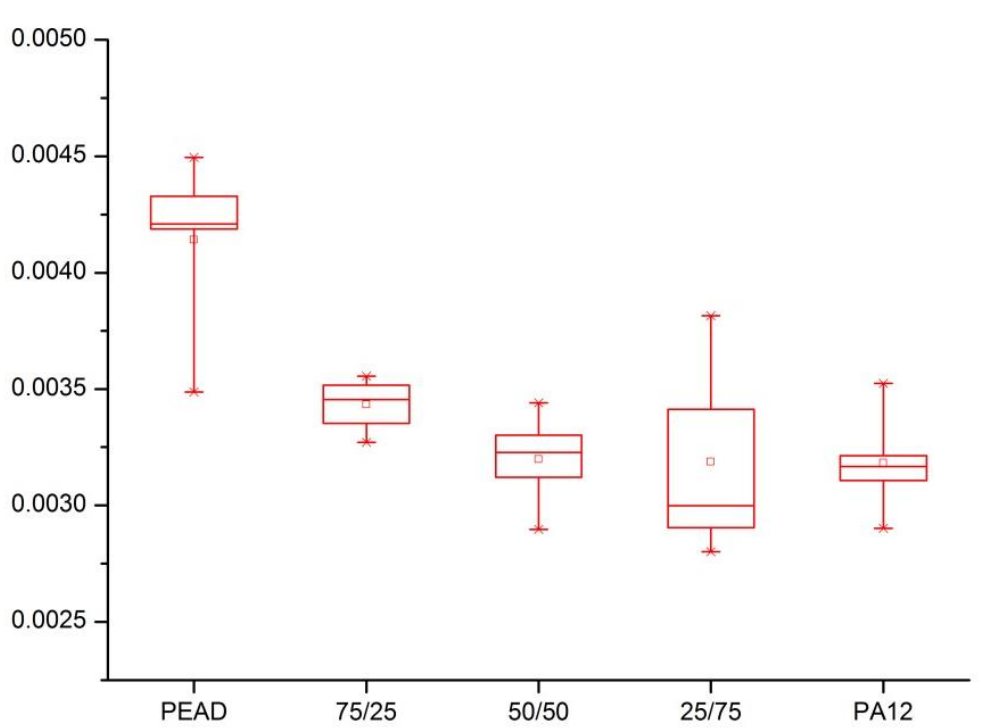

Figura 87. Box Plot - Creep Compliance.

Pela Tabela 34, nota-se que a blenda PEAD/PA12 25/75 obteve a menor taxa de fluência estacionária, enquanto a 75/25 obteve a maior, o que pode indicar que talvez a região terciária de fluência da blenda 75/25 aconteça em um intervalo de tempo menor que as demais blendas, ou seja, é provável que o escoamento e a ruptura da 75/25 estivessem mais perto de ocorrer próximo ao fim do ensaio do que para a 25/75.

Pela Figura 87, pode-se perceber que os valores do creep compliance dos materiais foram bem similares, indicando que na faixa de tensão usada (50\% do limite de escoamento), as respostas elásticas dos materiais foram razoavelmente próximas. Sendo assim, como o PEAD e a blenda 75/25 obtiveram valores levemente superiores aos demais materiais, conclui-se que o PEAD e a blenda 
75/25 têm módulos menores que os dos outros, o que é confirmado pelos dados comparativos de tração.

\subsection{Análise por Infravermelho (FTIR)}

\subsubsection{PEAD}

A Figura 88 ilustra o espectro IV do PEAD. Nele podem-se notar três picos característicos correspondentes aos três modos de vibração das ligações $\mathrm{C}-\mathrm{H}$, cujos valores de comprimento de onda se situam nas seguintes regiões: o modo stretching entre 3000 e $2840 \mathrm{~cm}^{-1}$, o modo pêndulo ou bending entre 1450 e 1375 $\mathrm{cm}^{-1}$ e no modo torção ou rocking entre 730 e $720 \mathrm{~cm}^{-1}[49,50]$.

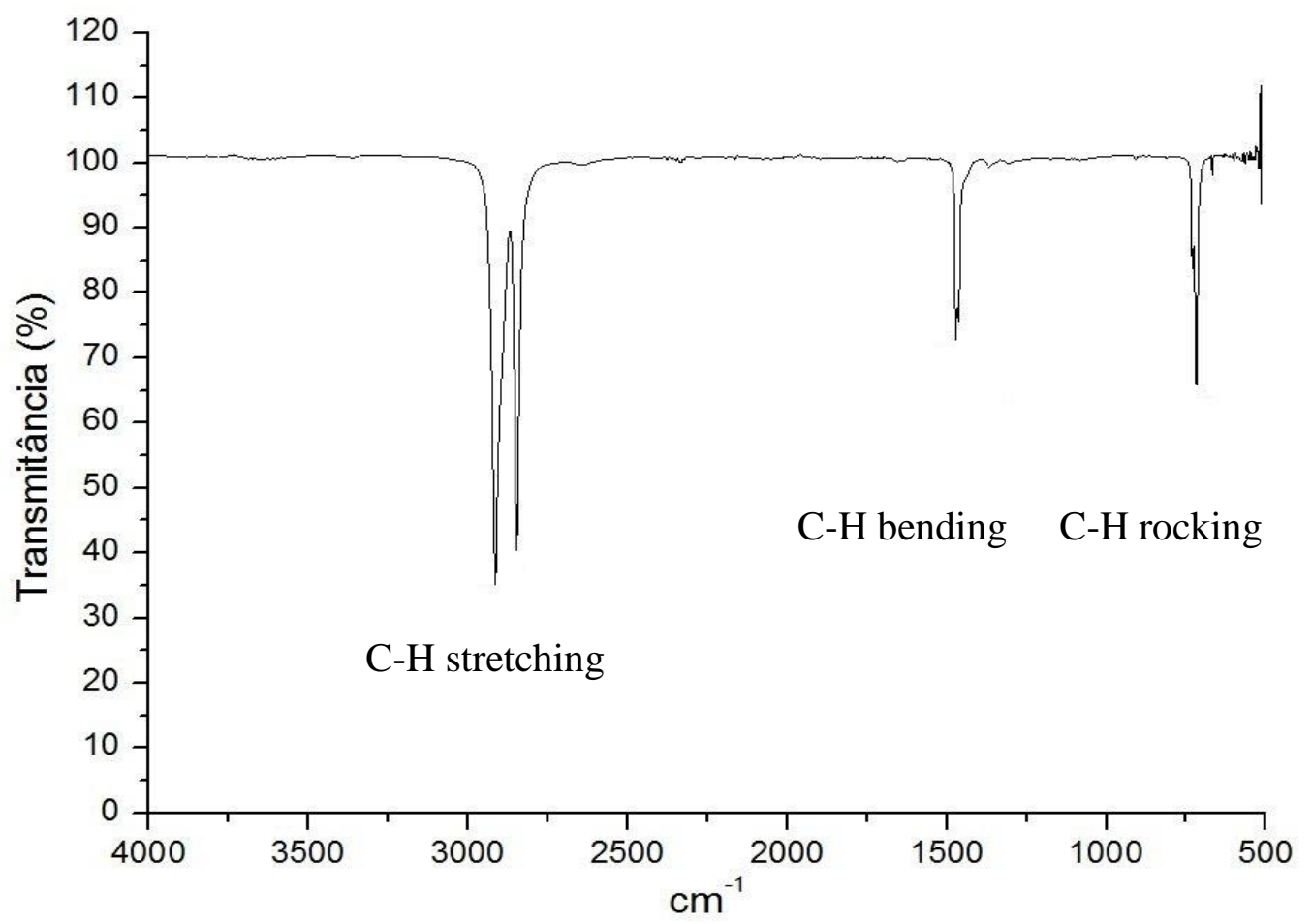

Figura 88. Espectro IV do PEAD.

\subsubsection{PA12}

A Figura 89 ilustra o espectro IV do PA12. Os picos de comprimentos de onda de 3291 e $3087 \mathrm{~cm}^{-1}$ representam a ligação N-H da amina primária alifática com modo de vibração stretching, os picos 2919 e $2851 \mathrm{~cm}^{-1}$ são os comprimentos de onda da ligação C-H com modo de vibração stretching similar aos picos da mesma faixa que aparecem no espectro do PEAD, o comprimento de onda 1744 $\mathrm{cm}^{-1}$ é característico da ligação $\mathrm{C}=\mathrm{O}$ stretching, o de $1637 \mathrm{~cm}^{-1}$ representa a 
ligação N-H bending e o pico $1546 \mathrm{~cm}^{-1}$ representa o radical $\mathrm{NH}_{2}$ com modo de vibração scissoring ou bending. Observa-se também absorbâncias nos comprimentos de onda de 1466 e $1371 \mathrm{~cm}^{-1}$, que são representativos da ligação CH com modo de vibração bending [25,49,50,51].

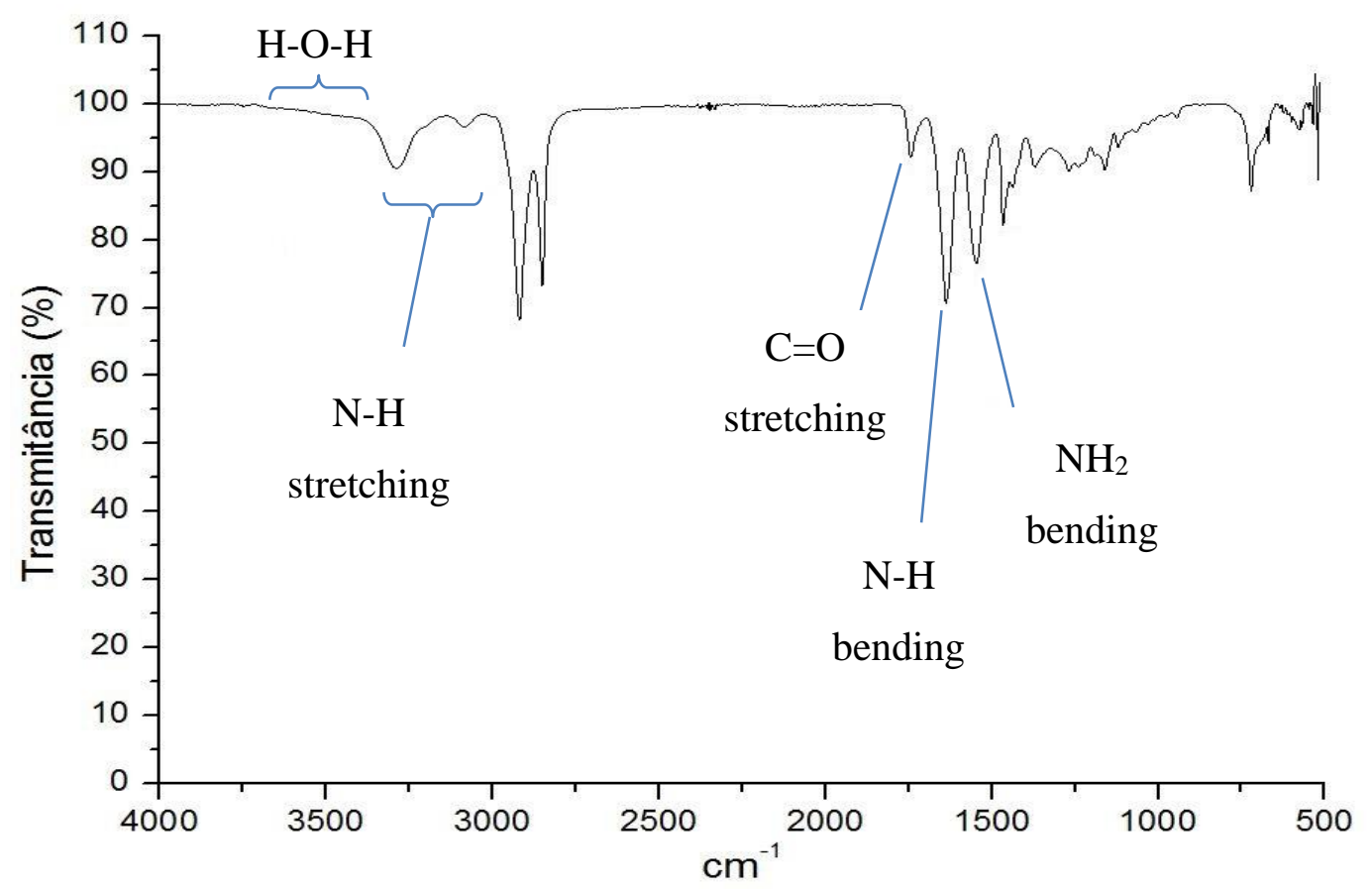

Figura 89. Espectro IV da PA12.

Além desses picos citados acima, tem também a presença de uma banda de transmitância bem fraca por volta de $3500 \mathrm{~cm}^{-1}$, que é característico da ligação O$\mathrm{H}$, ou seja, provavelmente a amostra de PA12 absorveu umidade, o que pode ser justificado pela alta higroscopia da poliamida [50].

\subsubsection{PEAD-alt-MAH}

Na Figura 90, é possível ver a ilustração do espectro IV do agente compatibilizante PEAD-alt-MAH. Logo nota-se que a banda da faixa 3400 - 3500 $\mathrm{cm}^{-1}$ se faz presente, ou seja, assim como a PA12, o compatibilizante também deve ter absorvido umidade do meio ambiente. A absorção de comprimento de onda de $2935 \mathrm{~cm}^{-1}$ equivale à energia da ligação C-H stretching, as de 1847, 1775 e $1701 \mathrm{~cm}^{-1}$ são características da ligação $\mathrm{C}=\mathrm{O}$ stretching, presente no compatibilizante, e a de $1456 \mathrm{~cm}^{-1}$ equivale à ligação C-H bending. Além desses, observa-se a presença de mais dois picos: os picos de 1216 e $919 \mathrm{~cm}^{-1}$, que 
representam as energias da ligação C-O stretching, presente na cadeia do anidrido maleico ilustrada na Figura 47 no item $4.1[50,52]$.

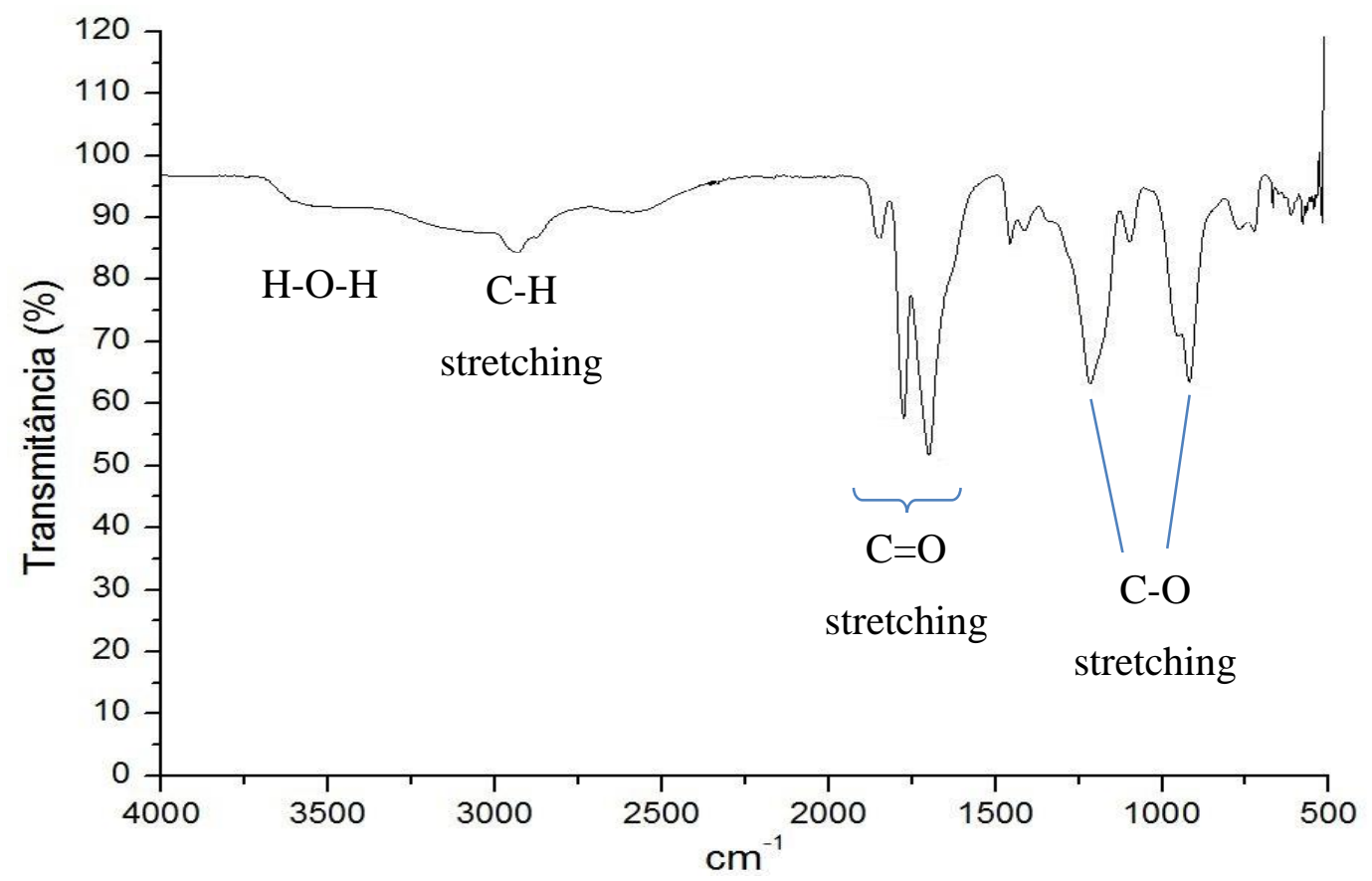

Figura 90. Espectro IV do agente compatibilizante PEAD-alt-MAH.

\subsubsection{PEAD/PA12 75/25}

Para esta composição de blendas, foram fabricados corpos de prova sem compatibilizante e com teores de $2 \%$ e $3 \%$ do mesmo. Alguns corpos de prova 75/25 sem compatibilizante foram fabricados com 5 minutos de residência e alguns com 3 minutos, com a finalidade de definir um tempo de residência padrão para as demais misturas e avaliar se a variação do tempo causava degradação em algum dos homopolímeros utilizados. Já os com compatibilizante foram fabricados usando 3 minutos de residência na extrusora.

Estando definidos os grupamentos químicos relacionados aos picos dos espectros do PEAD, PA12 e do PEAD-alt-MAH, é possível analisar as variações que ocorreram com a mistura destes materiais. As Figuras 91 e 92 ilustram os espectros IV das blendas PEAD/PA12/PEAD-alt-MAH 75/25/2 nos intervalos de comprimentos de onda de $4000-2500$ e $2000-1000 \mathrm{~cm}^{-1}$, respectivamente. 


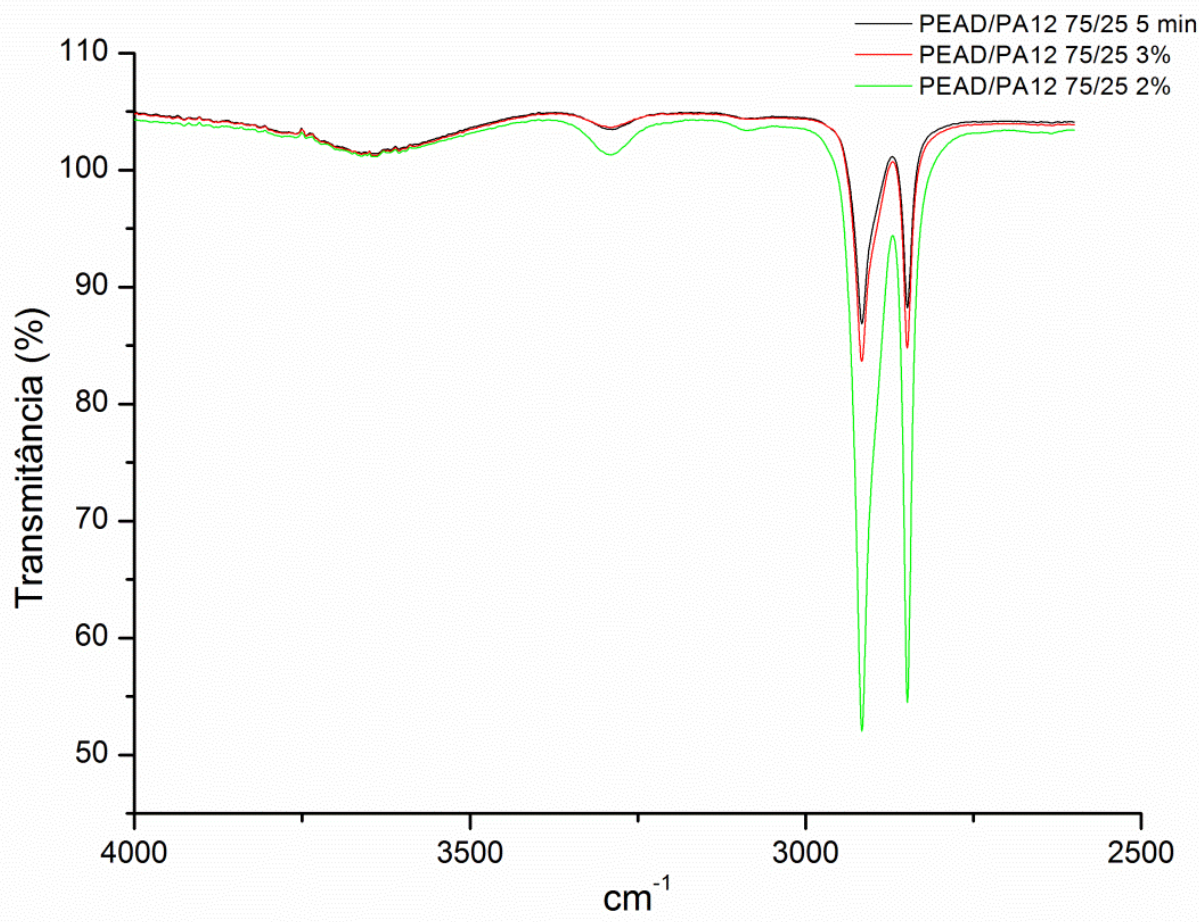

Figura 91. Espectro IV comparativo das blendas 75/25 no intervalo entre $4000-2500 \mathrm{~cm}^{-1}$.

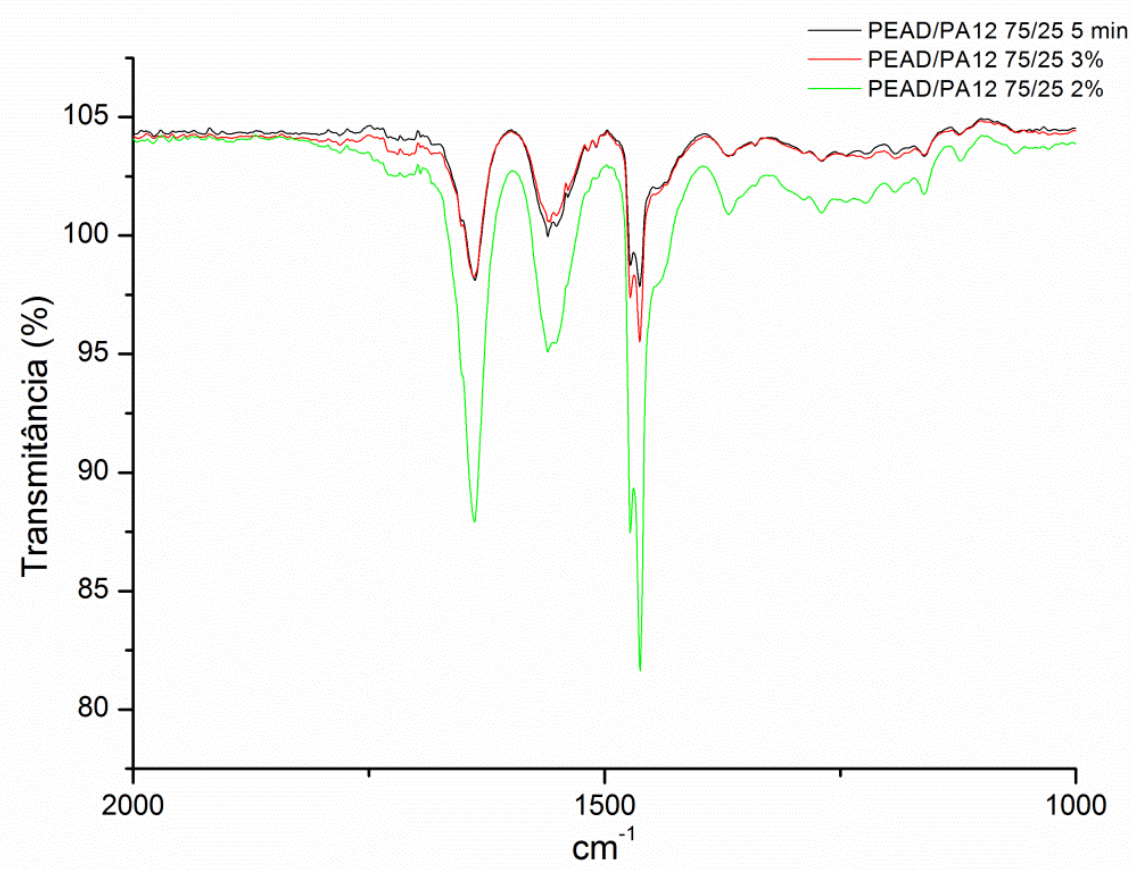

Figura 92. Espectro IV comparativo das blendas 75/25 no intervalo entre $2000-1000 \mathrm{~cm}^{-1}$.

Como pode ser visto, o espectro da blenda com 5 minutos de residência e o de 3 minutos praticamente se sobrepuseram e, além disso, não houve nenhum pico 
característico de degradação no de 5 minutos (como por exemplo um grande aumento no pico da ligação $\mathrm{C}=\mathrm{O}$ ), o que indica que o aumento do tempo de residência não causou degradação nem no PEAD nem no PA12. Apesar disso, todas as blendas ensaiadas neste trabalho foram processadas com 3 minutos de residência. Outro ponto que merece destaque é a banda na faixa de 3500 - 3800 $\mathrm{cm}^{-1}$ presente em todas as três blendas, o que indica que houve absorção de umidade, já que essa faixa é característica da ligação O-H. Essa absorção pode ter se dado durante o processamento do material na extrusora e/ou a exposição à umidade do ambiente.

Analisando os picos do espectro, percebe-se que a blenda sem compatibilizante se sobrepôs à com $3 \%$; e a blenda com $2 \%$ de compatibilizante apresentou os mesmos picos da com 3\%, porém com maior intensidade, o que indica uma maior presença dos grupamentos químicos característicos de cada pico. Tanto que alguns picos presentes somente no PEAD-alt-MAH, como os de 1216 e $919 \mathrm{~cm}^{-1}$, estão presentes no espectro da blenda com intensidades muito reduzidas, decorrente do baixo percentual desse componente, e também, da reação de compatibilização da blenda. Essa reação está representada na Figura 93, onde mostra a reação entre um anidrido e uma amida formando uma imida e um ácido carboxílico.

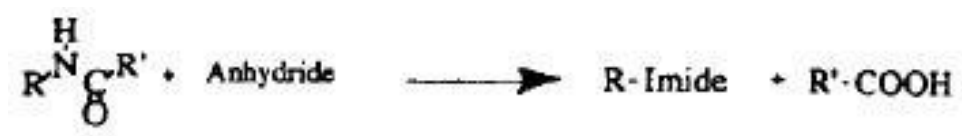

Figura 93. Reação entre uma amida e um anidrido [53].

Nesse mecanismo, a molécula de anidrido quebra o grupamento amida da poliamida e gera uma cadeia carboxílica como subproduto. Essa reação gera, além da ruptura da amida, uma condensação que irá consumir o grupamento carboxila, recuperando o equilíbrio da poliamida, já que o mesmo é afetado após a reação [53].

Como essa reação da Figura 93 não ilustra como seria a formação da imida, a Figura 94 mostra com mais detalhe a imida formada a partir desta reação. 


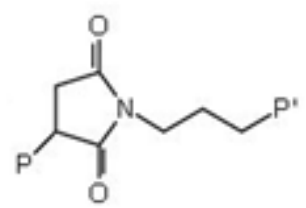

Figura 94. Representação da imida formada na reação de compatibilização [54].

Percebe-se que há a quebra de ligações C-O diminuindo a intensidade deste pico. Através destas reações, conclui-se que o radical anidrido maleico do compatibilizante tem afinidade com a poliamida e o radical PEAD tem afinidade com o polietileno [54]. Além disso, as bandas dos picos da blenda $2 \%$ são mais largas que as mesmas bandas das com 0 e $3 \%$.

\subsubsection{PEAD/PA12 50/50}

As Figuras 95 e 96 mostram os comparativos dos espectros IV das blendas 50/50 com 2 e 3\% de PEAD-alt-MAH nos intervalos de comprimento de onda de $4000-2500$ e $2000-1000 \mathrm{~cm}^{-1}$, respectivamente.

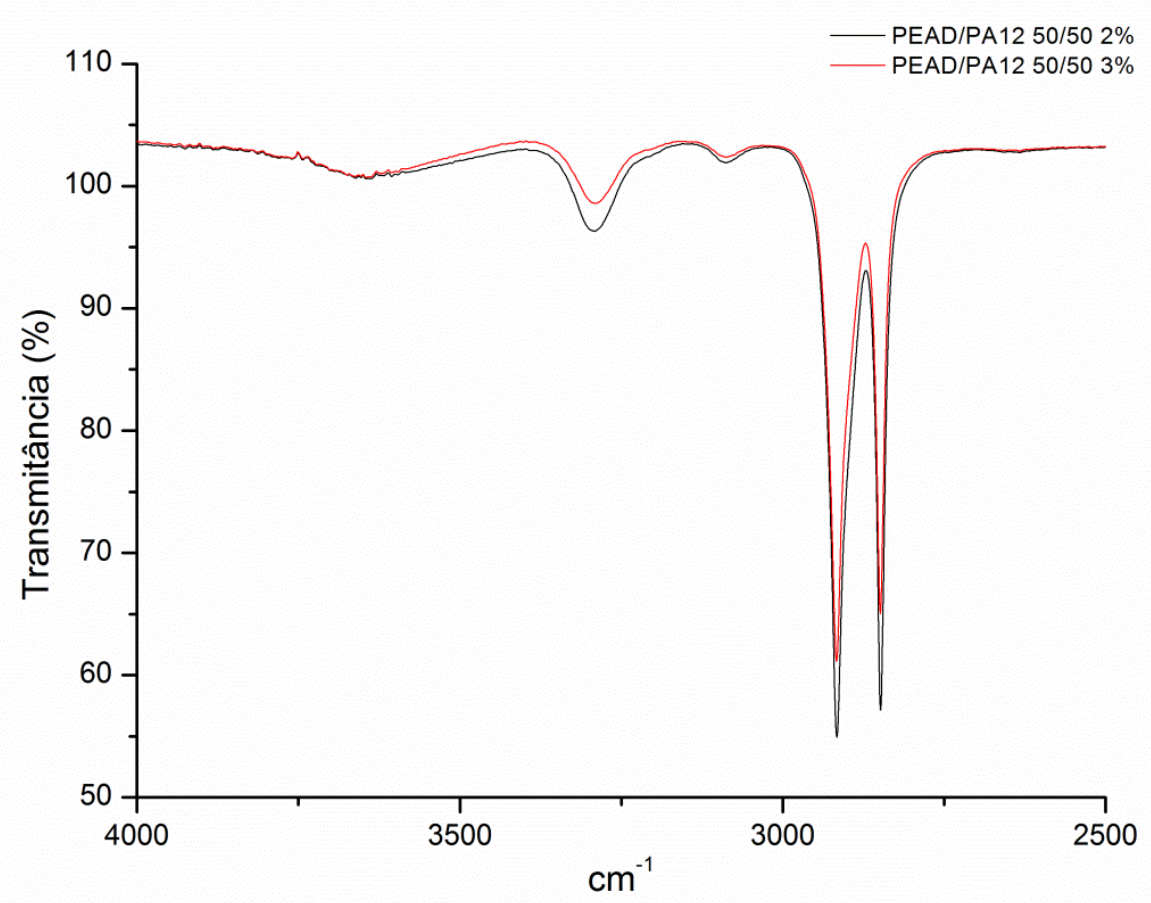

Figura 95. Espectro IV das blendas 50/50 no intervalo entre $4000-2500 \mathrm{~cm}^{-1}$. 


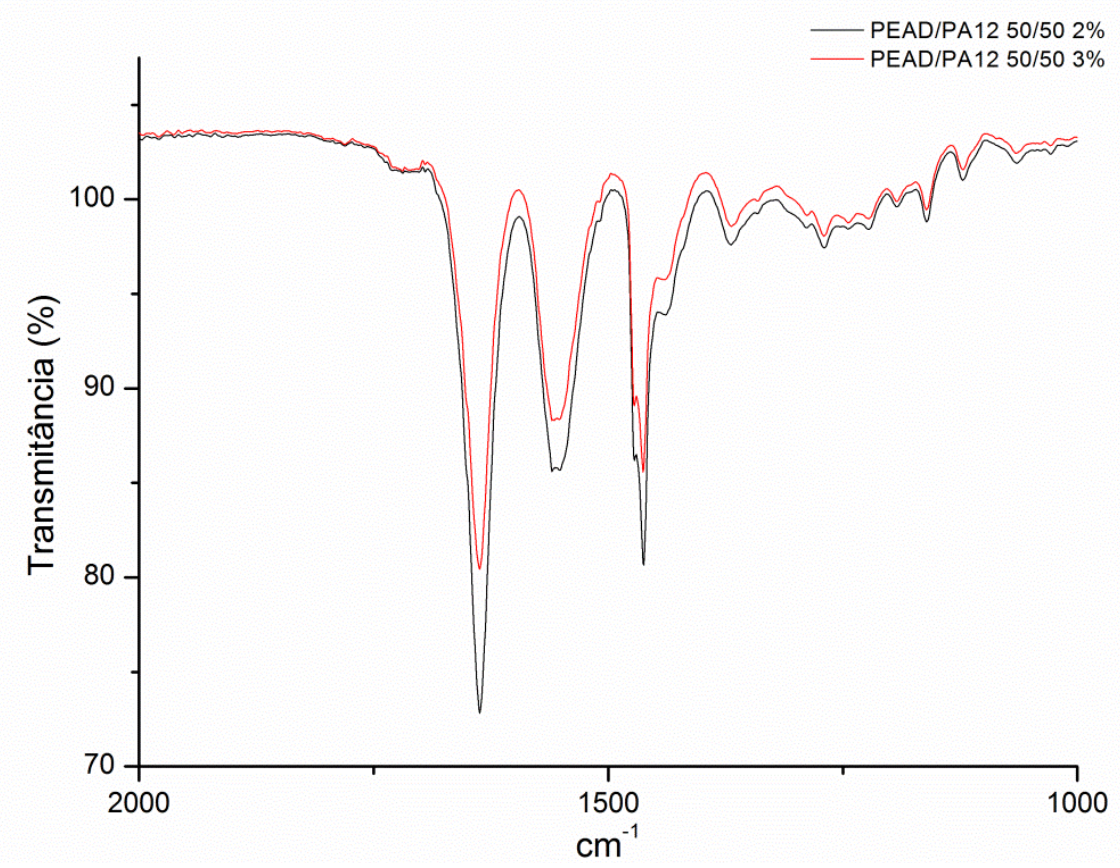

Figura 96. Espectro IV das blendas 50/50 no intervalo entre

$$
2000-1000 \mathrm{~cm}^{-1} \text {. }
$$

A análise para esta blenda é idêntica à da blenda 75/25. Os comprimentos de ondas dos picos são os mesmos do $75 / 25$, e os picos da blenda com $2 \%$ também têm intensidade e largura maiores que os da blenda com 3\%. Também se observa a presença de picos na área de absorção da ligação $\mathrm{O}-\mathrm{H}$, indicando a presença de umidade no material.

\subsubsection{PEAD/PA12 25/75}

As Figuras 97 e 98 mostram os comparativos dos espectros IV das blendas 25/75 com 2 e 3\% de PEAD-alt-MAH nos intervalos de comprimentos de onda de $4000-2500$ e $2000-1000 \mathrm{~cm}^{-1}$, respectivamente. 


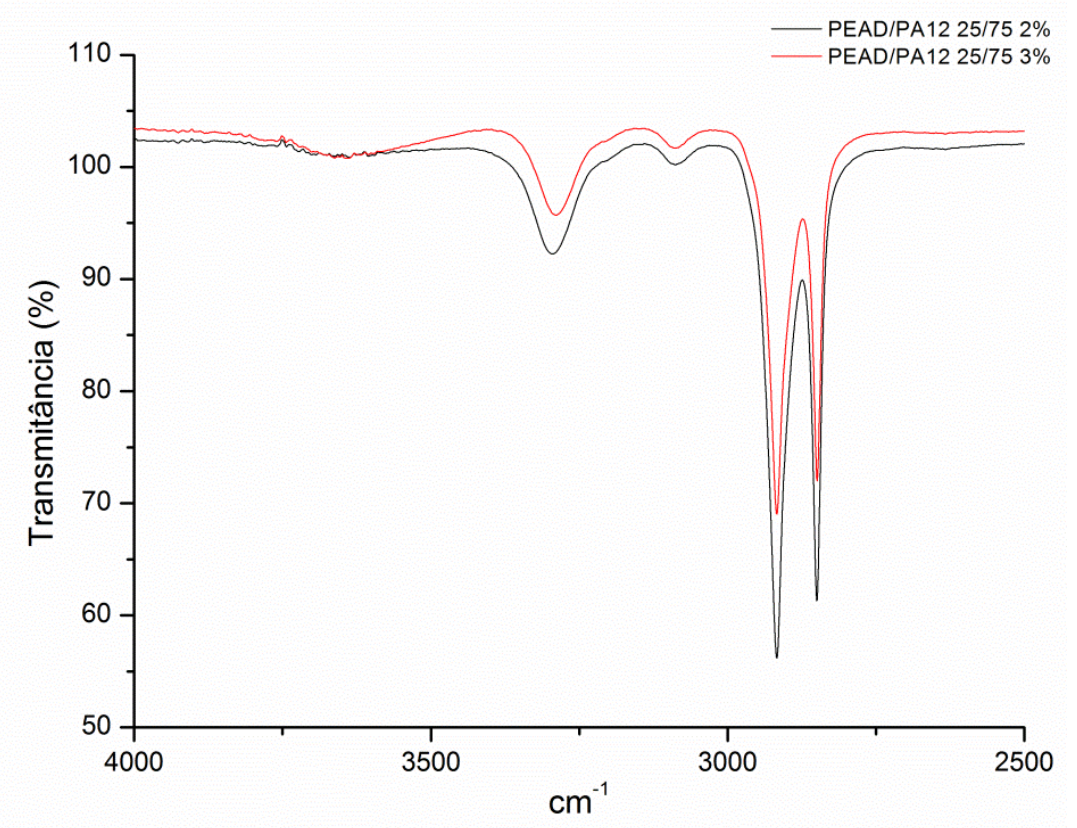

Figura 97. Espectro IV das blendas 25/75 no intervalo entre

$$
4000-2500 \mathrm{~cm}^{-1} \text {. }
$$

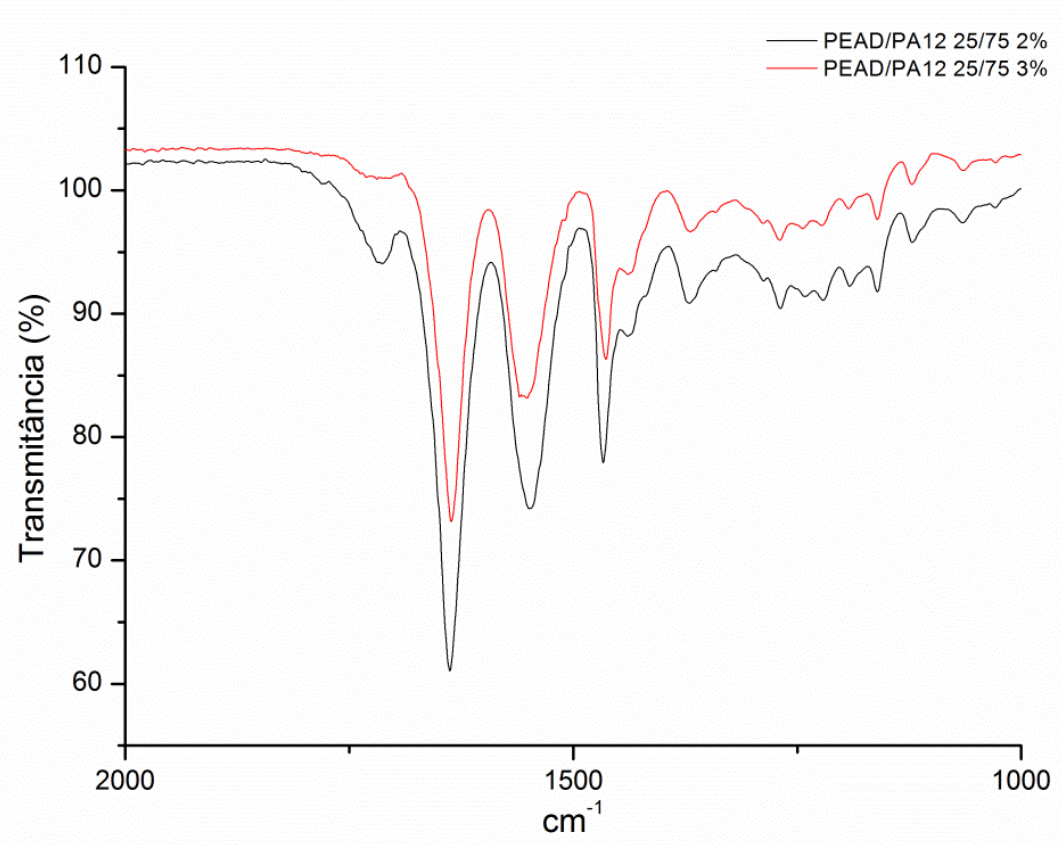

Figura 98. Espectro IV das blendas 25/75 no intervalo entre

$$
2000-1000 \mathrm{~cm}^{-1} \text {. }
$$

Para esta composição, a análise não é diferente das outras duas: os picos da blenda com $2 \%$ continuam sendo mais intensos, traduzindo maior quantidade dos grupamentos químicos característicos de cada pico. Nesta blenda, também houve a absorção de umidade. 


\subsubsection{Comparação}

Como todos os ensaios (mecânicos, químicos e térmicos) foram feitos com blendas $2 \%$, é conveniente comparar o espectro das blendas 75/25, 50/50 e 25/75 com 2\% de compatibilizante. As Figuras 99 e 100 mostram as comparações entre as três composições em dois intervalos de comprimentos de onda.

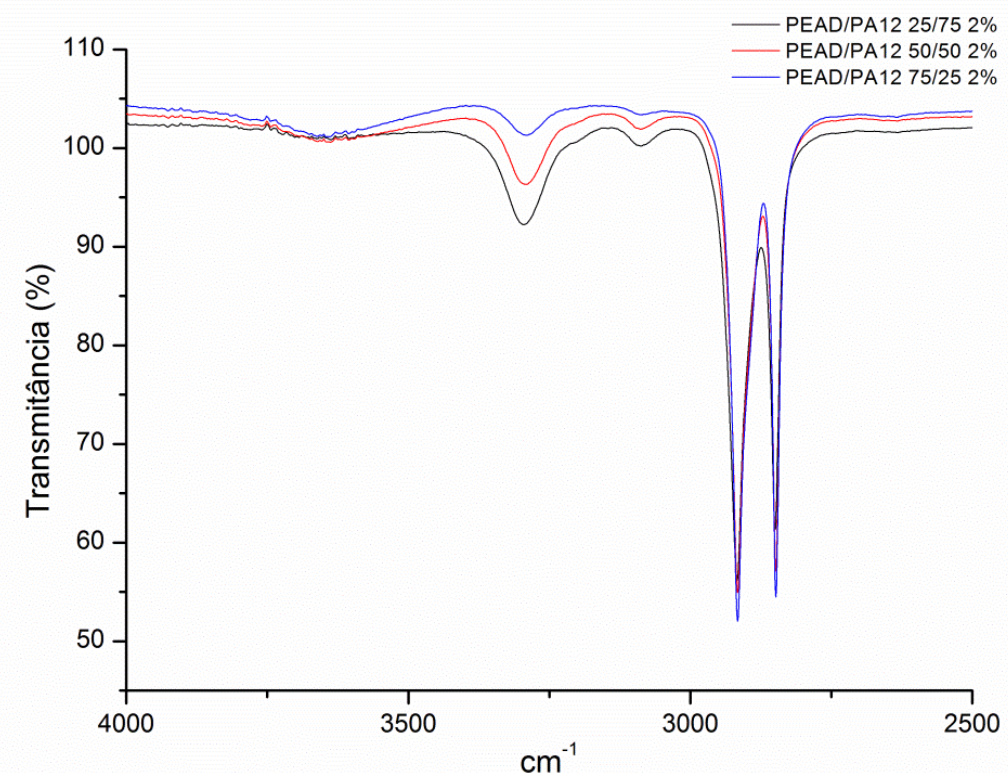

Figura 99. Comparativo dos espectros IV das blendas $2 \%$ no intervalo de comprimentos de onda de $4000-2500 \mathrm{~cm}^{-1}$.

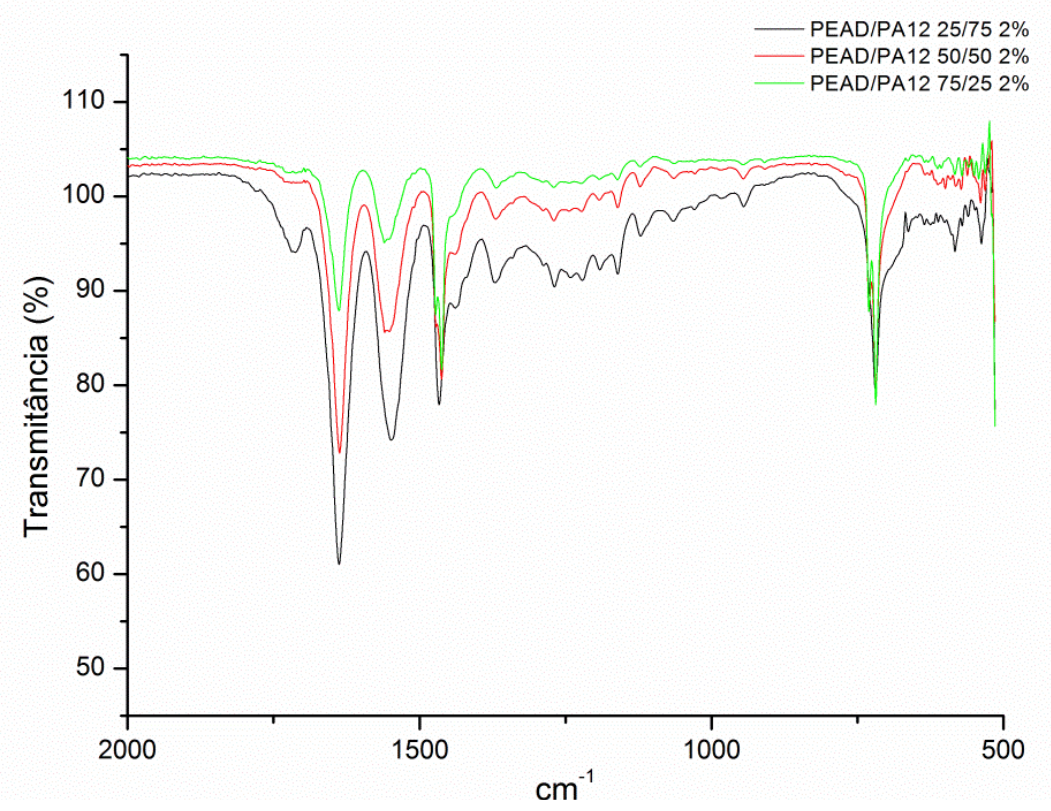

Figura 100. Comparativo dos espectros IV das blendas $2 \%$ no intervalo de comprimentos de onda de $2000-500 \mathrm{~cm}^{-1}$. 
Pode-se perceber que os picos referentes às ligações $\mathrm{N}-\mathrm{H}$ e $\mathrm{NH}_{2}(3291$, 3087, 1637 e $\left.1546 \mathrm{~cm}^{-1}\right)$ e às ligações $\mathrm{C}=\mathrm{O}\left(1744 \mathrm{~cm}^{-1}\right)$ tiveram maiores intensidades com o aumento da porcentagem de PA12 (25/75 > 50/50 > 75/25), decorrente da maior presença dessas ligações. Do outro lado, os picos referentes às ligações $\mathrm{C}-\mathrm{H}\left(3000\right.$ - 2840 e $\left.730-720 \mathrm{~cm}^{-1}\right)$ tiveram maiores intensidades de pico com o aumento da porcentagem de PEAD no material.

\subsection{Difração de Raios-X (DRX)}

\subsubsection{PEAD}

A Figura 101 mostra o difratograma do PEAD com os índices dos principais planos cristalinos destacados. Cada pico representa um plano cristalino e todos estes picos foram considerados no cálculo do grau de cristalinidade, porém no gráfico da Figura 101, apenas os principais estão listados. Este gráfico foi plotado com auxílio do software OriginPro 8.5.

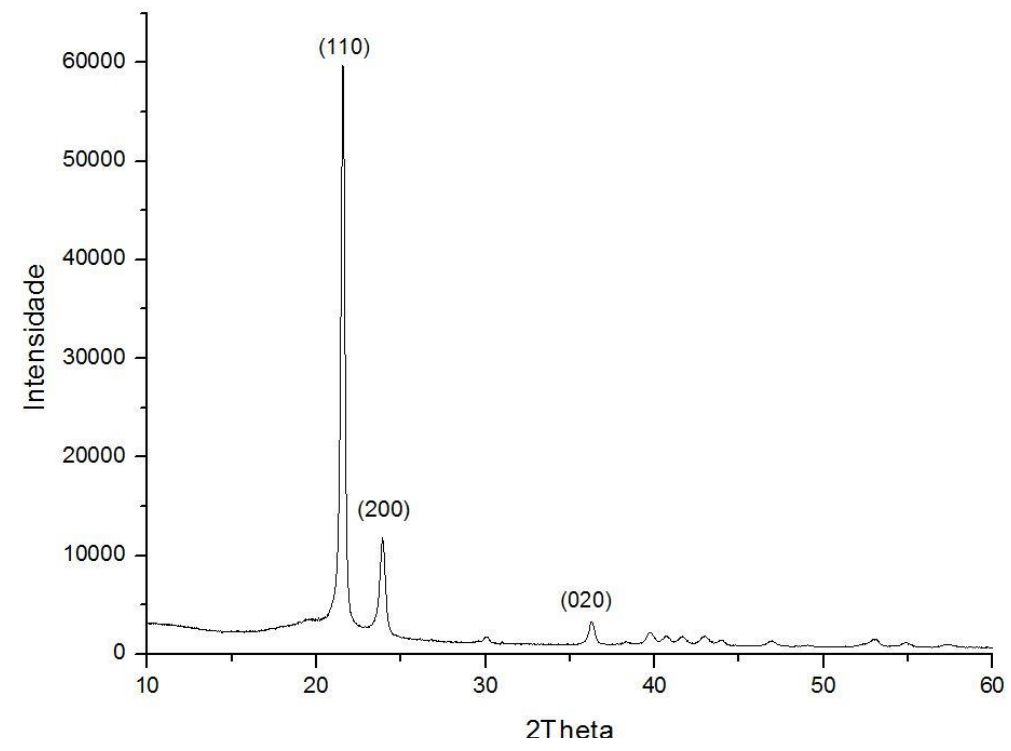

Figura 101. Difratograma do PEAD.

Percebe-se que o PEAD apresenta três picos bem intensos e outros picos não tão intensos, todos correspondentes à fase cristalina e uma banda correspondente à fase amorfa compreendida entre $14^{\circ}$ e $26^{\circ}$, aproximadamente.

O PEAD apresenta uma estrutura ortorrômbica [55] com o plano (110) correspondente ao pico localizado em $2 \theta=21,5^{\circ}$, o plano (200) em $2 \theta=23,8^{\circ}$ e o plano (020) em $2 \theta=36,1^{\circ}$. 
Para o cálculo da cristalinidade foi feito um ajuste da curva experimental empregando-se o software TOPAS. A Figura 102 mostra a curva original e as curvas ajustadas para as regiões cristalina e amorfa, sendo que para o ajuste da fase cristalina, foram utilizados dois tipos de PEAD com estruturas levemente diferentes denominados de PEAD 1 e PEAD 2, que juntos correspondem à fase cristalina do PEAD. O PEAD 1 possui um volume de célula menor que o PEAD

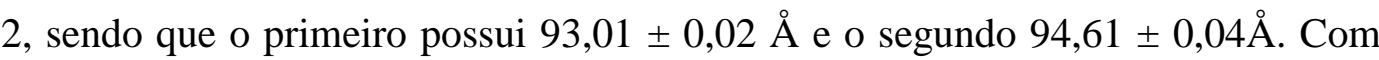
isso, os parâmetros da célula unitária do PEAD 1 são sempre menores que do PEAD 2.

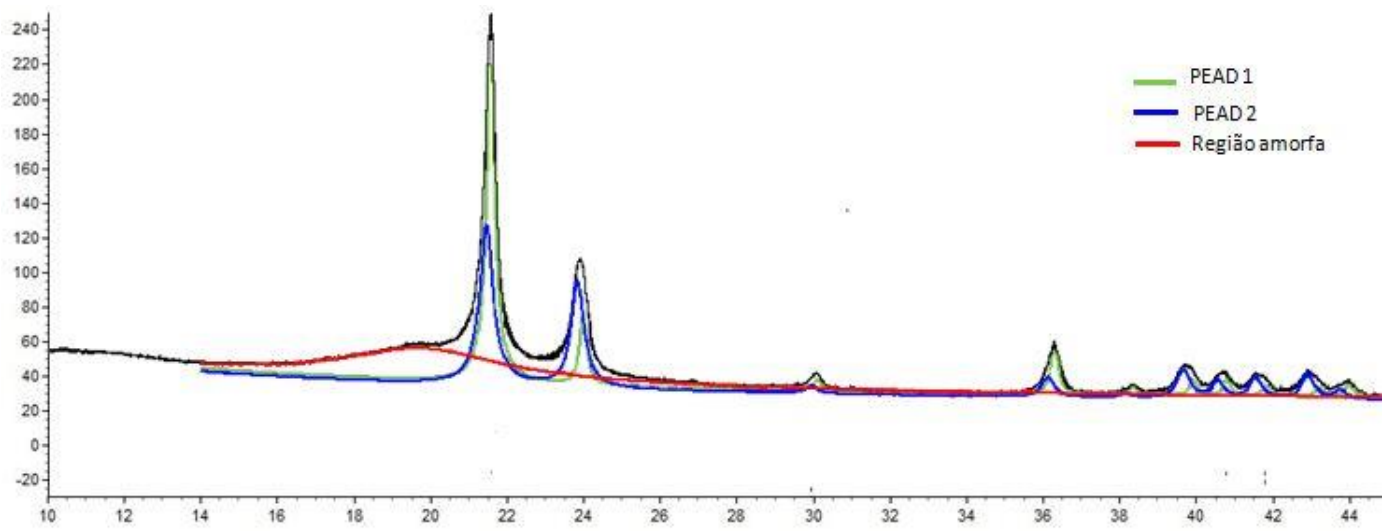

Figura 102. Difratograma do PEAD com seus respectivos picos representativos das regiões amorfa e cristalina.

A partir do gráfico da Figura 102 foi calculado que o grau de cristalinidade do PEAD é de 74,6\%, o que é bem plausível, já que o PEAD é um polímero bem cristalino e pode chegar a $\approx 95 \%$ de cristalinidade [33].

A Tabela 35 mostra as áreas das partes cristalina e amorfa avaliadas pelo programa de ajuste.

Tabela 35. Cálculo do grau de cristalinidade do PEAD.

\begin{tabular}{cc}
\hline & Área (u.a.) \\
\hline Cristalina & 33009,9 \\
Amorfa & 11239,9 \\
\hline Grau de cristalinidade (\%) & 74,6 \\
\hline
\end{tabular}

A Tabela 36 mostra os parâmetros de rede e o tamanho médio do cristalito obtidos, que são bem semelhantes aos descritos por Li e col. [55]. 
Tabela 36. Valores dos parâmetros de rede e do tamanho médio do cristalito do PEAD.

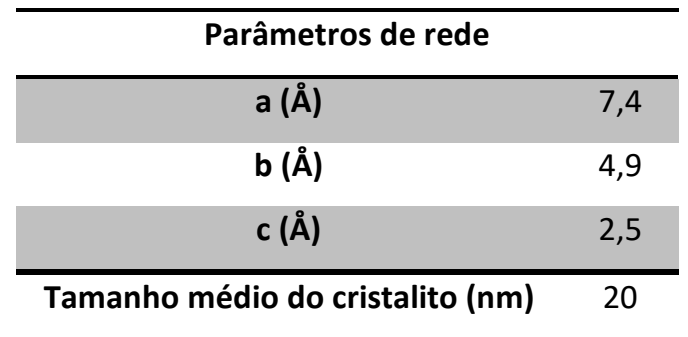

\subsubsection{PA12}

A Figura 103 mostra o difratograma da PA12. Neste material foram detectados diversos planos cristalinos, porém somente foram destacados os dois que apresentaram picos mais intensos.

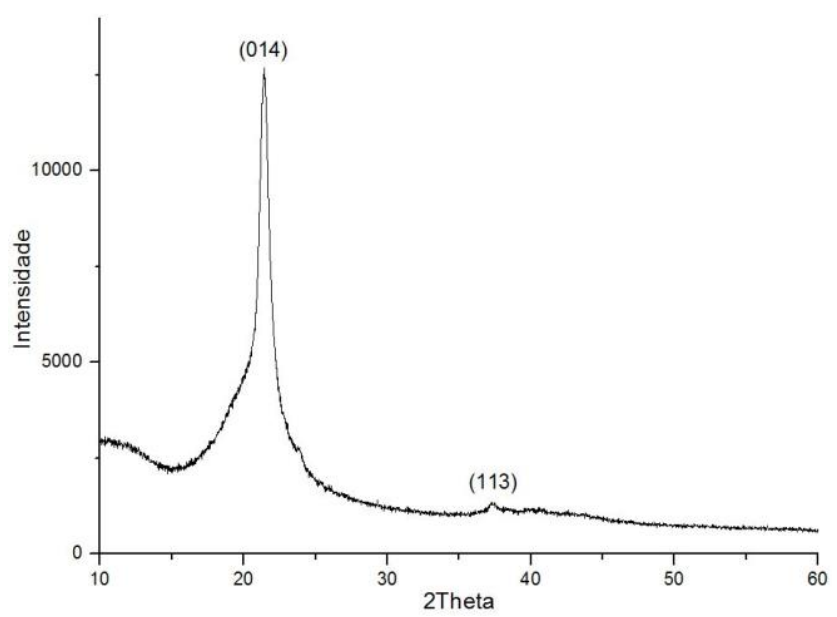

Figura 103. Difratograma da PA12.

Percebe-se que a fase amorfa da PA12 apresenta uma banda maior que a do PEAD, o que é justificável, já que a PA12 é menos cristalina que o PEAD. Tal banda compreende a faixa entre $14^{\circ}$ e $28^{\circ}$. De acordo com a Figura 104, o plano (014) está localizado em $2 \theta=21,4^{\circ}$ e o plano (113) em $2 \theta=37,2^{\circ}$.

Segundo a literatura, a PA12 apresenta mais de uma estrutura cristalina, já que a mesma varia de acordo com a temperatura e pressão. Dentre elas, destacamse a monoclínica e a hexagonal [56]. Para o ajuste deste difratograma, foi utilizada a estrutura hexagonal, que foi aquela que permitiu melhor ajuste aos dados experimentais. A Figura 104 mostra o difratograma da PA12 com suas respectivas bandas cristalina e amorfa após o ajuste. 


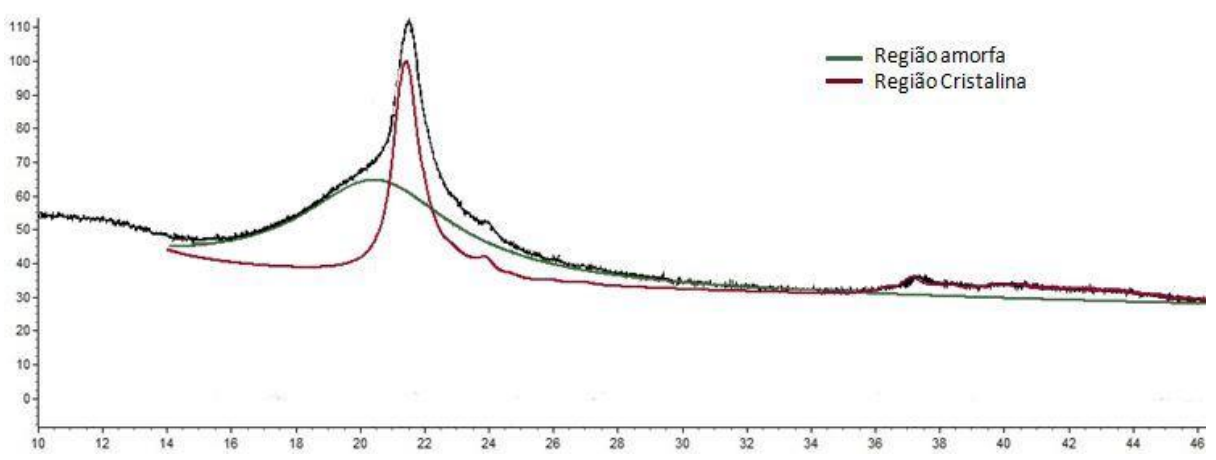

Figura 104. Difratograma da PA12 com seus respectivos picos representativos das regiões amorfa e cristalina.

A partir do gráfico da Figura 104, foi concluído que o grau de cristalinidade da PA12 é de 40,2\%. As Tabelas 37 e 38 mostram as áreas das partes cristalina e amorfa e o cálculo do grau de cristalinidade, bem como os parâmetros de rede e tamanho médio do cristalito, respectivamente.

Tabela 37. Cálculo do grau de cristalinidade da PA12.

\begin{tabular}{cc}
\hline & Área (u.a.) \\
\hline Cristalina & 13397,5 \\
Amorfa & 19922,4 \\
\hline Grau de cristalinidade (\%) & 40,2 \\
\hline
\end{tabular}

Tabela 38. Valores dos parâmetros de rede e do tamanho médio do cristalito da PA12.

\begin{tabular}{cc}
\hline \multicolumn{2}{c}{ Parâmetros de rede } \\
\hline a (Å) & 4,8 \\
c (Å) & 113,4 \\
\hline Tamanho médio do cristalito (nm) & 11 \\
\hline
\end{tabular}




\subsubsection{PEAD-alt-MAH}

A Figura 105 ilustra o difratograma do agente compatibilizante PEAD-altMAH.

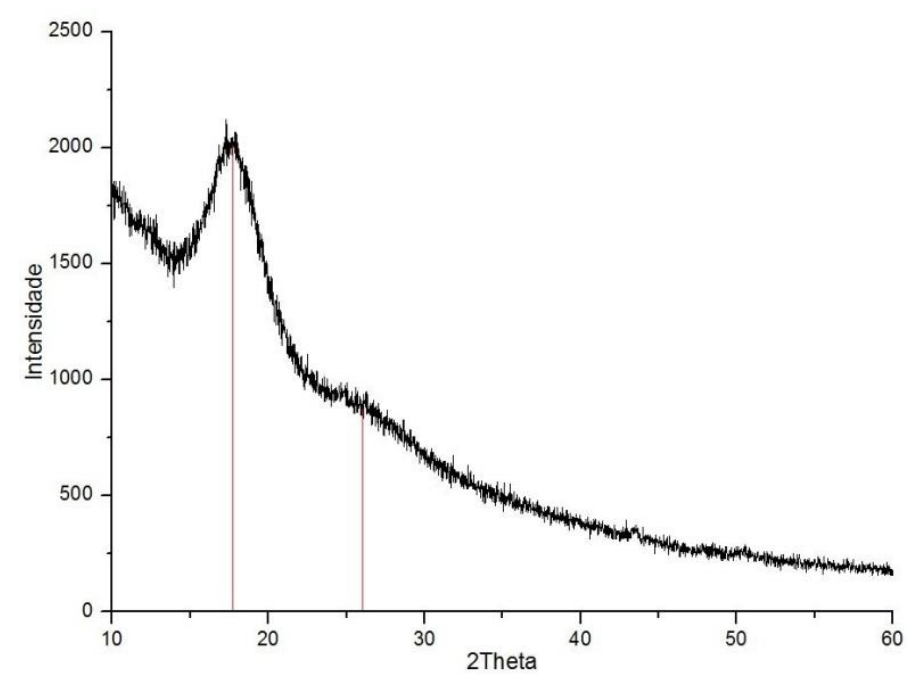

Figura 105. Espectrograma do PEAD-alt-MAH com os seus dois picos mais fortes destacados em linhas verticais.

$\mathrm{Na}$ análise do gráfico desta figura, percebe-se que este apresenta dois picos, porém não foi possível identificar os mesmos. Estima-se que se trata de um material na transição entre nanocristalino e amorfo, pois a intensidade dos picos é muito pequena em relação à linha base e também devido ao fato do tamanho do cristalito ser de $1,39 \mathrm{~nm}$. Além disso, como a porcentagem deste material nas blendas é pequena (2\%), esses picos não são visíveis no difratograma das blendas. Por isso, a contribuição desse material foi descartada na análise de cristalinidade das blendas.

\subsubsection{Blendas}

A Figura 106 mostra os gráficos das blendas 75/25, 50/50 e 25/75, respectivamente, com suas curvas características das áreas do PEAD, PA12 e da fase amorfa. Para o ajuste da fase do PEAD, foi utilizado somente o PEAD 2, o qual teve melhor ajuste. Percebe-se que os difratogramas das blendas apresentam os picos do PEAD e da PA12, com intensidades relativas coerentes com as proporções dos materiais usados na blenda e, também, que os picos referentes aos planos $h k l$ do PEAD e da PA12 descritos anteriormente se mantêm aproximadamente nos mesmos ângulos. 

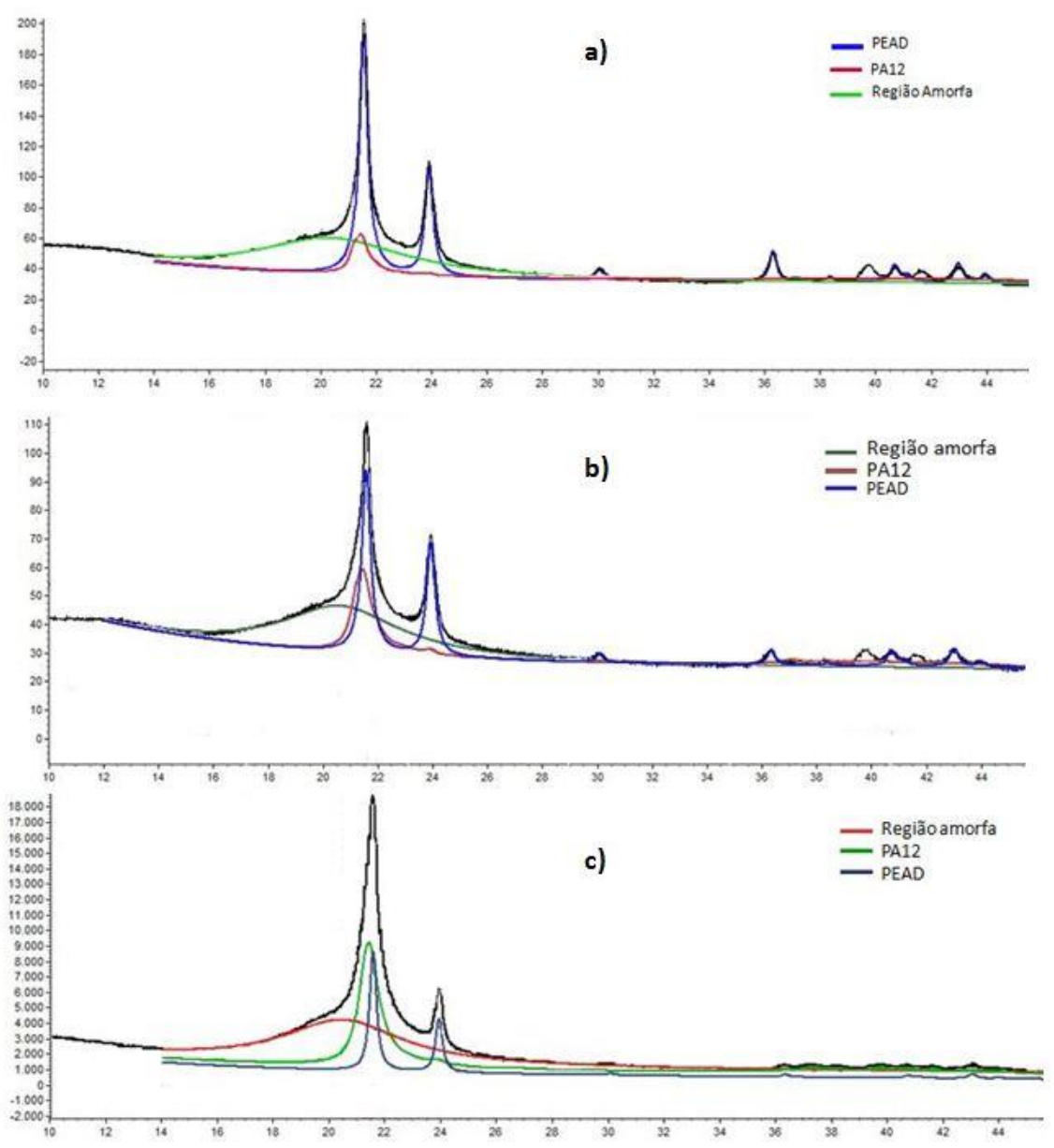

Figura 106. Difratogramas das blendas com os picos referentes ao PEAD, PA12 e a região amorfa: a) 75/25, b) 50/50 e c) 25/75.

A partir da análise da área de cada curva, pelo mesmo método empregado anteriormente, foi calculado o grau de cristalinidade de cada blenda, juntamente com os parâmetros de rede e o tamanho de cristalito do PEAD e da PA12. As Tabelas 39 a 41 mostram estes dados referentes às blendas 75/25, 50/50 e 25/75, respectivamente. Nestas tabelas também constam as áreas do PEAD e da PA12, o que possibilita o cálculo da porcentagem de cada polímero nas blendas. Esta porcentagem foi ligeiramente diferente da prevista teoricamente, provavelmente devido ao processamento do material na extrusora, ou seja, um erro experimental, já que é feita uma limpeza da extrusora antes do processamento com a passagem de PEAD puro para remover impurezas, gerando algum resquício de material na máquina. 
Tabela 39. Grau de cristalinidade e parâmetros de rede da blenda 75/25.

\begin{tabular}{ccc}
\hline \multicolumn{3}{c}{ PEAD/PA12 75/25 } \\
\hline PEAD & Área (u.a.) & Teor (PEAD/PA12) \\
PA12 & 20327,9 & $87,5 \%$ \\
Amorfa & 2880,9 & $12,5 \%$ \\
\hline Grau de cristalinidade (\%) & 18602,5 & - \\
\hline & Parâmetros de Rede & - \\
\hline a (Å) & PEAD & PA12 \\
\hline b (Å) & 7,4 & 4,8 \\
\hline c (Å) & 4,9 & - \\
\hline Tamanho médio do Cristalito (nm) & 25 & 113,4 \\
\hline
\end{tabular}

Tabela 40. Grau de cristalinidade e parâmetros de rede da blenda 50/50.

\begin{tabular}{|c|c|c|}
\hline \multicolumn{3}{|c|}{ PEAD/PA12 50/50 } \\
\hline & Área (u.a.) & Teor (PEAD/PA12) \\
\hline PEAD & 10370,4 & $63,9 \%$ \\
\hline PA12 & 5845,2 & $36,1 \%$ \\
\hline Amorfa & 14276,9 & - \\
\hline Grau de cristalinidade (\%) & 53,2 & - \\
\hline \multicolumn{3}{|c|}{ Parâmetros de Rede } \\
\hline & PEAD & PA12 \\
\hline$a(\AA ̊)$ & 7,4 & 4,8 \\
\hline b (Å) & 4,9 & - \\
\hline c (Å) & 2,4 & 113,4 \\
\hline Tamanho médio do Cristalito (nm) & 22 & 11 \\
\hline
\end{tabular}


Tabela 41. Grau de cristalinidade e parâmetros de rede da blenda 25/75.

\begin{tabular}{ccc}
\hline \multicolumn{3}{c}{ PEAD/PA12 25/75 } \\
\hline & Área (u.a.) & Teor (PEAD/PA12) \\
\hline PEAD & 5751,9 & $31,1 \%$ \\
PA12 & 12738,2 & $68,9 \%$ \\
Amorfa & 19815,3 & - \\
\hline Grau de cristalinidade (\%) & 48,3 & - \\
\hline & Parâmetros de Rede & \\
\hline a (Å) & PEAD & PA12 \\
b (Å) & 7,4 & 4,8 \\
c (Å) & 4,9 & - \\
\hline Tamanho médio do Cristalito (nm) & 21,0 & 113,4 \\
& 2,4 & 9,0 \\
\hline
\end{tabular}

É possível perceber através dos dados listados que os parâmetros de rede tiveram pouquíssimas variações com as composições das blendas, já o tamanho do cristalito diminuiu com a redução do teor de PEAD.

O grau de cristalinidade também diminuiu com a diminuição do teor de PEAD na blenda, conforme ilustra o gráfico da Figura 107. O PEAD e a PA12 apresentaram os graus de cristalinidades máximo e mínimo, respectivamente, e as blendas apresentaram graus de cristalinidade intermediários. A Figura 108 mostra a variação do tamanho do cristalito nos polímeros puros e nas blendas.

\section{Grau de cristalinidade (\%)}

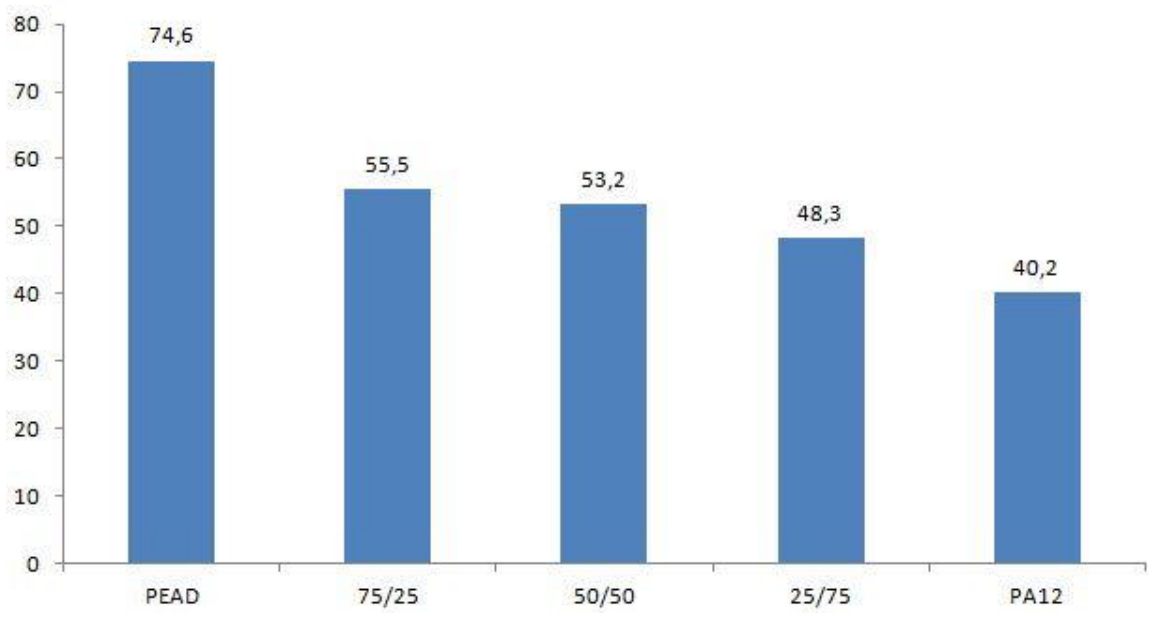

Figura 107. Comparação do grau de cristalinidade dos homopolímeros e das blendas. 


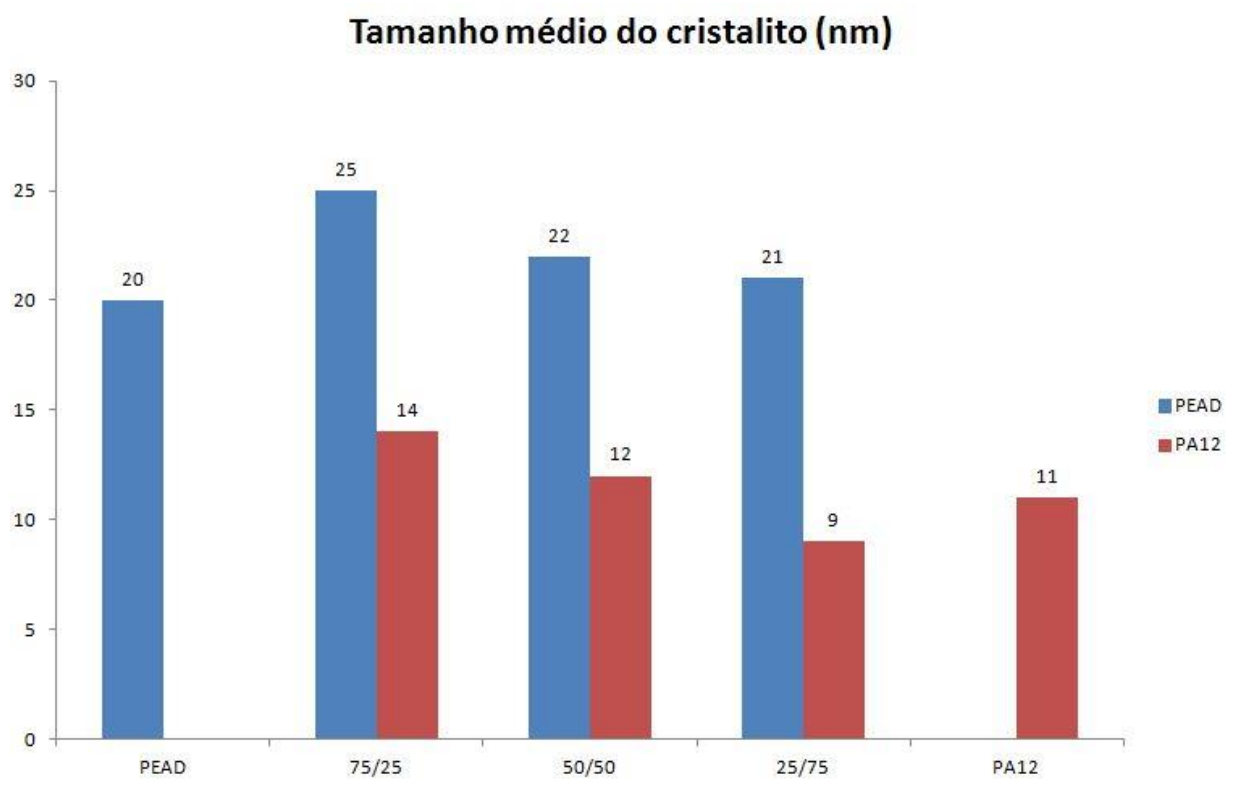

Figura 108. Variação do tamanho dos cristalitos.

Através dos gráficos e tabelas apresentados, observa-se que, em relação ao grau de cristalinidade, o PEAD tem um grau superior à PA12, o que já era esperado, devido à sua estrutura química mais simples e mais fácil de ser empacotada, como foi explicado no item 2.6. Já as blendas apresentaram graus de cristalinidade intermediários aos dos homopolímeros, sendo que com o aumento do teor de PA12, há a redução da sua cristalinidade. Dusunceli e Colak [57] realizaram um estudo usando PEUAMM e PTFE com o objetivo de fazer uma modelagem matemática das fases cristalina e amorfa em paralelo e em série e, alterando o grau de cristalinidade, analisou a variação no comportamento dos polímeros à tração, fluência e relaxação e generalizou o comportamento observado para todos os polímeros semicristalinos. Sendo assim, Dusunceli e Colak [57] dizem que a resistência mecânica dos polímeros semicristalinos, assim como a resistência à fluência, aumenta significativamente com o aumento da cristalinidade, o que entra em contradição com os dados obtidos neste trabalho, já que a blenda 25/75 obteve módulo de elasticidade, deformação na ruptura, limite de escoamento e tensão de ruptura maiores que a 50/50, que por sua vez obteve resistência maior que a 75/25. Ou seja, quanto menor o grau de cristalinidade, maior a resistência da blenda PEAD/PA12/PEAD-alt-MAH.

O mesmo acontece com a fluência, já que a taxa de fluência estacionária da 25/75 é inferior à 50/50, que por sua vez é inferior à 75/25 e quanto menor a taxa 
de fluência, maior a resistência à deformação por fluência, ou seja, quanto menor o grau de cristalinidade da blenda PEAD/PA12/PEAD-alt-MAH, maior a sua resistência à fluência, o que vai contra a conclusão de Dusunceli e Colak [57]. Quanto ao aumento da resistência à tração e à fluência nas blendas, o aumento do teor de PA12 tem papel fundamental nisso, pois sua resistência mecânica é superior ao do PEAD, porém este último possui maior deformação na ruptura. Essa diferença na resistência entre PA12 e PEAD está relacionada ao comportamento térmico dos polímeros, já que a $T_{g}$ do PEAD e da PA12 são $120^{\circ} \mathrm{C}$ e $37^{\circ} \mathrm{C}$, respectivamente $[44,58]$. Ou seja, como a $\mathrm{T}_{\mathrm{g}}$ da poliamida se encontra acima da temperatura ambiente usada nos ensaios mecânicos, pode-se dizer que no caso da poliamida o comportamento elástico se fez mais presente, enquanto no PEAD o comportamento viscoso ditou as características mecânicas do material. Para avaliar de um modo mais preciso a influência da $T_{g}$ e do grau de cristalinidade nas propriedades mecânicas, seria necessário a realização de ensaios de DSC (Calorímetro Diferencial de Varredura), não realizado no presente trabalho. Além disso, outro fator que implica em uma alta resistência da poliamida é a formação de ligações de hidrogênio entre as partes polares das cadeias, formando ligações intermoleculares mais fortes que no PEAD.

Em relação ao tamanho do cristalito das blendas, Hartono e col. [59] dizem que quanto maior for o grau de cristalização, maior o tamanho do cristalito do polímero, ou seja, a blenda 75/25 obteve um grau de cristalização maior que a $50 / 50$, que por sua vez obteve um grau maior que a 25/75, o que quer dizer que a blenda 75/25 obteve uma maior organização das cadeias poliméricas para a temperatura utilizada no processamento dos materiais.

Gupta e Purwar[60] constatam que quanto menor o tamanho do cristalito, menor o tamanho da esferulita da estrutura, que consiste em um grupamento de cristalitos e regiões amorfas. Ou seja, quanto maior o teor de PA12 na blenda, menor o tamanho dos cristalitos e consequentemente menor o tamanho das esferulitas dos polímeros. Gupta e Purwar [60] constatam também que a diminuição do tamanho da esferulita implica na diminuição do módulo de Young e no limite de escoamento, o que não confere com os resultados obtidos neste trabalho, já que os mesmos aumentaram com a diminuição do tamanho dos cristalitos e da provável redução do tamanho da esferulita dos polímeros. Gupta e Purwar [60] também dizem que com o aumento do tamanho da esferulita do 
polímero, a deformação no escoamento também aumenta, o que diverge do aumento desta propriedade na transição da blenda 75/25 para a 50/50 (11\% < $14 \%)$.

Nota-se também um aumento no tamanho do cristalito dos homopolímeros puros para as blendas, já que o tamanho do cristalito do PEAD nas blendas é maior que o tamanho do mesmo no PEAD puro. Utracki [61] explica que uma das maiores influências na blenda é a mudança no tamanho da esferulita e da morfologia semicristalina da matriz e da fase dispersa, ainda mais porque o PEAD tem uma temperatura de cristalização inferior à da PA12. Assim sendo, quando a fase dispersa é a PA12, esta se solidifica primeiro que a matriz de polietileno e quando a fase dispersa é o PEAD, a matriz se solidifica primeiro, ou seja, haveria uma matriz sólida com uma fase dispersa fundida, o que pode afetar no tamanho da fase dispersa. Além do mais, Utracki [61] também retrata que os agentes compatibilizantes afetam fortemente na morfologia da blenda, já que melhoram a adesão entre as fases, o que pode influenciar na cristalização das blendas.

\subsection{Análise reológica}

A análise da reologia dos polímeros gerou o gráfico da viscosidade dinâmica em função da taxa de cisalhamento ilustrado na Figura 109 em escala logarítmica. 


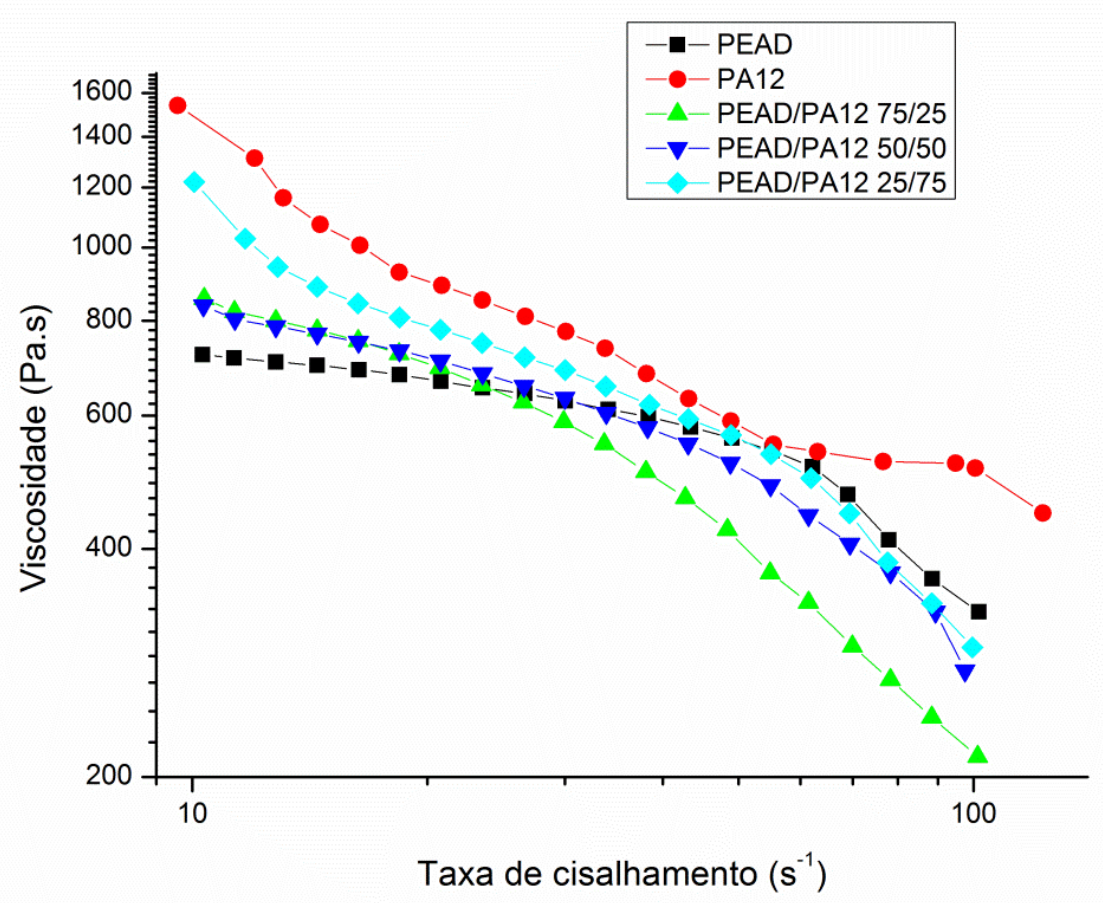

Figura 109. Viscosidade dinâmica $x$ taxa de cisalhamento a $200^{\circ} \mathrm{C}$.

Pelo gráfico, conclui-se que os materiais utilizados neste trabalho possuem comportamento pseudoplástico, já que a viscosidade diminui com o aumento da taxa de cisalhamento, caracterizando um fluido não-newtoniano. $\mathrm{O}$ comportamento pseudoplástico é o mais comum em polímeros fundidos e é consequência do desenovelamento e da orientação das macromoléculas, promovidas pelas taxas de cisalhamento aplicadas. Quando essas taxas são baixas, o gradiente de velocidades não é forte o suficiente para desenovelar as macromoléculas e a viscosidade é elevada; quando essas taxas aumentam, as macromoléculas começam a desfazer os nós entre elas e a viscosidade começa a diminuir. Quando as taxas são elevadas, as macromoléculas já desfizeram quase todos os nós entre elas e se orientarão na direção do fluxo, diminuindo a viscosidade [62].

Através deste gráfico, percebe-se que o PA12 possui viscosidade superior ao PEAD tanto em taxas de cisalhamento baixas quanto em altas, sendo essa diferença mais significativa em baixas taxas de cisalhamento. Este comportamento também é observado no trabalho de Cho e col. [63] em blendas de PELBD com PEAD, no qual a diferença entre a viscosidade do PELBD e o PEAD a baixas taxas de cisalhamento é maior que a altas taxas. Observa-se também que a baixas 
taxas de cisalhamento as blendas apresentam viscosidade intermediária aos homopolímeros, sendo a blenda 25/75 com viscosidade superior às outras duas composições, que obtiveram viscosidades semelhantes entre si, mostrando a influência da PA12 nas blendas. O aumento na viscosidade da blenda 25/75 em relação às outras também pode ser associado à melhora nas interações entre os polímeros e/ou a uma melhor dispersão da fase dispersa na matriz polimérica [64], o que será avaliado na análise morfológica a seguir. O mesmo não pode se afirmar do comportamento reológico das blendas a altas taxas de cisalhamento, já que apresentaram viscosidades inferiores às dos homopolímeros, sendo a blenda 75/25 com a viscosidade mais baixa entre todos os materiais. A baixa viscosidade implica em uma boa processabilidade em diversas condições de processo, como extrusão e injeção, que utilizam elevadas taxas de cisalhamento, da ordem de $10^{3}$ $\mathrm{s}^{-1}$ [65], ou seja, a blenda 75/25 apresenta uma melhor processabilidade em relação aos outros materiais estudados.

Outra observação que deve ser feita é que a curva da viscosidade do PEAD a baixas taxas de cisalhamento apresenta um comportamento quase constante, o que indica que o platô Newtoniano do PEAD termina em taxas de cisalhamento mais altas que o da PA12.

A partir do ensaio de reometria também foi gerado o gráfico da tensão de cisalhamento em função da taxa de cisalhamento, ilustrado na Figura 110. 


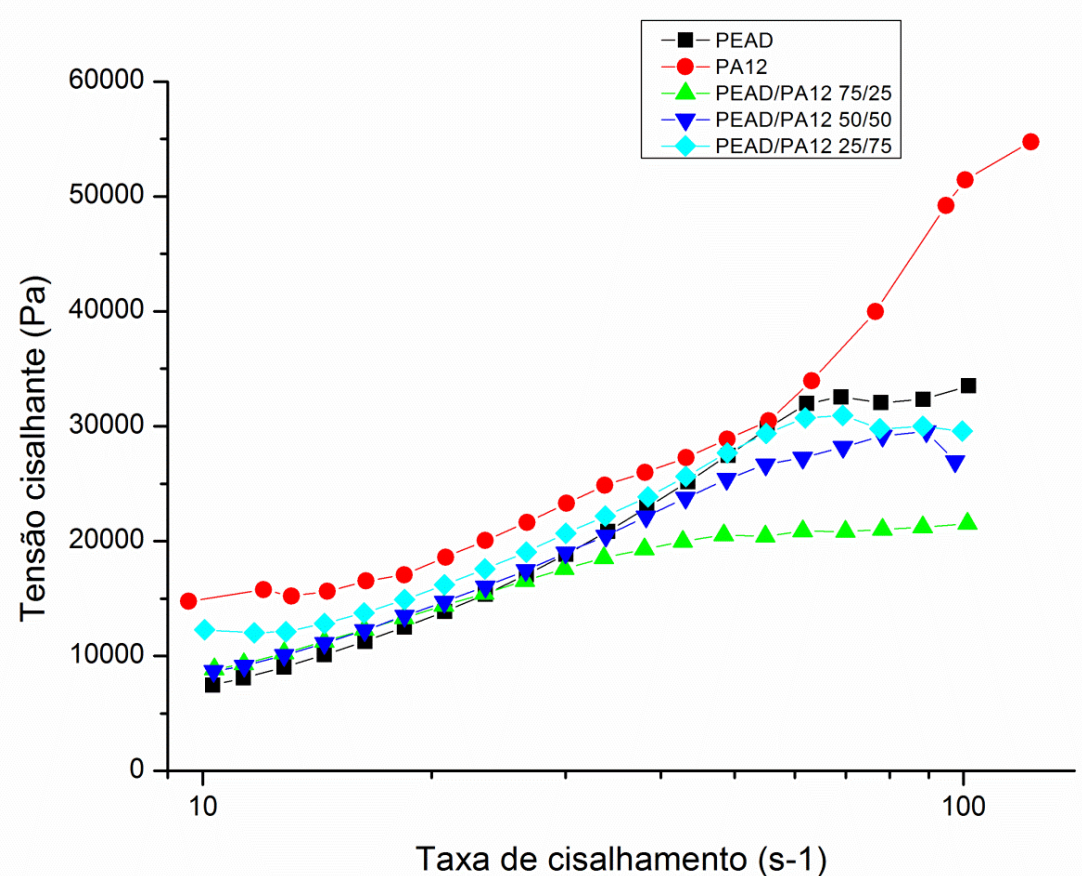

Figura 110. Tensão cisalhante $\mathrm{x}$ taxa de cisalhamento a $200^{\circ} \mathrm{C}$.

Como era de se esperar, a baixas taxas de cisalhamento a tensão cisalhante da PA12 é maior que a das blendas que por sua vez são maiores que a do PEAD. Já a altas taxas de cisalhamento, a tensão do PA12 é bem superior a do PEAD, que é maior do que as tensões nas blendas, sendo a da 75/25 a menor dentre todos os materiais estudados.

Essas relações também podem ser vistas no gráfico da viscosidade (Figura 110), o que mostra que a tensão cisalhante segue uma proporção em relação à viscosidade e a taxa de cisalhamento, dada pela Equação 10 [62]:

$$
\tau_{x y}=\eta(\dot{\gamma}) \dot{\gamma}_{x y}
$$

Nessa equação observa-se que a viscosidade $\eta(\dot{\gamma})$ depende da taxa de cisalhamento.

Percebe-se também pelo gráfico tensão cisalhante vs taxa de cisalhamento, que a PA12 apresenta um comportamento linear entre 20 e $60 \mathrm{~s}^{-1}$, aproximadamente. Esse tipo de comportamento é considerado típico para polímeros de alto peso molecular, no qual o comportamento do fluxo de cisalhamento é dependente da influência dos desenovelamentos físicos do estado transiente na rede molecular, que influencia a viscosidade medida em certas condições [66]. 
Porém, a partir de $70 \mathrm{~s}^{-1}$, a PA12 apresentou um aumento na inclinação da curva da tensão cisalhante, característica de materiais não-Newtonianos dilatantes. Ou seja, segundo o sugerido pelo gráfico, a partir de uma determinada taxa de cisalhamento a poliamida apresenta comportamento dilatante, já que é preciso aumentar a tensão para aumentar a taxa de cisalhamento. Esse comportamento vai contra o experimento de Haworth e col. [66], que mostra uma taxa de aumento constante das tensões cisalhantes no PA12 a altas taxas de cisalhamento.

Também se nota que as demais curvas de tensão cisalhante apresentam uma queda a partir de uma determinada taxa de cisalhamento, característica de materiais pseudoplásticos, sendo que as blendas apresentam tensões inferiores ao PEAD a altas taxas de cisalhamento, mostrando uma influência maior do PEAD do que a PA12 em elevadas taxas de cisalhamento.

Nessa região de pseudoplasticidade, na qual a viscosidade decresce com o aumento da taxa de cisalhamento, a viscosidade pode ser representada pela chamada Lei das Potências, expressa pela seguinte relação [62]:

$$
\log \eta=\log m+(n-1) \log \dot{\gamma}
$$

onde $\mathbf{m}$ e $\mathbf{n}$ são conhecidos, respectivamente, como consistência e índice da Lei das Potências. O valor de $\mathbf{n}$ é uma medida da "pseudoplasticidade" do polímero. Quando $\mathbf{n}=1$, a Equação 11 fica equivalente à do fluido Newtoniano, se $\mathbf{n}<1$, a viscosidade diminui com o aumento da taxa de cisalhamento e o polímero apresenta comportamento pseudoplástico e quanto mais $\mathbf{n} \rightarrow 0$ maior a pseudoplasticidade do polímero [62]. Os valores de $\mathbf{n}$ e $\mathbf{m}$ foram calculados a partir da inclinação do gráfico na Figura 109 e estão listados na Tabela 42. A PA12 não está incluída nesta tabela devido ao comportamento da tensão cisalhante vs taxa de deformação discutido anteriormente. 
Tabela 42. Valores da consistência e da pseudoplasticidade do PEAD e das blendas compatibilizadas com 2\% de PEAD-alt-MAH.

\begin{tabular}{ccc}
\hline PEAD/PA12 & m & $\mathbf{n}$ \\
\hline $\mathbf{1 0 0 / 0}$ & 2202 & 0,62 \\
$\mathbf{7 5 / 2 5}$ & 6875 & 0,26 \\
$\mathbf{5 0 / 5 0}$ & 3350 & 0,49 \\
$\mathbf{2 5 / 7 5}$ & 4339 & 0,44 \\
\hline
\end{tabular}

Através do gráfico de viscosidade x taxas de cisalhamento e a Tabela 42, percebe-se que entre as blendas, a 75/25 é a mais pseudoplástica. $\mathrm{O}$ valor de $\mathbf{m}$ seria a viscosidade do material quando $\mathbf{n}=1$, ou seja, a viscosidade que o polímero apresenta quando se encontra no platô Newtoniano.

A influência da composição da blenda na viscosidade está representada no gráfico da Figura 111 em escala logarítmica.

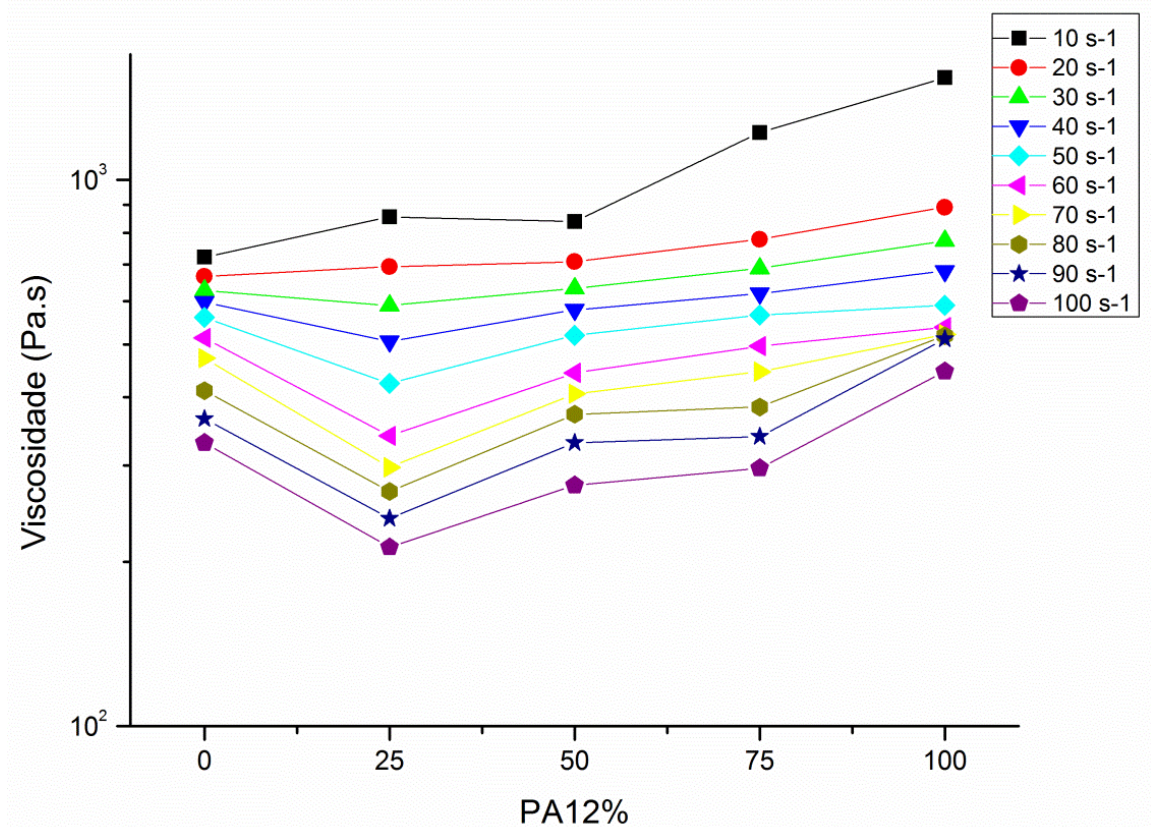

Figura 111. Viscosidade em função da composição da PA12 na blenda.

Neste gráfico fica claro o que foi mencionado anteriormente sobre o aumento da viscosidade em função do aumento do teor de PA12 na blenda independente da taxa de cisalhamento, sendo que em baixas taxas de cisalhamento, esse aumento ficou mais expressivo. Nota-se também que até $20 \mathrm{~s}^{-1}$ 
a blenda 75/25 obteve viscosidade superior à do PEAD e já em taxas de cisalhamento superiores, a blenda 75/25 obteve viscosidade inferior ao PEAD, o que reforça o que foi dito anteriormente sobre a boa processabilidade da blenda $75 / 25$.

\subsection{Morfologia}

A morfologia das blendas foi estudada por MEV a fim de avaliar a aderência e distribuição de fases e a influência da composição da blenda na fase dispersa e na matriz. A Figura 112 mostra a fratura do corpo de prova de 75/25 com 0\% de compatibilizante com ampliação de 25x como exemplo da área de onde foram retiradas as ampliações de 2000x e 5000x para análise da morfologia das blendas.

As Figuras 113, 114 e 115 ilustram as morfologias das blendas 75/25, 50/50

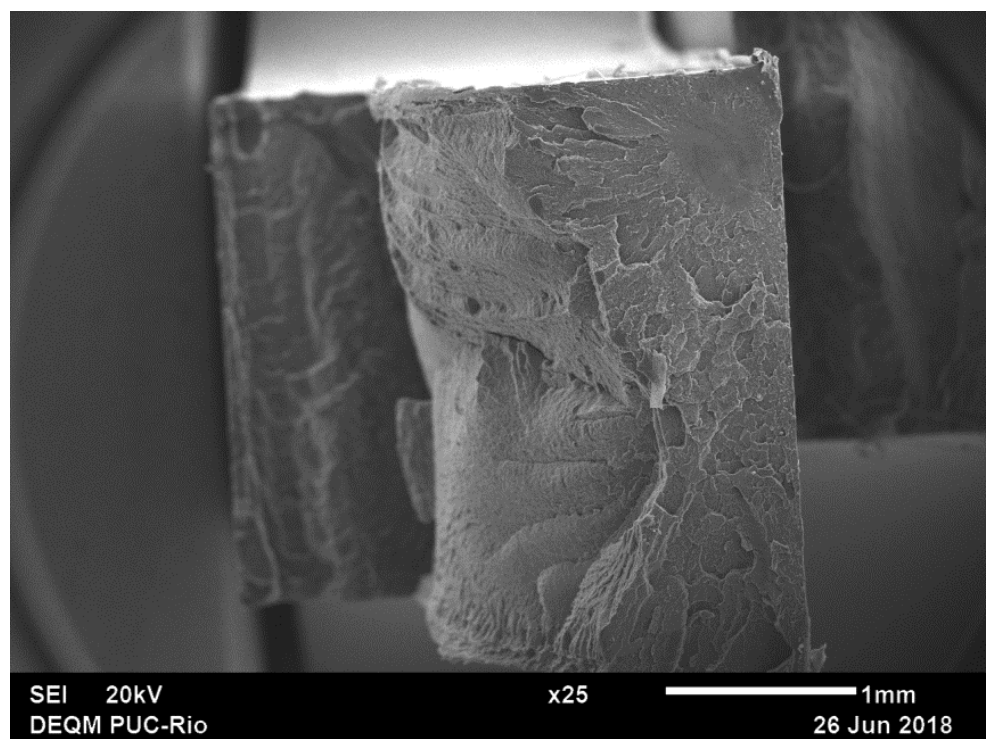

Figura 112. Fratura de um corpo de prova da blenda

$75 / 25$ com $0 \%$ de compatibilizante.

e 25/75, respectivamente, obtidas a partir do detector de elétrons secundários (SE), onde a seta vermelha indica o que seria um vazio (região sem material caracterizada por regiões escuras) e a seta amarela indica um exemplo de uma partícula da fase dispersa (que é caracterizada por partículas mais claras no meio de uma matriz com tons de cinza). 

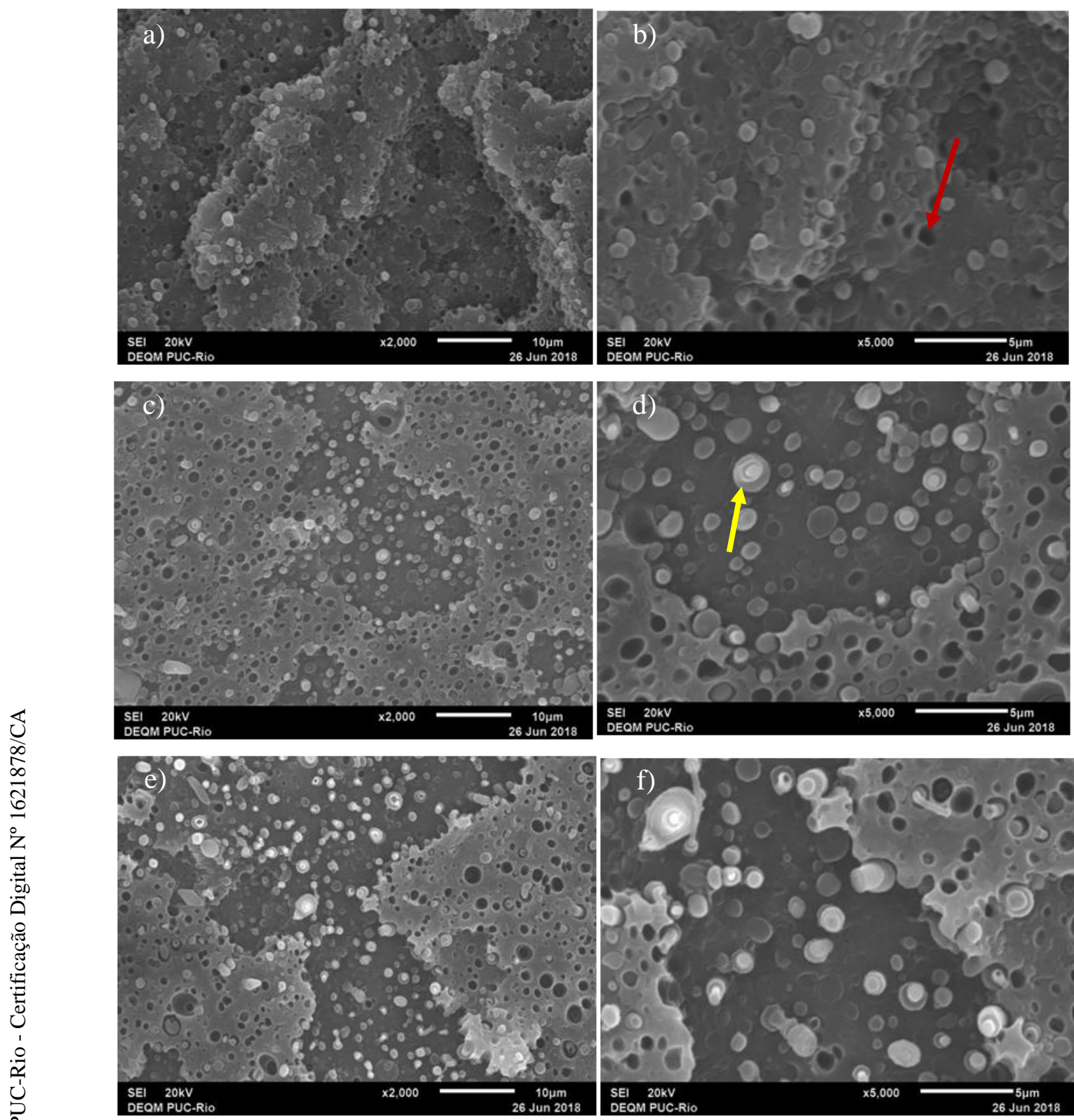

Figura 113. Morfologias da blenda $75 / 25$ com: a) e b) $0 \%$, c) e d) $2 \%$, e) e f) $3 \%$ de PEAD-alt-MAH, com magnificação de 2000x (a, c e e) e 5000x (b, d e f). 

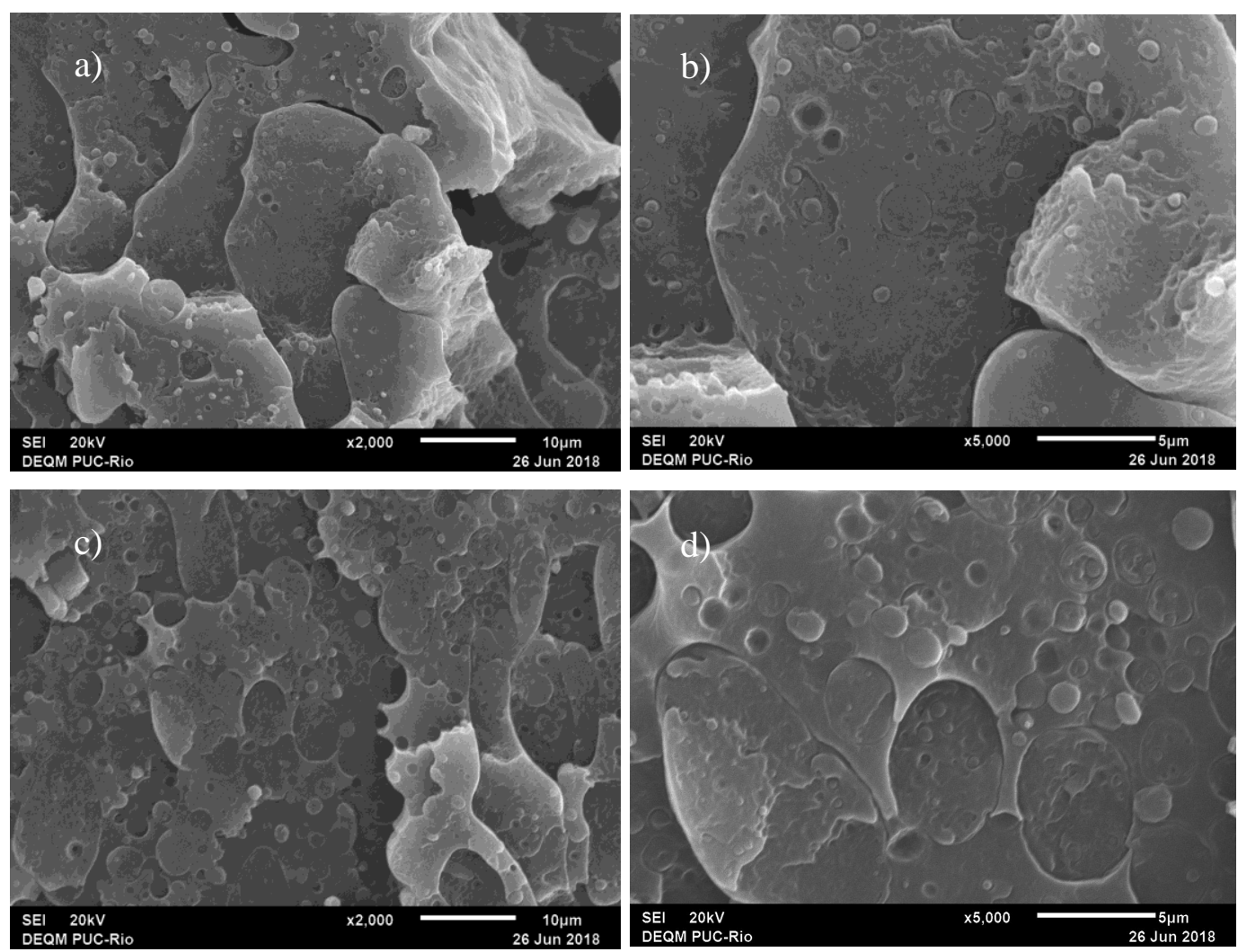

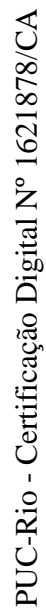
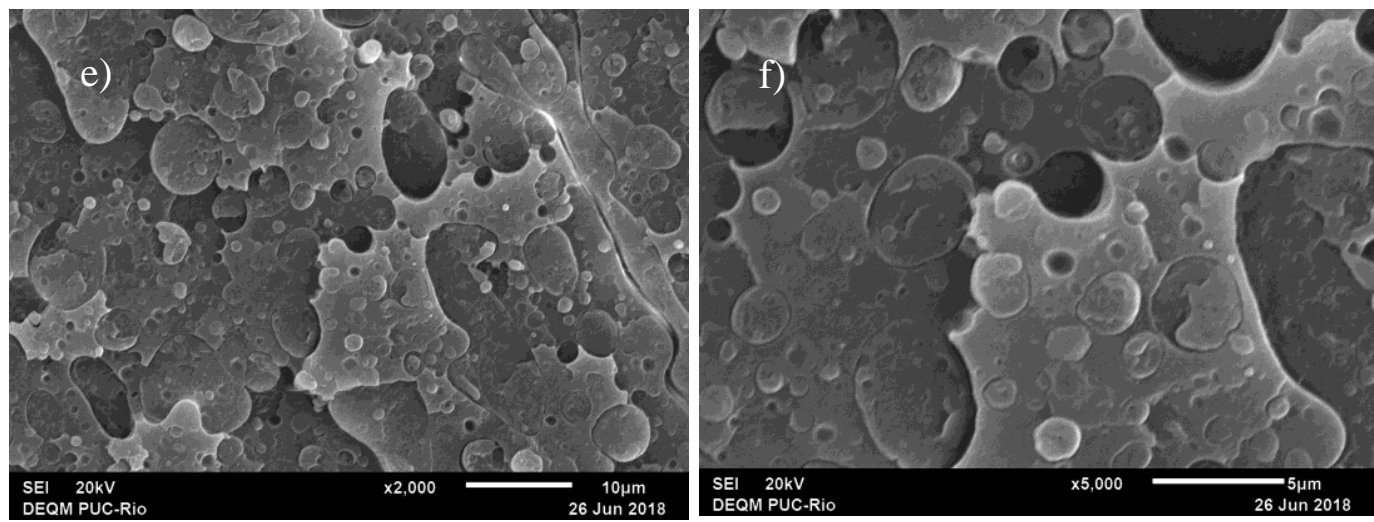

Figura 114. Morfologias da blenda 50/50 com: a) e b) $0 \%$, c) e d) $2 \%$, e) e f) 3\% de PEAD-alt-MAH, com magnificação de 2000x (a, c e e) e 5000x (b, d e f). 

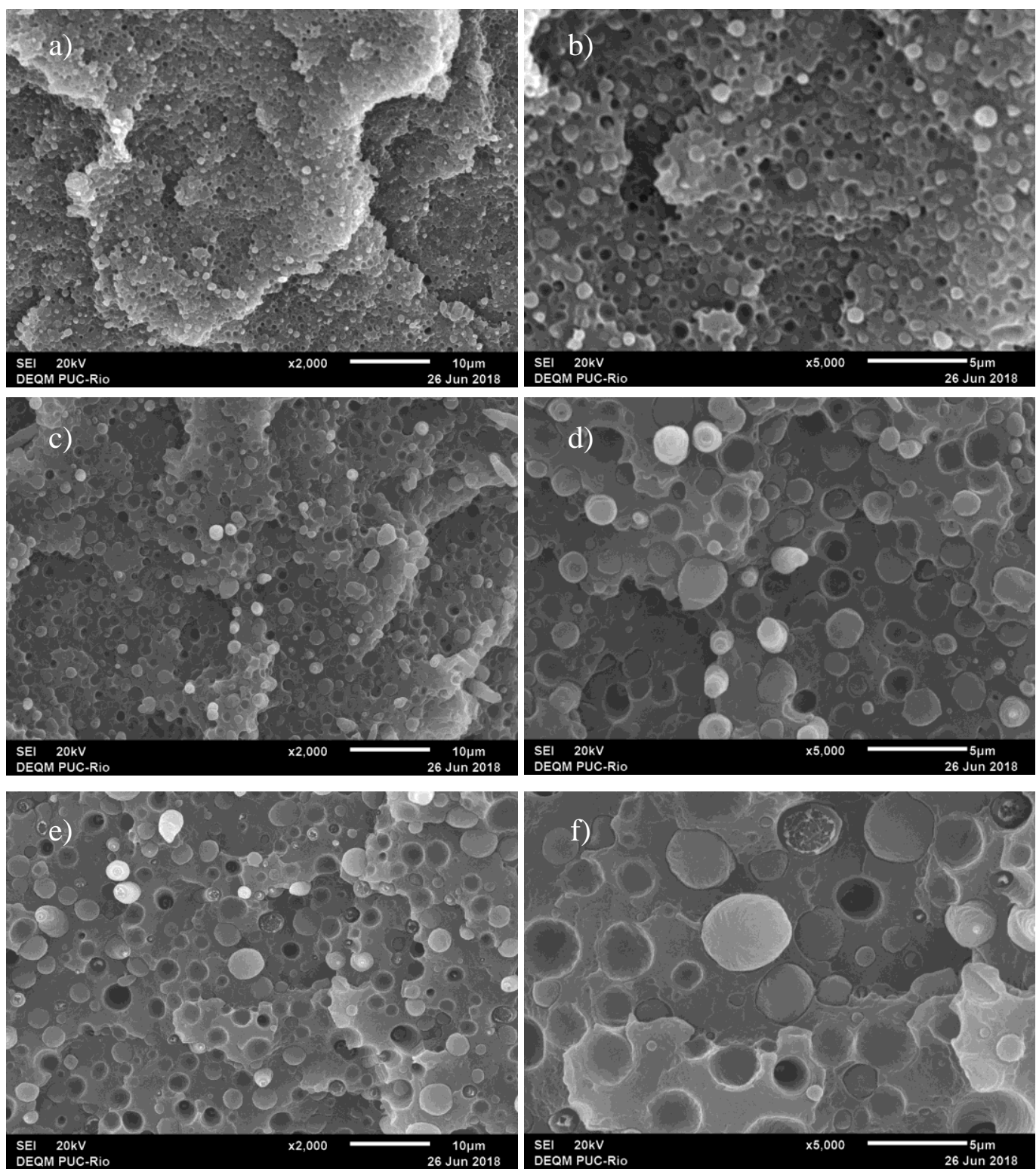

Figura 115. Morfologias da blenda 25/75 com: a) e b) 0\%, c) e d) $2 \%$,

e) e f) 3\% de PEAD-alt-MAH, com magnificação de 2000x (a, c e e) e 5000x

$$
\text { (b, d e f). }
$$

É notável que nas Figuras 113 e 115, a adição de compatibilizante aumentou a aderência entre as fases e, particularmente na Figura 115, a estrutura apresenta menos vazios, o que mostra que o agente compatibilizante cumpriu seu papel que é melhorar a aderência e melhorar a distribuição de carga, refletindo nas suas propriedades mecânicas, já que a adição de 2\% de PEAD-alt-MAH melhorou as resistências das blendas. É importante ressaltar que, na blenda 75/25, a fase dispersa é da PA12, enquanto na 25/75 é o PEAD. Não foi observada uma diferença significativa na morfologia das blendas com 3\% de compatibilizante em relação às com $2 \%$, exceto pelo leve aumento no diâmetro das partículas 
dispersas, o que pode ter acarretado na piora das propriedades mecânicas. Os valores dos diâmetros das partículas dispersas foram calculados a partir do software ImageJ e estão listados na Tabela 43.

ImageJ é um software de análise de imagem bastante usado em ciências biológicas e outros campos científicos. ImageJ usa um algoritmo que reconhece uma paleta de tons de pixels, variando entre o preto e o branco, e realiza diversos procedimentos para análise de imagens. Um exemplo dessa análise que pode ser feita por meio deste software é a análise morfológica [67].

Os procedimentos utilizados na análise destas morfologias foram: melhora no contraste da imagem, remoção de ruído e segmentação por tons de pixels, este último processo sendo chamado de Threshold, selecionando as partes mais claras, que são as partículas dispersas. Os procedimentos estão mais bem descritos no Anexo A.

Para a realização da quantificação das imagens, foram utilizadas imagens capturadas no detector de elétrons retroespalhados, como mostra a Figura 116, a qual ilustra, como exemplo, a morfologia da blenda 75/25 com 2\% de PEAD-altMAH.

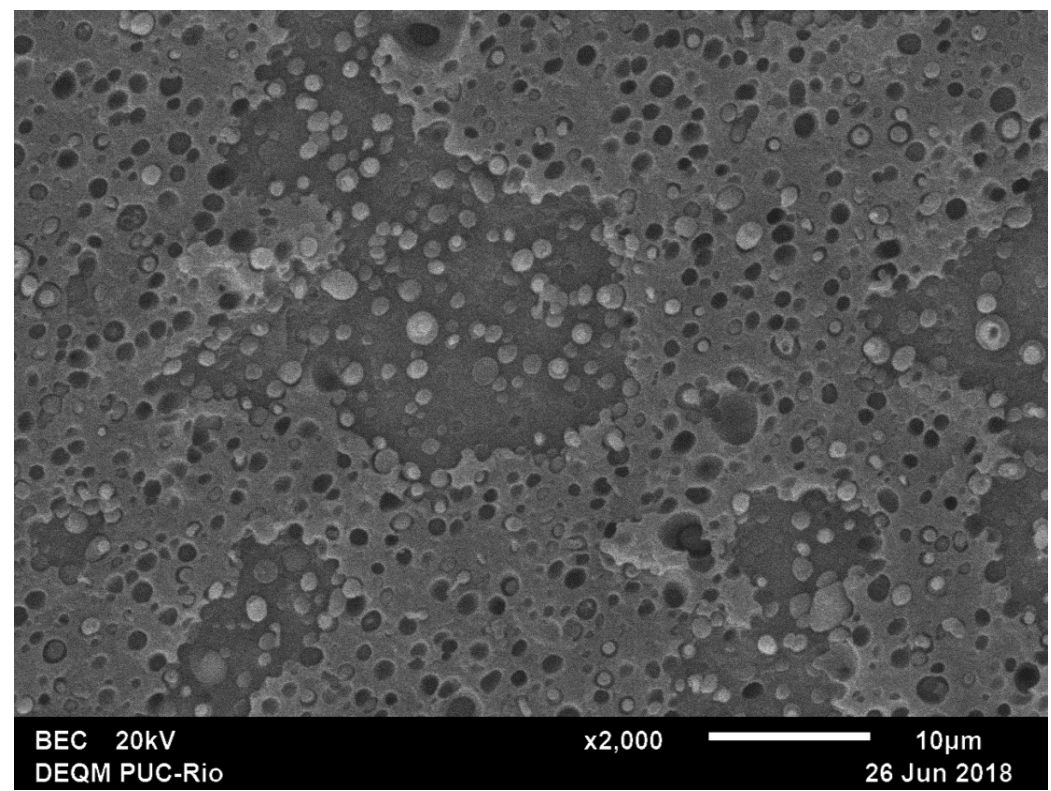

Figura 116. Morfologia da blenda 75/25 com $2 \%$ de PEAD-alt-MAH pelo detector BSE (x2000).

As imagens das blendas 50/50 não obtiveram contraste suficiente para realizar a segmentação de fases (Figura 117) e por isso não foi possível calcular o diâmetro da fase dispersa desta blenda. 


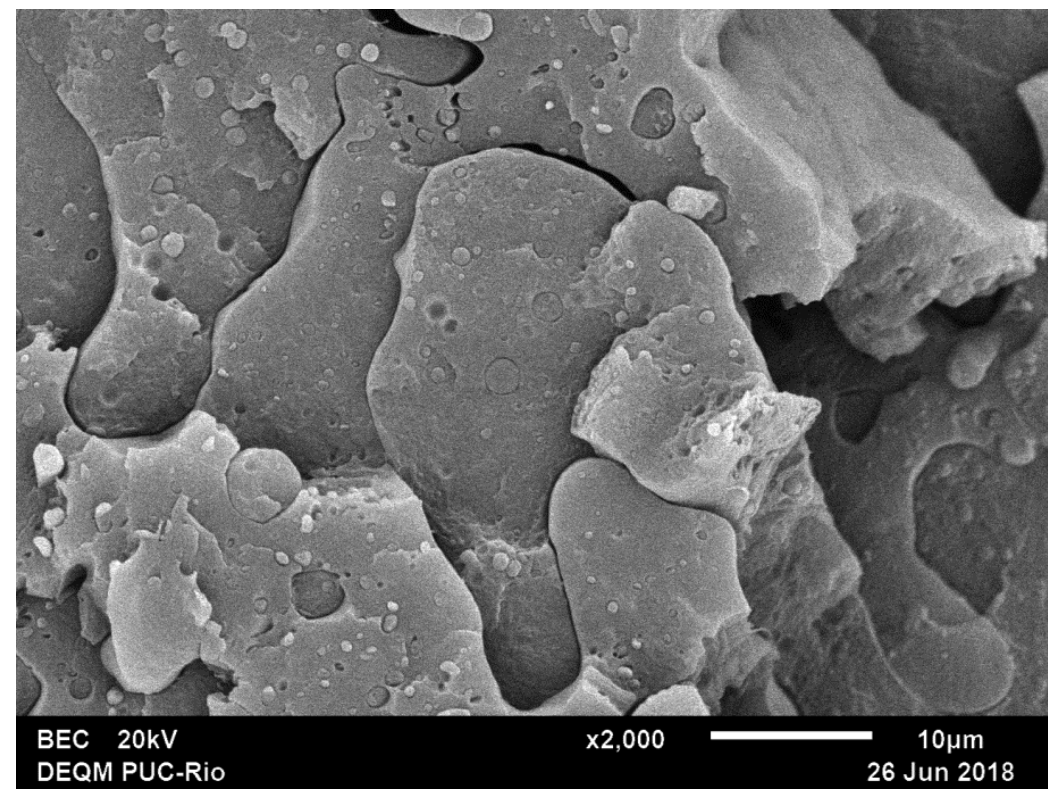

Figura 117. Morfologia da blenda 50/50 com $0 \%$ de PEAD-alt-MAH pelo detector BSE (x2000).

Os valores são correspondentes às médias e desvios padrões da distribuição estatística dos diâmetros.

Tabela 43. Valores dos diâmetros das fases dispersas das blendas 75/25 e $25 / 75$.

\begin{tabular}{ccc}
\hline PEAD/PA12 & \%PEAD-alt-MAH & Diâmetro $(\boldsymbol{\mu m})$ \\
\hline \multirow{2}{*}{$\mathbf{7 5 / 2 5}$} & $0 \%$ & $0,79 \pm 0,23$ \\
& $2 \%$ & $0,86 \pm 0,28$ \\
$\mathbf{2 5 / 7 5}$ & $3 \%$ & $0,98 \pm 0,35$ \\
\hline & $0 \%$ & $0,52 \pm 0,18$ \\
& $3 \%$ & $1,08 \pm 0,47$ \\
& $3 \%$ & $1,55 \pm 0,79$
\end{tabular}

Através destes dados, conclui-se que o diâmetro médio das partículas dispersas aumenta com a adição do agente compatibilizante, o que vai contra o esperado, que é a redução do diâmetro da fase dispersa devido à redução das tensões interfaciais. Além disso, foi percebido que a moda da distribuição de diâmetros da fase dispersa da blenda $75 / 25$, ou seja, o valor de diâmetro que mais se fez presente na imagem analisada desta blenda, apresentou uma queda com a adição de $2 \%$ de PEAD-alt-MAH, tendo um aumento com a adição de $3 \%$. Já a 
moda dos diâmetros da blenda 25/75 apresentou um constante aumento com a adição do compatibilizante. Os histogramas das distribuições de diâmetros destas blendas se encontram no Anexo B. Como as partículas são bem irregulares, recomenda-se que as capturas das imagens sejam feitas a partir do material embutido e devidamente polido ao invés de fraturado criogenicamente.

O aumento expressivo do diâmetro da fase dispersa da blenda 25/75 provavelmente se deve às diferenças nas temperaturas de cristalização dos polímeros, já que a temperatura de cristalização do PEAD é menor que a da PA12 fazendo com que as partículas de PEAD cristalizem depois do PA12. Assim sendo, a matriz de PA12 está sólida enquanto as gotículas de PEAD ainda estão fundidas durante a cristalização da blenda [61], assunto previamente discutido no item 5.4.4. Como a segmentação é aproximada e as partículas não são uniformes, há uma variação muito grande nos valores medidos. Para obter uma maior amostragem, estatisticamente falando, deveria ser realizada uma análise em um campo maior de varredura, como em um mosaico, abrangendo uma área maior da fratura, além do uso de algum método de segmentação mais sofisticado.

Nas Figuras 113d, 113f e 115d fica claro que algumas partículas dispersas apresentam formato fibrilar e algumas apresentam formato de gotas; reforçando a ideia de que blendas poliméricas também podem ser consideradas compósitos, seja particulado ou de fibras. O efeito dessa morfologia fica claro nas imagens dos corpos de prova fraturados e na Figura 118 que mostra a morfologia da fratura de um corpo de prova da blenda 50/50 com $2 \%$ de compatibilizante, onde ficam evidentes as fibras expostas na fratura criogênica. 


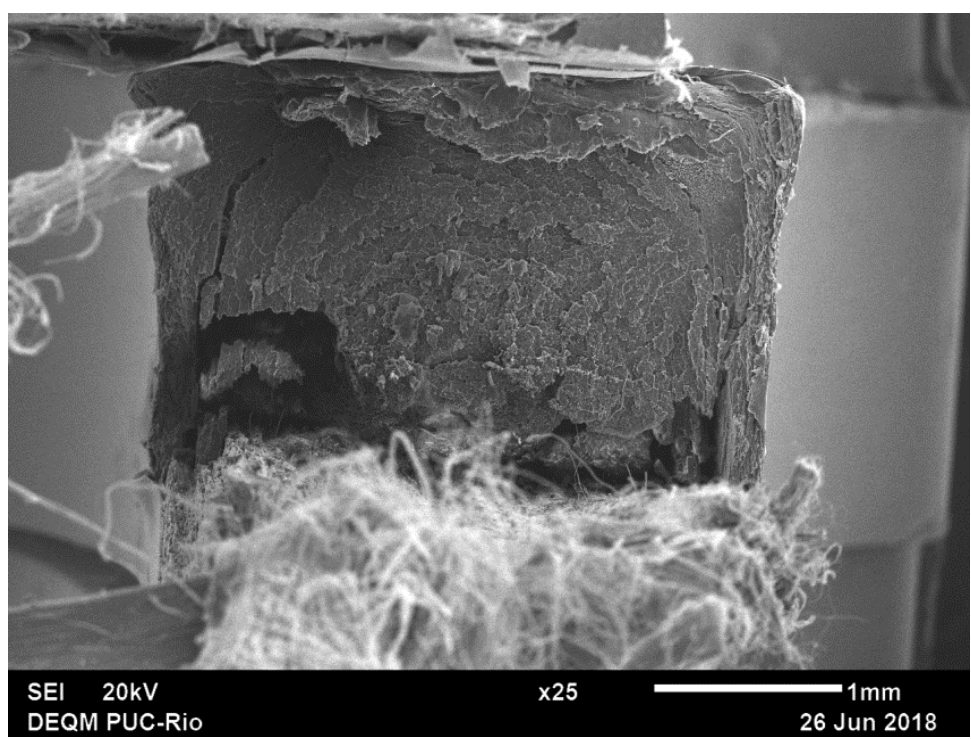

Figura 118. Fratura no corpo de prova $50 / 50$ com $2 \%$ de PEAD-alt-MAH (x25).

Analisando a morfologia da blenda 50/50, nota-se que este material possui uma microestrutura bastante diferente das outras duas composições, já que a estrutura é mais homogênea, não contém vazios e não é possível distinguir a fase dispersa e a matriz. A microestrutura é contida por domínios de um dos homopolímeros com outra fase dentro desses domínios, como está ilustrado na Figura 119.

Essa estrutura é chamada de co-contínua, onde cada fase apresenta-se de forma contínua e entrelaçada. Normalmente, observa-se uma morfologia do tipo fase dispersa/matriz, quando um dos polímeros encontra-se em baixa concentração, como é o caso das blendas 75/25 e 25/75. Com o aumento da fase em menor concentração, as partículas tornam-se muito próximas e começam a coalescer, alcançando o ponto de percolação. Acima desta concentração, maiores teores do componente em menor concentração são incorporados à estrutura em percolação até o momento em que ambos os componentes da mistura fazem parte de uma única estrutura [68]. 


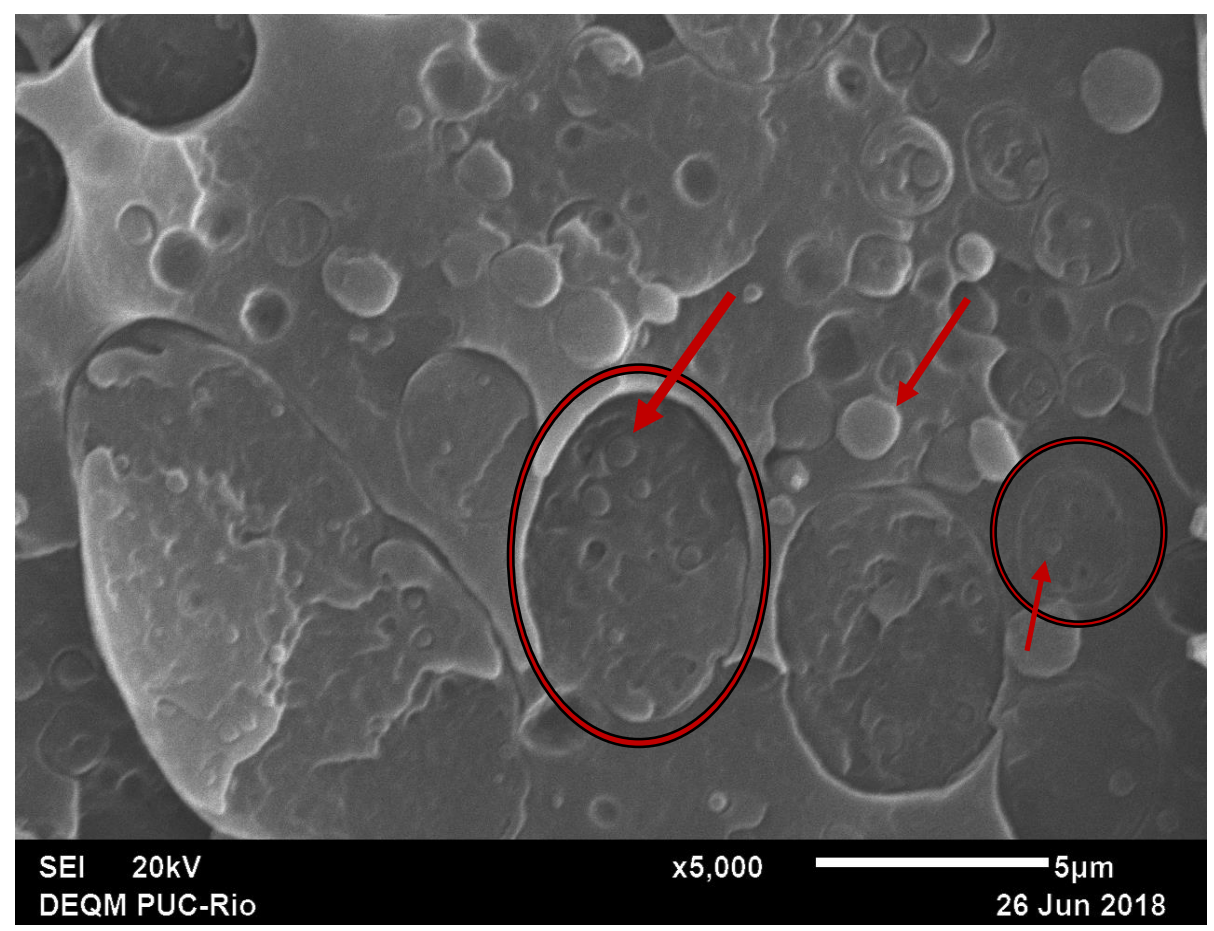

Figura 119. Micrografia da blenda 50/50 com 2\% de PEAD-alt-MAH com

aumento de 5000x, com os círculos indicando alguns domínios presentes e as setas indicando algumas fases distintas seja dentro dos domínios ou na matriz.

Diversas teorias e relações matemáticas têm sido propostas para estimar o ponto de inversão de fase, baseadas na razão de torque ou na razão de viscosidade entre os componentes da mistura. De acordo com estas teorias, quando a razão de viscosidade entre os componentes é diferente de um, o componente de menor viscosidade encapsula o componente de maior viscosidade e torna-se a fase contínua da mistura. Todas estas teorias predizem que a morfologia do tipo cocontínua é alcançada em um único valor de concentração. Entretanto, vários resultados experimentais têm mostrado que este tipo de morfologia não é formado em uma única fração volumétrica, mas sim, em uma faixa de composição [68].

Willis e col. [69] avaliaram a relação entre morfologia e processabilidade de blendas entre PP e PA6 e estabeleceu uma relação entre diâmetros das partículas dispersas e fração em massa de PA6 na blenda, como mostra o gráfico da Figura 120. Nele é possível ver que na faixa entre 45 e $65 \%$ de PA6, aproximadamente, há uma fase co-contínua, onde não há a morfologia matriz/fase dispersa. O mesmo ocorre com a blenda apresentada neste trabalho. 


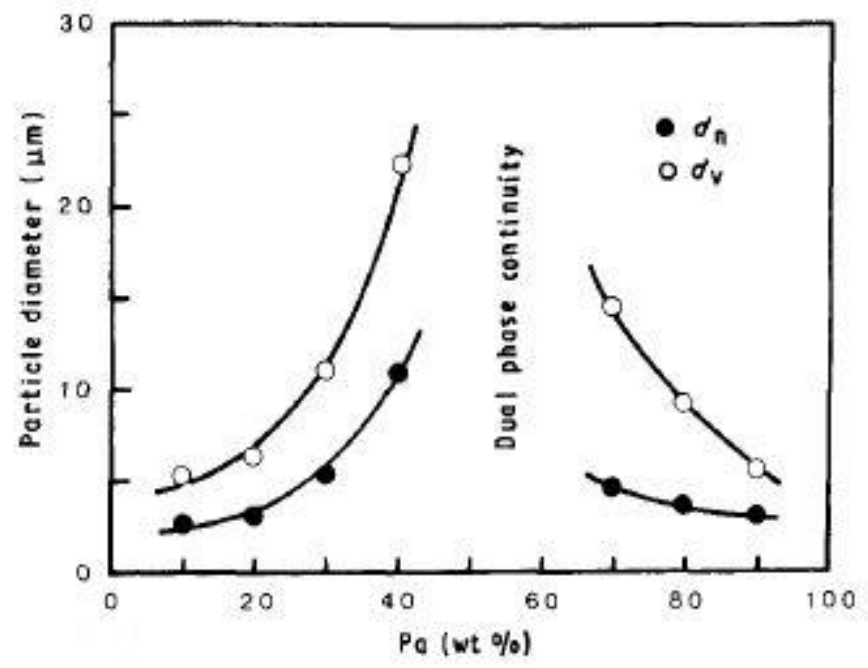

Figura 120. Diâmetro das partículas dispersas em função da porcentagem de PA6 na blenda PP/PA, onde mostra a faixa onde ocorre a fase co-contínua [69].

\subsection{Análise de custo}

Depois de feitas as análises das propriedades das blendas, é válido fazer uma análise de custo para avaliar a viabilidade do processamento destas blendas poliméricas a nível industrial. Na Tabela 44 constam os preços de cada constituinte da blenda, assim como os preços das blendas baseados na densidade de cada componente e nas suas proporções. Os preços do PEAD, PA12 e PEADalt-MAH foram baseados nos preços de oferta em tempo real através do Plasticker [70] com base na cotação do euro e dólar, também em tempo real.

Tabela 44. Preço por quilo das blendas compatibilizadas com $2 \%$ de PEADalt-MAH.

\begin{tabular}{cc}
\hline & Preço $/ \mathrm{kg}$ \\
\hline PEAD & $\mathrm{R} \$ 2,89 / \mathrm{kg}$ \\
PA12 & $\mathrm{R} \$ 5,68 / \mathrm{kg}$ \\
PEAD-alt-MAH & $\mathrm{R} \$ 12,82 / \mathrm{kg}$ \\
\hline PEAD/PA12 & \\
\hline $\mathbf{7 5 / 2 5}$ & $\mathrm{R} \$ 3,79 / \mathrm{kg}$ \\
$\mathbf{5 0 / 5 0}$ & $\mathrm{R} \$ 4,48 / \mathrm{kg}$ \\
$\mathbf{2 5} / 75$ & $\mathrm{R} \$ 5,15 / \mathrm{kg}$ \\
\hline
\end{tabular}


Como a função das blendas poliméricas é ter propriedades intermediárias aos seus constituintes, o mesmo acontece com o preço das mesmas, sendo que quanto maior o teor de PA12 na blenda, mais cara ela fica. A blenda 25/75, por exemplo, foi a que obteve a maior resistência, tendo seu limite de escoamento, módulo de elasticidade e tensão de ruptura representando 80\%, 120\% e 60\% em relação aos mesmos valores da PA12, respectivamente, com um preço $10 \%$ menor. Além disso, há o custo de processamento das blendas que teria que ser levado em consideração no cálculo da análise de custo da fabricação das blendas.

Ou seja, em escala industrial seria viável a produção destas blendas, pois teriam boas relações custo/benefício. 


\section{Conclusão}

A partir dos dados apresentados, conclui-se que para um melhor desempenho da blenda PEAD/PA12 é necessário a utilização de um agente compatibilizante, já que a morfologia e as propriedades mecânicas apresentaram melhora com a adição de 2\% de PEAD-alt-MAH. Percebe-se também que com a adição de $3 \%$ deste copolímero a blenda apresentou uma piora nas propriedades mecânicas em relação à com $2 \%$.

Em relação às propriedades das blendas com $2 \%$ de PEAD-alt-MAH, notase que com o aumento do teor de poliamida, as propriedades mecânicas apresentaram um aumento. Com isso, a blenda 25/75 foi a mais resistente e, ao mesmo tempo, a mais dúctil entre as três composições. A variação de composições dos homopolímeros afetou também nos modelos viscoelásticos, já que o modelo com melhor ajuste na blenda 75/25 foi o Modelo de 4 Parâmetros e nas blendas 50/50 e 25/75 o melhor modelo foi o Modelo de Stretched Burgers, sendo que este modelo poderia ser aplicado para todos os materiais, já que seus coeficientes de correlação apresentaram valores superiores a 0,99 . O valor do creep compliance serviu para mostrar que os comportamentos elásticos dos materiais são razoavelmente próximos e para confirmar que o PEAD e a blenda 75/25 têm módulos menores que os demais materiais. A blenda 25/75 se mostrou a blenda mais resistente à deformação após 24 horas de carga constante, já que a sua taxa de fluência estacionária foi a menor dentre todas as três composições, propriedade essa que apresentou um contínuo decréscimo com o incremento de PA12 na blenda.

É possível provar que os dados dos ensaios mecânicos são confiáveis, pois devido à análise de FTIR, conclui-se que não houve oxidação durante o processamento com a variação do tempo de residência, tampouco com a adição do compatibilizante. Outro fator importante a ser destacado é que durante o processamento houve certa absorção de umidade, fenômeno esse que pode ter sido facilitado pelas altas temperaturas utilizadas na extrusão. 
A partir da análise de difração de raios-x, conclui-se que o PEAD possui grau de cristalinidade superior ao da PA12. Com isso, as blendas apresentaram graus de cristalinidade intermediários aos seus homopolímeros, tendo um decréscimo com o incremento de PA12 no material. O mesmo conclui-se em relação ao tamanho dos seus cristalitos, já que este diminui com o incremento de PA12. Isto prova que as propriedades mecânicas dos polímeros não dependem somente dos seus graus de cristalinidade e tamanhos dos cristalitos, mas também das suas propriedades térmicas, já que a $\mathrm{T}_{\mathrm{g}}$ da PA12 é superior à temperatura ambiente, que é superior à $\mathrm{T}_{\mathrm{g}}$ do PEAD. Com isso, conforme as blendas apresentam um decréscimo dos seus graus de cristalinidade, a resistência mecânica aumenta, devido a uma maior proporção de PA12 no material.

Em relação às propriedades reológicas, concluiu-se que o PEAD tem forte influência sobre as blendas poliméricas, já que a altas taxas de cisalhamento as blendas apresentaram viscosidades bem abaixo dos homopolímeros, principalmente a blenda 75/25 que foi a blenda com menor viscosidade a altas taxas de cisalhamento, o que implica em uma boa extrusabilidade desta blenda. Outro fator importante notado nesta análise é que a PA12 apresenta um aumento significativo nas tensões cisalhantes a partir de $60 \mathrm{~s}^{-1}$, aproximadamente, característica de um material não-Newtoniano dilatante.

Foi avaliada também a morfologia das blendas e conclui-se que a blenda 50/50 apresentou morfologia co-contínua, enquanto as blendas 75/25 e 25/75 apresentaram morfologia do tipo matriz/fase dispersa, sendo que as fases dispersas foram PA12 e PEAD, respectivamente. Foi mostrado também que o compatibilizante melhorou a aderência entre as fases, embora o diâmetro da fase dispersa tenha aumentado. 


\section{Sugestões de Trabalhos Futuros}

Como neste trabalho foram feitos testes de tração apenas com duas proporções de PEAD-alt-MAH (2\% e 3\%), seria bom um trabalho com o uso de proporções mais variadas de compatibilizante para avaliar se há uma porcentagem "ótima" de compatibilização, onde se obtêm as melhores propriedades mecânicas possíveis para as blendas estudadas.

Outra sugestão de trabalhos futuros seria realizar ensaios DSC e TGA para avaliar as propriedades térmicas das blendas. Assim, seria possível avaliar a influência da $T_{g}$ nas propriedades mecânicas dos materiais, bem como suas temperaturas de degradação e energias de ativação.

Foi observado durante o processamento que os corpos de prova com $0 \%, 2 \%$ e 3\% apresentaram colorações distintas, logo seria interessante a realização do ensaio no colorímetro para quantificar a variação das cores e luminância das blendas, podendo ser útil para controle de qualidade do material.

Neste trabalho foi realizado o ensaio de reometria com uma faixa de taxas de cisalhamento de 10 a $100 \mathrm{~s}^{-1}$, portanto não foi possível visualizar o platô Newtoniano dos polímeros, já que o mesmo ocorre em baixíssimas taxas de cisalhamento, e também não foram obtidas as viscosidades dos materiais em condições de extrusão e injeção, já que os mesmos ocorrem em taxas de cisalhamento da ordem de $10^{3}$ e $10^{4} \mathrm{~s}^{-1}$. Portanto, uma sugestão de trabalhos futuros seria a utilização de uma faixa mais ampla de taxas de cisalhamento na análise reológica.

Como foi visto anteriormente, as partículas dispersas não apresentam tamanho regular, impossibilitando que haja uma segmentação exata do diâmetro das partículas. Logo, uma sugestão seria realizar uma varredura em uma área maior, como em um mosaico no MEV para ter uma melhor estatística dos diâmetros das fases dispersas a fim de avaliar melhor o efeito do compatibilizante nas blendas, e se possível, um método de segmentação mais aprimorado. Além disso, seria recomendável realizar a análise de imagens de uma superfície polida e não fraturada, pois assim a microestrutura mostraria apenas as diversas fases, sem 
apresentar as diversas marcas e relevos decorrentes da fratura da amostra e que não são de interesse para a análise. 


\section{Referências bibliográficas}

1. CANEVAROLO JR, S. V. Ciência dos polímeros: um texto básico para tecnólogos e engenheiros. São Paulo: Artliber Editora, 2002.

2. EBEWELE, R. O. Polymer science and technology. New York: CRC Press, 2000.

3. UTRACKI, L.; FAVIS, B. Handbook of Polymer Science and Technology. Nova York: MARCEL DEKKER, INC., Vol. 4, 1989.

4. CORRADINI, E.; RUBIRA, A. F.; MUNIZ, E. C. Miscibility of PVC/EVA hydrolysed blends by viscosimetric, microscopic and thermal analysis, European Polymer Journal, 33, pp. 1651-1658, 1997.

5. CHANDA, M.; ROY, S. K. Plastics Technology Handbook (4th ed.). Nova York: CRC PRESS, 1940.

6. UTRACKI, L. A.; DUMOULIN, M. M.; TOMA, P. Melt Rheology of High Density Polyethylenel Polyamide-6 Blends, Polymer Engineering \& Science, Vol. 26, pp. 34-44, 1986.

7. HERSH, S. P. The Electrostatic Characteristics of Textile Materials, Polymer Plastic Technology Engineering, Vol. 3, p. 29, 1974.

8. UTRACKI, L. A. Polymer Alloys and Blends: Thermodynamics and Rheology. Nova York: Hanser Publishers, 1989.

9. DA SILVA, A. L. et al. Polymer Blends Based on Polyolefin Elastomer and Polypropylene. Journal of Applied Polymer Science , Vol. 66, pp. 2005 - 2014, 1997.

10. COLEMAN, M. M.; PAINTER, P. C.; GRAF, J. F. Specific Interactions and the Miscibility of Polymer Blends. Lancaster, Pensilvânia: Technomic Publishing Company, 1991.

11. FIEGENBAUM, F. Estudo da Compatibilização das Blendas PP/PA6 e PA6/EPR. Dissertação de Mestrado - Universidade Federal do Rio Grande do Sul, Porto Alegre, 2007.

12. LEE, W. Surface morphology of immiscible polymer blend using scanning force microscopy. Polymer Testing, Vol. 23, pp. $101-105,2003$. 
13. UTRACKI, L. A.; WEISS, R. A. Multiphase Polymers Blend and Ionomers, Acs Symposium. Editors, 1989.

14. UTRACKI, L. A. Encyclopedic Dictionary of Commercial Polymer Blends. Toronto: ChemTec, 1994.

15. PADWA, A. R. Compatibilized Blends of Polyamide-6 and Polyethylene. Polymer Engineering and Science, Vol. 32, 1992.

16. PAUL, D. R.. Polymer Blends, Vol. 1. Nova York: ACADEMIC PRESS, 1978.

17. CARVAlho, T. J.; CAlumbY, R. B.; D'AlMEIDA, J. R., SPIETH, E. Propriedades Mecânicas e Morfologia de uma Blenda Polimérica de PP/HIPS Compatibilizada com SEBS. Polímeros: Ciência e Tecnologia, Vol. 10, pp. 82 $89,2000$.

18. YEH, J.; FAN-CHIANG, C.; YANG, S. Effects of Composition of Modified Polyamide on Barrier Properties of Polyethylene/Modified Polyamide Blends. Journal of Applied Polymer Science , Vol. 64, pp. 1531-1540, 1996.

19. MACOSKO, C. W. Morphology Development and Control in Immiscible Polymer Blends. Macromol. Symp. , pp. 171-184, 2000.

20. BRETAS, R. E.; DÁVILA, M. A. Reologia de Polímeros Fundidos. São Carlos: Editora Universidade de São Carlos, 2000.

21. HAN, C. D. Rheology and Processing of Polymeric Materials: Polymer Rheology (Vol. 1). Oxford: Oxford University Press, 2007.

22. ROCHA, M. C.; COUTINHO, F. M.; BALKER, S. Índice de Fluidez: Uma Variável de Controle de Processos de Degradação Controlada de Propileno por Extrusão Reativa. Polímeros: Ciência e Tecnologia, 1994.

23. RUDIN, A.; SCHREIBER, H. P.. SPE Journal , pp. 534-540, 1964.

24. SOUSA, J. A. Reometria Capilar de Polímeros. São Paulo: Universidade Federal de São Carlos, 1991.

25. REUSCH, W. Michigan State University - Department of Chemistry. Disponível em: <https://www2.chemistry.msu.edu/faculty/reusch/virttxtjml/spectrpy/infrared/i nfrared.htm>.

26. PAVIA, D. L. Introdução à Espectroscopia. 4 ed. Washington: CENGAGE Learning, 2010. 
27. GOBBO, L. A. Os compostos do clínquer Portland: sua caracterização por difração de raios-X e quantificação por refinamento de Rietveld. Dissertação de Mestrado - Instituto de Geociências, USP. São Paulo, 2003.

28. MURTHY, N. S. et al. Characterization of Polymer Blends and Alloys by Constrained Profile-Analysis of X-Ray Diffraction Scans. Journal of Applied Polymer Science ,Vol. 41, pp. 2265 - 2272, 1990.

29. STERN, P. G.; SEGERMAN, E.. On the Structure of Polypropylene Fiber. Polymer, Vol. 9, pp. 471 - 477, 1968.

30. POURGHAHRAMANI, P.; AKHGAR, B. N. Characterization of structural changes of mechanically activated natural pyrite using XRD line profile analysis. International Journal of Mineral Processing, Vol. 134, pp. 23 - 28, 2015 .

31. KYU, T.; NWABUNMA, D. Polyolefin Blends. Nova Jersey: Wiley Bicentennial, 2007.

32. COUTINHO, F. M.; MELlO, I. L.; MARIA, L. C. Polietileno: Principais Tipos, Propriedades e Aplicações. Polímeros: Ciência e Tecnologia, Vol. 13, pp. 1 - 13, 2003.

33. MILES, D. D.; BRISTON, J. H.. Polymer Technology. Londres: Temple Press Book, 1965.

34. GUITIÁN, R. Plástico Moderno, Vol. 45, 1995.

35. HARPER, C. A. Modern Plastics Handbook. Lutherville: McGraw-Hill, 1999.

36. ALEXANDRE, B. et al. Water barrier properties of polyamide 12/montmorillonite nanocomposite membranes: Structure and volume fraction effects. Journal of Membrane Science, pp. 186 - 204, 2008.

37. WIEBECK, H.; HARADA, J. Plásticos de Engenharia: Tecnologia e Aplicações. São Paulo: Artliber, 2005.

38. YEH, J. T.; FAN-CHIANG, C. C.; CHO, M. F. Effects of compatibilizer precursors on the barrier properties and morphology of polyethylene/polyamide blends. Polymer Bulletin, Vol. 35, pp. 371-378, 1995.

39. YEH, J.-T.; JYAN, C.-F. Effects of Polyethylenes on the Morphology, Barrier, and Impact Properties of Polyethylene/Modified Polyamide Blends. Polymer Engineering and Science, Vol. 38, 9, pp. 1482 - 1490, 1998. 
40. HAMID, F.; AKHBAR, S.; HALIM, K. H. Mechanical and Thermal Properties of Polyamide 6/PEAD-g-MAH/High Density Polyethylene. Procedia Engineering, Vol. 68, pp. 418 - 424, 2013.

41. KUDVA, R. A.; KESKKULA, H.; PAUL, D. R. Morphology and mechanical properties of compatibilized nylon 6/polyethylene blends. Polymer, Vol. 40, pp. $6003-6021,1999$.

42. JORDHAMO, G. M.; MANSON, J. A.; SPERLING, L. H. Phase continuity and inversion in polymer blends and simultaneous interpenetrating networks. Polymer Science, Vol. 26, p. 517, 1986.

43. Braskem. Polietileno de Alta Densidade JV060U. Folha de Dados .

44. Aldrich, S. Nylon 12 - Product Specification.

45. Aldrich, S. PEAD-alt-MAH. Product Specification .

46. Book, C. POLY(ETHYLENE-ALT-MALEIC ANHYDRIDE).

47. ANTONIO, S. G. Aplicação da difração de raios $X$ por policristais e do método de Rietveld de refinamento de estruturas cristalinas no estudo de polimorfos cristalinos de fármacos. Tese de Doutorado - Instituto de Química, Universidade Estadual Paulista, Araraquara, 2010.

48. NOVOA, D. M. Avaliação físico-química do polietileno de alta densidade processado pelo método de impressão $3 D$ por modelagem por fusão $e$ deposição FDM. Dissertação de Mestrado - Departamento de Engenharia Química e de Materiais, Pontifícia Universidde Católica do Rio de Janeiro, Rio de Janeiro, 2014.

49. REHMAN, I. ur., MOVASAGHI, Z., REHMAN, S. Vibrational Spectroscopy for Tissue Analysis. Nova York: CRC Press, 2012.

50. Texts, C. L. (2014). Infrared Spectroscopy Absorption Table.

51. BARROW, R. F.; LONG, D. A.; MILLEN, D. J. Vibrational Spectroscopy of Macromolecules. Molecular Spectroscopy, Vol. 1, 1, 1988.

52. DAVIDSON, G. Spectroscopic Properties of Inorganic and Organometallic Compounds, 35, 2001.

53. MARÉCHAL, P. et al. Amine/Anhydride Reaction versus Amide/Anhydride Reaction in Polyamide/Anhydride Carriers. Journal of Polymer Science, Vol. 33, pp. 757-766, 1995. 
54. MACOSKO, C. W.; JEON, H. K.; HOYE, T. R. Reactions at polymerpolymer interfaces for blend compatibilization. Progress in Polymer Science, Vol. 30, pp. 939 - 947, 2005.

55. LI, D. et al. Crystallographic texture evolution in high-density polyethyleneduring uniaxial tension. Polymer, Vol. 42, pp. 4903 - 4913, 2001.

56. LI, L.; KOCH, M. H.; DE JEU, W. H. Crystalline Structure and Morphology in Nylon-12: A Small-and-Wide-Angle X-ray Scattering Study. Macromolecules, Vol. 36, pp. 1626 - 1632, 2003.

57. DUSUNCELI, N.; COLAK, O. U. Modelling effects of degree of crystallinity on mechanical behavior of semicrystalline polymers. International Journal of Plasticity, Vol. 24, pp. 1124 - 1242, 2008.

58. MOHANTY, S.; VERMA, S. K.; NAYAK, S. K.. Dynamic mechanical and thermal properties of MAPE treated jute/PEAD composites. Composites Science and Technology, Vol. 66, pp. 538 - 547, 2006.

59. HARTONO, A. et al. Effect of Mechanical Treatment Temperature on Electrical Properties and Crystallite Size of PVDF Film. Advances in Materials Physics and Chemistry, Vol. 3, pp. 71 - 76, 2013.

60. GUPTA, A. K.; PURWAR, S. N. Crystallization of PP in PP/SEBS Blends and Its Correlation with Tensile Properties. Journal of Applied Polymer Science, Vol. 29, pp. 1595 - 1609, 1984.

61. UTRACKI, L. A. Polymer Blends Handbook, Vol. 1. Kluwer Academic Publishers, 2002.

62. BRETAS, R. E.; D'ÁVILA, M. A. Reologia de Polímeros Fundidos. 2 ed. São Carlos: EdUFSCar, 2005.

63. CHO, K. et al. Rheological and Mechanical Properties in Polyethylene Blends. Polymer Engineering and Science, Vol. 38, pp. 1969 - 1975, 1998.

64. LECOUVET, B. et al. Structure-property relationships in polyamide 12/halloysite nanotube nanocomposites. Polymer Degradation and Stability, Vol. 96, pp. 226 - 235, 2011.

65. CHO, J. W.; PAUL, D. R. Nylon 6 nanocomposites by melt compounding. Polymer, Vol. 42, pp. 1083 - 1094, 2001.

66. HAWORTH, B. et al. Shear viscosity measurementes on Polyamide-12 polymers for laser sintering. Rapid Prototyping Journal , Vol. 19, 1, pp. 28 36,2013 
67. RUEDEN, C. T. et al. ImageJ2: ImageJ for the next generation of scientific image data. BMC Bioinformatics, 529, 2017.

68. MOREIRA, A. F.; JÚNIOR, F. C.; SOARES, B. G. Morfologia Co-Contínua na Mistura Poliestireno/Copolímero de Etileno-Acetato de Vinila. Polímeros: Ciência e Tecnologia, Vol. 12, pp. 136 - 146, 2002.

69. WILliS, J. M.; CALDAS, V.; FAVIS, B. D. Processing-morphology relationships of compatibilized polyolefin/polyamide blends. Journal of Materials Science, Vol. 26, pp. 4742 - 4750, 1991.

70. Plasticker: the home of plastics. Real Time Price List. Disponível em: $<$ https://plasticker.de/preise/pms_en.php?kat=Mahlgut\&aog=A\&show=ok\&ma ke=ok> Acesso em: 29 de Agosto de 2018. 


\section{ANEXO A - ETAPAS DO PROCESSO DE SEGMENTAÇÃO}

Tomando como exemplo a microestrutura da blenda 75/25 com $0 \%$ de compatibilizante obtida pelo detector BSE:

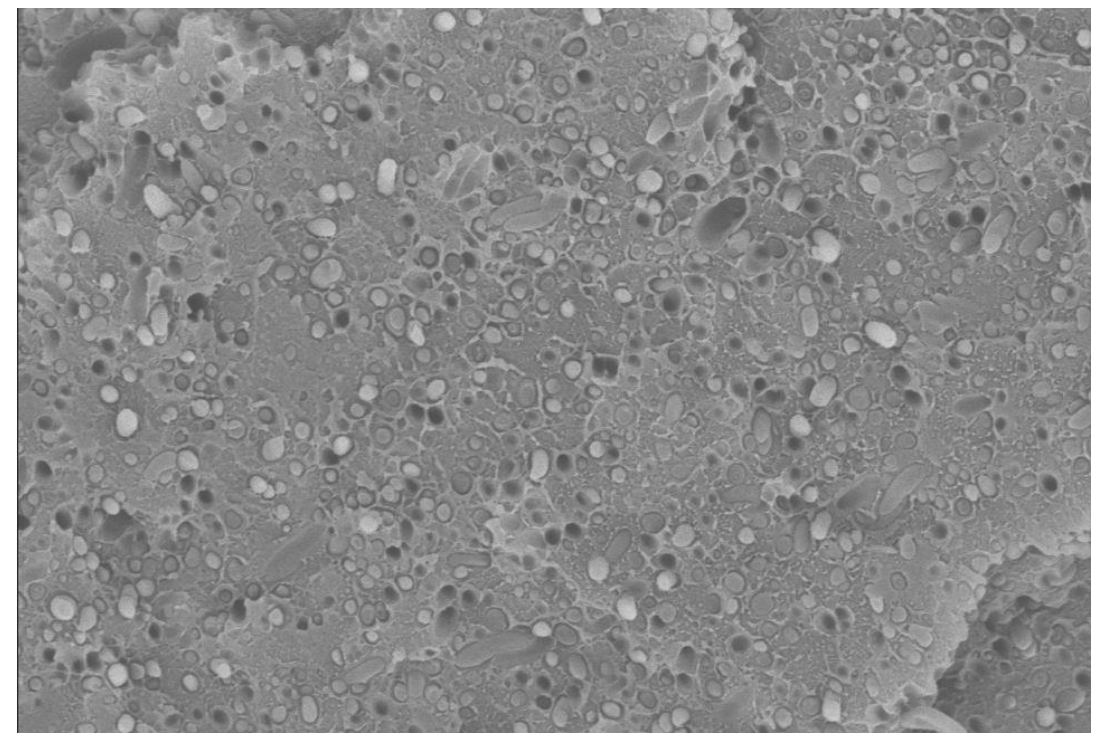

Figura A-1 Microestrutura da blenda 75/25 0\% pelo detector BSE com ampliação de 2000x.

A partir desta imagem e da distribuição de pixels, obtém-se, através do Fiji, o histograma desta imagem (Figura A-2).

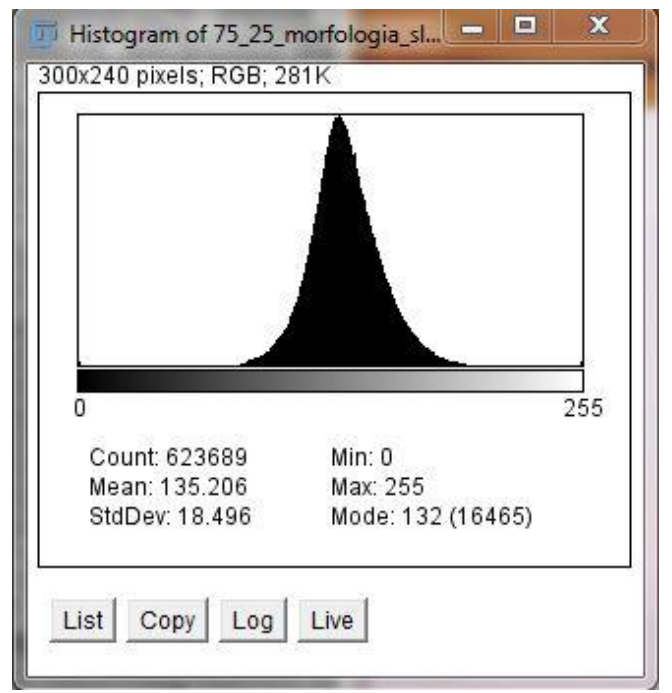

Figura A-2. Histograma de tons de pixels da imagem da Figura A-1. 
Através de um recurso do Fiji, denominado Enhance Contrast, cujo Template está ilustrado na Figura A-3, é possível melhorar o contraste da imagem através do alargamento do histograma de pixels, aumentando o espectro de tons dos mesmos, e com isso, melhorando a distribuição de tons de cinza, e também, abrilhantando as partículas mais claras. A imagem com esse filtro aplicado e seu histograma estão representados na Figura A-4.

Percebe-se que com a melhor distribuição do histograma, a imagem melhora seu contraste, já que tem maior distribuição dos tons de pixels.

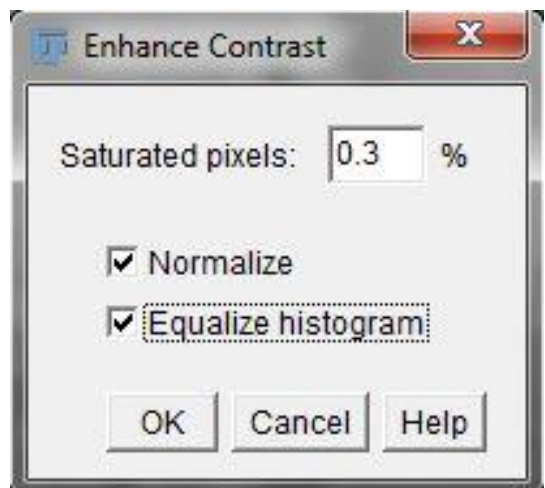

Figura A-3. Template do filtro Enhance Contrast.

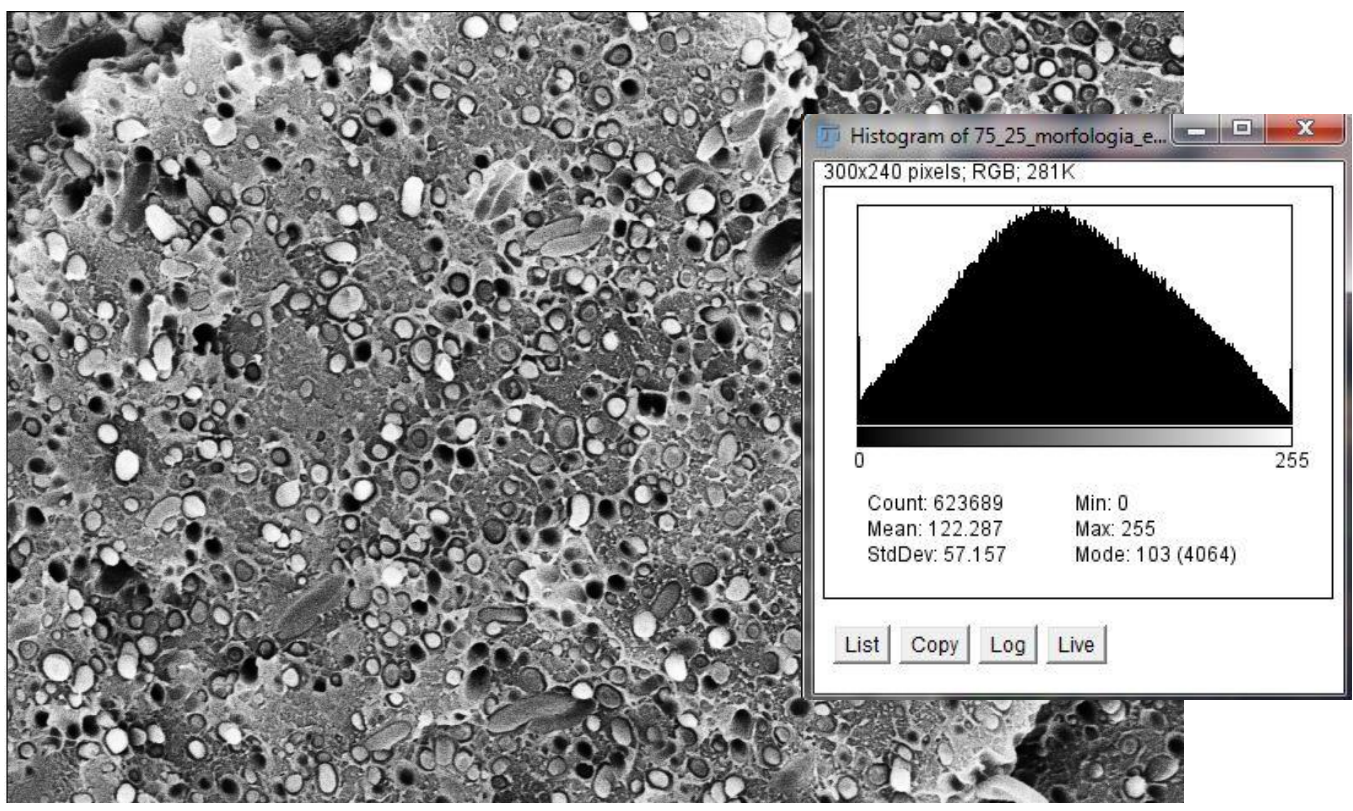

Figura A-4. Imagem com contraste melhorado e seu histograma de tons dos pixels. 
Porém, a imagem ainda não está pronta para a segmentação, pois apesar de ter melhorado o contraste, a imagem é bem ruidosa, característica das imagens geradas no MEV. Com isso, aplica-se o filtro chamado Non-Local Means Denoising. Diferentemente dos filtros "local means", que calculam o valor médio de um grupo de pixels envolvendo um pixel alvo, borrando a imagem, o filtro "non-local means" calcula um valor médio de todos os pixels da imagem, ponderado em o quão similar esses pixels são do pixel alvo, dando uma filtragem mais limpa a imagem. A imagem com este filtro aplicado e seu histograma estão representados na Figura A-5.

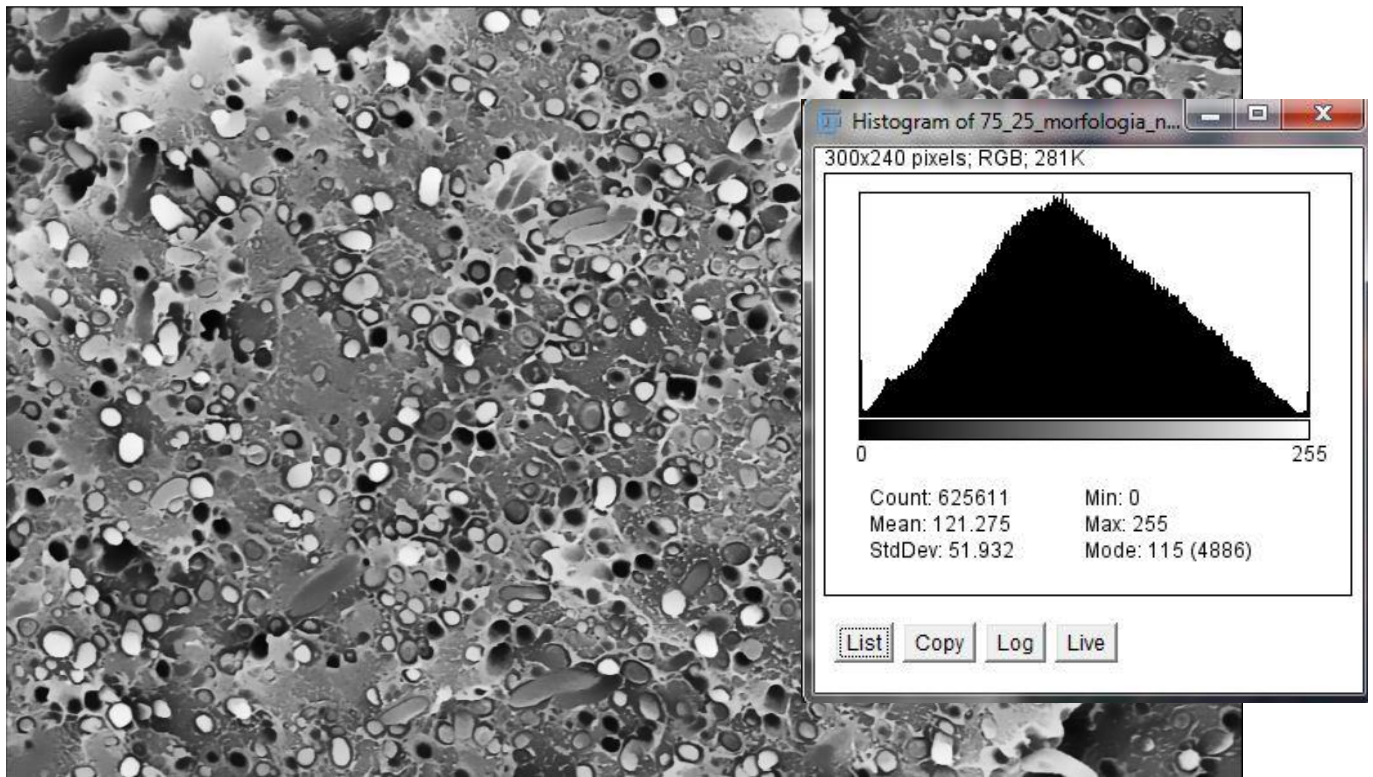

Figura A-5. Imagem com o contraste melhorado e aplicação de filtro de remoção de ruído e seu histograma.

A partir da aplicação dos filtros mencionados acima, a imagem está pronta para ser segmentada. Na segmentação, o usuário do software escolhe quais pixels do histograma da Figura A-5 irá segmentar. Como o interesse está nas partículas da fase dispersa e estas são caracterizadas por pixels claros, os pixels segmentados foram os da extrema direita do histograma. $O$ filtro de segmentação chama-se Threshold e o template do mesmo com a imagem antes da aplicação do filtro encontram-se representados na Figura A-6. 


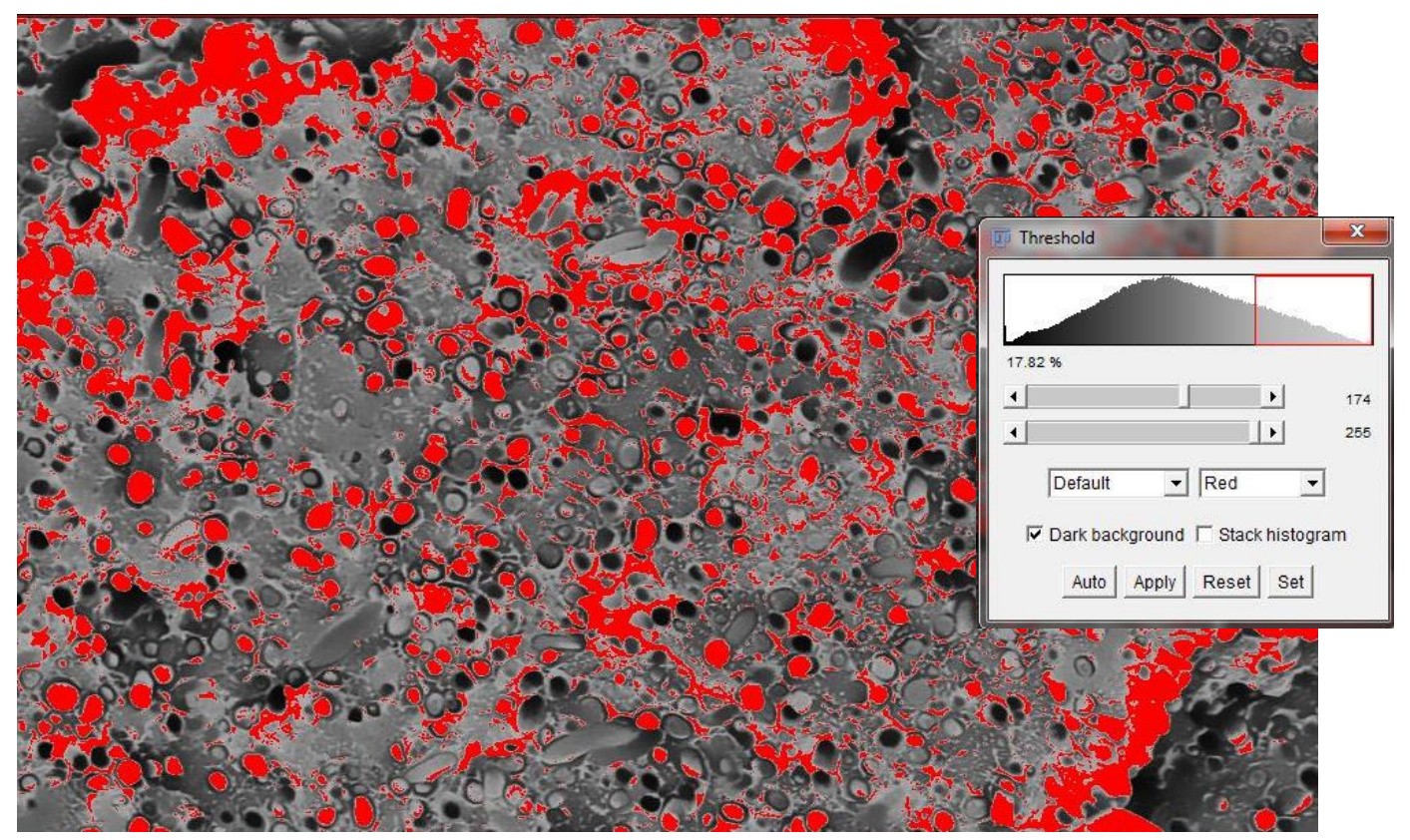

Figura A-6. Imagem antes de ser segmentada seguida do template do

Threshold, onde o retângulo vermelho indica os pixels segmentados.

Como é possível perceber através da Figura A-6, após a segmentação, a imagem originada apresenta mais informações do que o requerido, ou seja, além das partículas dispersas, apresenta também algumas partes da matriz. Com isso, realiza-se uma filtragem, seja manual ou por parâmetros. Esta última consiste em uso do filtro Biovoxxel - Extended Particle Analyzer (Figura A-7), no qual além de filtrar por área, também filtra por circularidade, perímetro, diâmetro mínimo, roundness, dentre outros parâmetros. 


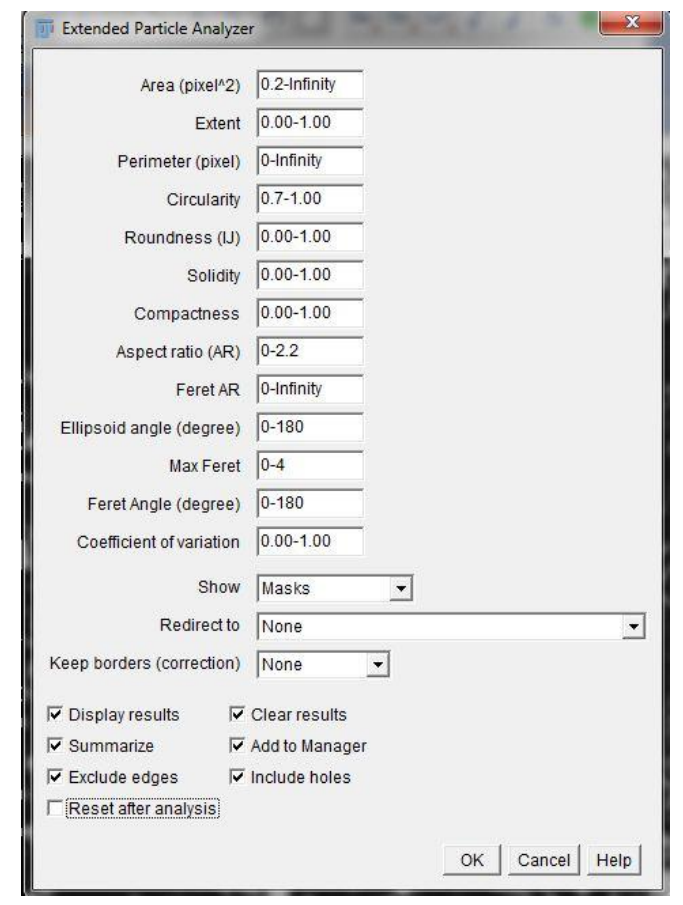

Figura A-7. Biovoxxel - Extended Particle Analyzer.

Depois de feita a filtragem descrita acima, obtém-se a imagem das partículas dispersas segmentadas na Figura A-8, da qual se pode obter o diâmetro médio das partículas.

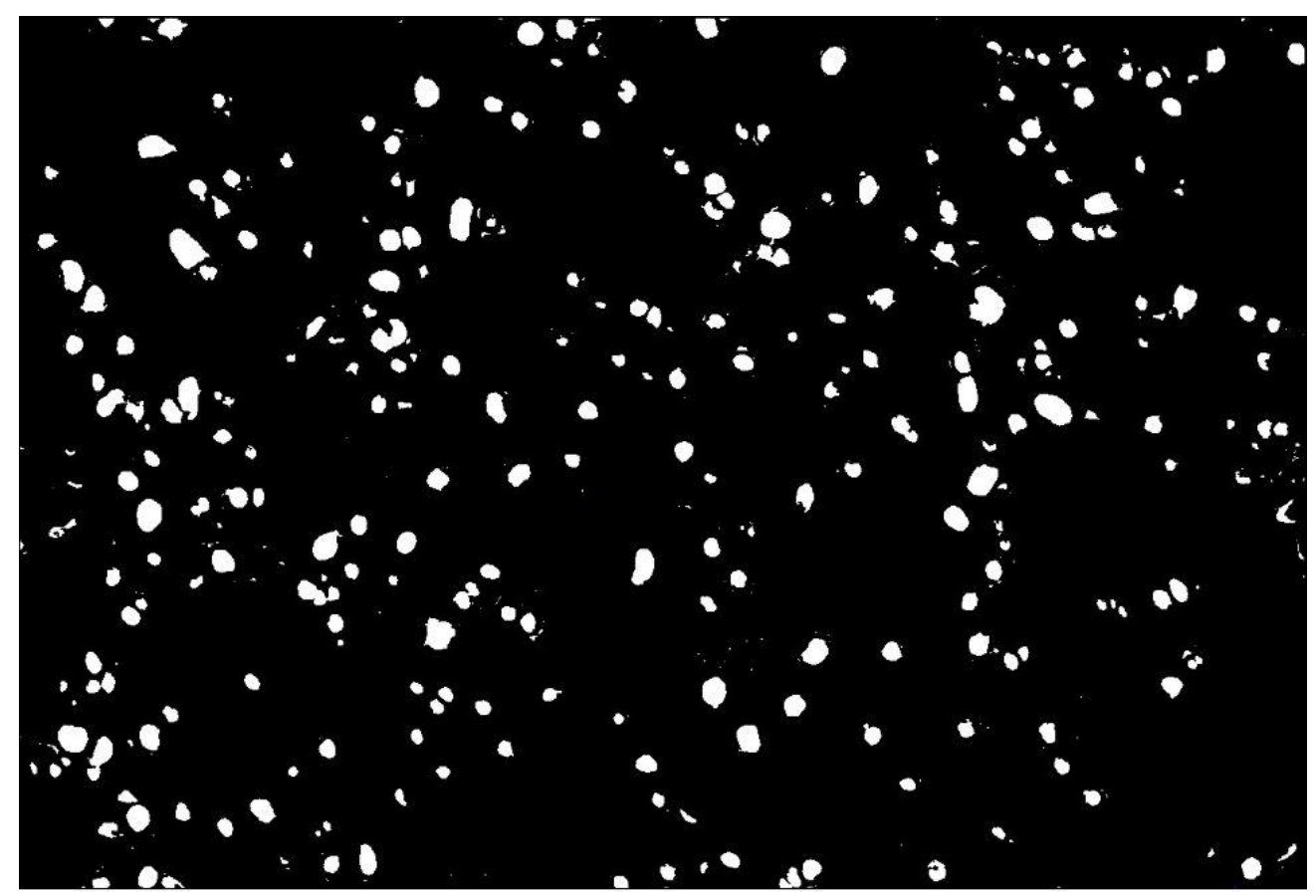

Figura A-8. Imagem segmentada. 


\section{ANEXO B - HISTOGRAMAS DOS DIÂMETROS DAS FASES DISPERSAS}

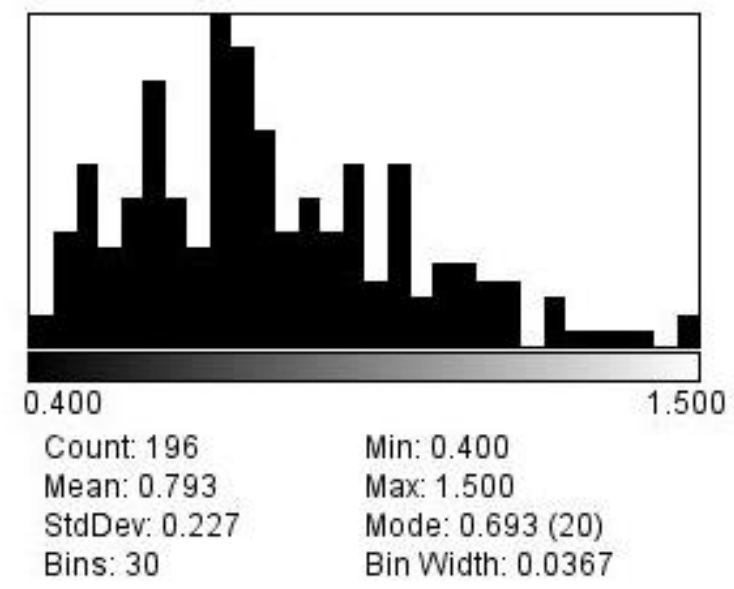

Figura B-1. Diâmetros da fase dispersa da blenda 75/25 com $0 \%$ de compatibilizante.

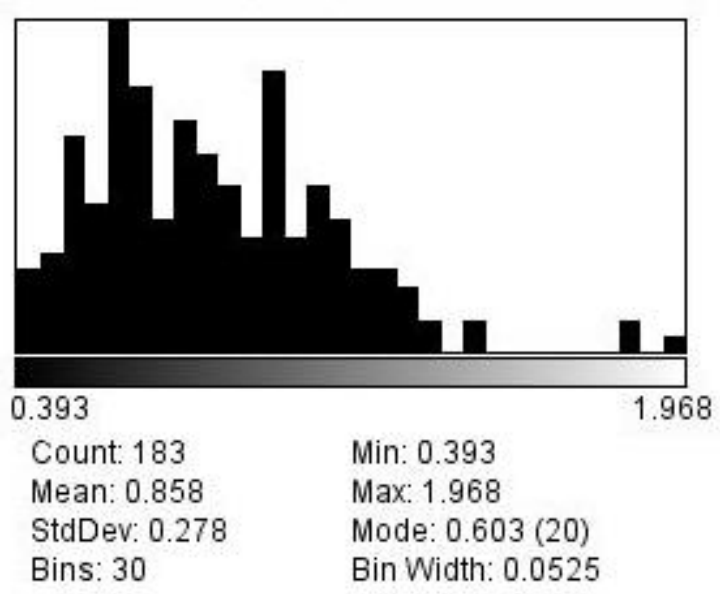

Figura B-2. Diâmetros da fase dispersa da blenda 75/25 com $2 \%$ de compatibilizante. 


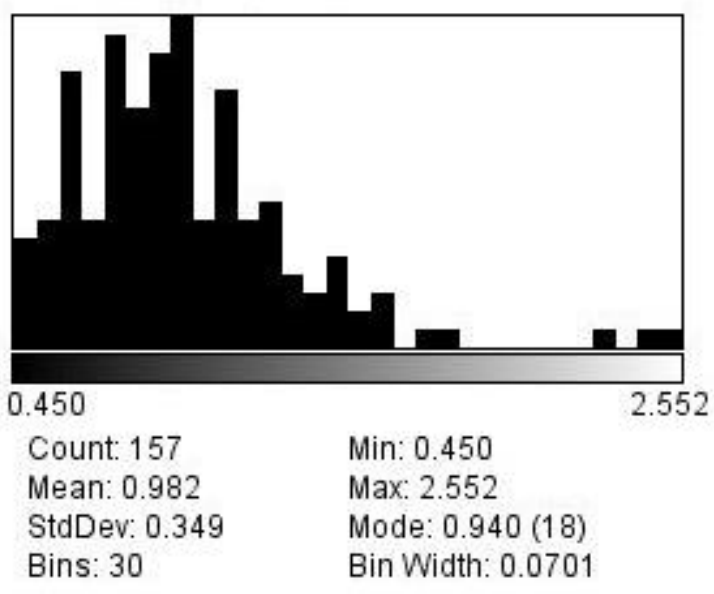

Figura B-3. Diâmetros da fase dispersa da blenda 75/25 com $3 \%$ de compatibilizante.

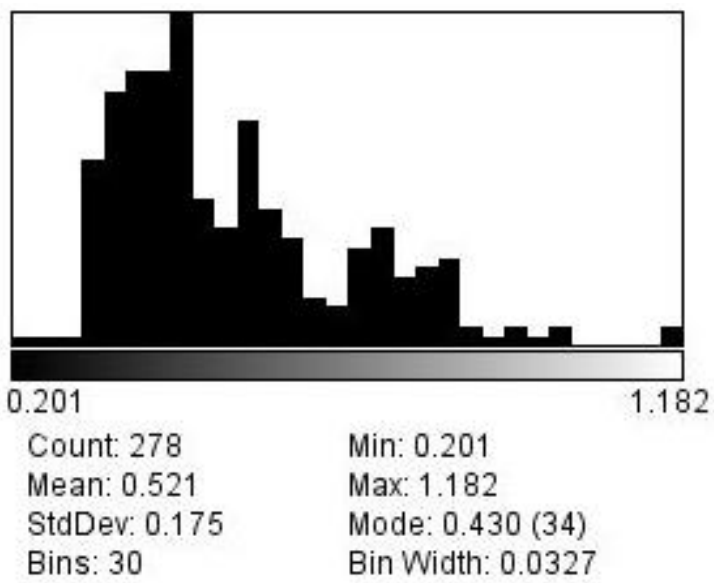

Figura B-4. Diâmetros da fase dispersa da blenda 25/75 com $0 \%$ de compatibilizante. 


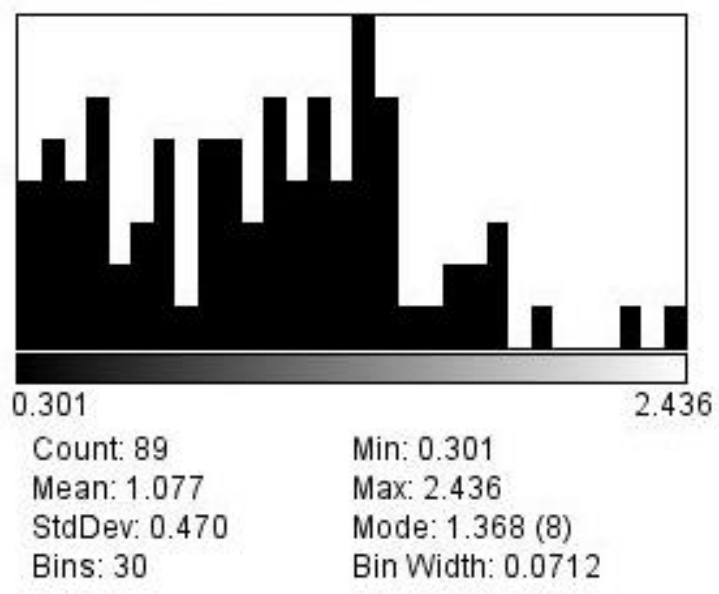

Figura B-5. Diâmetros da fase dispersa da blenda $25 / 75$ com $2 \%$ de compatibilizante.

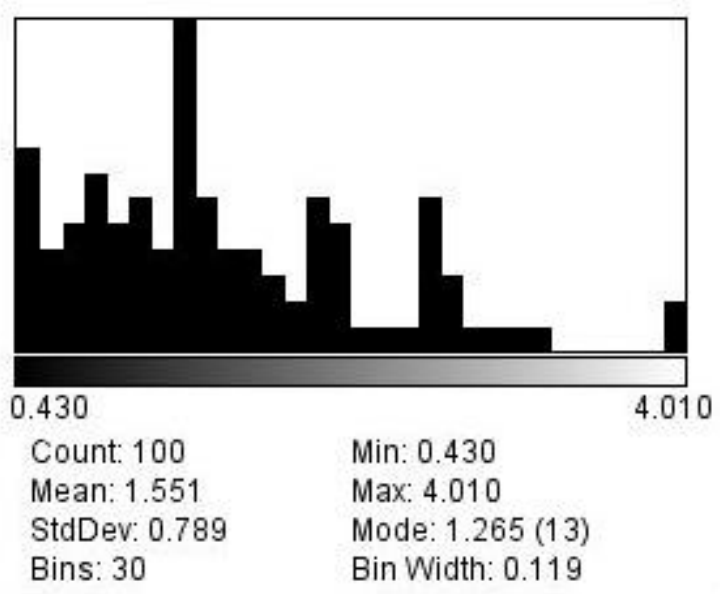

Figura B-6. Diâmetros da fase dispersa da blenda 25/75 com $3 \%$ de compatibilizante. 